\title{
Beschwerdebild und Lebensqualität bei Hypoparathyreoidismus anhand eines neu entwickelten Fragebogens
}

\author{
INAUGURAL-DISSERTATION \\ zur Erlangung des Doktorgrades \\ der Medizinischen Fakultät der \\ Georg-August-Universität zu Göttingen
}

vorgelegt von

Deborah Wilde

\author{
aus \\ Würzburg
}

Göttingen 2019 
Dekan:

Referent/in

Ko-Referent/in:

Drittreferent/in:
Prof. Dr. rer. nat. H. K. Kroemer

Prof. Dr. H. Siggelkow

Prof. Dr. W. Himmel

Prof. Dr. C. Herrmann-Lingen

Datum der mündlichen Prüfung: $\quad 28.10 .2020$ 
Hiermit erkläre ich, die Dissertation mit dem Titel "Beschwerdebild und Lebensqualität bei Hypoparathyreoidismus anhand eines neu entwickelten Fragebogens" eigenständig angefertigt und keine anderen als die von mir angegebenen Quellen und Hilfsmittel verwendet zu haben.

Göttingen, den 


\section{$\underline{\text { Inhaltsverzeichnis }}$}

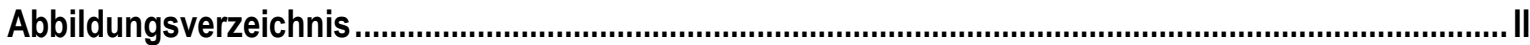

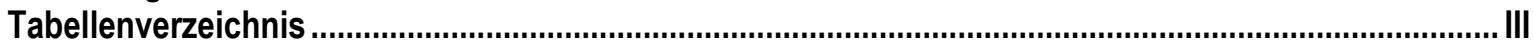

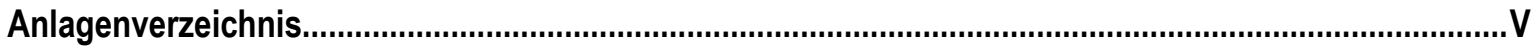

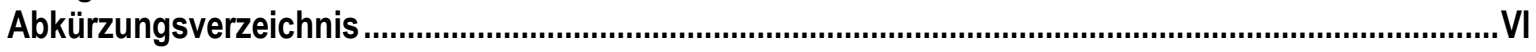

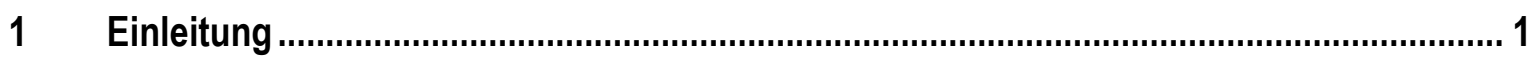

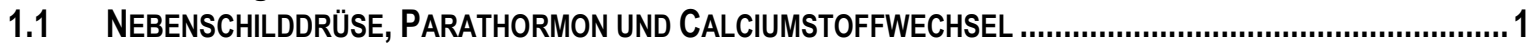

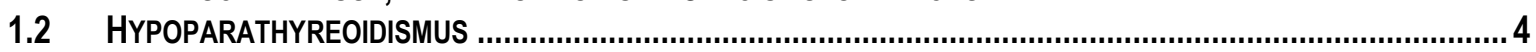

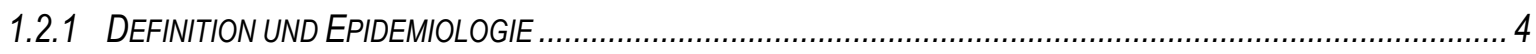

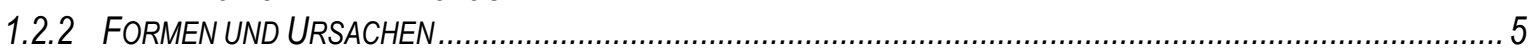

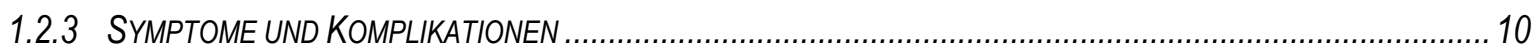

1.3 THERAPIE DES HYPOPARATHYREOIDISMUS UND NEBENWIRKUNGEN...............................................13

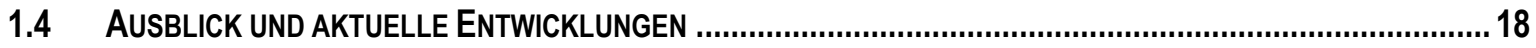

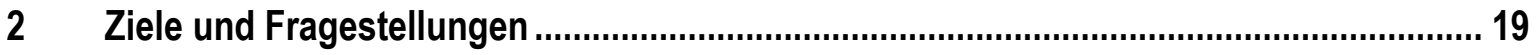

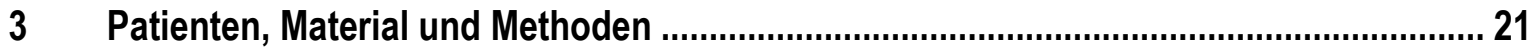

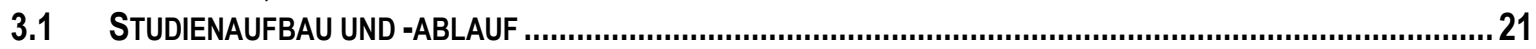

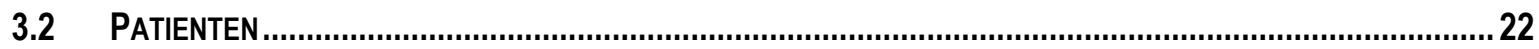

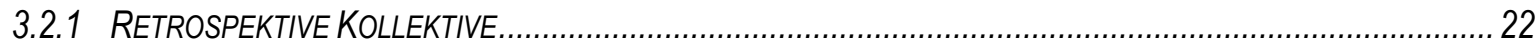

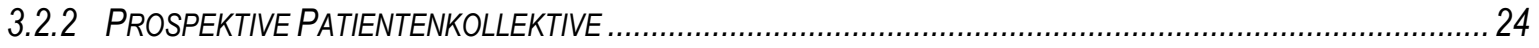

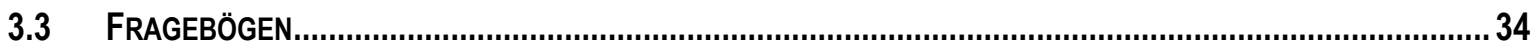

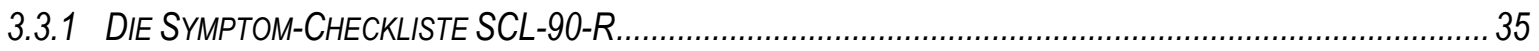

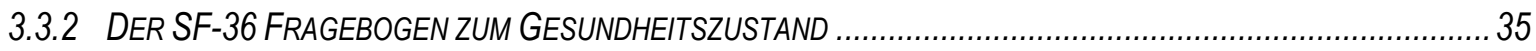

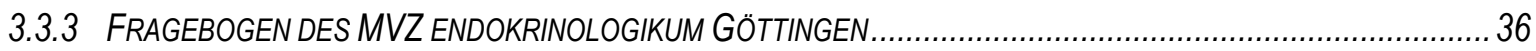

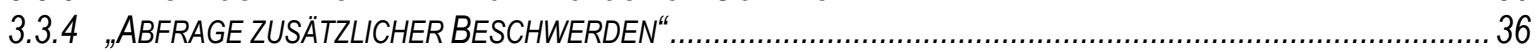

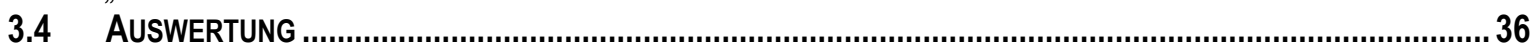

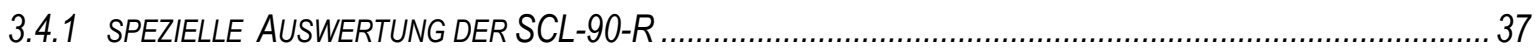

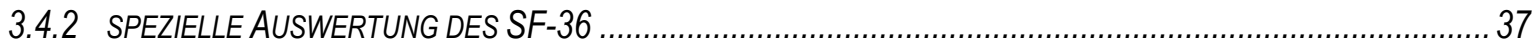

3.4.3 AUSWERTUNG DES FRAGEBOGENS DES MVZ ENDOKRINOLOGIKUM GÖTTINGEN UND DER „ABFRAGE

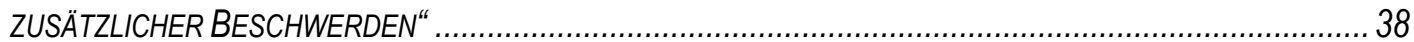

3.5 KONZIPIERUNG, VORSTELLUNG UND AUSWERTUNG DES NEUEN FRAGEBOGENS .....................................38

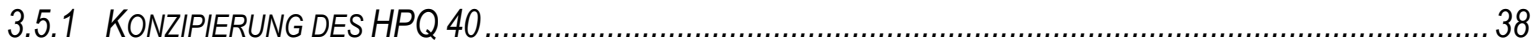

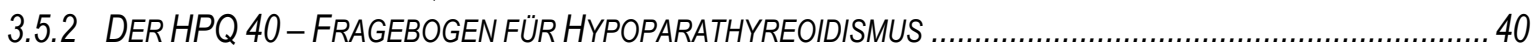

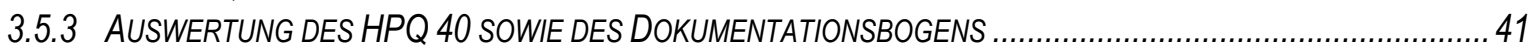

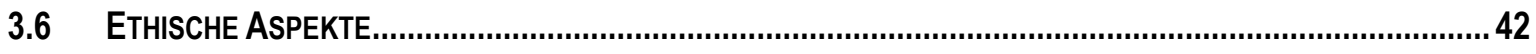

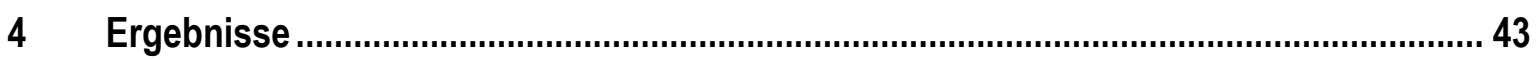

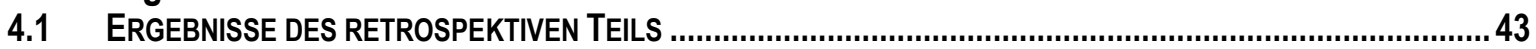

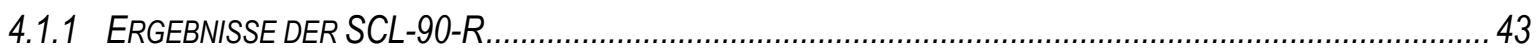

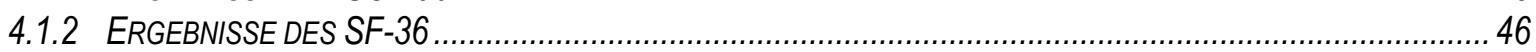

4.1.3 ERGEBNISSE DES FRAGEBOGENS DES MVZ ENDOKRINOLOGIKUM GÖTTINGEN ......................................... 48

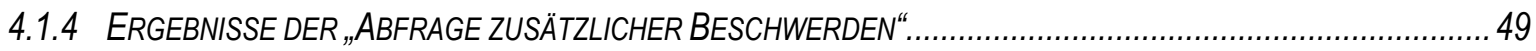

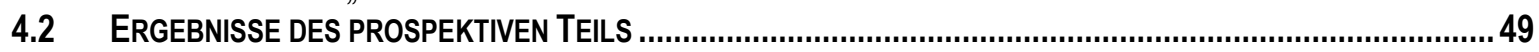

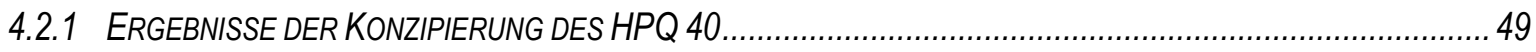

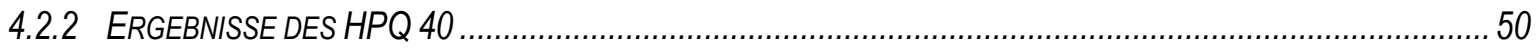

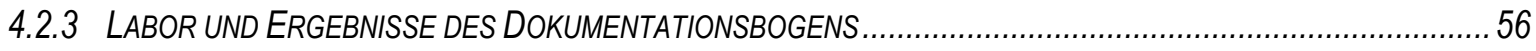

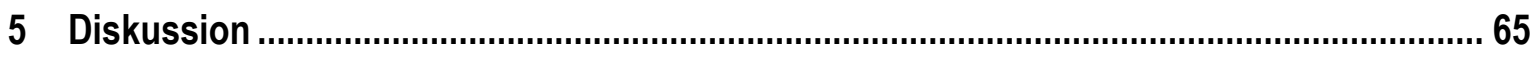

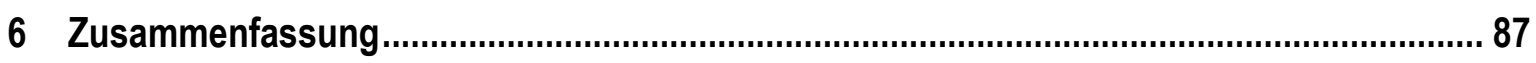

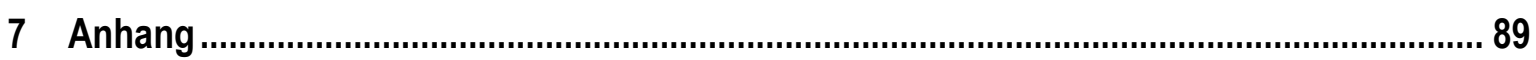

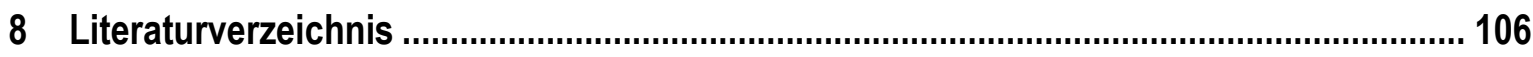




\section{Abbildungsverzeichnis}

Abbildung 1: bildliche Darstellung bekannter Funktionen des Parathormons (PTH) im Calcium- und Phosphatstoffwechsel...

Abbildung 2: Häufigkeit von Patienten ohne, mit einer/ zwei/ fünf angegeben Komplikationen auf dem

Dokumentationsbogen im Kollektiv HypoPT 2016.

Abbildung 3: Dauermedikation Nebenschilddrüse im Patientenkollektiv HypoPT 2016 .................................2.25

Abbildung 4: Häufigkeit der Operation eines primären Hyperparathyreoidismus in der Gruppe pHPT 2016 ... 27

Abbildung 5: Häufigkeiten der Dosierung von Calcitriol und Alfacalcidol sowie Dihydrotachysterol über alle ein solches Präparat einnehmenden Patienten aus dem Kollektiv HypoPT 2016 ........................................34

Abbildung 6: Darstellung der T-Werte der einzelnen Skalen der SCL-90-R in der SHG 2013 als Boxplots..... 44

Abbildung 7: Mittelwerte der Skalenwerte der SCL-90-R in der gesamten SHG 2013 im Vergleich zum gesunden Normkollektiv

Abbildung 8: Mittelwerte der Skalenwerte der SCL-90-R in der Subgruppe der Frauen der SHG 2013 im Vergleich zu Frauen des gesunden Normkollektivs.

Abbildung 9: Mediane der Skalen des SF-36 im Kollektiv der SHG 2015 im Vergleich zum gesunden Normkollektiv

Abbildung 10: Mittelwerte der Skalenwerte des HPQ 40 im HypoPT 2016-Kollektiv im Vergleich zu den SD-

OP 2016 und pHPT 2016-Patienten .

Abbildung 11: Mittelwerte der Skalenwerte für die Skala Vitalität des HPQ 40 im HypoPT 2016-Kollektiv im Vergleich zu SD-OP 2016 und pHPT 2016-Patienten vor und "nach Ausschluss" von Patienten mit vermutlich falschem Antwortverhalten ...

Abbildung 12: prozentualer Anteil der Art der Schilddrüsenoperation in den Patientenkollektiven HypoPT 2016 und SD-OP 2016

Abbildung 13: Boxplots für die Skalenwerte der Skala Schmerz und Krämpfe aufgetrennt nach Operationsart und Studiengruppe .....

Abbildung 14: Skalenwerte für die Skala ängstliche Depression im Vergleich von negativ gescreenten zu positiv gescreenten Patienten.

Abbildung 15: für Albumin korrigierte Calciumwerte im Serum für Patienten aus der Praxis Göttingen aufgeteilt nach Studiengruppe.

Abbildung 16: Phosphatwerte im Serum für Patienten aus der Praxis Göttingen aufgeteilt nach Studiengruppe

Abbildung 17: Parathormonwerte im Serum für Patienten aus der Praxis Göttingen und Calcium-PhosphatProdukt für alle Patienten aus beiden Praxen aufgeteilt nach Studiengruppe.

Abbildung 18: Calciumwerte bzw. Phosphatwerte im 24-h-Urin für alle Patienten aus beiden Praxen aufgeteilt nach Studiengruppe.

abbildung 19: Korrelation der Skalenwerte für Schmerz und Krämpfe mit dem Parathormonlevel im Serum für Patienten aus allen Studiengruppen; Lineare Regression und LOESS-Kurve

Abbildung 20: Korrelation der Skalenwerte für Schmerz und Krämpfe mit dem Calcium-Phosphat-Produkt für HypoPT 2016-Patienten; Lineare Regression und LOESS-Kurve.

Abbildung 21: Übersicht über Komplikationen des Hypoparathyreoidismus (Nierensteine, Niereninsuffizienz, GFR < $60 \mathrm{ml} / \mathrm{min} / 1,73 \mathrm{~m}^{2}$, Nephrokalzinose, Katarakt, BGC, hypo/hyperkalzämische Krisen) in verschiedenen Studien

Abbildung 22: Übersicht über Laborwerte bei Hypoparathyreoidismuspatienten (Serumcalcium, -phosphat und -magnesium, Calcium-Phosphat-Produkt und PTH im Serum) in verschiedenen Studien

Abbildung 23: bildliche Darstellung möglicher Funktionen von Parathormon (PTH) an Skelettmuskel, Gehirn und weiteren Organen sowie mögliche Wirkung von TIP39 als endogener Ligand am PTH2-Rezpetor 73 


\section{Tabellenverzeichnis}

Tabelle 1: Übersicht über die Ätiologie des Hypoparathyreoidismus mit Erläuterungen unterteilt nach angeborenen (genetischen), autoimmunen, erworbenen und weiteren Formen bzw.

Differentialdiagnosen

Tabelle 2: mögliche Symptome und Komplikationen des Hypoparathyreoidismus mit Erläuterungen und Quellenangaben

Tabelle 3: Substitutionstherapie des Hypoparathyreoidismus: verschiedene Vitamin-D-Formen unterteilt in "aktive" und "native" Formen.

Tabelle 4: Charakteristika des Patientenkollektivs Selbsthilfegruppe 2013 (Alter beim Ausfüllen der Fragebögen, Geschlecht, Dauermedikation, Bedarfsmedikation)

Tabelle 5: Charakteristika des Patientenkollektivs der Selbsthilfegruppe 2015 (Alter beim Ausfüllen des Fragebogens, Geschlecht)

Tabelle 6: Charakteristika (Alter, Geschlecht, Praxis) der drei Patientenkollektive HypoPT 2016, SD-OP 2016 und pHPT 2016 als Übersicht.

Tabelle 7: Charakteristika (Art und Grund der Schilddrüsenoperation) der zwei Patientenkollektive HypoPT 2016 und SD-OP 2016 als Übersicht.

Tabelle 8: Charakteristika (Dauermedikation Nebenschilddrüse, Zeit bis Erstmedikation) der drei Patientenkollektive HypoPT 2016, SD-OP 2016 und pHPT 2016 als Übersicht.

Tabelle 9: Charakteristika (Komplikationen und Vorerkrankungen laut Dokumentationsbogen, weitere Medikation) der drei Patientenkollektive HypoPT 2016, SD-OP 2016 und pHPT 2016 als Übersicht.... 30

Tabelle 10: Laborparameter der drei Patientenkollektive HypoPT 2016, SD-OP 2016 und pHPT 2016 mit jeweiligem Normbereich: für Albumin korrigiertes Calcium (= korr.), Phosphat, Calcium-PhosphatProdukt, $25(\mathrm{OH}) \mathrm{D}_{3}, \mathrm{PTH}$ und TSH im Serum, GFR, Calcium und Phosphat im 24-h-Urin.

Tabelle 11: Laborparameter der beiden pHPT 2016-Subgruppen (operiert und nicht operiert) mit jeweiligem Normbereich: für Albumin korrigiertes Calcium (korr.) und PTH im Serum

Tabelle 12: Mittelwert \pm Standardabweichung der täglichen Dosierung der verschiedenen Nebenschilddrüsenmedikamente (Vitamin-D-Speicherform, Kombipräparat, Thiazide, rhPTH, Magnesium) sowie Anzahl der das jeweilige Präparat einnehmenden Patienten.

Tabelle 13: Mittelwert \pm Standardabweichung der täglichen Dosierung von aktivem Vitamin D (verschiedene Subgruppen) und der Calcium-Dauermedikation sowie Anzahl der das jeweilige Präparat einnehmenden Patienten.

Tabelle 14: Skalenwerte, T-Werte und p-Werte des Skalenwertvergleiches aus der Analyse der SCL-90-R in der SHG 2013 im Vergleich zum gesunden Normkollektiv....

Tabelle 15: Skalenwerte, T-Werte und p-Werte des Skalenwertvergleichs der SCL-90-R in der Subgruppe der Frauen der SHG $2013 \mathrm{im}$ Vergleich zu Frauen aus dem gesunden Normkollektiv.

Tabelle 16: Skalenwerte und zugehörige p-Werte des SF-36 im Kollektiv der SHG 2015 im Vergleich zum gesunden Normkollektiv

Tabelle 17: Summenskalen des SF-36 im Kollektiv der SHG 2015 im Vergleich zum gesunden Normkollektiv

Tabelle 18: Skalen des Fragebogens des MVZ endokrinologikum Göttingen mit zugehörigen Items und Prozentsatzanalyse

Tabelle 19: Inhalte der auffälligen Items der „Abfrage zusätzlicher Beschwerden" mit Angabe des Medians..49

Tabelle 20: Skalen des HPQ 40 mit Cronbachs $\alpha$ und zugehörigen Items sowie deren Korrelation mit der Skala (Hauptkomponente) in der rotierten Komponentenmatrix (= Ladung)

Tabelle 21: Skalenwerte und zugehörige p-Werte aus der Analyse des HPQ 40 im HypoPT 2016-Kollektiv im Vergleich zum SD-OP und pHPT 2016-Kollektiv.....

Tabelle 22: Skalenwerte und zugehörige p-Werte aus der Analyse des HPQ 40 im HypoPT 2016-Kollektiv im Vergleich zu den SD-OP 2016 und pHPT 2016-Patienten nach Ausschluss von Patienten mit vermutlich falschem Antwortverhalten

Tabelle 23: Skalenwerte und zugehörige p-Werte aus der Analyse des HPQ 40 im HypoPT 2016-Kollektiv im Vergleich zu operierten und nicht operierten pHPT 2016-Patienten für die Skala Schmerz und Krämpfe

Tabelle 24: Häufigkeiten des negativen/positiven Depressionsscreenings in den drei Studienkollektiven HypoPT, SD-OP und pHPT 2016 
Tabelle 25: Norm- und Zielbereich der Laborparameter Calcium, Phosphat, Calcium-Phosphat-Produkt und PTH im Serum sowie Calcium und Phosphat im Urin für die beiden Praxen Göttingen und Saarbrücken

Tabelle 26: Anteil der Laborwerte (Calcium [korr.], Phosphat im Serum und Urin, PTH und Calcium-PhosphatProdukt im Serum) im Normbereich bzw. Zielbereich in gültigen Prozent sowie dazugehörige Anzahl und Abweichungen vom Normbereich/ Zielbereich für alle drei Studienkollektive.

Tabelle 27: Anteil von PTH im Normbereich in gültigen Prozenten sowie dazugehörige Anzahl und Abweichungen vom Normbereich für die (nicht) operierten pHPT 2016-Subgruppen .

Tabelle 28: Korrelation (Spearman-Koeffizient) der Skala Schmerz und Krämpfe mit Medikamentendosierungen (Calcium-Dauermedikation, Alfacalcidol, Thiazide, Magnesium) sowie mit dem Laborparameter Serum-PTH über alle Patienten

Tabelle 29: Korrelation (Spearman-Koeffizient) der Skala Schmerz und Krämpfe mit der Medikamentendosierung von Thiaziden sowie mit dem Laborparameter Calcium-Phosphat-Produkt über alle Patienten der Gruppe HypoPT 2016.

Tabelle 30: Skalenwerte und zugehörige p-Werte aus der Analyse des HPQ 40 bei Patienten ohne Einnahme von aktivem Vitamin D (气Kollektiven pHPT und SD-OP 2016) im Vergleich zur (Nicht-) Einnahme verschiedener aktiver Vitamin-D-Präparate im HypoPT 2016-Kollektiv (= Calcitriol, Alfacalcidol, Dihydrotachysterol, keine Einnahme).....

Tabelle 31: Übersicht über die Medikation (Calcium-Dauermedikation, aktives Vitamin D [Alfcalcidol, Calcitriol], Kombination, Magnesium, Thiazide, rhPTH) von Hypoparathyreoidismuspatienten in verschiedenen Studien

Tabelle 32: Übersicht über die Dosierung der Medikamente für Hypoparathyreoidismus (CalciumDauermedikation, Alfacalcidol, Calcitriol, Vitamin-D-Speicherform, Magnesium, Thiazide ) in verschiedenen Studien

Tabelle 33: Übersicht über Komplikationen des Hypoparathyreoidismus (Nierensteine, Niereninsuffizienz, GFR <60 ml/min $/ 1,73 \mathrm{~m}^{2}$, Nephrokalzinose, Katarakt, BGC, hypo/hyperkalzämische Krisen) in verschiedenen Studien

Tabelle 34: Übersicht über den Anteil der Patienten mit Laborparametern (Serumcalcium, Serumphosphat, Calcium im 24-h-Urin, Calcium-Phosphat-Produkt) im Normbereich/ Zielbereich in verschiedenen Studien

Tabelle 35: Diäten der drei Patientenkollektive HypoPT 2016, pHPT 2016 und SD-OP 2016 als Übersicht ... 89

Tabelle 36: Laborparameter der beiden pHPT 2016-Subgruppen (operiert und nicht operiert) mit jeweiligem Normbereich: Phosphat, Calcium-Phosphat-Produkt, TSH im Serum sowie Calcium und Phosphat im 24-h-Urin.

Tabelle 37: Skalen des HPQ 40 (ängstliche Depression, Vitalität, Schmerz und Krämpfe, neurovegetative Symptome, gastrointestinale Symptome) und zugehörige Items

Tabelle 38: Skalenwerte und zugehörige p-Werte aus der Analyse des HPQ 40 für die Skala Schmerz und Krämpfe von total thyreoidektomierten und anders operierten HypoPT bzw. SD-OP 2016-Patienten ...90

Tabelle 39: Analyse der Operationsart innerhalb des HypoPT 2016-Kollektivs: Skalenwerte und zugehörige pWerte für die Skala Schmerz und Krämpfe von Patienten mit unterschiedlicher Thyreoidektomie .........90

Tabelle 40: Analyse der Operationsart innerhalb des SD-OP 2016-Kollektivs: Skalenwerte und zugehörige pWerte für die Skala Schmerz und Krämpfe von Patienten mit unterschiedlicher Thyreoidektomie .........91

Tabelle 41: Anteil der Laborwerte (Calcium [korr.], Phosphat im Serum und Urin) im Normbereich in gültigen Prozenten sowie dazugehörige Anzahl und Abweichungen vom Normbereich für die (nicht) operierten pHPT 2016-Subgruppen. 


\section{Anlagenverzeichnis}

Anlage 1: Symptom-Checkliste SCL-90-R 92

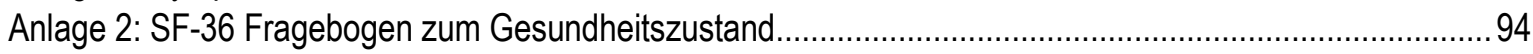

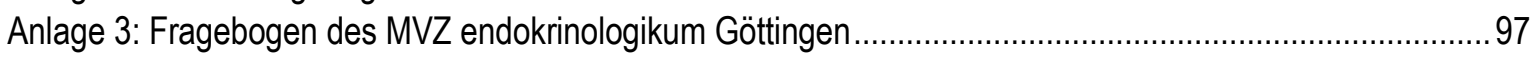

Anlage 4: „Abfrage zusätzlicher Beschwerden“; gemeinsames Ergebnis mit cand. med. L. Wilken ............... 100

Anlage 5: HPQ 40 - Fragebogen für Hypoparathyreoidismus; gemeinsames Ergebnis mit cand. med. L.

Wilken.......

Anlage 6: Dokumentation Hypoparathyreoidismus; gemeinsames Ergebnis mit cand. med. L. Wilken......... 102

Anlage 7: HPQ 28 - Fragebogen für Hypoparathyreoidismus; gemeinsames Ergebnis mit cand. med. L. Wilken.

Anlage 8: Dokumentation Hypoparathyreoidismus nach Überarbeitung; gemeinsames Ergebnis mit cand. med. L. Wilken 


\section{Abkürzungsverzeichnis}

$\mathrm{ADH}$

$\mathrm{AHO}$

AIRE

ANOVA

$B G C$

BMD

CAMP

CaSR

CP-Produkt

d

ESE

FDA

FGF23

$\mathrm{G}(\mathrm{q} / \mathrm{s})$-Protein

GFR

GSI

h

HDR-Syndrom

HPQ (40 bzw. 28)

HypoPT 2016

IE

korr.

LOESS

MVZ

PHP

pHPT 2016

PTH

PTH/PTHrP-Rezeptor $=$

PTH1-Rezeptor

PTH2-Rezeptor

PTHrP

rhPTH

SCL-90-R

SD-OP 2016 autosomal dominante Hypokalzämie

Albright's hereditary osteodystrophy

autoimmune regulator

einfaktorielle Varianzanalyse (one-way analysis of variance)

basal ganglia calcification

bone mineral density

cyclisches Adenosinmonophosphat

calciumsensitiver Rezeptor

Calcium-Phosphat-Produkt

day $=$ Tag

European Society of Endocrinology

Food and Drug Administration

fibroblast growth factor 23

Guaninnukleotid-bindendes Protein (q/s-Unterform)

glomeruläre Filtrationsrate

Global Severity Index

hour $=$ Stunde

hypoparathyroidism-deafness-renal dysplasia-syndrome

Fragebogen für Hypoparathyreoidismus (mit 40 bzw. 28 Fragen)

Studienkollektiv mit Patienten mit postoperativem Hypoparathyreoidismus aus dem Jahr 2016

internationale Einheiten

(für Albumin) korrigiert

local regression

medizinisches Versorgungszentrum

Pseudohypoparathyreoidismus

Kontrollkollektiv mit Patienten mit (nicht) operiertem primären Hyperparathy-

reoidismus aus dem Jahr 2016

Parathormon [natürliches Hormon]

Rezeptor für Parathormon und Parathormon-related Protein = Parathormon1-

Rezeptor

Parathormon2-Rezeptor

Parathormon-related Protein

rekombinantes humanes Parathormon [Medikament]

Symptom-Checkliste SCL-90-R [Fragebogen]

Kontrollkollekitv mit Patienten mit Schilddrüsenoperation ohne postoperativen Hypoparathyreoidmus aus dem Jahr 2016

SF-36

SHG 2013

Short Form-36 health survey = SF-36 Fragebogen zum Gesundheitszustand

Selbsthilfegruppe 2013

Selbsthilfegruppe 2015 
TE

TIP39

TSH

VDR

vs.

$1,25(\mathrm{OH})_{2} \mathrm{D}_{3}$

$25(\mathrm{OH}) \mathrm{D}_{3}$
Thyreoidektomie

tuberoinfundibular peptide of 39 residues

Thyreoidea-stimulierendes Hormon

Vitamin-D-Rezeptor

versus

$1 \alpha, 25$-Dihydroxycholecalciferol $=$ Calcitriol

25-Hydroxycholecalciferol $=$ Calcidiol 


\section{Einleitung}

Der Hypoparathyreoidismus (Nebenschilddrüsenunterfunktion), eine Hormonstörung, die sich unter anderem im Calcium- und Phosphatstoffwechsel manifestiert, galt lange als eine der letzten endokrinologischen Erkrankungen, die nicht mit dem ursächlich mangelnden Hormon behandelt werden konnte. Auch wenn das fehlende Parathormon seit Mai 2017 eine bedingte Zulassung durch die Europäische Kommission hat (Natpar 2017), wird ein Großteil der Patienten ${ }^{1}$ standardmäßig mit einer Kombination aus Calcium und aktivem Vitamin D behandelt. Mit dieser Substitution kann die physiologische Calcium- und Phosphathomöostase nicht komplett wiederhergestellt werden (Clarke et al. 2016; Mannstadt et al. 2017). Patienten berichten trotz aktueller Standardtherapie und regelmäßigen Kontrollen von einer hohen Krankheitslast und zeigen eine eingeschränkte Lebensqualität (Astor et al. 2016; Hadker et al. 2014). Darüber hinaus weisen die Betroffenen ein erhöhtes Risiko für renale Komplikationen und neuropsychiatrische Erkrankungen auf (Mitchell et al. 2012; Underbjerg et al. 2014). Bislang gibt es wenige Erkenntnisse darüber, welche Parameter die Beschwerden der Patienten beeinflussen und inwiefern die berichteten Krankheitsmanifestationen auf die Nebenschilddrüsenunterfunktion selbst oder deren Behandlung zurückzuführen sind (Bilezikian et al. 2016; Bollerslev et al. 2015; Clarke et al. 2016). Vielleicht auch deswegen, weil bislang kein etabliertes Instrument zur deren einheitlichen Erfassung existiert (Cusano et al. 2014; Shoback et al. 2016). Dabei wäre gerade ein Hypoparathyreodismus-spezifisches Messinstrument entscheidend für ein besseres Verständnis der Krankheit und der mit ihr verbundenen eingeschränkten Lebensqualiät (Mannstadt et al. 2017).

Ziel dieser Arbeit war die Konzipierung und erste Testung eines Fragebogens speziell für Hypoparathyreoidismus und damit verbunden die Erforschung der Symptomatik und ihrer Hintergründe bei dieser Erkrankung. Im Folgenden werden zunächst die (Patho)Physiologie der Krankheit, ihre Ursachen, Symptomatik und Therapie genauer erläutert. Anschließend wird auf die Ziele und Fragestellungen genauer eingegangen.

\subsection{Nebenschilddrüse, Parathormon und Calciumstoffwechsel}

Die Nebenschilddrüsen des Menschen - auch Glandulae parathyroideae oder Epithelkörperchen genannt sind vier erbsengroße, rotbraune bis gelbliche endokrine Drüsen, die meist dorsal der Schilddrüse zwischen deren beiden Kapselblättern liegen. Das Organparenchym, das der 3. und 4. Schlundtasche entstammt, ist durch bindegewebige Septen gegliedert und erhält eine eigene Blutversorgung aus der Arteria thyroidea inferior oder superior (Groscurth 2004). Eine ektope Lage im Hals-/Nackenbereich oder zusätzliche Epithelkörperchen sind möglich (Abate und Clarke 2016). Die sekretorisch aktiven Hauptzellen der Nebenschilddrüsen werden in ihrer Aktivität über den calciumsensitiven Rezeptor (CaSR) gesteuert. Dies ist ein G-Protein (=Guaninnukleotid-bindendes Protein)-gekoppelter Rezeptor, der bei einem Anstieg des ionisierten Plasmacalciums im physiologischen Bereich rasch über den Inositolphosphatweg, Calciumfreisetzung (Kurtz 2014), Inhibition der Adenylatcyclase und diverse weitere Mechanismen (Brown und MacLeod 2001; C

\footnotetext{
${ }^{1}$ Im Folgenden wird nur die männliche Form von Substantiven genannt, es sollen jedoch selbstverständlich immer beide Formen angesprochen sein. Zur besseren Lesbarkeit wurde auf die Nennung beider Geschlechter verzichtet.
} 
Zhang et al. 2015) zu einer Hemmung der Parathormonsekretion führt sowie auf mRNA (messenger Ribonukleinsäure)-Ebene langfristig die Hormonausschüttung beeinflusst. Sinkt das extrazelluläre Calcium unter $4 \mathrm{mg} / \mathrm{dl}$ wird Parathormon (= PTH) vermehrt freigesetzt (Marx 2000). Mithilfe dieses Mechanismus ist eine schnelle Anpassung der Parathormonsekretion an den Serumcalciumspiegel und dessen Änderungen möglich (Akerstrom et al. 2005).

Das Parathormon ist ein 84 Aminosäuren langes Peptidhormon, das als Pre-Pro-Hormon in den Nebenschilddrüsen gebildet wird und dessen N-terminale 34 Aminosäuren nach posttranslationaler Modifikation für die physiologische Wirkung am PTH-Rezeptor verantwortlich sind (Gensure et al. 2005). Dabei scheinen Nterminale PTH-Fragmente (PTH 1-34) zur Rezeptoraktivierung auszureichen (Tregear et al. 1973).

Das PTH spielt eine entscheidende Rolle in der Calciumhomöostase des menschlichen Organismus, indem es den Blutcalciumspiegel über verschiedene Mechanismen erhöht. Dazu bindet es an den sogenannten PTH/PTHrP-Rezeptor (Rezeptor für Parathormon und Parathormon-related Protein; auch PTH1-Rezeptor), der dann über ein Gs-Protein CAMP (= cyclisches Adenosinmonophosphat) generiert und über die Proteinkinase A eine Signalkaskade initiiert (Gardella und Jüppner 2001). Daneben werden Effekte über einen GqProtein- oder MAP(= mitogen-activated protein)-Kinase-vermittelten Signalweg diskutiert (Gensure et al. 2005; Miao et al. 2001). Der PTH1-Rezeptor scheint nicht nur in den primären Zielgeweben des PTHs, Knochen und Niere, sondern auch in einer Vielzahl weiterer Gewebe wie beispielsweise Haut, Leber, Hirn, Skelettmuskulatur oder Gefäßen exprimiert zu werden (Urena et al. 1993).

Mit derselben Affinität wie das PTH kann auch das - vor allem para- und autokrin wirkende - Parathormonrelated Protein (PTHrP) an den PTH/PTHrP-Rezeptor binden, welches zunächst als Mediator tumorbedingter Hyperkalzämie identifiziert wurde. Physiologisch spielt es unter anderem in der embryonalen Entwicklung von langen Knochen und Brustdrüsen, aber auch bei der Laktation und in der Placenta eine Rolle (Mundy 1990; Wysolmerski 2012).

Das PTH kann außerdem an den PTH2-Rezeptor (Parathormon2-Rezeptor) binden, der hauptsächlich im zentralen Nervensystem exprimiert wird, dessen endogener Ligand allerdings TIP39 (tuberoinfundibular peptide of 39 residues) zu sein scheint. Mögliche Wirkungen werden u. a. im Bereich der nozizeptiven Verarbeitung und des Affektverhaltens vermutet (Dobolyi et al. 2010).

Der Abbau des PTHs erfolgt proteolytisch in Leber, Nebenschilddrüse und Niere, wobei weiterhin biologisch aktive Fragmente entstehen können (Kurtz 2014). Ist das Calcium im Normbereich, machen allerdings Cterminale PTH-Fragmente (PTH 34/37-84), welche den für die physiologische Hormonwirkung wichtigen PTH1-Rezeptor nicht aktivieren können, rund 80 \% des PTHs im Blut aus (D'Amour 2012; Pines et al. 1994). Daher sollte bei der Messung des PTH-Spiegels im Blut ein Parathormon-Assay der zweiten oder dritten Generation verwendet werden, der möglichst nur intaktes und vollständiges PTH (1-84) detektiert (Eastell et al. 2014).

Ein Rezeptor für das carboxyterminale Ende des PTHs wurde ebenfalls beschrieben, seine genaue Funktion ist allerdings unklar (Inomata et al. 1995). Möglicherweise wirken carboxyterminale PTH-Fragmente über diesen Rezeptor am Knochen antagonistisch zum vollständigen PTH am PTH1-Rezeptor (Murray et al. 2005). 
Im Calciumstoffwechsel agieren Parathormon und Vitamin $D_{3}$ (Cholecalciferol/Calciol) weitgehend synergistisch und werden in ihrer Wirkung teilweise von Calcitonin antagonisiert.

Bei einem niedrigen Spiegel an freiem Calcium im Blut bewirkt das PTH über drei verschiedene Mechanismen eine Anhebung des Serumcalciums (s. auch Abbildung 1):

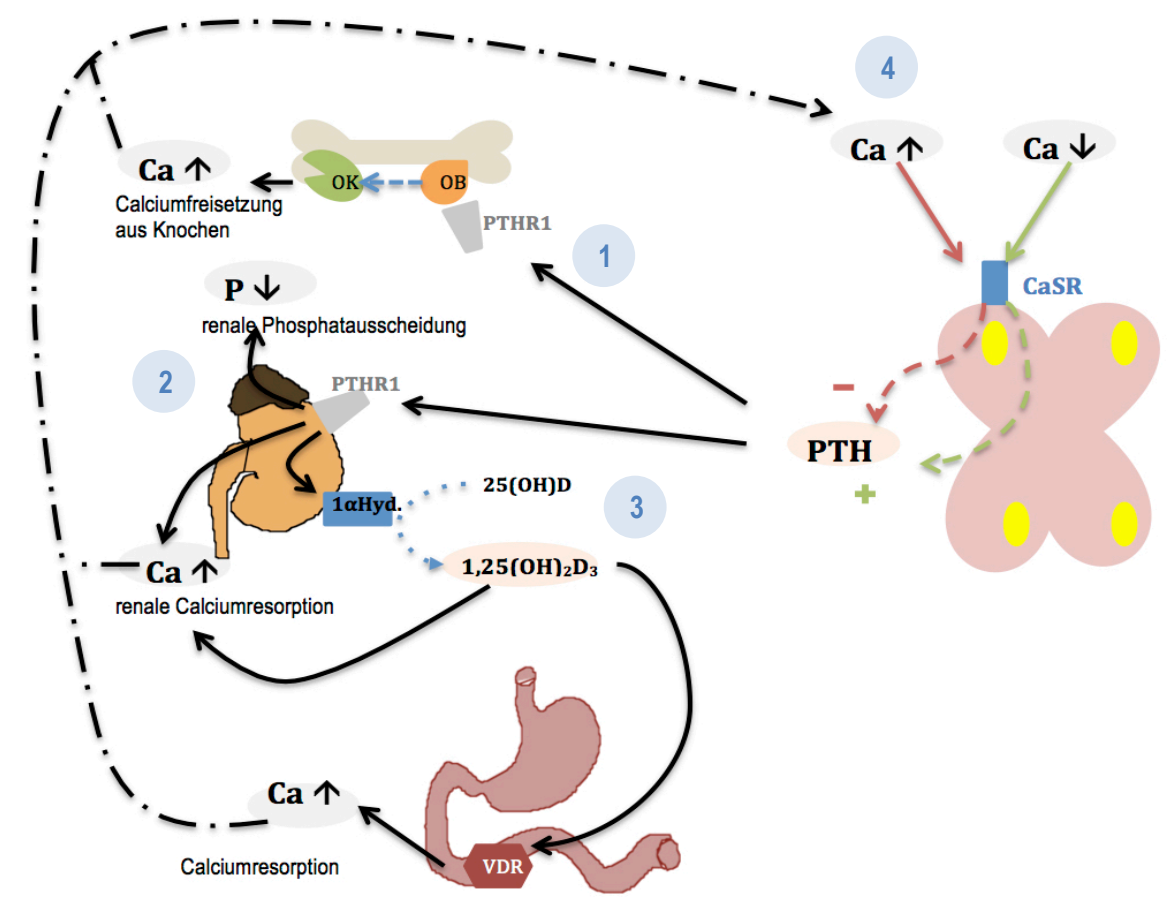

Abbildung 1: bildliche Darstellung bekannter Funktionen des Parathormons (PTH) im Calcium- und Phosphatstoffwechsel: Wirkung auf Knochen (1) und Niere (2) sowie Stimulation der Aktivierung von Vitamin D und damit Wirkung auf den Gastrointestinaltrakt (3); bei steigendem Calciumspiegel wird die PTH-Sekretion über den CaSR (4) gehemmt; weitere Details $\mathrm{s}$. Text (Abkürzungen: $\mathrm{Ca}=$ Calcium, $\mathrm{P}=$ Phosphat, $\mathrm{OB}=$ Osteoblasten, $\mathrm{OK}=$ Osteoklasten, 1aHyd. $=$ 1a-Hydroxylase, PTHR1 $=$ PTH-Rezeptor $1 ;$ VDR $=$ (intranukleärer) Vitamin-D-Rezeptor; CaSR $=$ Calciumsensitiver Rezeptor)

Zum einen stimuliert PTH am Knochen den Abbau von Calcium und anorganischem Phosphat durch Osteoklasten, indem diese u. a. indirekt über RANKL (= receptor activator of NF-KB ligand) von Osteoblasten aktiviert werden (Gardella et al. 2016). Außerdem wirkt PTH an weiteren Zelltypen im Knochen, z. B. an Stromazellen, und veranlasst eine Umbildung der organischen Knochensubstanz. Therapeutisch eingesetztes Parathormon führt bei intermittierender Applikation zu einer Zunahme der Knochenmasse, aber bei kontinuierlicher Gabe zu einem Verlust an Knochensubstanz (Potts 2005).

Zum anderen wird in der Niere im distalen Nephron u. a. über den TRPV5 (transient receptor potential vanilloid 5)-Kanal und weitere komplexe Mechanismen die Calciumresorption initiert und im proximalen Tubulus durch Beeinflussung von Natrium-Phosphat-Cotransportern die Phosphatausscheidung erhöht (Forster et al. 2006; Ko 2017). Der phosphaturische Effekt des Parathormons soll vermutlich verhindern, dass das aus dem Knochen freigesetzte Phosphat im Blut zusammen mit Calciumionen ausfällt, was zu einer Verminderung des freien Serumcalciums führen würde und der PTH-Wirkung entgegenstünde (Oberleithner 2014).

Ein weiterer wichtiger Effekt des PTHs in der Niere ist die vermehrte Expression der $1 \alpha$-Hydroxylase, welche die Vitamin- $\mathrm{D}_{3}$-Vorstufe 25-Hydroxycholecalciferol (Calcidiol $\left.=25(\mathrm{OH}) \mathrm{D}_{3}\right)$ in das aktive $1 \alpha, 25$-Dihydroxycholecalciferol (Calcitriol = 1,25(OH) ${ }_{2} \mathrm{D}_{3}$ ) überführt (Brenza und DeLuca 2000; Garabedian et al. 1972). 
Das aktive Vitamin $\mathrm{D}_{3}$ (Calcitriol) wirkt in der Niere synergistisch mit PTH bei der Calciumresorption, allerdings wird durch Vitamin $D_{3}$ auch Phosphat vermehrt resorbiert (DeLuca und Schnoes 1976; Haussler et al. 1998). Die Hauptwirkung von Calcitriol findet im Gastrointestinaltrakt statt, wo es ebenfalls die Calcium- und Phosphatresorption fördert, indem es an den intranukleären Vitamin-D-Rezeptor (VDR) bindet und verschiedene Transportmoleküle beeinflusst (DeLuca und Schnoes 1976; Mawer und Davies 2001). Über diesen Effekt lässt PTH indirekt das Serumcalcium weiter ansteigen (Potts 2005).

Langfristig wird über die Anhebung des Calciumspiegels und die damit verbundene Hemmung der PTHSekretion sowie über den Calcitriol-vermittelten Anstieg des Serumphosphates der Knochenaufbau wieder gefördert (Oberleithner 2014).

Der vermeintliche Gegenspieler des PTHs, das Calcitonin, wird bei einem Anstieg des Serumcalciums über den Normbereich hinaus ausgeschüttet. Es führt über denselben Natriumcotransporter wie PTH zur vermehrten renalen Phosphatausscheidung (Kurtz 2014), allerdings anders als PTH auch zu einer verstärkten Calciumausscheidung in der Niere (Cochran et al. 1970). Darüber hinaus steht auch die durch Calcitonin vermittelte Hemmung von Osteoklasten und deren Knochenabbau im Gegensatz zur PTH-Wirkung. Dies trägt bei hohen Stoffwechselraten im Knochen zu einer raschen Senkung des Serumcalciumspiegels bei (Davey und Findlay 2013). Durch Hemmung der Darmmotilität und der Produktion von Verdauungssäften wird vermutlich auch die intestinale Calciumresorption vermindert (Kurtz 2014). Dennoch ist die physiologische Bedeutung des Calcitonins noch nicht abschließend geklärt (Felsenfeld und Levine 2015). Wahrscheinlich kann es vor der Entwicklung einer akuten Hyperkalzämie schützen, abgesehen davon wurden schmerzlindernde Effekte beschrieben (Ito und Yoshimura 2017).

Das Parathormon beeinflusst zwar durch die oben genannten Mechanismen den Phosphatspiegel im Serum, hat aber eine weitaus bedeutendere Funktion in der Calciumhomöostase. Der wichtigste Modulator des Phosphathaushaltes ist FGF23 (fibroblast growth factor 23), welcher in der Niere mithilfe des Corezeptor $\alpha$ klotho die Phosphatresorption hemmt sowie den Spiegel an aktiviertem Vitamin $D_{3}$ vermindert. Beides Mechanismen, die das Serumphosphat senken. Es wird außerdem vermutet, dass FGF23 und PTH sich in Ihrer Synthese und Sekretion gegenseitig beeinflussen (Bergwitz und Jüppner 2010; Quarles 2012)

\subsection{HYPOPARATHYREOIDISMUS}

\subsubsection{DEFINITION UND EPIDEMIOLOGIE}

Der Hypoparathyreoidismus ist gekennzeichnet durch Hypokalzämie, Hyperphosphatämie sowie vermehrte renale Calciumausscheidung und Mangel an aktivem Vitamin $\mathrm{D}_{3}$ bei einer insuffizienten PTH-Produktion oder Sekretion in den Nebenschilddrüsen. Diese Störung kann angeboren (primär) oder erworben sein (sekundär) (Shoback 2008; Weisman 2010).

Laut der aktuellen Leitlinie der European Society of Endocrinology (ESE) wird ein chronischer Hypoparathyreoidismus diagnostiziert, wenn sich das ionisierte oder für Albumin korrigierte Serumcalcium (= korr.) unter dem Normbereich befindet bei gleichzeitig unangemessen niedrigem PTH-Spiegel im Blut. Dies drückt das 
Unvermögen der Nebenschilddrüse aus, den Calciumspiegel adäquat anzuheben, genaue Grenzwerte werden nicht genannt (Bollerslev et al. 2015). Die Bezeichnung chronischer Hypoparathyreoidismus als dauerhafter Zustand der Erkrankung dient als Abgrenzung gegenüber dem transienten/protrahiertem Hypoparathyreoidismus, der häufig nach chirurgischen Eingriffen an der (Neben)Schilddrüse auftritt, aber meist nach 6-12 Monaten rückläufig ist (Bilezikian et al. 2011).

Daneben kann man die Nebenschilddrüsenunterfunktion auch über die Notwendigkeit medikamentöser Behandlung der bei ihr typischerweise auftretenden Symptome definieren, sogar teilweise ohne dass sich gravierende laborchemische Änderungen zeigen (relativer Hypoparathyreoidismus) (K Ritter et al. 2015; Stack et al. 2015).

Bis dato gibt es in den unterschiedlichen Leitlinien bzw. Handlungsempfehlungen noch keine weltweit einheitliche Definition dieser Erkrankung (Bollerslev et al. 2015; Brandi et al. 2016; Stack et al. 2015).

Verschiedene Studien haben sich in den letzten Jahren mit der Prävalenz des Hypoparathyreoidismus befasst: Dänische Studien schätzten sie auf ca. 24/100.000 Einwohner, wovon über $80 \%$ operationsbedingt sind (Underbjerg et al. 2013, 2015). In einer italienischen Studie wurde die Prävalenz auf 27/100.000 Einwohner geschätzt (Cianferotti et al. 2018). Untersuchungen aus Norwegen (Astor et al. 2016) und den USA (Clarke et al. 2016) geben ebenfalls Werte in diesen Größenbereichen an, wobei Abweichungen nicht nur durch regionale Unterschiede, sondern auch durch unterschiedliche Krankheitsdefinitionen und Auswertungsmethoden zu erklären sind. Es zeigt sich, dass das weibliche Geschlecht häufiger betroffen und postoperativer Hypoparathyreoidismus die häufigste Erkrankungsursache ist. Das liegt vermutlich daran, dass bei Frauen Schilddrüsenerkrankungen wie beispielsweise Hyperthyreose häufiger vorkommen (Garmendia Madariaga et al. 2014) und operiert werden und so die Wahrscheinlichkeit eines postoperativen Hypoparathyreoidismus als Komplikation höher ist.

Aufgrund der niedrigen Prävalenz kann der Hypoparathyreoidismus als orphan disease bezeichnet werden (Brandi et al. 2016).

\subsubsection{FORMEN UND URSACHEN}

Bei der Nebenschilddrüsenunterfunktion werden je nach Ursache verschiedene Formen unterschieden. Die Krankheit kann angeboren sein oder im Laufe des Lebens auftreten, sich isoliert oder im Rahmen von Syndromen manifestieren (Marx 2000).

Während die Ätiologie des Hypoparathyreoidismus klassischerweise in genetisch, idiopathisch, autoimmun und postoperativ unterteilt wird (Shoback et al. 2016), ist durch moderne Forschungsmethoden die Gruppe der idiopathischen Erkrankung immer kleiner geworden, und es gibt nun ein komplexes Feld an möglichen Erkrankungsursachen (Bilezikian et al. 2011).

Die Tabelle 1 versucht einen Überblick über die möglichen Ursachen der Nebenschilddrüsenunterfunktion zu geben. Zu beachten ist jedoch, dass trotz der Vielfalt der postoperative (iatrogene) Hypoparathyreoidismus mit weitem Abstand der häufigste Erkrankungsgrund ist. 
Tabelle 1: Übersicht über die Ätiologie des Hypoparathyreoidismus mit Erläuterungen unterteilt nach angeborenen (genetischen), autoimmunen, erworbenen und weiteren Formen bzw. Differentialdiagnosen; ohne Anspruch auf Vollständigkeit

\begin{tabular}{|c|c|}
\hline Ätiologie & Erläuterung \\
\hline \multicolumn{2}{|l|}{ angeboren (genetisch) } \\
\hline - isoliert: & $\begin{array}{l}\text { meist Mutationen im PTH(Parathormon)-Gen oder Genen von Tran- } \\
\text { skriptionsfaktoren (z. B. GCMB') }\end{array}$ \\
\hline - Syndrome: & u. a. DiGeorge, HDR ${ }^{1}, \mathrm{HRD}^{1}$, Kearns-Sayre (Mitochondriopathie) \\
\hline - idiopathisch & $\begin{array}{l}\text { isolierte Nebenschilddrüsenunterfunktion ohne (bisher) bekannte } \\
\text { Ursache }\end{array}$ \\
\hline \multicolumn{2}{|l|}{ autoimmun } \\
\hline - isoliert: & z. B. Autoantikörper gegen den calciumsensitiven Rezeptor (CaSR) \\
\hline - Syndrome: & Polyendokrines Autoimmunsyndrom Typ 1 (Mutation im AIRE'-Gen) \\
\hline \multicolumn{2}{|l|}{ erworben } \\
\hline $\begin{array}{l}\text { - postoperativ (auch iatro- } \\
\text { gen): }\end{array}$ & $\begin{array}{l}\text { Eingriffe an Nebenschilddrüse, Schilddrüse, Larynx oder zentrale } \\
\text { Halsdissektion }\end{array}$ \\
\hline anderweite Zerstörung: & $\begin{array}{l}\text { Bestrahlung, Tumorinfiltration, Ablagerungen bei Hämochromatose, } \\
\text { Morbus Wilson }\end{array}$ \\
\hline \multicolumn{2}{|l|}{$\begin{array}{l}\text { weitere Formen bzw. Differential- } \\
\text { diagnosen }\end{array}$} \\
\hline $\begin{array}{l}\text { - Pseudohypoparathyreoi- } \\
\text { dismus: }\end{array}$ & $\begin{array}{l}\text { periphere PTH-Resistenz z. T. mit dem Bild der } \mathrm{AHO}^{1} \text { durch Mutati- } \\
\text { onen in der Rezeptorsignalkaskade }\end{array}$ \\
\hline $\begin{array}{l}\text { - funktioneller Hypoparathy- } \\
\text { reoidisums: }\end{array}$ & $\begin{array}{l}\text { beeinträchtige PTH-Funktion an Zielorganen verursacht durch Mag- } \\
\text { nesium-Mangel z. B. im Rahmen von Diarrhoe, Malnutrition oder } \\
\text { Alkoholismus }\end{array}$ \\
\hline $\begin{array}{l}\text { - ADH: (autosomal dominan- } \\
\text { te Hypokalzämie) }\end{array}$ & $\begin{array}{l}\text { Aktivierende Mutationen im CaSR, die schon bei sehr geringem } \\
\text { Serumcalcium die PTH-Sekretion unterdrücken }\end{array}$ \\
\hline
\end{tabular}

${ }^{1}$ Abkürzungen: $\mathrm{AHO}=$ Albright's hereditary osteodystrophy; $A I R E$ = autoimmune regulator; $G C M B=$ glial cell missing gene; HDR = hypoparathyroidism-deafness-renal dysplasia ; HRD= hypoparathyroidism-retardation-dysmorphism; weitere Erläuterungen s. Text

Bei den genetischen Formen des isolierten Hypoparathyreoidismus treten Mutationen im PTH-Gen oder in für die Entwicklung der Nebenschilddrüse wichtigen Transkriptionsfaktoren und deren Genen (z. B. GCMB= glial cell missing gene) auf. Daraus resultiert eine ungenügende PTH-Produktion oder eine fehlerhafte Nebenschilddrüsenanlage (Sunthornthepvarakul et al. 1999; Thomee et al. 2005).

Die Erbgänge der isolierten Erkrankungsformen können autosomal-dominant oder rezessiv sein (Cole et al. 2000), daneben wird auch eine x-chromosomal assoziierte Nebenschilddrüsenunterfunktion beschreiben (Whyte und Weldon 1981).

Ein Hypoparathyreoidismus als Teil von komplexeren Syndromen kann beispielsweise beim DiGeorgeSyndrom vorkommen, welches durch Thymusfehlbildung mit Immundefizienz, Herzmissbildungen und Hypoparathyreoidismus gekennzeichnet ist. Dieses Syndrom gehört wie das Velocardiofaziale-Syndrom (Gaumenund Herzfehlbildung, Gesichtsanomalien) zum Komplex des Mikrodeletionssyndroms 22q11.2. Dies kann alternativ auch als $\mathrm{CATCH} 22$ (= cardiac anomalies, anomalous face, thymic hypoplasia, cleft palate, hypo- 
calcemia) bezeichnet werden und weist eine große phänotypische Variabilität und viele Überschneidungen zwischen den einzelnen Erkrankungen/Syndromen auf (Kobrynski und Sullivan 2007; Shprintzen 2008).

Andere Erkrankungen, bei denen die Nebenschilddrüse mitbetroffen ist, sind beispielsweise das HDR (hypoparathyroidism-deafness-renal dysplasia)-Syndrom und das HRD (hypoparathyroidism-retardationdysmorphism)-Syndrom. Letzteres wird teilweise synonym mit dem Sanjad-Sakati-Syndrom, teilweise als Überbegriff für das Sanjad-Sakati- und das Kenney-Caffey-Syndrom verwendet, da beide Syndrome wahrscheinlich einen gemeinsamen genetischen Ursprung haben (Diaz et al. 1999; Parvari et al. 2002). Weiterhin kann ein Hypoparathyreoidismus bei mitochondrialen Erkrankungen wie dem Kearns-Sayre-Syndrom auftreten (Bilezikian et al. 2011). Allen diesen Krankheitsbildern ist gemeinsam, dass die genetischen Grundlagen zwar immer besser verstanden werden, ihr Auftreten jedoch sehr selten ist.

Ein idiopathischer Hypoparathyreoidismus liegt dann vor, wenn eine isolierte Nebenschilddrüsenunterfunktion auftritt ohne ersichtlichen Grund und ohne positive Familiengeschichte, die auf eine genetische Ursache schließen ließe - wobei eine de novo-Mutation nicht ausgeschlossen ist und vielleicht nur noch nicht untersucht wurde (Bilezikian et al. 2011; Cole et al. 2000). In früheren Arbeiten wurde der Term „idiopathisch“ z. T. synonym für isolierte (genetische) Formen des Hypoparathyreoidismus verwendet (Bassett und Thakker 1995), was in der heutigen Terminologie verwirrt.

Der autoimmun bedingte Hypoparathyreoidismus ist nach der postoperativen Form die zweihäufigste Ursache einer Nebenschilddrüsenunterfunktion. Es sind zwar genetische Ursachen, wie z. B. Mutationen im AIRE (autoimmune regulator) Gen bekannt, allerdings manifestiert sich die Erkrankung meist erst schrittweise im Laufe des Lebens. Im Falle der oben genannten AIRE-Genmutation, eines wichtigen Autoimmunsupressors, liegt ein Polyendokrines Autoimmunsyndrom Typ 1 (APS1= autoimmune polyendocrine syndrome type 1) vor. Es manifestiert sich - neben dem Hypoparathyreoidismus - durch mukokutane Candidiasis und Nebenniereninsuffizienz, weiterhin sind ein Diabetes Mellitus, Gonadeninsuffizienz, Alopezie und viele andere Zusatzerkrankungen möglich (Aaltonen et al. 1997; Eisenbarth und Gottlieb 2004). Für die Entwicklung der Nebenschilddrüsen-Komponente dieser Erkrankung wird das gewebsspezifische NALP 5 (= NACHT leucine-richrepeat protein 5) als mögliches Autoantigen vermutet (Alimohammadi et al. 2008).

Isolierter autoimmuner Hypoparathyreoidismus kann durch CaSR-Autoantikörper bedingt sein, die vermutlich zur Destruktion der Nebenschilddrüse führen können, den CaSR direkt aktivieren oder auch als Ausdruck der Schädigung verstanden werden (Brown 2009; Kifor et al. 2004).

Rund drei Viertel aller Fälle von Hypoparathyreoidismus sind iatrogen bedingt im Rahmen von chirurgischen Eingriffen an der Nebenschilddrüse selbst, an Schilddrüse, Larynx oder bei zentraler Halsdissektion (Shoback et al. 2016).

In aktuellen Studien kommt es in 1,9 \% (K Ritter et al. 2015) bis zu 8,5 \% (Nawrot et al. 2014) der Fälle bei Thyreoidektomien zu einem permanenten postoperativen Hypoparathyreoidismus. Die Studienlage zur postoperativen Hypokalzämie und Nebenschilddrüsenunterfunktion ist vielfältig und aufgrund einer fehlenden einheitlichen Definition für Hypoparathyreoidismus und verschiedenen Operationstechniken nicht immer leicht zu 
vergleichen. Daher wird die wahre Prävalenz des permanenten postoperativen Hypoparathyreoidismus eher zwischen 6-12 \% vermutet, meist bedingt durch intraoperative Unterbindung der Blutzufuhr, versehentliche Entfernung oder mechanisches/thermisches Trauma der Nebenschilddrüsen (Lorente-Poch et al. 2015a). Dabei hängt die Komplikationsrate offenbar von der Erfahrung des Operateurs ab (Hauch et al. 2014; Paek et al. 2013).

In Deutschland entwickeln nach einer Schätzung jährlich ca. 1200 Menschen einen postoperativen Hypoparathyreoidismus (Bohrer et al. 2007), in einer landesweiten dänischen Kohortenstudie ergab sich eine jährliche Inzidenz von 0.8/100.000 Einwohner (Underbjerg et al. 2013).

Als Risikofaktoren für die Entwicklung eines iatrogenen Hypoparathyreoidismus nach Schilddrüseneingriffen gelten das Resektionsausmaß (zentrale Lymphadenektomie und totale > subtotale Thyreoidektomie), die zugrundeliegende Erkrankung (Immunthyreopathie > Struma nodosa), die Anzahl intraoperativ verifizierter Epithelkörperchen (unter 2 > über 2) und der Nachweis versehentlich mitentfernter Nebenschilddrüsen im pathologischen Resektat (Dralle 2015; Feroci et al. 2014; Giordano et al. 2012; Sitges-Serra et al. 2010). Daneben werden u. a. weibliches Geschlecht, wiederkehrende Struma, ein großes Gewicht des Resektates, Eingriffe aufgrund von Schilddrüsenkrebs oder Voroperationen als mögliche weitere Risikofaktoren für eine postoperative Nebenschilddrüsenfunktionseinschränkung diskutiert (Lorente-Poch et al. 2015a; Stack et al. 2015; Thomusch et al. 2003).

In den aktuellen Leitlinien der ESE für chronischen Hypoparathyreoidismus wird vermutet, dass von allen Patienten mit postoperativer Hypokalzämie ca. 60-70 \% in den ersten 4-6 Wochen vollständig regenerieren. Hier liegt ein transienter Hypoparathyreoidismus vor (Bollerslev et al. 2015), der z. B. durch eine zeitweise Ischämie der Nebenschilddrüsen bedingt sein kann (Stack et al. 2015).

Erholt sich der Calciumstoffwechsel des Patienten im Laufe dieser ersten Wochen nicht, wird teilweise von protrahiertem Hypoparathyreoidismus geredet (Sitges-Serra et al. 2010). Aus diesem Kollektiv entwickeln jedoch lediglich $21 \%$ innerhalb eines Jahres eine chronische (permanente) Nebenschilddrüsenunterfunktion, wobei der wichtigste Prädiktor die Anzahl der in situ verbleibenden funktionsfähigen Epithelkörperchen zu sein scheint: Je mehr Nebenschilddrüsen vorhanden sind, umso geringer die Wahrscheinlichkeit einer dauerhaften Beeinträchtigung (Lorente-Poch et al. 2015b).

Je nach Autor wird ab 6-12 Monate bestehender Unterfunktion von einem permanenten Hypoparathyreoidismus gesprochen (K Ritter et al. 2015; Shoback 2008).

Selbstverständlich werden verschiedene Maßnahmen zur Vermeidung einer postoperativen Hypokalzämie erprobt, beispielsweise das intraoperative PTH-Monitoring (Richards et al. 2003; Richards et al. 2008). Wenn der Versuch die Nebenschilddrüse in situ zu erhalten scheitert, kann eine Autotransplantation in den Musculus sternocleidomastoideus (Palazzo et al. 2005) oder eine Kryokonservierung der Epithelkörperchen für eine später mögliche Transplantation (Liu et al. 2015) erfolgen. Daneben wird teilweise postoperativ prophylaktisch Calcium und Vitamin D substituiert (Tolone et al. 2013), damit möglicherweise angeschlagene Nebenschilddrüsen schneller regenerieren. Die Anwendung minimalinvasiver Operationstechniken konnten noch keinen deutlichen Vorteil hinsichtlich des postoperativen Hypoparathyreoidismus zeigen ( $P$ Zhang et al. 2015). Präoperativ kann beispielsweise versucht werden, durch Gabe von Dexamethason die Wahrscheinlichkeit des Auftretens eines transienten postoperativen Hypoparathyreoidismus und seiner Symptome zu vermindern 
(Schietroma et al. 2013), wobei ein möglicher Mechanismus das verminderte Auftreten von Vasospasmen sein könnte. All diese Versuche sind in ihrer Wirksamkeit umstritten, und die vermutlich effektivste Maßnahme bleibt, wie bereits erwähnt, der Erhalt von möglichst vielen funktionsfähigen Epithelkörperchen in situ (Lorente-Poch et al. 2015b). Wahrscheinlich kann schon eine einzige funktionierende Nebenschilddrüse den Verlust der anderen kompensieren (Song et al. 2014).

Eine weitere mögliche Ursache einer Nebenschilddrüsenunterfunktion kann z. B. eine Störung im Magnesiumhaushalt sein, wodurch ein funktioneller Hypoparathyreoidismus entsteht, da bei sehr niedrigen Magnesiumspiegeln unter anderem die PTH-Sekretion eingeschränkt ist und eine reversible PTH-Resistenz auftreten kann (Bilezikian et al. 2016; Singh et al. 2006). Aber auch eine Hypermagnesiämie kann durch Bindung des Magnesiums an den CaSR die PTH-Sekretion vermindern (Shoback et al. 2016).

Darüber hinaus können Metallablagerung im Rahmen von Hämochromatose oder Morbus Wilson zur Nebenschilddrüsenunterfunktion führen (Abate und Clarke 2016).

Pseudohypoparathyreoidismus (PHP) ist ein Überbegriff für verschiedene Formen der peripheren Organresistenz gegen die Wirkung des PTHs (C Ritter et al. 2015). Meist liegen dabei Defekte im Bereich des GNAS (guanine nucleotide-binding protein G-s alpha subunit)-Gens vor, welches die alpha-Untereinheit des GsProteins im PTH1-Rezeptor kodiert. Dies führt dazu, dass PTH zwar im Übermaß im Blut vorhanden ist, aber aufgrund einer gestörten Rezeptorsignalkaskade die bestehende Hypokalzämie und Hyperphosphatämie beim Patienten nicht ausgleichen kann (Levine 1999; Mantovani et al. 2012).

PHP Typ 1a und 1c treten gleichzeitig mit den typischen Merkmalen der Albright-Osteodystrophie (AHO= Albright's hereditary osteodystrophy) auf wie u. a. Kleinwuchs, Übergewicht und Brachydaktylie. Sie sind neben der PTH-Resistenz auch durch andere Hormonresistenzen gekennzeichnet, z. B. gegen TSH (= Thyreoidea-stimulierendes Hormon) oder GnRH (= Gonadotropin-releasing-Hormon). Die beiden Formen lassen sich nur molekulargenetisch unterscheiden.

Patienten mit PHP Typ 1b zeigen keine ausgeprägte AHO, und die Hormonresistenz ist meist auf die renale PTH-Wirkung beschränkt. Bei PHP Typ 2 ist die fehlende PTH-Wirkung wahrscheinlich auf einen Defekt distal der cAMP-Generierung zurückzuführen (Levine 2012; Weisman 2010).

Eine AHO ohne Hormonstörung des Kalziumstoffwechsels bezeichnet man als PseudoPseudohypoparathyreoidismus (Kruse 1997).

Im Falle einer familiären hyperkalziurischen Hypokalzämie (auch ADH - autosomal dominante Hypokalzämie) liegen meist aktivierende Mutationen im CaSR vor, die die Rezeptorsensitivität erhöhen und schon bei niedrigem Serumcalcium zu einer Unterdrückung PTH-Sekretion führen. Laborchemisch ist meist eine Hypokalzämie und Hyperkalziurie bei niedrigen PTH-Spiegeln zu finden, da der Rezeptor in der Niere vermutlich auch direkt die Calciumreabsorption beeinflusst (Guarnieri et al. 2012). 


\subsubsection{SYMPTOME UND KOMPLIKATIONEN}

Beim Hypoparathyreoidismus wird eine Vielzahl von körperlichen und psychischen Symptomen beobachtet, deren Kausalzusammenhang mit den pathophysiologischen Veränderungen dieser Krankheit noch nicht für alle Erscheinungen abschließend geklärt ist.

Die klassischen Zeichen der durch den Parathormonmangel hervorgerufenen Hypokalzämie sind: periorale und akrale Parästhesien, Muskelkrämpfe und Laryngo- und Bronchospasmen bis hin zu Krampfanfällen. In der klinischen Untersuchung zeigt sich dabei ein positives Trousseau- (Karpalspasmus bei übermäßigem Aufpumpen der Blutdruckmanschette) und/oder Chvostek-Zeichen (Lippenzucken beim Beklopfen des Nervus facialis auf der Wange) als Ausdruck der neuromuskulären Erregbarkeit (Shoback 2008). Im Rahmen eines akuten postoperativen Abfalls des Serumcalciumspiegels nach Schilddrüseneingriffen können diese Symptome wesentlich drastischer ausgeprägt sein als bei chronischer Hypokalzämie (Abate und Clarke 2016).

Mitchell et al. (2012) konnten mit ihrer Studie häufige Langzeitkomplikationen des permanenten Hypoparathyreoidismus aufzeigen, wie Nephrokalzinose, Nierensteine oder Basalganglienverkalkung (BGC = basal ganglia calcification). Diese kommen wahrscheinlich durch die Hyperphosphatämie, das erhöhte CalciumPhosphat-Produkt (= CP-Produkt) und die damit verbundenen ektopen Kalzifikation von Geweben zustande. Dabei tragen sowohl die fehlende phosphaturische Wirkung des Parathormons als auch die Behandlung mit Vitamin-D-Präparaten synergistisch zu einem erhöhten Serumphosphatlevel bei (Shoback et al. 2016). Ektope Kalzifikationen könnten auch bei chronischer Hyperphosphatämie ohne ein erhöhtes Calcium-PhosphatProdukt auftreten (Brandi et al. 2016). Im Bezug auf die Nierenfunktion sind vor allem therapiebedingte hyperkalzämische Episoden bei bereits bestehender Hyperphosphatämie kritisch und erhöhen das Risiko eines chronischen Nierenversagens. Dennoch herrscht Uneinigkeit darüber, welcher Anteil der Langzeitkomplikationen auf die Therapie und welcher auf die Krankheit an sich zurückzuführen ist (Mitchell et al. 2012; Rejnmark et al. 2015; Shoback et al. 2016).

Eine Verkalkung der Basalganglien, auch Morbus Fahr genannt, kommt außer bei Parathormonmangel noch im Rahmen anderer Erkrankungen, wie Tuberöser Sklerose, oder bei intrauterinen Infektionen vor (Saleem et al. 2013). An der Pathogenese der BGC bei Hypoparathyreoidismus sind neben den oben beschriebenen Störungen des Calciumstoffwechsels wahrscheinlich verschiedene osteogene Moleküle beteiligt, wie PiT1 (phosphate transporter) oder CA-II (carbo-anhydrase II), deren Expression im Nukleus Caudatus sich von anderen Orten der grauen Substanz unterscheidet (Goswami et al. 2014). Inwiefern die BGC mit denen bei Hypoparathyreoidismus beobachteten neurologischen Symptomen zusammenhängt ist unklar: Aggarwal et al. (2013) fanden keine Korrelation zwischen in diversen Tests beobachteten neuropsychologischen, cerebellären und extrapyramidalen Symptomen und der BGC bei idiopathischem Hypoparathyreoidismus. Es bestand jedoch ein Zusammenhang mit dem Calcium-Phosphat-Produkt.

Der veränderte Knochenstoffwechsel bei chronischem Hypoparathyreoidismus resultiert in einer erhöhten Knochendichte und -masse bei erniedrigtem Knochenumsatz und abnormaler Mikroarchitektur des Knochens (Rubin und Bilezikian 2010). Der genaue Effekt dieser Veränderungen auf Knochenqualität und Frakturrisiko bleibt noch umstritten (Clarke 2014). Darüber hinaus wurde eine Assoziation von idiopathischem Hypopa- 
rathyreoidismus mit spondylarthopathischen Veränderungen beschrieben (Goswami et al. 2008; Jakkani et al. 2011).

Weitere Studien zeigten vermehrtes Auftreten von Angstsymptomen, Depressionen, globale kognitive Dysfunktion, mögliche kardiale Komplikationen und ein erhöhtes Infektionsrisiko (s. Tabelle 2). Diese Tabelle soll einen Überblick über die in der Literatur zu findende Vielfalt von Krankheitsmanifestationen, Symptomen und Komplikationen und des Hypoparathyreoidismus geben, erhebt aber keinen Anspruch auf Vollständigkeit. 
Tabelle 2: mögliche Symptome und Komplikationen des Hypoparathyreoidismus mit Erläuterungen und Quellenangaben

\begin{tabular}{|c|c|c|}
\hline Symptome und Komplikationen & Anmerkung & Quellen (Auswahl) \\
\hline $\begin{array}{ll}\text { neuromuskulär } \\
\text { - } & \text { Muskelkrämpfe- und Spasmen } \\
- & \text { Kribbelparästhesien und Taubheitsgefühle } \\
\text { - } & \text { Krampfanfälle }\end{array}$ & $\begin{array}{l}\text { vermutlich durch Hypokalz- } \\
\text { ämie bedingt }\end{array}$ & $\begin{array}{l}\text { (Marx 2000) } \\
\text { (Shoback 2008) }\end{array}$ \\
\hline $\begin{array}{cl}\text { renal } & \\
- & \text { Nephrokalzinose } \\
- & \text { Nephrolithiasis } \\
- & \text { chron. Niereninsuffizienz }\end{array}$ & $\begin{array}{l}\text { u. a. durch ektope Kalzifika- } \\
\text { tionen verursacht }\end{array}$ & $\begin{array}{l}\text { (Mitchell et al. 2012) } \\
\text { (Underbjerg et al. 2013) }\end{array}$ \\
\hline $\begin{array}{ll}\text { Knochenstoffwechsel } \\
\text { - } & \text { erhöhte Knochenmineraldichte } \\
\text { - } & \text { erniedrigter Knochenumsatz } \\
\text { - } & \text { abnormale Mikroarchitektur }\end{array}$ & $\begin{array}{l}\text { unklarer Effekt auf Kno- } \\
\text { chenqualität und Frakturri- } \\
\text { siko }\end{array}$ & $\begin{array}{l}\text { (Rubin und Bilezikian } \\
\text { 2010) } \\
\text { (Clarke 2014) }\end{array}$ \\
\hline $\begin{array}{ll}\text { neurologisch und/oder psychisch } \\
\text { - } & \text { Angst und Phobie } \\
\text { - } & \text { Somatisierung } \\
\text { - } & \text { Depression } \\
\text { - } & \text { globale kognitive Funktionseinschränkung (z. B. } \\
& \text { Gestaltwahrnehmung, Gedächtnisfunktion) } \\
\text { - } & \text { extrapyramidale/cerebelläre Symptome } \\
\text { - } & \text { Konzentrationsstörungen, „,brain fog“ }\end{array}$ & & $\begin{array}{l}\text { (Arlt et al. 2002) } \\
\text { (Underbjerg et al. 2014) } \\
\text { (Aggarwal et al. 2013) } \\
\text { (Hadker et al. 2014) }\end{array}$ \\
\hline Basalganglienverkalkung (M. Fahr) & $\begin{array}{l}\text { Zusammenhang mit neuro- } \\
\text { (psycho)logischen Symp- } \\
\text { tomen umstritten }\end{array}$ & $\begin{array}{l}\text { (Aggarwal et al. 2013) } \\
\text { (Mitchell et al. 2012) } \\
\text { (Goswami et al. 2012) }\end{array}$ \\
\hline Katarakt & $\begin{array}{l}\text { unterschiedliche Ergebnis- } \\
\text { se je nach Ätiologie }\end{array}$ & $\begin{array}{l}\text { (Underbjerg et al. 2014) } \\
\text { (Underbjerg et al. 2015) } \\
\text { (Arlt et al. 2002) }\end{array}$ \\
\hline \begin{tabular}{ll}
\multicolumn{2}{l}{ kardiovaskulär } \\
- & congestive heart failure (Herzinsuffizienz) \\
- & ischämische Herzerkrankung \\
- & Schlaganfall \\
- & Arrhythmien
\end{tabular} & $\begin{array}{l}\text { unterschiedliche Ergebnis- } \\
\text { se je nach Ätiologie, } \\
\text { Hypokalzämie als mögliche } \\
\text { Ursache }\end{array}$ & $\begin{array}{l}\text { (Shoback et al. 2016) } \\
\text { (De Sanctis et al. 2012) } \\
\text { (Underbjerg et al. 2015) } \\
\text { (Ballane et al. 2012) }\end{array}$ \\
\hline $\begin{array}{l}\text { Lebensqualität } \\
\text { - } \quad \text { eingeschränkte gesundheitsbezogene Lebens- } \\
\text { qualität (SF-36) } \\
\text { - } \quad \text { physische Einschränkungen (niedrige körperliche } \\
\text { Summenskala) } \\
\text { - Einschränkungen im Alltag, Sozial - und Arbeits- } \\
\quad \text { leben }\end{array}$ & $\begin{array}{l}\text { Patienten mit postoperati- } \\
\text { vem Hypoparathyreoidis- } \\
\text { mus z. T. stärker einge- } \\
\text { schränkt }\end{array}$ & $\begin{array}{l}\text { (Cusano et al. 2014) } \\
\text { (Astor et al. 2016) } \\
\text { (Sikjaer et al. 2016) } \\
\text { (Hadker et al. 2014) }\end{array}$ \\
\hline $\begin{array}{ll}\text { weitere } & \text { Symptome } \\
\text { - } & \text { Infektionsrisiko } \\
- & \text { gastrointestinale Beschwerden (Steatorrhoe) } \\
- & \text { Muskeldegeneration, Schmerzen und Kraftverlust } \\
- & \text { Veränderungen von Zähnen, Haut und } \\
& \text {-anhangsgebilden }\end{array}$ & & $\begin{array}{l}\text { (Shoback et al. 2016) } \\
\text { (Abboud et al. 2011) } \\
\text { (Underbjerg et al. 2014) } \\
\text { (Dai et al. 2012) } \\
\text { (Sikjaer et al. 2016) } \\
\text { (Srirangarajan et al. } \\
\text { 2014) }\end{array}$ \\
\hline
\end{tabular}

Es ist darauf zu achten, dass es je nach Ätiologie des Hypoparathyreoidismus verschiedene Symptomhäufigkeiten geben kann. So wurde beispielsweise in dänischen Studien ein erhöhtes Risiko für Kataraktbildung bei nicht postoperativem Hypoparathyreoidisimus gefunden, bei postoperativem Hypoparathyreoidismus war jedoch kein erhöhtes Risiko im Vergleich zu gesunden Kontrollen feststellbar (Clarke et al. 2016; Underbjerg 
et al. 2014, 2015). Ähnlich verhielt es sich mit kardiovaskulären Erkrankungen (Underbjerg et al. 2013), wobei es mehrere Fallberichte zu Hypokalzämie-bedingtem Herzversagen im Rahmen einer Nebenschilddrüsenunterfunktion gibt (Ballane et al. 2012). Vermutlich ist die kardiale Kontraktilität aufgrund des geringen Serumcalciumspiegels vermindert, möglich ist aber auch eine direkte Parathormonwirkung an den Kardiomyozyten (Abate und Clarke 2016).

In einer Onlineumfrage bei Patienten mit Hypoparathyreoidismus gaben die Befragten an, dass Muskelschmerzen und Krämpfe zu den häufigsten Symptomen unter laufender Standardtherapie gehören (Hadker et al. 2014). Darüber hinaus können Muskelenzyme im Serum (z. B. die Kreatinkinase) erhöht und die Muskelkraft reduziert, sowie histologische Veränderungen der Skelettmuskulatur im Sinne einer Degeneration erkennbar sein (Dai et al. 2012; Sikjaer et al. 2016).

Bei Patienten, deren Ursache des Hypoparathyreoidismus in einem komplexen Syndrom begründet ist, können weitere syndromspezifische Symptome auftreten, wie z. B. Taubheit und Nierenfehlbildungen beim HDRSyndrom (Bilezikian et al. 2011; Shoback et al. 2016).

Neben psychischen Beschwerden wie Angst, Depressivität oder kognitiven Funktionsstörungen haben Patienten mit Nebenschilddrüsenunterfunktion eine hohe Gesamtbeschwerdelast (Arlt et al. 2002; Hadker et al. 2014). Mehrere Studien zeigten Einschränkungen der Lebensqualität, je nach Vergleichskollektiv umfasste diese Einschränkung physische und/oder psychische Dimensionen (Cusano et al. 2014; Sikjaer et al. 2016). Außerdem sind viele Patienten in ihrem Alltags- und Arbeitsleben beeinträchtigt (Astor et al. 2016; Hadker et al. 2014). Daher legen die aktuellen europäischen Leitlinien bei der Hypoparathyreoidismustherapie nicht nur Wert auf Symptom- und Laborwertkontrolle, sondern auch das Gesamtwohlbefinden (overall well-being) und die Lebensqualität des einzelnen Patienten (Bollerslev et al. 2015).

Trotz der oben erwähnten Komplikationen eines permanenten Hypoparathyreoidismus konnten Underbjerg et al. (2013) in ihrer Studie keine erhöhte Mortalität bei Patienten mit postoperativem Hypoparathyreoidismus feststellen, deren Operationsgrund nicht-maligne war. Ob dieses Ergebnis auf alle Patienten mit dieser Erkrankung übertragbar ist, bleibt fraglich, da weitere Studien zur generellen oder ursachenspezifischen Mortalität aus anderen Ländern bislang fehlen (Clarke et al. 2016).

\subsection{TherapiE des HYPOPARATHYREOIDISMUS UND NEBENWIRKUNGEN}

In der Therapie des Hypoparathyreoidismus muss zwischen der Behandlung einer akuten Hypokalzämie und der Dauertherapie des chronischen Calciummangels unterschieden werden.

Erstere tritt meist postoperativ auf und äußerst sich in der Maximalvariante mit den oben beschriebenen Symptomen wie Spasmen oder Krampfanfällen. Diese akute Hypokalzämie sollte intravenös behandelt werden, beispielweise nach Empfehlung von Brandi et al. (2016) mit ein bis zwei Ampullen 10\%iger Calciumglukonatlösung ( $\approx 90-180 \mathrm{mg}$ elementares Calcium) auf 50ml 5\%tiger Dextrose über 15 Minuten mit anschließender intravenöser Erhaltungstherapie. Die beiden Hauptziele der akuten Hypokalzämie-Therapie sind eine unmittelbare Symptomkontrolle und die Einstellung des Serumcalciums im unteren Normbereich. Des Weiteren sollte auf den Magnesiumspiegel im Serum geachtet werden, um eine ggf. vorliegende durch Hypomagnesiämie bedingte PTH-Resistenz zeitnah zu korrigieren (Bilezikian et al. 2016). 
Während der Akuttherapie ist der Herzrhythmus zu überwachen, da es je nach Infusionsgeschwindigkeit zu Arrhythmien kommen kann (Schafer und Shoback 2000). Weitere Nebenwirkungen intravenöser Calciumgabe sind Venenreizung, Kalzifikation von Weichgeweben oder Nekrosen, falls es zu Paravasaten kommt (Kagen et al. 2000). Calciumglukonat ist gegenüber Calciumchlorid bei der intravenösen Therapie zu bevorzugen, da es bei Extravasation mit geringerer Wahrscheinlichkeit Gewebsnekrosen hervorruft (Bilezikian et al. 2016).

Als präventive Maßnahme gegen eine akute postoperative hypokalzämische Krise schlagen Stack et al. (2015) neben einer sofortigen empirischen kombinierten Calcium- und Calcitriolgabe, welche mit der Gefahr einer Übertherapie normokalzämischer Patienten verbunden ist, eine stufenweise Therapieeskalation vor. Die kontinuierliche intravenöse Calciumgabe wird erst an dritter Stelle empfohlen. Die Theorie dahinter besagt, dass eine milde Hypokalzämie die Nebenschilddrüsen postoperativ zur Parathormonsekretion stimulieren kann.

Es wird an verschiedenen Methoden gearbeitet, um eine mögliche postoperative Hypokalzämie frühestmöglich vorherzusagen, z. B. mithilfe einer kombinierten intakten PTH- und Serumcalciummessung, um diejenigen Patienten herauszufiltern, die tatsächlich einer intensivierten - und z. T. kostspieligen - Therapie und Überwachung bedürfen (Saba et al. 2017).

Seit der Zulassung von rhPTH (rekombinantes humanes Parathormon) im Mai 2017 ist auch eine direkte Behandlung der akuten Hypokalzämie mit dem fehlenden Hormon denkbar. Einige Autoren berichten von erfolgreichem Einsatz von rhPTH(1-34) als Add-on bei anderswertig therapierefraktärer schwerer Hypokalzämie zur Symptomkontrolle und (Teil-)Normalisierung des Calciumhaushaltes (Andrysiak-Mamos et al. 2016; Shah et al. 2015). Systematische Studien, inwiefern eine alleinige oder kombinierte rhPTH-Therapie der bisherigen Akuttherapie überlegen ist, stehen noch aus.

Wesentliche Ziele der langfristigen Hypoparathyreoidismustherapie sind neben der Normalisierung der Calciumwerte in Serum und Urin eine ausreichende Symptomfreiheit und Verhinderung von Kalzifikationen in Niere und anderen Weichgeweben. Sowohl Brandi et al. (2016) als auch Bollerslev et al. (2016) schlagen dafür eine Einstellung des Serumcalciums im unteren oder knapp unter dem Normbereich, eine normwertige Calciumausscheidung im Urin und ein Calcium-Phosphat-Produkt von $<4,4 \mathrm{mmol}^{2} / /^{2}$ vor.

Als Standardtherapie hat sich dafür eine Kombination aus einem Calcium- mit einem (aktiven) Vitamin-DPräparat etabliert. Für die orale Calciumsubstitution kommt sowohl das kostengünstigere Calciumcarbonat mit $40 \%$ Calciumanteil als auch Calciumcitrat mit geringerem Anteil an elementarem Calcium infrage (Straub 2007). Letzteres ist bei Patienten mit Achlorhydrie zu bevorzugen, da es in diesem Fall nahrungsunabhängig besser resorbiert wird (Recker 1985). Dies ist auch für Patienten unter Therapie mit Protonenpumpeninhibitoren relevant, bei denen außerdem auf eine therapiebedingte Hypomagnesiämie und der damit verbundenen verminderten PTH-Sekretion geachtet werden sollte (Epstein et al. 2006). Bilezikian et al. (2016) schätzen den täglichen Bedarf an elementarem Calcium bei Hypoparathyreoidismuspatienten auf 1000-3000 mg. Dabei sollte man auf Hyperkalziurie als mögliche Nebenwirkung achten (Bollerslev et al. 2015), kann aber auch vom phosphatbindenden Effekt des Calciums profitieren und somit gleichzeitig den Serumphosphathaushalt kontrollieren (Malberti 2013). 
Eine Übersicht über die verschiedenen Vitamin-D-Präparate und ihre Eigenschaften gibt Tabelle 3. Es kann in der Hypoparathyreoidismustherapie zwischen „aktiven“ und „nativen“ Vitamin-D-Formen unterschieden werden. Erstere wirken direkt (Calcitriol) oder nach Aktivierung in der Leber (Alfacalcidol), letztere müssen, wie bereits unter Punkt 1.1 erwähnt, über verschiedene Zwischenstufen $\left(25(\mathrm{OH}) \mathrm{D}_{3}, 1,25(\mathrm{OH})_{2} \mathrm{D}_{3}\right)$ im Körper enzymatisch aktiviert werden (Jones 2013; Lawson et al. 1971). Dieser Aktivierungsprozess läuft vermutlich für beide nativen Vitamin-D-Formen (Cholecalciferol und Ergocalciferol = Vitamin-D-Speicherformen) analog ab, ist jedoch für Cholecalciferol wesentlich intensiver untersucht, weshalb hier nur dessen Metaboliten dargestellt werden (Jones et al. 1998).

Tabelle 3: Substitutionstherapie des Hypoparathyreoidismus: verschiedene Vitamin-D-Formen (Präparate, pharmakologische Eigenschaften, Anmerkungen und Quellenangaben) unterteilt in „aktive" und „native" Formen; HWZ = Halbwertszeit, IE = internationale Einheiten, $d=$ day, $\mathrm{h}=$ hour

\begin{tabular}{|c|c|c|c|c|}
\hline & Präparat & $\begin{array}{l}\text { pharmakologische } \\
\text { Eigenschaften }\end{array}$ & Anmerkung & Quellen \\
\hline \multirow[t]{3}{*}{$\begin{array}{l}\text { "aktive“ } \\
\text { Vitamin-D- } \\
\text { Formen }\end{array}$} & $\begin{array}{l}\text { Alfacalcidol }(1 \mathrm{a}- \\
\text { Hydroxychole- } \\
\text { calciferol = } \\
\left.1 \mathrm{aOHD}_{3}\right)\end{array}$ & $\begin{array}{l}\text { Wirkungsbeginn: } 1-7 \mathrm{~d} \\
\text { Wirkungsdauer: ca. } 5-7 \mathrm{~d} \\
\text { HWZ: ca. } 4 \mathrm{~h} \\
\text { Dosis: } 0,5-4 \mu \mathrm{g} / \mathrm{d}\end{array}$ & $\begin{array}{l}\text { in Leber aktiviert; } \\
\text { längere biologische } \\
\text { Wirksamkeit, aber } \\
\text { geringere Potenz als } \\
\text { Calcitriol -> höhere } \\
\text { Dosis nötig }\end{array}$ & $\begin{array}{l}\text { (Fukushima et al. 1976) } \\
\text { (Alfacalcidol(1APharma } \\
\text { () 2014) } \\
\text { (Okano et al. 1982) } \\
\text { (Halabe et al. 1994) } \\
\text { (Brickman et al. 1976) } \\
\text { (Bollerslev et al. 2015) }\end{array}$ \\
\hline & $\begin{array}{l}\text { Dihydrotachyste- } \\
\text { rol }\end{array}$ & $\begin{array}{l}\text { Wirkungsbeginn: } 4-7 \mathrm{~d} \\
\text { Wirkungsdauer: } 7-21 \mathrm{~d} \\
\text { HWZ: ca. } 6-8 \mathrm{~h} \\
\text { Dosis: } 0,3-1 \mathrm{mg} / \mathrm{d}\end{array}$ & $\begin{array}{l}\text { (halb)synthetisches } \\
\text { Vitamin-D-Analogon; in } \\
\text { Leber aktiviert; } \\
\text { Nierenversagen und } \\
\text { Hyperkalzämie be- } \\
\text { schrieben }\end{array}$ & $\begin{array}{l}\text { (Haussler und Cordy } \\
\text { 1982) } \\
\text { (Quack et al. 2005) } \\
\text { (Jensterle et al. 2010) } \\
\text { (Bilezikian et al. 2016) } \\
\text { (Bollerslev et al. 2015) } \\
\text { (Koytchev et al. 1994) }\end{array}$ \\
\hline & $\begin{array}{l}\text { Calcitriol }(1 \mathrm{a}, 25- \\
\text { Dihydroxychole- } \\
\text { calciferol }= \\
\left.1,25(\mathrm{OH})_{2} \mathrm{D}_{3}\right)\end{array}$ & $\begin{array}{l}\text { Wirkungsbeginn: } 1-3 \mathrm{~d} \\
\text { Wirkungsdauer: } 2-3 \mathrm{~d} \\
\text { HWZ: } 5-8 \mathrm{~h} \\
\text { Dosis: } 0,25-2 \mu \mathrm{g} / \mathrm{d}\end{array}$ & $\begin{array}{l}\text { wegen kürzerer Wirk- } \\
\text { dauer besser steuerbar } \\
\text { bei Intoxikation/ Hyper- } \\
\text { kalzämie }\end{array}$ & $\begin{array}{l}\text { (Kanis und Russell } \\
\text { 1977) } \\
\text { (Neer et al. 1975) } \\
\text { (Shoback 2008) } \\
\text { (Bilezikian et al. 2016) }\end{array}$ \\
\hline $\begin{array}{l}\text { „native“ } \\
\text { Vitamin-D- } \\
\text { Formen; } \\
\text { auch } \\
\text { Vitamin-D- } \\
\text { Speicher- } \\
\text { formen }\end{array}$ & $\begin{array}{l}\text { Cholecalciferol } \\
\text { (Vitamin } D_{3} \text {, Calci- } \\
\text { ol), Ergocalcifer- } \\
\left.\text { ol (Vitamin } D_{2}\right)\end{array}$ & $\begin{array}{l}\text { Wirkungsbeginn: } 10-14 \mathrm{~d} \\
\text { Wirkungsdauer: } 14-75 \mathrm{~d} \\
\text { HWZ: } 2-3 \text { Wochen } \\
\text { Dosis: } 400-200.000 \mathrm{IE} / \mathrm{d}\end{array}$ & $\begin{array}{l}\text { langwirksam da Fett- } \\
\text { speicher -> Intoxikati- } \\
\text { onsgefahr; } \\
\text { zweite Wahl wegen } \\
\text { schlechterer Steuer- } \\
\text { barkeit; } \\
\text { Dosis von Begleitmedi- } \\
\text { kation abhängig }\end{array}$ & $\begin{array}{l}\text { (Lowe et al. 2011) } \\
\text { (Bollerslev et al. 2015) } \\
\text { (Bilezikian et al. 2016) } \\
\text { (Avioli 1974) }\end{array}$ \\
\hline
\end{tabular}

Aufgrund der reduzierten Aktivität der 1a-Hydroxylase in der Niere bei Parathormonmagel und dadurch verminderten Aktivierung von nativem Vitamin D wird in der Hypoparathyreoidismustherapie mit aktiven VitaminD-Präparaten gearbeitet, bevorzugt Cacitriol und Alfacalcidol (Bollerslev et al. 2015; Haussler und Cordy 1982). Wie die Tabelle 3 verdeutlicht, unterschieden sich die verschiedenen Vitamin-D-Präparate hinsichtlich ihrer pharmakologischen Eigenschaften, was in der Therapie Vor- und Nachteile mit sich bringen kann. Bei Dihydrotachysterol scheint beispielsweise aufgrund von längerer Wirkdauer ein höheres Risiko für Hyperkalzämie und damit verbundenem Nierenversagen zu bestehen (Quack et al. 2005).

Trotz der reduzierten 1a-Hydroxylase-Aktivität ist eine Therapie mit (hoch dosierten) nativen Vitamin-DFormen möglich. Dies erklärt sich unter anderem durch die vorhandene, wenn auch geringere Bindungsaffini- 
tät von nativem Vitamin $D_{3}$ an den VDR und die potentiell Calcitriol-ähnliche Wirkung von $25(\mathrm{OH}) \mathrm{D}_{3}$, welches nach wie vor in der Leber produziert wird. Darüber hinaus ist es möglich, dass bestimmte Gewebe selbstständig 1,25(OH $)_{2} \mathrm{D}_{3}$ generieren (Brandi et al. 2016; Rejnmark et al. 2014). Dabei ist Cholecalciferol gegenüber Ergocalciferol wegen höherer Potenz zu bevorzugen (Armas et al. 2004). Unter gleichzeitiger Therapie mit aktivem Vitamin D ist eine Dosierung von 400-800 IE (= internationale Einheiten) nativem Vitamin D ausreichend ( $=$ „additiv") erfolgt eine alleinige Therapie mit nativen Vitamin-D-Formen, ist eine Tagesdosis von 25.000-200.000 IE nötig (= „high dose“) (Avioli 1974; Bollerslev et al. 2015). Vitamin-D-Speicherformen können als Monopräparat oder als Kombipräparat mit einer fixen Menge an Calcium zusammen angewandt werden.

Für eine bessere Langzeiteinstellung können Thiazide (12,5-50 mg/d) verwendet werden, die sowohl eine Hyperkalziurie mindern als auch das Serumcalcium anheben (Maschio et al. 1981; Stack et al. 2015), wodurch häufig die Medikation mit Vitamin D und Calcium reduziert werden kann. Außerdem kann das Therapiekonzept diätetische Maßnahmen oder bei starker (therapiebedingter) Hyperphosphatämie Phosphatbinder beinhalten (Bilezikian et al. 2011), welche neben den oben erwähnten Calciumsalzen außerdem Sevelamer oder Lanthanumverbindungen umfassen (Malberti 2013).

Während einer Therapie mit Calcium- und aktiven Vitamin-D-Präparaten sollte neben den Calcium-, Phosphat- und Magnesiumwerten auch die Nierenfunktion überwacht werden (Bollerslev et al. 2015). Grundproblem bei der medikamentösen Einstellung von Patienten mit Nebenschilddrüsenunterfunktion ist, hypokalzämische Krisen wirksam zu vermeiden ohne dabei durch die Substitution von Calcium- und Vitamin-D-Präparaten eine (intermittierende) Hyperkalzämie mit ihren Folgen wie Übelkeit, Erbrechen bis hin zu Fatigue oder Koma hervorzurufen (Walker Harris und Jan De Beur 2009). Während eine schnelle Korrektur therapiebedingter Hyperkalzämie unter dem kürzer wirksamen Calcitriol besser möglich ist (Kanis und Russell 1977), zeigen neuste Erkenntnisse, dass eine Therapie mit Vitamin $D_{2}$ (Ergocalciferol) bezüglich der Vermeidung einer Hypokalzämie vorteilhaft erscheint (Streeten et al. 2017).

Die bisherige Standardtherapie birgt außerdem die Gefahr von Hyperkalziurie und Hyperphosphatämie (Walker Harris und Jan De Beur 2009) und trägt somit nicht unwesentlich zur Entstehung von renalen Komplikationen wie Nephrolithiasis oder reduzierter Nierenfunktion bei (Mitchell et al. 2012; Winterborn et al. 1978). Wie bereits unter Punkt 1.2.3 erwähnt, ist nicht immer exakt zu differenzieren, welcher Anteil der Komplikationen eines Hypoparathyreoidismus durch die Krankheit bedingt und welcher der Therapie zuzuschreiben ist (Bilezikian et al. 2016). Shoback et al. (2016) sehen zumindest die renale Problematik als Folge der oralen Substitutionstherapie und sprechen sich daher neben Laborkontrollen für eine regelmäßige Nierensonografie aus. Zusammenfassend lässt sich feststellen, dass die Kontrolle von Langzeitkomplikationen unter bisheriger Standardtherapie des Hypoparathyreoidismus unzureichend ist.

Seit der bedingten Zulassung von rhPTH(1-84) durch die EMA/EC (European Medicines Agency/ European Commission) im Mai 2017 steht für die Hypoparathyreoidismustherapie in Europa das fehlende Hormon zur Substitution zur Verfügung (Natpar 2017). Während Brandi et al. (2016) eine Anwendung von rhPTH(1-84), welches durch die FDA (Food and Drug Administration) in den Vereinigten USA bereits 2015 zugelassen 
wurde, für bestimmte Indikationen empfehlen, wird sich in den aktuellsten europäischen Leitlinien (noch) gegen eine routinemäßige Anwendung ausgesprochen (Bollerslev et al. 2015).

Grundsätzlich existieren für therapeutische Zwecke zum einen das rhPTH(1-84), das in der Länge dem kompletten physiologischen PTH gleicht, und zum anderen das rhPTH(1-34) oder auch Teriparatid, welches dem N-terminalen Ende des physiologischen PTHs entspricht (Cusano et al. 2013a).

Mögliche Therapieeffekte, die in unterschiedlichen Studien beobachtet wurden, sind Abnahme der Hyperkalziurie unter Teriparatidtherapie (Winer et al. 1996) und Erhöhung der Knochenstoffwechselparameter im Serum (und Urin) unter Behandlung mit rhPTH(1-34) (Winer et al. 2003) oder rhPTH(1-84), wobei sich bei letzterem unter Langzeittherapie ein steady state nach 2,5 Jahren einstellte (Cusano et al. 2013b). Bei Anwendung von rhPTH(1-84) konnte außerdem eine Reduktion des Bedarfs an aktivem Vitamin D und/oder Calcium (Cusano et al. 2013b; Mannstadt et al. 2013) sowie unterschiedliche Ergebnisse bezüglich der Knochenmineraldichte $(B M D=$ bone mineral density) beobachtet werden (Gafni et al. 2012; Rubin et al. 2010; Sikjaer et al. 2011). Die unterschiedlichen Effekte auf den Knochenstoffwechsel könnten durch verschiedene Dosierungsschemata und Halbwertszeiten erklärt werden, da der Effekt von PTH auf den Knochen von der Wirkungsdauer abhängig zu sein scheint (Rejnmark et al. 2014; Sikjaer et al. 2011). So ist aus der Osteoporosetherapie ein anaboler Effekt auf den Knochen bei intermittierender Gabe von niedrig dosiertem rhPTH bekannt, wohingegen dauerhaft erhöhte PTH-Werte bei Hyperparathyreoidismus zu einem Überwiegen kataboler Effekte führen (Bilezikian 2008). Darüber hinaus reicht die Messung der BMD und Knochenstoffwechselmarker nicht aus, um über die Knochenqualität zu urteilen, da man die mögliche positive Wirkung von PTH auf die Mikrostruktur und Biomechanik mitberücksichtigen sollte (Rubin et al. 2016).

Mehrere Studien beschäftigten sich in den letzten Jahren mit dem Effekt der rhPTH(1-34) bzw. (1-84)Therapie auf die Lebensqualität, die Ergebnisse sind unterschiedlich (Cusano et al. 2014; Santonati et al. 2015; Sikjaer et al. 2014). Sikjaer et al. (2014) beobachteten beispielsweise keine signifikante Zunahme in den meisten Bereichen der Lebensqualität unter Gabe von rhPTH(1-84) im Vergleich zur Placebogruppe, was sie u. a. mit großen Schwankungen im Calciumhaushalt mit Hyperkalzämie unter intermittierender PTH Gabe begründen. Tatsächlich scheint eine kontinuierliche rhPTH über eine Pumpe bezüglich eines gleichbleibenden Serumcalciumspiegels und Reduktion der Hyperkalziurie vorteilhaft zu sein und sich einer physiologischeren PTH-Substitution anzunähern (Winer et al. 2012).

Besonders profitieren von einer Therapie mit rhPTH könnten Patienten, die unter bisheriger Standardtherapie schwer einstellbar sind, einen extrem hohen Bedarf an Calcium und/oder aktivem Vitamin D haben, renale Komplikationen oder eine chronische Hyperphosphatämie aufweisen (Brandi et al. 2016). Die empfohlene Dosierung liegt bei 50-100 $\mu \mathrm{g} / \mathrm{d}$ für rhPTH(1-84) bzw. 2x 35-40 $\mu \mathrm{g} / \mathrm{d}$ für rhPTH(1-34) (Mannstadt et al. 2013; Winer et al. 2003), bei momentan hohen (ca. \$110.000) jährlichen Therapiekosten (Siggelkow 2017). Die im Tierversuch mit rhPTH(1-34) aufgetretenen Osteosarkome (Vahle et al. 2002) sind in den beiden bislang längsten rhPTH-Anwendungsstudien sowie in einer Surveillance-Studie der FDA nicht beobachtet worden (Andrews et al. 2012; Lakatos et al. 2016; Rubin et al. 2016). Dennoch wurden unter rhPTH(1-84) mögliche Nebenwirkungen wie Hypo/Hyperkalzämie, Muskelkrämpfe, Kopfweh, Übelkeit, Fatigue und Befindlichkeitsstörungen beschrieben (Lakatos et al. 2016; Mannstadt et al. 2013; Rubin et al. 2016). Inwiefern eine rhPTH- 
Therapie gefürchteten Langzeiffolgen wie extraskelettale Kalzifikationen positiv beeinflussen kann, bleibt bislang offen (Mannstadt et al. 2017).

\subsection{AUSBLICK UND AKTUELLE ENTWICKLUNGEN}

Verschiedene Präventionsstrategien zur Vermeidung eines postoperativen Hypoparathyreoidismus, der als häufigste Ursache einer Nebenschilddrüsenunterfunktion gilt, wurden bereits unter Punkt 1.2.2 beschrieben, wie beispielsweise die Autotransplantation von entfernten Epithelkörperchen z. T. nach Kryokonservierung in den Musculus sternocleidomastoideus. Da der da Erfolg dieser Verfahren fraglich bleibt (Lorente-Poch et al. 2017; Shepet et al. 2013; Sitges-Serra et al. 2018), zielen neueste Versuche auf die allogene Transplantation von ganzen Epithelkörperchen (Agha et al. 2016) oder immunologisch vermeintlich besser tolerierten makroverkapselten Nebenschilddrüsenzellen ab (Khryshchanovich und Ghoussein 2016).

Darüber hinaus gibt es neue Entwicklungen im Bereich der Diagnostik für das frühe Erkennen des Hypoparathyreoidismus und seiner Komplikationen: Sieniawski et al. (2016) identifizierten den Abfalls des intakten, gemessenen PTHs sechs Stunden postoperativ um > $65 \%$ oder unter eine bestimmte Grenze als den verlässlichsten Risikomarker bezüglich der Entwicklung einer Nebenschilddrüsenunterfunktion. Garcia-Pascual et al. (2017) empfehlen, 1 1 ,25-Dihydroxycholecalciferol zu messen, um Hinweis auf eine mögliche Hyperkalziurie bei Patienten unter Standardtherapie mit Calcium und aktivem Vitamin D zu bekommen. Ein frühzeitiges Erkennen der hohen Calciumausscheidung im Urin und Ändern der Medikation könnte renalen Langzeitkomplikationen vorbeugen.

Auf dem Gebiet der Hypoparathyreoidismustherapie gibt es auch nach der Zulassung des fehlenden Hormones zur Behandlung weitere, neue Forschungsansätze: Der oral verfügbare niedermolekulare PTH1Rezeptor-Agonist PCO371 zeigte im Tiermodell erste Erfolg versprechende Ergebnisse in Bezug auf die Calciumhomöostase (Tamura et al. 2016), ebenso wie ein subkutan zu injizierendes langwirksames PTHAnalogon (LA-PTH= long-acting PTH analog) (Shimizu et al. 2016). Calzilytika (calcilytics) wie Ronacaleret sind CaSR-Antagonisten, welche die PTH-Sekretion u. a. über Minderung der Rezeptorsensitivität für Calcium stimulieren. Zwar ist ihre Anwendung in der Osteoporosetherapie bislang erfolglos geblieben, ihr Wirkmechanismus lässt jedoch über eine Anwendung bei Krankheiten mit Nebenschilddrüsen-Restfunktion nachdenken. Erste Versuche wurden für die ADH beschrieben. Aufgrund der ektopen, renalen CaSR-Expression könnte jedoch auch eine potentielle Wirkung bei komplett parathyreoidektomierten Patienten möglich sein (Letz et al. 2010; Nemeth und Goodman 2016).

Auf zellulärer Ebene gelang es, aus mesenchymalen Stammzellen Zellen mit in vivo nebenschilddrüsenähnlicher Funktion zu gewinnen (Park et al. 2015). Ähnliche Ergebnisse werden sich für aus menschlichem Fettgewebe gewonnene Stammzellen (adipose-derived stem cells = ADSCs) erhofft (Zhao und Luo 2016). Die Forschung auf diesem Gebiet befindet sich jedoch erst am Anfang und mögliche Therapieoptionen lassen sich bislang noch nicht ableiten. 


\section{Ziele und Fragestellungen}

Arlt et al. (2002) untersuchten das Befinden von Patienten mit postoperativem Hypoparathyreoidismus mit drei verschiedenen etablierten Fragebögen, welche insgesamt über 100 Fragen beinhalteten. Aggarwal et al. (2013) nutzen zehn verschiedene neuropsychologische Test zur Charakterisierung der Patientenbeschwerden. Die Tatsache, dass in beiden Studien mehrere verschiedene Messinstrumente angewandt wurden und die daraus resultierende Länge der Untersuchung, macht solche Erhebungen zu umfangreich und im Praxisalltag nicht praktikabel. Auch Onlineumfragen wie die Studie von Hadker et al. (2014) in den USA mögen für epidemiologische Zwecke aufschlussreich sein, sind jedoch nicht praxistauglich. In unserer retrospektiven Analyse mussten wir selbst feststellen, dass Fragebögen, die allgemein nach den Beschwerden von Patienten fragen und nicht krankheitsspezifisch sind, teilweise undifferenzierte Ergebnisse liefern (Wilde et al. 2017), aus denen sich nur schwer auf die krankheitstypischen Beschwerden schließen lässt. Dennoch waren diese Ergebnisse wichtig, um auf Basis eines analytisch-empirischen Ansatzes (Bühner 2011) ein für den Hypoparathyreoidismus charakteristisches Messinstrument für den Klinik-/Praxisalltag zu entwickeln.

Ein speziell für eine Krankheit entwickelter Fragebogen bietet die Möglichkeit, die Beschwerden der Patienten treffender abzubilden und ermöglicht somit vielleicht, diese auch besser zu verstehen (Prior et al. 2012; Webb et al. 2002). Daher wurde neben dem entworfenen Fragebogen ein Dokumentationsbogen entwickelt für Hintergrundinformationen der Patienten, wie beispielsweise Erkrankungsdauer, Medikation und Komplikationen, um mögliche Einflussparameter auf die Beschwerden zu erfassen.

Um eine Grundlage für die Konzipierung eines Fragebogens speziell für Hypoparathyreoidismus zu haben, werden im retrospektiven Studienteil verschiedene, validierte, von Patienten mit dieser Krankheit ausgefüllte Fragebögen unter den folgenden Fragestellungen analysiert:

- Welche Beschwerdekomplexe weisen unsere Patientenkollektive auf?

- Welche Einschränkungen sind im Bereich der Lebensqualität zu finden?

Die Ergebnisse dieser Analyse dienen vor allem der Erstellung des neuen, krankheitscharakteristischen Fragebogens. Dieser wird prospektiv zusammen mit einem Dokumentationsbogen für Hypoparathyreoidismus angewandt, mit dem Ziel, folgende Fragen näher zu ergründen:

- Welche Merkmale weist unser Kollektiv (im Vergleich zu Vorstudien) auf?

- Sind die erhobenen Beschwerden charakteristisch für das Krankheitsbild des Hypoparathyreoidismus?

- Kann man sie von Patienten mit anderen endokrinologischen Erkrankungen abgrenzen?

- Sind die gefundenen Beschwerden bereits bekannt und/oder können neue Beschwerdekomplexe aufgedeckt werden?

- Sind mögliche Zusammenhänge zwischen den angegebenen Beschwerden und anderen Parametern wie beispielsweise Laborergebnissen oder der Medikation erkennbar?

- Inwiefern ist die Lebensqualität abgebildet?

- Ist der Fragebogen für den Praxisalltag geeignet und welche psychometrischen Eigenschaften weist er auf? 
Es soll also nicht nur überprüft werden, ob der Fragebogen ein geeignetes Instrument für die Evaluation des Hypoparathyreoidismus darstellt, sondern auch, ob neue Erkenntnisse zum Verständnis dieser Krankheit und ihrer Folgen mithilfe des Bogens gewonnen werden können. 


\section{Patienten, Material und Methoden}

\subsection{StUdienAUfBAU UND -ABLAUF}

Die Studie gliederte sich in einen retrospektiven und einen prospektiven Teil.

Im retrospektiven Teil wurden verschiedene Fragebögen, die von an Hypoparathyreoidismus erkrankten Personen ausgefüllt worden waren, im Hinblick auf psychische Beschwerden und Einschränkungen der Lebensqualität analysiert.

Die Ergebnisse dieser Analyse dienten der Erstellung des HPQ 40 - Fragebogen für Hypoparathyreoidismus (kurz HPQ 40), eines krankheitscharakteristischen Fragebogens, sowie des Bogens „Dokumentation Hypoparathyreoidismus".

Diese Fragebögen wurden im prospektiven Teil der Studie an einem Kollektiv von Patienten mit postoperativem Hypoparathyreoidismus angewandt. Als Vergleichsgruppen dienten ein Kollektiv von Patienten mit Hyperparathyreoidismus sowie Schilddrüsen-Operierte ohne postoperativen Hypoparathyreoidismus. Die Patienten wurden aus zwei ambulanten endokrinologischen Einrichtungen in Göttingen und Saarbrücken rekrutiert. Alle für die Studie infrage kommenden Patienten des Studien- und der Vergleichskollektive wurden vor Beginn des prospektiven Studienteils nach den unter Punkt 3.2.2 aufgeführten Kriterien identifiziert und soweit möglich mit einem elektronischen Aktenvermerk im Computersystem der Praxis versehen. Neue Patienten konnten vom jeweiligen Arzt auch während der Erstuntersuchung hinsichtlich einer möglichen Studieneignung evaluiert werden.

An der Praxisanmeldung wurde jeder vorab identifizierte Patient nach Interesse an der Studienteilnahme gefragt. Wenn er interessiert war, hatte der Patient während der Wartezeit auf das persönliche Arztgespräch die Möglichkeit, die Studieninformationsschrift für Patienten zu lesen. Während der anschließenden Routineuntersuchung beim behandelnden Arzt wurde er nochmals über die Studie informiert und konnte Nachfragen stellen. Nach Einverständnis des Patienten und dem Unterschreiben der Einwilligungserklärung in zweifacher Ausführung erhielt jeder Studieneilnehmer ein Set mit Einwilligungserklärung, HPQ 40 Fragebogen und dem Bogen "Dokumentation Hypoparathyreoidismus“. Der Dokumentationsbogen konnte direkt von der behandelnden Ärztin gemeinsam mit dem Patienten vervollständigt werden, das Ausfüllen des Fragebogens erfolgte anschließend in - idealerweise - ruhiger Umgebung durch den Patienten selbst.

Alle Bögen wurden nummeriert und datiert in der jeweiligen Praxis gesammelt. Daten zur aktuellen Medikation und Laborwerten zum Studienzeitpunkt wurden im Anschluss aus dem Praxissystem erhoben.

Die Datenerhebung erfolgte von Januar 2016 - Dezember 2016. Für die Studie infrage kommende Patienten, die in diesem Zeitraum keinen regulären Termin im MVZ (= medizinisches Versorgungszentrum) endokrinologikum Göttingen hatten, wurden per Anschreiben über die Studie informiert mit der Bitte, bei Interesse an einer Teilnahme einen persönlichen Termin zu vereinbaren.

Alle Daten wurden pseudonymisiert, d. h. anhand der Patientennummer des Praxissystems bzw. der Fragebogennummer und ohne Namen, in einer Tabelle erfasst und weiter ausgewertet. 


\subsection{Patienten}

\subsubsection{RETROSPEKTIVE KOLLEKTIVE}

Die vier im retrospektiven Teil der Studie angewandten Fragebögen wurden von zwei unterschiedlichen Personengruppen ausgefüllt.

Hierbei wurden als Patienten bewusst die Mitglieder der Selbsthilfeorganisation Netzwerk Hypopara (ehemals AG Hypopara) befragt, weil bei dieser Gruppe eine besonders hohe und ausgeprägte Beschwerdelast vermutet wurde. So sollte es ermöglicht werden, möglichst viele für die Krankheit relevante Beschwerden zu erfassen.

Die erste Gruppe von Erkrankten erhielt sowohl die Symptom-Checkliste SCL-90-R als auch den Fragebogen des MVZ endokrinologikum Göttingen im Rahmen eines Vortrages auf dem 1. Bundestreffen Hypopara 2013 in Hamburg mit Bitte um anonyme Rücksendung in den beigefügten vorfrankierten Umschlägen. Alle innerhalb von sechs Monaten im MVZ endokrinologikum Göttingen eingegangenen Fragebögen wurden bei der Analyse berücksichtigt.

Da es sich bei allen Befragten um Mitglieder des Netzwerk Hypopara handelte, wird dieses Kollektiv übersichtshalber als "Selbsthilfegruppe 2013 = SHG 2013" bezeichnet. 
Die Tabelle 4 beschreibt die Charakteristika und Medikamentenverteilung dieses Patientenkollektivs.

Tabelle 4: Charakteristika des Patientenkollektivs Selbsthilfegruppe 2013 (Alter beim Ausfüllen der Fragebögen, Geschlecht, Dauermedikation, Bedarfsmedikation); Alter als Mittelwert \pm Standardabweichung (Range), Anzahl = n, Häufigkeit in \%; gemeinsame Daten mit cand. med. L. Wilken

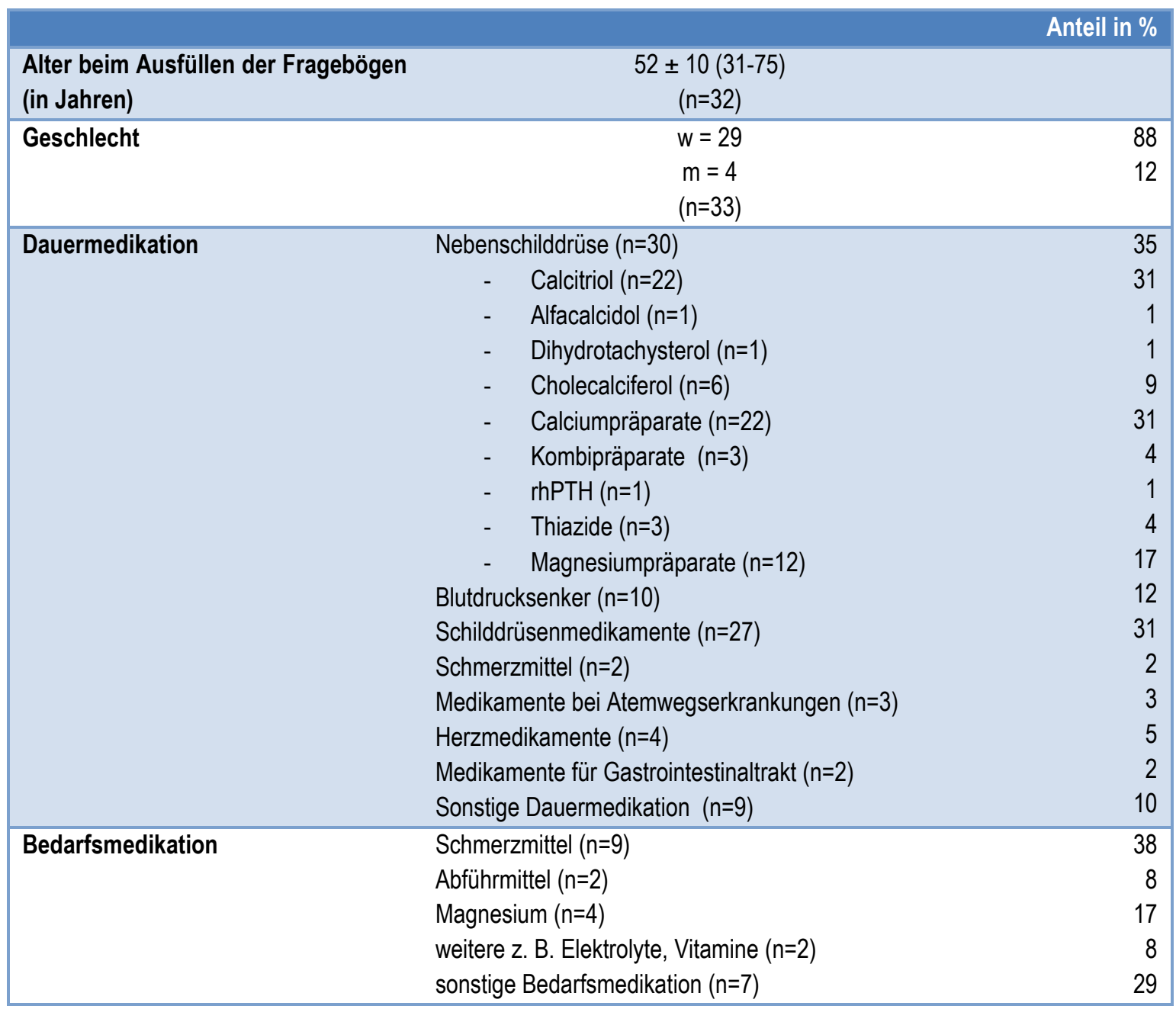

Die Befragten waren überwiegend weiblich und Calcitriol war das am häufigsten eingenommene aktive Vitamin-D-Präparat in diesem Kollektiv.

Die zweite Patientengruppe füllte den SF-36 Fragebogen zum Gesundheitszustand sowie den Fragebogen „Abfrage zusätzlicher Beschwerden“ im Rahmen des 2. Hypopara Bundestreffen 2015 in Göttingen aus. Die Patienten bekamen eine kurze Erläuterung zu den Bögen und hatten anschließend ca. 20 Minuten Zeit zum Ausfüllen. Die Charakterisierung dieses als „Selbsthilfegruppe 2015 = SHG 2015“ bezeichneten Patientenkollektivs ist in Tabelle $5 \mathrm{zu}$ finden. Auch hier waren die Befragten überwiegend weiblich.

Tabelle 5: Charakteristika des Patientenkollektivs der Selbsthilfegruppe 2015 (Alter beim Ausfüllen des Fragebogens [Mittelwert \pm Standardabweichung und Range], Geschlecht in $\mathrm{n}$ und \%); gemeinsame Daten mit cand. med. L. Wilken

\begin{tabular}{|lcr|}
\hline & & Anteil in \% \\
\hline Alter beim Ausfüllen der Fragebö- & $54 \pm 14(24-76)$ & \\
gen (in Jahren) & $(\mathrm{n}=27)$ & 81,5 \\
\hline Geschlecht & $\mathrm{w}=22$ & 18,5 \\
\end{tabular}


Da es sich in beiden Kollektiven um Mitglieder des Netzwerk Hypopara handelte, sind Überschneidungen zwischen den Personen aus der SHG 2013 und der SHG 2015 möglich.

Die Ursache des Hypoparathyreoidismus und bekannte Vorerkrankungen der beiden Gruppen von Befragten konnten mithilfe der angewandten Fragebögen nicht systematisch und daher nur unvollständig erhoben werden. Aus diesem Grund konnte bei der Auswertung keine Rücksicht auf Vorerkrankungen genommen werden. Die retrospektive Auswertung diente allerdings auch vielmehr zur Fragengenerierung für den prospektiven, neuen Fragebogen als zur Ursachenforschung. Dennoch wurde diese Tatsache zum Anlass genommen, bei der prospektiven Analyse ein besonderes Augenmerk auf die Erfassung von Hintergrundinformationen der Patienten zu legen, indem ein spezieller Dokumentationsbogen Hypoparathyreoidismus erstellt wurde, in welchem u. a. Vorerkrankungen systematisch abgefragt wurden.

\subsubsection{PROSPEKTIVE PATIENTENKOLLEKTIVE}

Das prospektive Studienkollektiv der an Hypoparathyreoidismus Erkrankten setzte sich aus Patienten des MVZ endokrinologikum Göttingen und der endokrinologischen Praxis Dr. Stamm in Saarbrücken zusammen, die im Zeitraum von Januar 2016 bis einschließlich Dezember 2016 in die genannten Einrichtungen kamen.

Für die Studie geeignete Patienten wurden zuvor nach den folgenden Kriterien ermittelt und mit einem elektronischen Akteneintrag im Praxissystem gekennzeichnet:

- Alle Patienten waren im Alter von $>18$ bis $\leq 85$ Jahre und hatten einen postoperativen Hypoparathyreoidismus, der mind. 6 Monate bestand, unabhängig vom Grund der Operation.

- Die Diagnose musste mindestens im aktuellen Arztbrief stehen, dabei war es unerheblich, ob diese durch die Laborkonstellation oder durch klinische Symptome und deren Behandlungsbedürftigkeit begründet war. Bislang gibt es noch keine weltweit einheitliche Definition des Hypoparathyreoidismus; auch ein Patient mit erniedrigtem aber nicht fehlendem PTH kann ein inadäquat niedriges Serumcalcium aufweisen und symptomatisch sein.

- Patienten mit transientem, idiopathischem oder genetischem Hypoparathyreoidismus wurden nicht eingeschlossen. Schwangerschaft, fehlende Einwilligung oder Möglichkeit, den Fragebogen zu verstehen und zu beantworten, sowie polyglanduläres Autoimmunsyndrom galten ebenfalls als Ausschlusskriterien.

Andere Vorerkrankungen wurden systematisch durch den Dokumentationsbogen Hypoparathyreoidismus erfasst und galten daher nicht als Ausschlusskriterien. Grund dafür ist die Seltenheit der Erkrankungen, die bei weiteren Ausschlusskriterien keine ausreichend große Studiengruppe ermöglicht hätte.

Alle Patienten, auf die die oben genannten Kriterien zutrafen und die in die Studienteilnahme einwilligten, wurden eingeschlossen. Dieses Patientenkollektiv - im Verlauf mit „HypoPT 2016“ abgekürzt - zeigte u. a. folgende in Abbildung 2 und Abbildung 3 dargestellte Merkmale. Die durchschnittliche Erkrankungsdauer des Hypoparathyreoidimus lag bei $12,55 \pm 9,76$ Jahren. 


\section{Häufigkeit von Komplikationen im HypoPT 2016-Kollektiv}

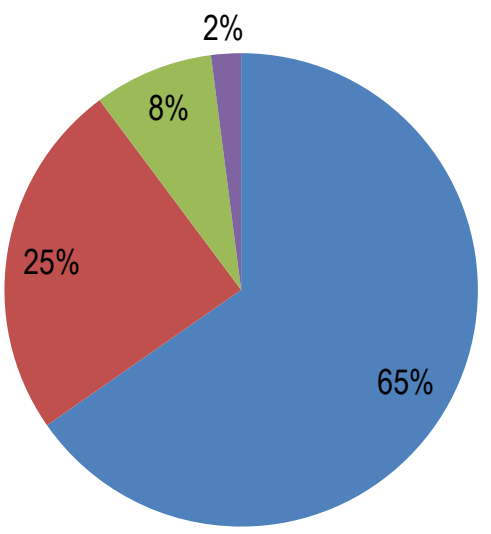

$$
\begin{aligned}
& \text { keine Komplikation } \\
& \text { angegeben } \\
& \text { eine Komplikation } \\
& \text { angegeben } \\
& \text { zwei Komplikationen } \\
& \text { angegebn } \\
& \text { fünf Komplikationen } \\
& \text { angegeben }
\end{aligned}
$$

Abbildung 2: Häufigkeit (in \%) von Patienten ( $n=49)$ ohne, mit einer/ zwei/ fünf angegeben Komplikationen auf dem Dokumentationsbogen im Kollektiv HypoPT 2016

Bei mehr als die Hälfte der Patienten wurden keine Hypoparathyreoidismus-typischen Komplikationen festgestellt. Ein Viertel der Patienten hatte eine Komplikation.

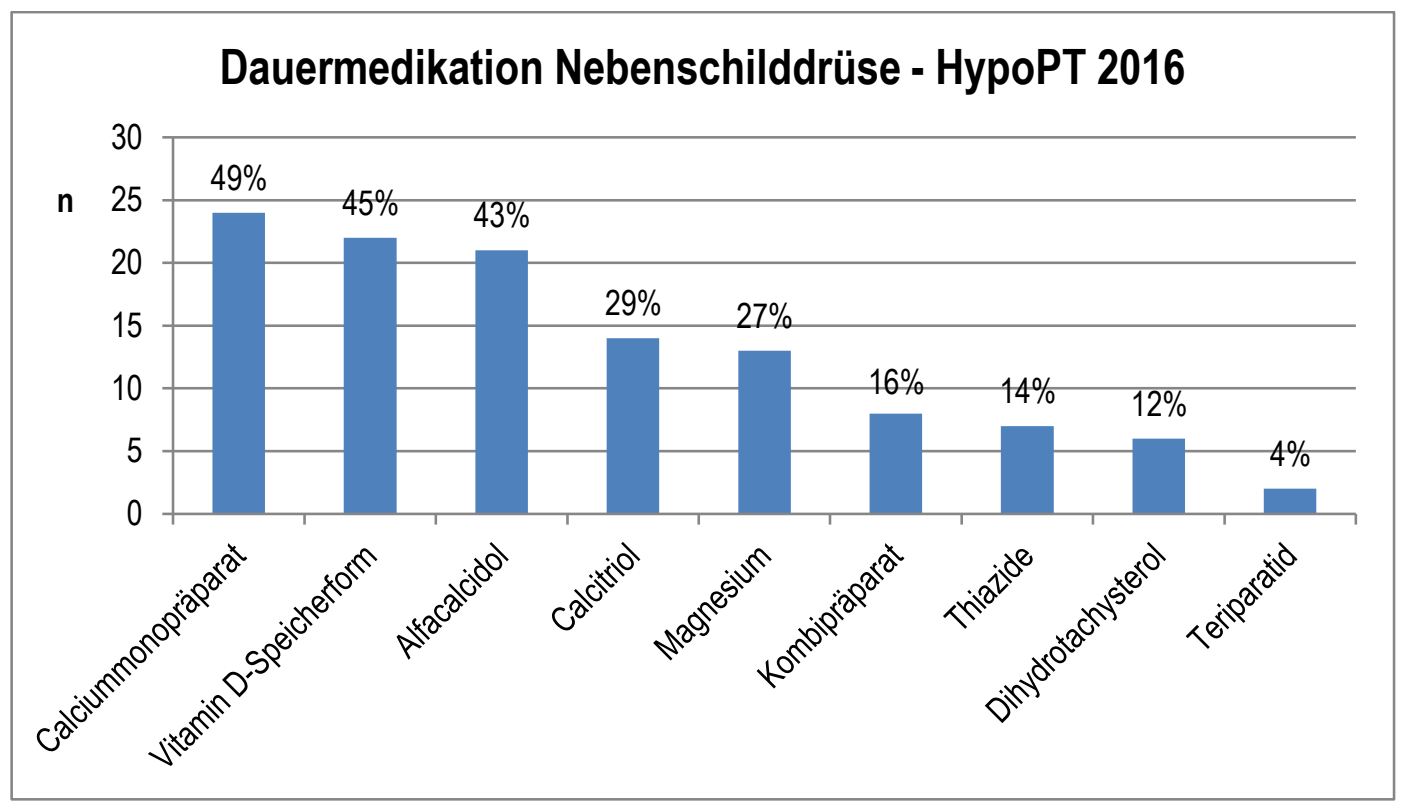

Abbildung 3: Dauermedikation Nebenschilddrüse (Anzahl = $\mathrm{n}$, Anteil am Patientenkollektiv $=\%$ ) im Patientenkollektiv HypoPT 2016 ( $n=49)$

Die verschiedenen aktiven Vitamin-D-Präparate (Subgruppen: Alfacalcidol, Calcitriol und Dihydrotachysterol) werden aufgrund ihrer unterschiedlichen pharmakologischen Eigenschaften im Folgenden nach den drei oben genannten inhaltlichen Subgruppen getrennt dargestellt. 47\% der HypoPT 2016-Patienten nahmen eine Kombination aus einem reinen Calciummono- und einem aktiven Vitamin-D-Präparat ein. 57 \% nahmen eine Kombination aus aktivem Vitamin D und Calcium in irgendeiner Form (Monopräparat oder als Kombipräparat mit nativem Vitamin D) ein. 
Weitere Merkmale sind im Folgenden in den Übersichtstabellen Tabelle 6 bis Tabelle 10 sowie im Anhang in Tabelle 35 zu finden.

Als Kontrollgruppen wurden zwei verschiedene Patientenkollektive ausgewählt. Die entsprechenden Vergleichspatienten wurden vor Beginn des prospektiven Studienteils identifiziert und anschließend nach $\mathrm{Ge}$ schlecht und Alter \pm 3 Jahre zu den HypoPT 2016-Patienten gematcht.

Als erste Vergleichsgruppe dienten Patienten mit Zustand nach Schilddrüsen-Operation (kurz "SD-OP 2016"), für die folgende Auswahlkriterien zutreffen mussten:

- Der Eingriff an der Schilddrüse musste in mindestens einem Arztbrief dokumentiert sein, unabhängig davon, wann er stattfand.

- Es wurden sowohl total, subtotal als auch hemithyreoidektomierte Patienten in die Studie eingeschlossen, da es um den Eingriff an der Schilddrüse an sich ging. Der Operationsgrund wurde systematisch für alle Patienten erfasst.

- Ausschlusskriterien waren postoperativer (permanenter) Hypoparathyreoidismus und polyglanduläres Autoimmunsyndrom sowie gleichzeitiger Hyperparathyreoidismus und dessen Operation.

Als zweites Vergleichskollektiv wurden Patienten mit der Erkrankung Hyperparathyreoidismus herangezogen. Hierbei handelt es sich ebenfalls um eine die Nebenschilddrüsen betreffende Calciumstoffwechselstörung. Für diese als „pHPT 2016“ bezeichneten Patienten galten folgende Kriterien:

- Die Patienten mussten einen im aktuellen Arztbrief erfassten primären Hyperparathyreoidismus haben oder wegen eines solchen operiert worden sein (s. Abbildung 4). Die Diagnose konnte durch Laborparameter und deren Dynamik sowie in der klinischen Präsentation begründet sein.

- Nur Patienten mit primärem Hyperparathyreoidismus wurden berücksichtigt. Dieser durfte aber zusätzlich sekundäre Anteile besitzen. Patienten mit ausschließlich sekundärem oder tertiärem Hyperparathyreoidismus wurden nicht erfasst.

- Die Patienten mit Zustand nach Operation eines primären Hyperparathyreoidismus durften keinen postoperativen (permanenten) Hypoparathyreoidismus aufweisen. Bei dieser Teilgruppe ging es vor allem um den Eingriff an der Nebenschilddrüse und dessen laborchemische Konsequenzen. Diese Kontrollen wurden bei der Auswertung besonders berücksichtigt. 


\section{Häufigkeit der Operation eines pHPT in der Gruppe \\ pHPT 2016}

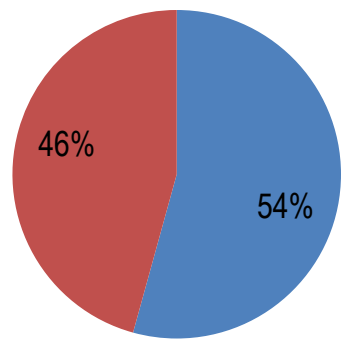

operiert

nicht operiert

Abbildung 4: Häufigkeit (in \%) der Operation eines primären Hyperparathyreoidismus (pHPT) in der Gruppe pHPT $2016(n=35)$

Gemeinsame Ausschlusskriterien beider Vergleichskollektive waren:

- Schwangerschaft, Alter $<18$ oder $>85$ sowie fehlende Einwilligung in die Studie oder Möglichkeit den Fragebogen zu verstehen und zu beantworten.

Alle diejenigen Patienten, die einwilligten und den genannten Kriterien entsprachen, wurden in die Studie eingeschlossen. Insgesamt nahmen 151 Patienten an der Studie teil (65 HypoPT 2016, 49 SD-OP 2016, 37 pHPT 2016), deren Daten alle zur Skalenbildung des HPQ 40 verwendet werden konnten (s. Punkt 3.5.1 und 4.2.1).

In der weiteren statistischen Analyse und für die Gruppenvergleiche wurden Daten von insgesamt 123 Patienten ausgewertet. Dabei handelte es sich um 49 Patienten der Studiengruppe HypoPT 2016, denen 39 Patienten aus der Gruppe SD-OP 2016 bzw. 35 Patienten aus der Gruppe pHPT 2016 als Kontrollen zugeordnet wurden. Nicht jedem HypoPT 2016-Patienten konnte ein Match nach Geschlecht und Alter aus beiden Gruppen zugeteilt werden. Da die statistische Analyse allerdings keinen signifikanten Unterschied in der Altersbzw. Geschlechterverteilung zwischen den drei so gebildeten Kollektiven zeigte ( $p=0,166$ bzw. $p=0,517$ ), wurden die Gruppen als gut vergleichbar - wenn auch nicht 100\%ig gematcht - angesehen, und es konnten zur weiteren Analyse alle 123 Patienten berücksichtigt werden (s. Tabelle 6).

Die folgenden Übersichtstabellen Tabelle 6 bis Tabelle 10 zeigen die Charakteristika aller drei in dieser Arbeit untersuchten Patientenkollektive nach dem Matchen (insgesamt 123 Patienten) im Vergleich. 
Tabelle 6: Charakteristika (Alter, Geschlecht, Praxis) der drei Patientenkollektive HypoPT 2016, SD-OP 2016 und pHPT 2016 als Übersicht $(n=$ Anzahl, \% = gültige Prozent des jeweiligen Parameters bzw. seiner Ausprägung nach Studiengruppe [Spaltenhäufigkeit]); p-Wert des Chi-Quadrat- bzw. Fishers exakten Tests (sowie ANOVA nur für Alter); gemeinsame Daten mit cand. med. L. Wilken

\begin{tabular}{|c|c|c|c|c|c|c|c|c|c|c|}
\hline & & \multicolumn{2}{|c|}{ НуроРТ 2016} & \multicolumn{2}{|c|}{ SD-OP 2016} & \multicolumn{2}{|c|}{ pHPT 2016} & \multicolumn{2}{|c|}{ gesamt } & \multirow[t]{2}{*}{ p-Wert } \\
\hline & & $\mathrm{n}$ & $\%$ & $\mathrm{n}$ & $\%$ & $\mathrm{n}$ & $\%$ & $\mathrm{n}$ & $\%$ & \\
\hline Alter & & $\begin{array}{r}57,33 \pm \\
10,52^{1}\end{array}$ & & $\begin{array}{r}55,31 \pm \\
9,961\end{array}$ & & $\begin{array}{r}59,91 \pm \\
10,63^{1}\end{array}$ & & $\begin{array}{r}57,42 \pm \\
10,45^{1}\end{array}$ & & 0,166 \\
\hline \multirow[t]{2}{*}{ Geschlecht } & weiblich & 41 & 83,7 & 36 & 92,3 & 29 & 82,9 & 106 & 86,2 & 0,517 \\
\hline & männlich & 8 & 16,3 & 3 & 7,7 & 6 & 17,1 & 17 & 13,8 & \\
\hline \multirow[t]{2}{*}{ Praxis } & Göttingen & 35 & 71,4 & 35 & 89,7 & 30 & 85,7 & 100 & 81,3 & 0,074 \\
\hline & Saarbrücken & 14 & 28,6 & 4 & 10,3 & 5 & 14,3 & 23 & 18,7 & \\
\hline
\end{tabular}

${ }^{1}$ Alter abweichend in Jahren (Mittelwert \pm Standardabweichung) und nicht „n“

Tabelle 7: Charakteristika (Art und Grund der Schilddrüsenoperation) der zwei Patientenkollektive HypoPT 2016 und SD-OP 2016 als Übersicht $(n=$ Anzahl, \% = gültige Prozent des jeweiligen Parameters bzw. seiner Ausprägung nach Studiengruppe [Spaltenhäufigkeit], freie Felder = keine Angabe für jeweilige Subgruppe); p-Wert des Chi-Quadratbzw. Fishers exakten Tests; signifikante Werte dick hervorgehoben; gemeinsame Daten mit cand. med. L. Wilken

\begin{tabular}{|c|c|c|c|c|c|c|c|c|}
\hline & & \multicolumn{2}{|c|}{ НуроРТ 2016} & \multicolumn{2}{|c|}{ SD-OP 2016} & \multicolumn{2}{|c|}{ gesamt } & \multirow{2}{*}{$\begin{array}{l}\text { p- } \\
\text { Wert }\end{array}$} \\
\hline & & $n$ & $\%$ & $\mathrm{n}$ & $\%$ & $\mathrm{n}$ & $\%$ & \\
\hline \multirow{6}{*}{$\begin{array}{l}\text { Art der Schild- } \\
\text { drüsen- } \\
\text { operation }\end{array}$} & total & 24 & 49,0 & 9 & 23,1 & 33 & 37,5 & 0,003 \\
\hline & hemi & & & 7 & 17,9 & 7 & 8,0 & \\
\hline & subtotal & 3 & 6,1 & 3 & 7,7 & 6 & 6,8 & \\
\hline & near total & 1 & 2,0 & & & 1 & 1,1 & \\
\hline & hemi und subtotal & 1 & 2,0 & & & 1 & 1,1 & \\
\hline & $\begin{array}{l}\text { nicht } \\
\text { näher klassifiziert }\end{array}$ & 20 & 40,8 & 20 & 51,3 & 40 & 45,5 & \\
\hline \multirow{6}{*}{$\begin{array}{l}\text { Grund der } \\
\text { Schilddrüsen- } \\
\text { operation }\end{array}$} & Struma & 21 & 42,9 & 18 & 47,4 & 39 & 44,8 & 0,331 \\
\hline & Karzinom & 14 & 28,6 & 7 & 18,4 & 21 & 24,1 & \\
\hline & M. Basedow & 6 & 12,2 & 5 & 13,2 & 11 & 12,6 & \\
\hline & Knoten & 3 & 6,1 & 7 & 18,4 & 10 & 11,5 & \\
\hline & pHPT & 2 & 4,1 & & & 2 & 2,3 & \\
\hline & $\begin{array}{l}\text { weitere } \\
\text { (Thyreoidektomie nicht } \\
\text { näher klassifiziert, } \\
\text { Thyreoiditis de Quer- } \\
\text { vain, Zyste etc.) }\end{array}$ & 3 & 6 & & 2,6 & 4 & 4,4 & \\
\hline
\end{tabular}

Wie Tabelle 7 zeigt, bestand eine signifikante Assoziation zwischen der Art der Schilddrüsenoperation und der Studiengruppenzugehörigkeit, nicht aber zwischen letzterer und dem Grund der Schilddrüsenoperation. 
Tabelle 8: Charakteristika (Dauermedikation Nebenschilddrüse, Zeit bis Erstmedikation) der drei Patientenkollektive HypoPT 2016, SD-OP 2016 und pHPT 2016 als Übersicht $(n=$ Anzahl, \% = gültige Prozent des jeweiligen Parameters bzw. seiner Ausprägung nach Studiengruppe [Spaltenhäufigkeit], freie Felder = keine Angabe für jeweilige Subgruppe); p-Wert des Chi-Quadrat- bzw. Fishers exakten Tests; signifikante Werte dick hervorgehoben; gemeinsame

Daten mit cand. med. L. Wilken

\begin{tabular}{|c|c|c|c|c|c|c|c|c|c|c|}
\hline & & \multicolumn{2}{|c|}{$\begin{array}{l}\text { HypoPT } \\
2016\end{array}$} & \multicolumn{2}{|c|}{$\begin{array}{l}\text { SD-OP } \\
2016\end{array}$} & \multicolumn{2}{|c|}{ pHPT 2016} & \multicolumn{2}{|c|}{ gesamt } & \multirow[t]{2}{*}{ p-Wert } \\
\hline & & $\mathrm{n}$ & $\%$ & $\mathrm{n}$ & $\%$ & $\mathrm{n}$ & $\%$ & $\mathrm{n}$ & $\%$ & \\
\hline \multicolumn{11}{|c|}{ Dauermedikation Nebenschilddrüse } \\
\hline \multirow[t]{5}{*}{ aktives Vitamin D } & keine Einnahme & 7 & 14,3 & 39 & 100 & 33 & 97,1 & 79 & 64,8 & $<0,001$ \\
\hline & Calcitriol & 14 & 28,6 & & & 1 & 2,9 & 15 & 12,3 & \\
\hline & Alfacalcidol & 21 & 42,9 & & & & & 21 & 17,2 & \\
\hline & $\begin{array}{l}\text { Dihydrotachy- } \\
\text { sterol }\end{array}$ & 6 & 12,2 & & & & & 6 & 4,9 & \\
\hline & $\begin{array}{l}\text { Kombination ( } 2 x \\
\text { aktives Vitamin } D)\end{array}$ & 1 & 2 & & & & & 1 & 0,8 & \\
\hline \multirow{3}{*}{$\begin{array}{l}\text { Kombipräparat } \\
\text { (Calcium + natives } \\
\text { Vitamin D) }\end{array}$} & $\begin{array}{l}\text { Calcimagon } \circledast / \\
\text { Calcilac® }\end{array}$ & 6 & 12,5 & & & 2 & 5,7 & 8 & 6,6 & 0,098 \\
\hline & Calcimed $(\mathbb{2}$ & 1 & 2,1 & 1 & 2,6 & & & 2 & 1,6 & \\
\hline & Calcigen $®$ & 1 & 2,1 & & & & & 1 & 0,8 & \\
\hline \multicolumn{2}{|c|}{ Vitamin-D-Speicherform } & 22 & 44,9 & 21 & 53,8 & 22 & 64,7 & 65 & 53,3 & 0,215 \\
\hline \multicolumn{2}{|c|}{$\begin{array}{l}\text { Calcium-Dauermedikation (Monopräpa- } \\
\text { rat) }\end{array}$} & 24 & 49 & & & & & 24 & 19,4 & $<0,001$ \\
\hline \multicolumn{2}{|l|}{ rhPTH } & 2 & 4,1 & 1 & 2,6 & & & 3 & 2,4 & 0,779 \\
\hline \multicolumn{2}{|l|}{ Thiazide } & 7 & 14,3 & & & 5 & 14,3 & 12 & 9,8 & 0,021 \\
\hline \multicolumn{2}{|l|}{ Magnesium } & 13 & 26,5 & 2 & 5,1 & 1 & 2,9 & 16 & 13 & 0,002 \\
\hline \multirow{4}{*}{$\begin{array}{l}\text { Zeit bis Erstmedika- } \\
\text { tion in Monaten }\end{array}$} & sofort & $27^{1}$ & 64,3 & & & & & $27^{1}$ & 64,3 & \\
\hline & $1-6$ & $5^{1}$ & 11,9 & & & & & 51 & 11,9 & \\
\hline & $12-24$ & 61 & 14,3 & & & & & 61 & 14,3 & \\
\hline & $\geq 84$ & 41 & 9,5 & & & & & 41 & 9,5 & \\
\hline
\end{tabular}

1Zeit bis Erstmedikation abweichend in Monaten, nicht "n“

Beim Chi-Quadrat- bzw. Fishers exaktem Test zeigte sich wie in Tabelle 8 dargestellt eine hoch signifikante Assoziation zwischen der Variablen Studiengruppe und der Calcium- bzw. aktiven Vitamin-D-Medikation. Eine Kombination dieser beiden Medikamentengruppen gilt als Standardmedikation zur Behandlung einer Nebenschilddrüsenunterfunktion und wird daher von den Patienten des Kollektivs HypoPT 2016 wesentlich häufiger eingenommen. Weitere gängige Medikamente der Hypoparathyreoidismustherapie sind Thiazide und Magnesium. Für diese beiden Präparate ließen sich ebenfalls signifikante Zusammenhänge mit der Variablen Studiengruppe beobachten. 
Tabelle 9: Charakteristika (Komplikationen und Vorerkrankungen laut Dokumentationsbogen, weitere Medikation) der drei Patientenkollektive HypoPT 2016, SD-OP 2016 und pHPT 2016 als Übersicht $(n=$ Anzahl, \% = gültige Prozent des jeweiligen Parameters bzw. seiner Ausprägung nach Studiengruppe [Spaltenhäufigkeit], freie Felder = keine Angabe für jeweilige Subgruppe); $p$-Wert des Chi-Quadrat- bzw. Fishers exakten Tests; signifikante Werte dick hervorgehoben; gemeinsame Daten mit cand. med. L. Wilken

\begin{tabular}{|c|c|c|c|c|c|c|c|c|c|c|}
\hline & & \multicolumn{2}{|c|}{$\begin{array}{l}\text { НypoРT } \\
2016\end{array}$} & \multicolumn{2}{|c|}{$\begin{array}{l}\text { SD- OP } \\
2016\end{array}$} & \multicolumn{2}{|c|}{$\begin{array}{l}\text { pHPT } \\
2016\end{array}$} & \multicolumn{2}{|c|}{ gesamt } & \multirow[t]{2}{*}{ p-Wert } \\
\hline & & $\mathrm{n}$ & $\%$ & $\mathrm{n}$ & $\%$ & $\mathrm{n}$ & $\%$ & $\mathrm{n}$ & $\%$ & \\
\hline \multirow{6}{*}{$\begin{array}{l}\text { Komplikationen des } \\
\text { Hypopara- } \\
\text { thyreoidismus }\end{array}$} & Nierensteine & 6 & 12,5 & 3 & 7,7 & 8 & 23,5 & 17 & 14 & 0,144 \\
\hline & Niereninsuffizienz & 5 & 10,9 & 2 & 5,3 & 3 & 8,6 & 10 & 8,4 & 0,651 \\
\hline & Nephrokalzinose & 4 & 8,5 & & & & & 4 & 3,4 & 0,038 \\
\hline & Katarakt & 5 & 10,4 & 1 & 2,8 & 1 & 3 & 7 & 6 & 0,331 \\
\hline & $\begin{array}{l}\text { Basalganglien- } \\
\text { verkalkung }\end{array}$ & 1 & 3,2 & & & & & 1 & 1,4 & 1 \\
\hline & $\begin{array}{l}\text { hypo/hyperkalzämische } \\
\text { Krisen }\end{array}$ & 4 & 10,5 & & & & & 4 & 4,3 & 0,038 \\
\hline \multirow[t]{10}{*}{ Vorerkrankungen } & Hypertonus & 23 & 47,9 & 14 & 35,9 & 19 & 55,9 & 56 & 46,3 & 0,225 \\
\hline & Arthrose/ Rheuma & 16 & 35,6 & 9 & 24,3 & 9 & 28,1 & 34 & 29,8 & 0,538 \\
\hline & Neoplasien & 14 & 29,8 & 9 & 23,1 & 4 & 11,8 & 27 & 22,5 & 0,168 \\
\hline & neurologisch /psychisch & 9 & 19,6 & 9 & 23,1 & 2 & 5,9 & 20 & 16,8 & 0,122 \\
\hline & Osteoporose & 2 & 4,9 & 8 & 22,2 & 9 & 26,5 & 19 & 17,1 & 0,026 \\
\hline & Herzerkrankungen & 9 & 18,4 & 2 & 5,4 & 4 & 12,1 & 15 & 12,6 & 0,202 \\
\hline & Asthma/ COPD 1 & 4 & 8,3 & 8 & 21,1 & 1 & 2,9 & 13 & 10,7 & 0,041 \\
\hline & $\begin{array}{l}\text { gastrointestinale Erkran- } \\
\text { kungen }\end{array}$ & 6 & 12,8 & 3 & 7,9 & 2 & 6,1 & 11 & 9,3 & 0,531 \\
\hline & Diabetes Mellitus & 4 & 8,7 & 3 & 7,9 & 1 & 2,9 & 8 & 6,7 & 0,654 \\
\hline & $\begin{array}{l}\text { belastende psychische } \\
\text { Ereignisse }\end{array}$ & 6 & 13,3 & 4 & 11,4 & 2 & 5,7 & 12 & 10,4 & 0,639 \\
\hline \multirow[t]{11}{*}{ weitere Medikation } & $\begin{array}{l}\text { Calcium } \\
\text { Bedarfsmedikation }\end{array}$ & 3 & 6,3 & & & 1 & 2,9 & 4 & 3,3 & 0,308 \\
\hline & $\begin{array}{l}\text { Schilddrüsen- } \\
\text { medikation }\end{array}$ & 49 & 100 & 38 & 97,4 & 16 & 45,7 & 103 & 83,7 & $<0,001$ \\
\hline & $\begin{array}{l}\text { Blutdruck- } \\
\text { medikation }\end{array}$ & 24 & 49 & 15 & 38,5 & 19 & 54,3 & 58 & 47,2 & 0,421 \\
\hline & Herzmedikation & 9 & 18,8 & 3 & 7,7 & 8 & 22,9 & 20 & 16,4 & 0,194 \\
\hline & Lungenmedikation & 3 & 6,3 & 7 & 17,9 & 1 & 2,9 & 11 & 9 & 0,050 \\
\hline & $\begin{array}{l}\text { gastrointestinale Medika- } \\
\text { tion }\end{array}$ & 8 & 16,7 & 6 & 15,4 & 4 & 11,4 & 18 & 14,8 & 0,811 \\
\hline & Psychopharmaka & 7 & 14,6 & 7 & 18,4 & 3 & 8,6 & 17 & 14 & 0,513 \\
\hline & Schmerzmedikation & 5 & 10,4 & 3 & 7,7 & 2 & 5,7 & 10 & 8,2 & 0,779 \\
\hline & Antirheumatika & 4 & 8,3 & 2 & 5,3 & 1 & 2,9 & 7 & 5,8 & 0,633 \\
\hline & $\begin{array}{l}\text { Osteoporose- } \\
\text { medikation }\end{array}$ & & & 2 & 5,1 & 1 & 2,9 & 3 & 2,5 & 0,370 \\
\hline & andere Medikation & 17 & 35,4 & 10 & 25,6 & 6 & 17,1 & 33 & 27 & 0,177 \\
\hline
\end{tabular}

${ }^{1} \mathrm{COPD}=$ chronische obstruktive Lungenerkrankung

Nephrokalcinose und hypo/hyperkalzämische Krisen gelten als typische Komplikationen eines Hypoparathyreoidismus und dessen Therapie und wiesen als Variablen beide einen signifikanten p-Wert auf (s. Tabelle 9). Wie alle aufgeführten Komplikationen wurden diese vom behandelnden Arzt im Dokumentationsbogen erfasst. 
Betrachtete man die Nierenfunktion der HypoPT 2016-Patienten im Labor, so hatten sechs Patienten (12,2 \%) eine chronische Niereninsuffizienz im Stadium III oder höher mit einer glomerulären Filtrationsrate $(G F R)<60$ $\mathrm{ml} / \mathrm{min} / 1,73 \mathrm{~m}^{2}$.

Bezüglich der Vorerkrankungen fiel eine signifikante Assoziation auf zwischen den Variablen Osteoporose und Studiengruppe, welche sich auch im Einzelvergleich der HypoPT 2016-Patienten mit den pHPT 2016Patienten $(p=0,011)$ bzw. dem SD-OP 2016 Kollektiv $(p=0,039)$ darstellte. Prozentual gesehen hatten in der HypoPT 2016-Gruppe im Vergleich zu beiden Kontrollgruppen die wenigsten Patienten eine Osteoporose angegeben. Bei den pHPT 2016-Patienten hingegen wurde der höchste Anteil festgestellt, was darin begründet sein könnte, dass eine Nebenschilddrüsenüberfunktion zu verändertem Knochenstoffwechsel und zu erniedrigter BMD und Osteoporose als dessen Folge führen kann (Cipriani et al. 2015; Siilin et al. 2011).

Der Zusammenhang von Studiengruppe und Schilddrüsenmedikation war im Chi-Quadrat-Test signifikant, da fast alle Patienten der Gruppen HypoPT 2016 und SD-OP 2016 aufgrund der Thyreoidektomie auf eine Schilddrüsenhormonsubstitution angewiesen waren, wohingegen die pHPT-Patienten nur teilweise ein solches Präparat einnahmen.

Der Anteil an pulmonalen Erkrankungen sowie die Lungenmedikation war im SD-OP 2016 Kollektiv am höchsten, der $p$-Wert war in beiden Fällen signifikant. Tatsächlich wurde in verschiedenen Studien eine Auswirkung der Hypothyreose auf diverse Lungenparameter (Sauerstoffpartialdruck, maximal expiratory pressure, maximal inspiratory pressure) und Exarzerbationen bei chronisch obstruktiver Lungenerkrankung beschrieben. Darüber hinaus konnte ein Zusammenhang zwischen der Einschränkung der Lungenfunktion bzw. der Exarzerbationshäufigket und der Höhe des TSHs festgestellt werden (Sarinc Ulasli et al. 2013; Terzano et al. 2014). Dies könnte eine mögliche Erklärung dafür sein, dass mehr Patienten aus dem SD-OP 2016Kollektiv pulmonale Erkrankungen sowie eine dafür benötigte Medikation angaben, da der durchschnittliche TSH Wert in diesem Kollektiv höher war als im HypoPT 2016-Kollektiv (1,32 vs. 1,11), wenngleich dieser Unterschied nicht signifikant war ( $p=1,00$; vgl. Tabelle 10). Ein zufällig vermehrtes Auftreten von Lungenerkrankungen in diesem Kollektiv kann nicht ausgeschlossen werden.

Weitere Informationen zur Diät der Patienten sind im Anhang in Tabelle 35 zu finden; hier zeigten sich keine signifikanten Auffälligkeiten. 
Die wichtigsten Laborparameter für alle drei Studienkollektive sind der Tabelle 10 zu entnehmen.

Tabelle 10: Laborparameter ( $n=$ Anzahl; Mittelwerte \pm Standardabweichung) der drei Patientenkollektive HypoPT 2016, SD-OP 2016 und pHPT 2016 mit jeweiligem Normbereich: für Albumin korrigiertes Calcium (= korr.), Phosphat, Calcium-Phosphat-Produkt (= CP-Produkt), 25(OH) $\mathrm{D}_{3}$, PTH und TSH im Serum, GFR, Calcium und Phosphat im 24-h-Urin (Einheiten in Klammern); Kruskal-Wallis-Test mit Dunn-Bonferroni Post-hoc-Test zum Vergleich der HypoPT Gruppe mit den beiden jeweiligen Kontrollgruppen (nicht aber der beiden Kontrollgruppen untereinander); Bonferroni-Korrektur für die Anzahl der Laborparameter $(\mathrm{n}=10 ; \alpha \leq 0,005),{ }^{*}=$ nach Korrektur signifikanter $p$ Wert; gemeinsame Daten mit cand. med. L. Wilken

\begin{tabular}{|c|c|c|c|c|c|c|c|c|}
\hline & & $\begin{array}{l}\text { HypoPT } \\
2016\end{array}$ & $\begin{array}{l}\text { SD-OP } \\
2016\end{array}$ & p-Wert & $\begin{array}{l}\text { pHPT } \\
2016\end{array}$ & p-Wert & $\begin{array}{l}\text { ge- } \\
\text { samt }\end{array}$ & $p$-Wert \\
\hline $\begin{array}{l}\text { Serumcalcium (korr.; } \\
\text { mmoll/) }\end{array}$ & $n$ & 46 & 35 & & 32 & & 113 & \\
\hline Normbereich: $2,0-2,6^{* *}$ & $\begin{array}{l}\text { Mittel- } \\
\text { wert }\end{array}$ & $\begin{array}{l}2,09 \\
\pm 0,16\end{array}$ & $\begin{array}{l}2,23 \pm \\
0,09\end{array}$ & $<0,001^{*}$ & $\begin{array}{l}2,41 \pm \\
0,17\end{array}$ & $<0,001^{*}$ & $\begin{array}{l}2,22 \\
\pm 0,20\end{array}$ & $<0,001^{*}$ \\
\hline Serumphosphat (mmol/l) & $n$ & 48 & 38 & & 33 & & 119 & \\
\hline Normbereich: 0,8-1,6** & $\begin{array}{l}\text { Mittel- } \\
\text { wert }\end{array}$ & $\begin{array}{l}1,26 \pm \\
0,19\end{array}$ & $\begin{array}{l}1,10 \pm \\
0,14\end{array}$ & $<0,001^{*}$ & $\begin{array}{l}0,93 \pm \\
0,16\end{array}$ & $<0,001^{*}$ & $\begin{array}{l}1,11 \pm \\
0,22\end{array}$ & $<0,001^{*}$ \\
\hline CP-Produkt (mmol/1/2) & $\mathrm{n}$ & 46 & 38 & & 33 & & 117 & \\
\hline Normbereich: $<4,4$ & $\begin{array}{l}\text { Mittel- } \\
\text { wert }\end{array}$ & $\begin{array}{l}2,71 \\
\pm 0,40\end{array}$ & $\begin{array}{l}2,46 \pm \\
0,25\end{array}$ & 0,022 & $\begin{array}{l}2,33 \pm \\
0,35\end{array}$ & $<0,001^{*}$ & $\begin{array}{l}2,52 \\
\pm 0,40\end{array}$ & $<0,001^{*}$ \\
\hline $25(\mathrm{OH}) \mathrm{D}_{3}(\mathrm{nmol} / \mathrm{l})$ & $n$ & 48 & 38 & & 33 & & 119 & \\
\hline Normbereich: $50-150^{* *}$ & $\begin{array}{l}\text { Mittel- } \\
\text { wert }\end{array}$ & $\begin{array}{l}101,78 \\
\pm 46,83\end{array}$ & $\begin{array}{l}78,26 \pm \\
29,17\end{array}$ & & $\begin{array}{l}86,53 \pm \\
28,70\end{array}$ & & $\begin{array}{l}90,04 \pm \\
38,32\end{array}$ & 0,058 \\
\hline PTH im Serum (pmol/l) & $n$ & 47 & 37 & & 33 & & 117 & \\
\hline Normbereich: 1,6-6,9* & $\begin{array}{l}\text { Mittel- } \\
\text { wert }\end{array}$ & $\begin{array}{l}1,79 \pm \\
0,98\end{array}$ & $\begin{array}{l}4,72 \pm \\
1,55\end{array}$ & $<0,001^{*}$ & $\begin{array}{l}7,19 \pm \\
3,33\end{array}$ & $<0,001^{*}$ & $\begin{array}{l}4,24 \pm \\
3,03\end{array}$ & $<0,001^{*}$ \\
\hline $\begin{array}{l}\text { Serummagnesium } \\
(\mathrm{mmol} / \mathrm{l})\end{array}$ & $\mathrm{n}$ & 40 & 31 & & 23 & & 94 & \\
\hline Normbereich: 0,66-1,07 & $\begin{array}{l}\text { Mittel- } \\
\text { wert }\end{array}$ & $\begin{array}{l}0,78 \pm \\
0,07\end{array}$ & $\begin{array}{l}0,82 \pm \\
0,18\end{array}$ & 0,021 & $\begin{array}{l}0,82 \pm \\
0,11\end{array}$ & 0,039 & $\begin{array}{l}0,80 \pm \\
0,13\end{array}$ & 0,008 \\
\hline TSH basal (mlU/l) & $n$ & 32 & 35 & & 29 & & 96 & \\
\hline Normbereich: 0,27-4,2 & $\begin{array}{l}\text { Mittel- } \\
\text { wert }\end{array}$ & $\begin{array}{l}1,11 \pm \\
1,26\end{array}$ & $\begin{array}{l}1,32 \pm \\
1,61\end{array}$ & 1,000 & $\begin{array}{l}1,45 \pm \\
0,64\end{array}$ & 0,014 & $\begin{array}{l}1,29 \pm \\
1,26\end{array}$ & 0,014 \\
\hline $\begin{array}{l}\text { GFR } \\
\left(\mathrm{m} / / \mathrm{min} / 1,73 \mathrm{~m}^{2}\right)\end{array}$ & $n$ & 49 & 39 & & 33 & & 121 & \\
\hline Normbereich: $51-120^{* *}$ & $\begin{array}{l}\text { Mittel- } \\
\text { wert }\end{array}$ & $\begin{array}{l}80,57 \pm \\
17,63\end{array}$ & $\begin{array}{l}90,56 \pm \\
14,29\end{array}$ & 0,012 & $\begin{array}{l}85,15 \pm \\
15,92\end{array}$ & 0,653 & $\begin{array}{l}85,04 \pm \\
16,57\end{array}$ & 0,016 \\
\hline $\begin{array}{l}\text { Calcium 24-h-Urin } \\
\text { (mmol/d) }\end{array}$ & $\mathrm{n}$ & 25 & 11 & & 8 & & 44 & \\
\hline Normbereich: 2,5-7,5 & $\begin{array}{l}\text { Mittel- } \\
\text { wert }\end{array}$ & $\begin{array}{l}5,39 \pm \\
2,90\end{array}$ & $\begin{array}{l}3,31 \pm \\
1,70\end{array}$ & 0,269 & $\begin{array}{l}7,78 \pm \\
3,20\end{array}$ & 0,105 & $\begin{array}{l}5,30 \pm \\
3,03\end{array}$ & 0,007 \\
\hline $\begin{array}{l}\text { Phosphat 24-h-Urin } \\
\text { (mmol/d) }\end{array}$ & $\mathrm{n}$ & 21 & 11 & & 11 & & 43 & \\
\hline Normbereich: 19,37-50,5 & $\begin{array}{l}\text { Mittel- } \\
\text { wert }\end{array}$ & $\begin{array}{l}21,76 \pm \\
6,23\end{array}$ & $\begin{array}{l}22,10 \pm \\
11,55\end{array}$ & & $\begin{array}{l}23,63 \pm \\
15,68\end{array}$ & & $\begin{array}{l}22,33 \pm \\
10,46\end{array}$ & 0,655 \\
\hline
\end{tabular}

${ }^{* *}$ kombinierter Normbereich für beide Praxen, separate Normbereiche: Serumcalcium $=2,0-2,6$ (Göttingen) und 2,15-2,58 (Saarbrücken); Serumphosphat $=0,8-1,6$ und $0,81-1,45 ; 250 H D 3=50-117,5$ und 50-150; PTH $=1,7-6,89$ und $1,6-6,9 ; \mathrm{GFR}=>60$ und $51-120$

Wichtig anzumerken ist, dass aufgrund des metrischen Datenniveaus die Mittelwerte der Laborwerte dargestellt wurden, die Gruppenunterschiede allerdings mit dem Kruskal-Wallis-Test untersucht wurden, da nicht alle Laborparameter normalverteilt waren. Außerdem wurden neben dem p-Wert für den gesamten KruskalWallis-Test (p-Wert gesamt) nur die paarweisen Vergleiche zwischen HypoPT 2016 und pHPT 2016 bzw. SDOP 2016 aufgelistet, nicht aber die Vergleiche beiden Kontrollgruppen untereinander.

Nach der Bonferroni-Korrektur zeigten sich signifikante Unterschiede bezüglich des Serumcalciums, des Serumphosphates und des PTHs im Serum bei den HypoPT 2016-Patienten im Vergleich zu den beiden 
Kontrollgruppen. Hinsichtlich des Calcium-Phosphat-Produktes war der Unterschied zwischen den Kollektiven pHPT 2016 und HypoPT 2016 signifikant.

Betrachtet man das in Bezug auf die Operation ihrer Grunderkrankung inhomogene Kollektiv der pHPT 2016Patienten genauer, so ergab der Mann-Whitney-U-Test als nicht-parametrischer Test für zwei Subgruppen nach Bonferroni-Korrektur einen signifikanten Unterschied für die Parameter Serumcalcium (korr.) und PTH im Serum, was aufgrund der Erkrankungen und durch den Einfluss der Operation zu erwarten war (s. Tabelle 11 und Tabelle 36 im Anhang). Bezüglich der Laborwerte ist dieses Vergleichskollektiv also als nicht homogen zu betrachten.

Tabelle 11: Laborparameter ( $\mathrm{n}=$ Anzahl; Mittelwerte \pm Standardabweichung) der beiden pHPT 2016-Subgruppen (operiert und nicht operiert) mit jeweiligem Normbereich: für Albumin korrigiertes Calcium (korr.) und PTH im Serum; Mann-Whitney-U-Test zum Vergleich der pHPT-Subgruppen untereinander; Bonferroni-Korrektur für die Anzahl der Laborparameter $(n=7 ; \alpha \leq 0,007),{ }^{*}=$ nach Korrektur signifikanter $p$-Wert

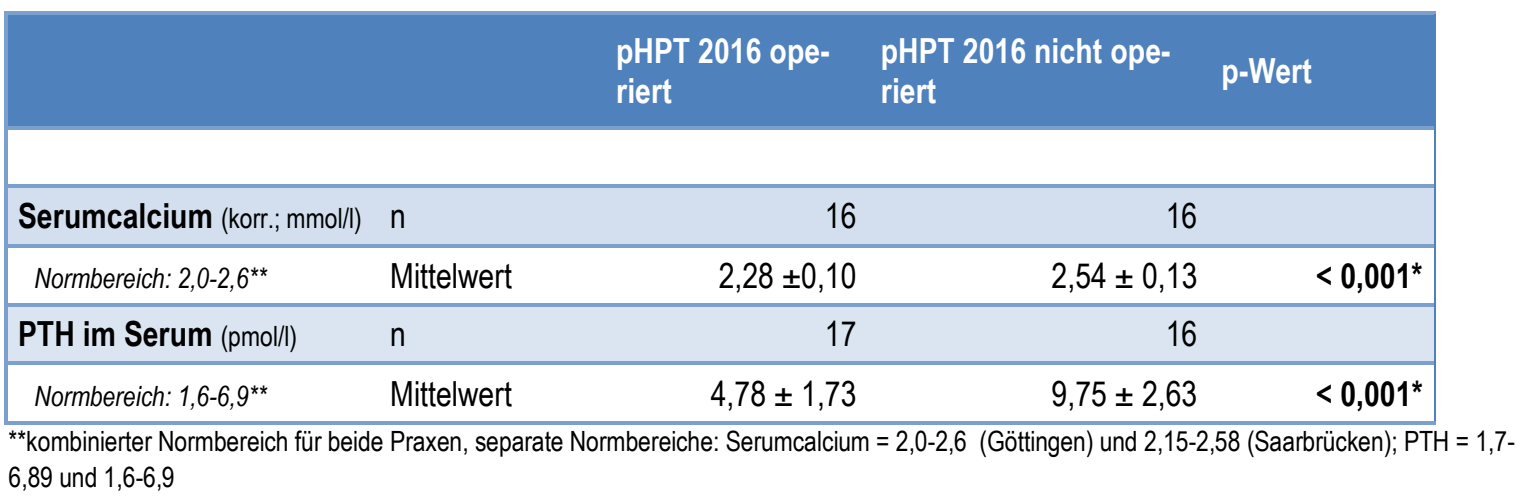

Bei den eigenommenen Nebenschilddrüsenmedikamenten präsentierten sich folgende, in Tabelle 12 und Tabelle 13 dargestellte, durchschnittliche Dosierungen:

Tabelle 12: Mittelwert \pm Standardabweichung der täglichen Dosierung der verschiedenen Nebenschilddrüsenmedikamente (Vitamin-D-Speicherform, Kombipräparat, Thiazide, rhPTH, Magnesium) sowie Anzahl der das jeweilige Präparat einnehmenden Patienten (n) bezogen auf alle Patienten bzw. Patienten des HypoPT 2016Kollektivs; gemeinsame Daten mit cand. med. L. Wilken

\begin{tabular}{|c|c|c|c|c|c|c|}
\hline & \multicolumn{2}{|c|}{ Vitamin-D-Speicherform/d (in IE) } & \multicolumn{2}{|c|}{ Kombipräparat $1 / \mathrm{d}$ (in IE) } & \multicolumn{2}{|c|}{ Thiazide/d (in mg) } \\
\hline & alle Patienten & НуроРТ 2016 & alle Patienten & НуроРТ 2016 & $\begin{array}{l}\text { alle Patien- } \\
\text { ten }\end{array}$ & $\begin{array}{l}\text { НypoPT } \\
2016\end{array}$ \\
\hline $\mathrm{n}$ & 65 & 22 & 11 & 8 & 12 & 7 \\
\hline \multirow[t]{3}{*}{$\begin{array}{l}\text { Mittel- } \\
\text { wert }\end{array}$} & $\begin{array}{l}3550,62 \pm \\
6497,11\end{array}$ & $\begin{array}{l}7165,64 \pm \\
10298,98\end{array}$ & $\begin{array}{l}809,91 \pm \\
554,68\end{array}$ & $\begin{array}{l}856,50 \pm \\
647,47\end{array}$ & $22,92 \pm 9,64$ & $\begin{array}{l}25,00 \pm \\
7,22\end{array}$ \\
\hline & \multicolumn{2}{|c|}{ Teriparatid $(\mu \mathrm{g})$} & \multicolumn{4}{|c|}{ Magnesium/d (in mg) } \\
\hline & alle Patienten & НуроРТ 2016 & alle Patienten & НуроРТ 2016 & & \\
\hline $\mathrm{n}$ & 3 & 2 & 16 & 13 & & \\
\hline $\begin{array}{l}\text { Mittel- } \\
\text { wert }\end{array}$ & $15,67 \pm 7,51$ & $13,50 \pm 9,19$ & $\begin{array}{l}203,06 \pm \\
254,25\end{array}$ & $\begin{array}{l}225,00 \pm \\
269,97\end{array}$ & & \\
\hline
\end{tabular}

Dass die durchschnittliche Dosis an Vitamin-D-Speicherformen bei den HypoPT 2016-Patienten deutlich höher war und stärker streute, lag womöglich daran, dass einige Patienten dieser Studiengruppe eine sogenannte high dose-Therapie erhielten, wohingegen andere das native Vitamin D nur additiv zur ihrer sonstigen Substitutionstherapie einnahmen. 
Tabelle 13: Mittelwert \pm Standardabweichung der täglichen Dosierung von aktivem Vitamin D (verschiedene Subgruppen) und der Calcium-Dauermedikation sowie Anzahl der das jeweilige Präparat einnehmenden Patienten ( $n$ ) bezogen auf alle Patienten bzw. Patienten des HypoPT 2016-Kollektivs; gemeinsame Daten mit cand. med. L. Wilken

\begin{tabular}{|c|c|c|c|c|}
\hline & \multicolumn{2}{|c|}{ Calcitriol/d (in $\mu g$ ) } & \multirow{2}{*}{$\begin{array}{l}\text { Alfacalcidol/d (in } \mu \mathrm{g} \text { ) } \\
\text { НyроРТ } 2016\end{array}$} & \multirow{2}{*}{$\begin{array}{l}\text { Dihydrotachysterol/d (in } \mu \mathrm{g} \text { ) } \\
\text { HypoPT } 2016\end{array}$} \\
\hline & alle Patienten & НуроРТ 2016 & & \\
\hline $\mathrm{n}$ & 15 & 14 & 21 & 6 \\
\hline \multirow[t]{3}{*}{ Mittelwert } & $0,76 \pm 0,68$ & $0,78 \pm 0,70$ & $1,07 \pm 0,42$ & $833,33 \pm 597,18$ \\
\hline & \multicolumn{2}{|c|}{ Calcium (Mono) ${ }^{1 / d}$ (in mg) } & \multicolumn{2}{|c|}{ Calcium (Kombi)²/d (in mg) } \\
\hline & \multicolumn{2}{|l|}{ НуроРТ 2016} & \multicolumn{2}{|l|}{ НуроРТ 2016} \\
\hline$n$ & \multicolumn{2}{|l|}{24} & \multicolumn{2}{|l|}{8} \\
\hline Mittelwert & \multicolumn{2}{|c|}{$990,67 \pm 884,94$} & \multicolumn{2}{|l|}{$787,50 \pm 412,09$} \\
\hline
\end{tabular}

${ }^{1}$ Calciumanteil aus Monopräparaten ${ }^{2}$ Calciumanteil aus Kombipräparaten

Die in Tabelle 13 dargestellten hohen Werte für Dihydrotachysterol sind der Umrechnung der Dosierung der Dihydrotachysterol-Präparate von $\mathrm{mg}$ nach $\mu \mathrm{g}$ geschuldet ist. Die Abbildung 5 gibt einen genaueren Überblick über die Dosierung der verschiedenen aktiven Vitamin-D-Präparate bzw. ihrer inhaltlichen Subgruppen.

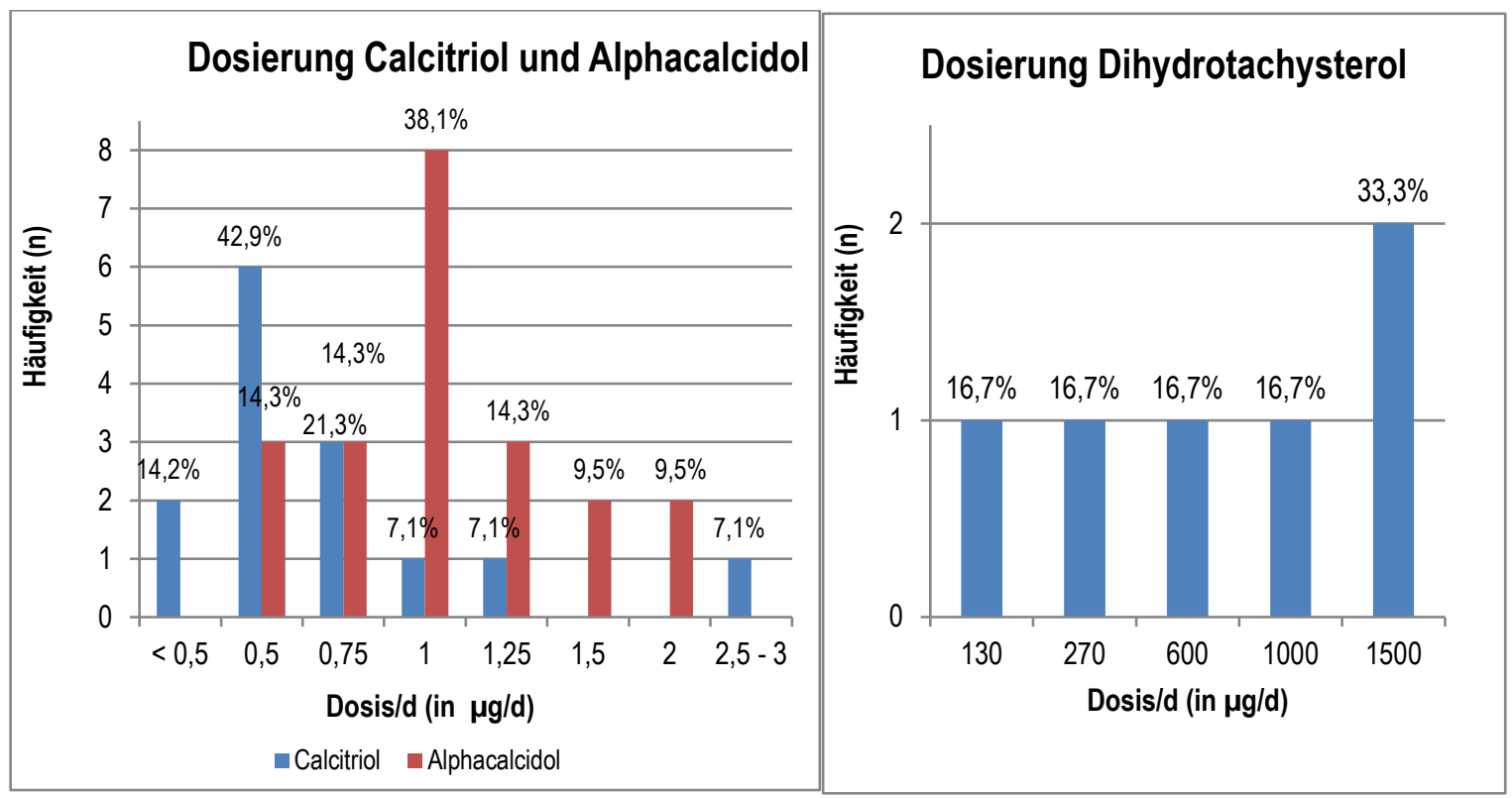

Abbildung 5: Häufigkeiten (n und \%) der Dosierung von Calcitriol und Alfacalcidol sowie Dihydrotachysterol über alle ein solches Präparat einnehmenden Patienten aus dem Kollektiv HypoPT 2016 (Calcitriol: n=14; Alfacalcidol: $n=21$; Dihydrotachysterol: $n=6$ )

Die meisten Patienten aus der Gruppe HypoPT 2016 nahmen eine tägliche Dosis von 0,5 $\mu$ Calcitirol $(42,9 \%)$ bzw. 1 ug Alfacalcidol (38,1\%) ein.

\subsection{FRAGEBÖGEN}

Alle in dieser Arbeit angewandten Fragebögen enthielten einzelne Fragen (auch Items genannt), die sich zu inhaltlichen Subgruppen (auch [Fragebogen]Skalen genannt) zusammenfassen ließen. Die Items konnten in der Regel auf einer mehrstufigen Antwortskala (z. B. „gar nicht" bis „sehr") beantwortet und diese Antworten in ordinalskalierte "Rohwerte“ (z. B. $0=$ "gar nicht" bis $3=$ "sehr") umgewandelt werden. Die Analyse der Fragebögen fand soweit möglich nach Zusammenfassung der Rohantworten der Items auf Skalenebene statt. 


\subsubsection{DIE SYMPTOM-CHECKLISTE SCL-90-R}

Die Symptom-Checkliste SCL-90-R (kurz: SCL-90-R; s. Anlage 1) ist ein psychologisches Instrument zur Erfassung von subjektiver psychischer Belastung in einem vorgegebenen Zeitraum von sieben Tagen (Franke 2002). Die Patienten müssen dazu 90 Fragen zu psychischen und körperlichen Symptomen auf einer fünfstufigen Skala von "überhaupt nicht (0)" bis „sehr stark (4)" beantworten. Der Zeitaufwand dafür beträgt ca. 15 Minuten.

Die verschiedenen Items werden dann auf den folgenden neun Skalen zusammengefasst:
1. Somatisierung
6. Aggressivität / Feindseligkeit
2. Zwanghaftigkeit
7. phobische Angst
3. Unsicherheit im Sozialkontakt
8. paranoides Denken
4. Depressivität
9. Psychotizismus

5. Ängstlichkeit

Darüber hinaus kann die generelle psychische Belastung in Form des GSI = Global Severity Index bestimmt werden. Dieser wird berechnet, indem man zunächst die Summenwerte aller Skalen addiert, den so erhaltenen Wert kürzt man mit "GS“ ab. Teilt man den GS nun durch die Anzahl aller (beantworteten) Fragen des Testes erhält man den GSI.

Im Testmanual wird außerdem empfohlen, die erhaltenen Zahlenrohwerte zur besseren Einordnung z. B. von Einzelfällen in T-Werte zu transformieren (entsprechende Tabellen dafür finden sich im Manual). Hierbei ist der Mittelwert T = 50 und die Standardabweichung hat einen Betrag von 10. T-Werte zwischen 40-60 sind klinisch unauffällig (Franke 2002), ein T-Wert von T > 60 allerdings bedeutet eine auffällige Abweichung von der Normpopulation.

\subsubsection{DER SF-36 FRAGEBOGEN ZUM GESUNDHEITSZUSTAND}

Der SF-36 Fragebogen zum Gesundheitszustand (Short Form-36 health survey, kurz: SF-36, s. Anlage 2) ist ein Messinstrument zur krankheitsübergreifenden Erfassung der gesundheitsbezogenen Lebensqualität (Morfeld 2014). Er besteht aus 36 Fragen, deren Antwortmöglichkeiten von „ja/nein“ bis hin zu sechsstufigen Antwortskalen differieren, die Bearbeitungszeit beträgt ca. 10 Minuten (Bullinger und Kirchberger 1998). Die verschiedenen Items werden auf acht Skalen abgebildet:
1. körperliche Funktionsfähigkeit
5. Vitalität
2. körperliche Rollenfunktion
6. soziale Funktionsfähigkeit
3. körperliche Schmerzen
7. emotionale Rollenfunktion
4. allgemeine Gesundheitswahrnehmung
8. psychisches Wohlbefinden

Auf Skalenebene bedeutet ein besonders niedriger Wert eine besonders hohe Beeinträchtigung in dem jeweiligen Gebiet. 
Des Weiteren kann über alle Skalen hinweg eine körperlicher und ein psychischer Summenwert auf einer Summenskala angegeben werden. Auch hier deutet ein niedriger Wert auf eine hohe körperliche bzw. psychische Einschränkung hin.

\subsubsection{FRAGEBOGEN DES MVZ ENDOKRINOLOGIKUM GÖTTINGEN}

Der Fragebogen des MVZ endokrinologikum Göttingen (s. Anlage 3) ist zur Erhebung des allgemeinen Gesundheits- und Krankheitsstatus bei der Aufnahme von Patienten in die Behandlung in der endokrinologischen Praxis gedacht. Er umfasst insgesamt über 70 Fragen, die meist mit Ja/Nein zu beantworten sind und selten Freitextantworten erfordern. Die Fragen können zu 15 Symptom- oder Beschwerdeskalen zusammengefasst werden, von denen im Rahmen dieser Arbeit folgende analysiert wurden:
1. Schmerz
4. Depressivität
2. Genuss- und Suchtmittel
5. unspezifische Symptome
3. psychische Symptome

Hierbei handelt es sich um Skalen, die eher psychische Beschwerden abbilden, wohingegen die Analyse von eher körperlichen Beschwerden Gegenstand der Arbeit von cand. med. L. Wilken waren.

\subsection{4 „ABFRAGE ZUSÄTZLICHER BESCHWERDEN“}

Ziel der Erstellung dieses Fragebogens war das Aufdecken von zusätzlichen Beschwerden zur Konzipierung des Hypoparathyreoidismus-charakteristischen Fragebogens HPQ 40, die in den anderen angewandten Fragebögen nicht (ausreichend) erfasst wurden und somit übersehen worden wären.

Zur Bildung dieses Bogens wurden in Kooperation mit cand. med. L. Wilken und ihren Daten alle handschriftlichen Kommentare und Zusatzangaben aus den von den Patienten ausgefüllten Fragebögen systematisch erfasst. Diese Informationen wurden gesammelt und auf inhaltliche Überschneidungen überprüft. Diejenigen Beschwerden, die von mindestens zwei oder mehr Patienten unabhängig voneinander genannt wurden, wurden im neuen Fragebogen „Abfrage zusätzlicher Beschwerden“ (s. Anlage 4) zusammengefasst, da ihre mindestens zweifache zusätzliche Nennung als Zeichen der Relevanz dieser Beschwerden gewertet wurde. Besonders lange Textkommentare wurden auf der Bedeutungsebene auf die Kernaussage reduziert.

Der Fragebogen „Abfrage zusätzlicher Beschwerden“ umfasst insgesamt zehn Beschwerden sowie zwei freie Felder zum Einfügen weiterer Beschwerden, um sicherzustellen, dass alle Beschwerden der Patienten erfasst wurden. Die Fragen können auf einer fünfstufigen Skala von „0 = überhaupt nicht“ bis „4 = sehr stark" beantwortet werden.

\subsection{AUSWERTUNG}

Die Rohdaten der Antworten jedes Fragebogens (Werte von 0 bis 4) wurden zunächst in Tabellen eingegeben und im Falle des SF-36 und der SCL-90-R mithilfe von vorgegebener Syntax im Statistikprogramm SPSS Statistics Version 22 und 24 (IBM) ausgewertet, um die Fragebogenskalen zu erhalten. Fehlende Angaben wurden freigelassen oder als fehlend (= 999) kodiert, Kommentare systematisch erfasst und bei doppelten Antworten die höhere gewertet. 
Die weitere statistische Analyse erfolgte mit SPSS Statistics unter Beratung vom Institut für Medizinische Statistik Göttingen (u. a. Herr Dr. Leha und Herr Dr. Jung).

Das globale Signifikanzniveau wurde bei $\alpha=0,05$ festgelegt und $p$-Werte wurden nach Bonferroni adjustiert. Ausnahmen im prospektiven Studienteil bildeten die deskriptive Statistik mit Tabelle 6 bis Tabelle 9 sowie Tabelle 35, welche nicht korrigiert wurden, da der p-Wert hier als Indikator für Homogenitität gedacht war, sowie die Nebenfragestellungen, für die nur auf der Skala Schmerz und Krämpfe getestet wurde. Diese Analysen hatten einen explorativen Charakter und dienten dem Aufdecken neuer, bislang unbekannter Zusammenhänge. Nach Rücksprache mit dem Institut für Medizinische Statistik war daher eine BonferroniAdjustierung nicht angezeigt.

\subsubsection{SPEZIELLE AUSWERTUNG DER SCL-90-R}

Um die Fragebogenskalen auszuwerten, wurde für die Daten der SCL-90-R ein metrisches Messniveau angenommen, ausgehend von dem dazugehörigen Manual, in dem für die Referenzpopulation ausschließlich Mittelwerte inklusive Standardabweichung der einzelnen Fragebogenskalen zu finden waren, was mindestens ein Intervallsklavenniveau implizierte. Dies steht im Widerspruch zu der empirischen Herangehensweise, dass die Messung von subjektiven Empfindungen und Beeinträchtigungen nie absolut metrisch erfolgen kann (Kallus 2016), allerdings sind im Testhandbuch keine Mediane zu finden, die man zu einem Vergleich auf Ordinalskalenniveau hätte verwenden könnten. Daher wurde sich an der allgemein anerkannten Literatur orientiert und zum Vergleich unserer Patienten mit der gesunden Normpopulation der t-Test bei einer Stichprobe angewandt.

Für die Korrelation der Skalenwerte mit dem Alter wurde allerdings der für ordinal skalierte Daten geeignete Spearman-Koeffizient verwendet.

Um einzelne auffällige Items zur Konzipierung des HPQ 40 herauszufinden wurde für jedes Item außerdem der Median über die Antworten aller Patienten gebildet, da die Rohdaten (Werte von 0 bis 4 ) ein ordinales Messniveau aufwiesen.

\subsubsection{SPEZIELLE AUSWERTUNG DES SF-36}

Zum Vergleich der Ergebnisse der Fragebogenskalen des SF-36 konnte mithilfe von entsprechenden Tabellen des Testmanuals jedem Patientenergebnis der Wert einer von der Altersgruppe und vom Geschlecht her passenden Vergleichsperson aus dem Normkollektiv zugeordnet werden.

Unter der oben genannten Annahme, dass subjektives Empfinden nicht metrisch messbar ist, wurde bei diesen Daten ein Ordinalskalenniveau angenommen, weshalb der Wilcoxon-Test zur Ermittlung des p-Wertes angewandt werden konnte.

Bei der Analyse der Summenskalen wurde allerdings - aufgrund der vom Manual vorgegebenen Daten wieder der t-Test bei einer Stichprobe durchgeführt.

Auch bei diesem Fragebogen wurden Mediane der Rohantworten für jedes Item gebildet, um auffällige Fragen für den HPQ 40 herauszufiltern. 


\subsubsection{AUSWERTUNG DES FRAGEBOGENS DES MVZ ENDOKRINOLOGIKUM GÖTTINGEN UND DER „ABFRAGE ZUSÄTZLICHER BESCHWERDEN"}

Zur Analyse des Fragebogens des MVZ endokrinologikum Göttingen wurde der Prozentsatz der Patienten, die mit ,ja“ geantwortet hatten, für jedes Item und die jeweiligen Skalen berechnet. Ein Prozentwert von 0,34 (als Dezimalzahl) bedeutete beispielsweise, dass $34 \%$ aller befragten Patienten dies Beschwerde angaben (also die Frage mit ,ja“ beantworteten). War der Prozentsatz $\geq 40$, wurde das Item oder die Skala als auffällig angesehen.

Da die „Abfrage zusätzlicher Beschwerden“ - im Gegensatz zur ausschließlich dichotomen Antwortmöglichkeit des Fragebogens des MVZ endokrinologikum - auf einer fünfstufigen Skala erfolgte, konnten die relevanten Skalen anhand des Medians ermittelt werden. Ein Item das über alle Patienten gesehen mit Median $\geq 2$ beantwortet wurde, wurde als auffällig angesehen.

Aufgrund mangelnder Daten zur Vergleichbarkeit wurde bei diesen beiden Fragebögen auf die Anwendung von Signifikanztests verzichtet. Die Auswertung beider Bögen erfolgte in Kooperation mit cand. med. L. Wilken.

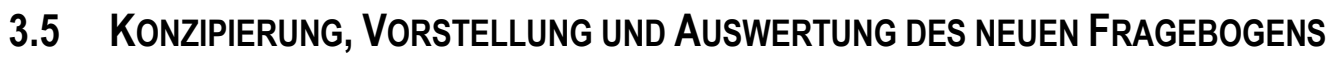

Die Erstellung des HPQ 40 - Fragebogens für Hypoparathyreoidismus war ein zentraler Bestandteil dieser Arbeit. Die Ergebnisse des retrospektiven Studienteils, die der Konzipierung dieses neuen Fragebogens dienten, sind im Ergebnisteil unter Punkt 4.1 detailliert dargestellt. Der Übersicht halber wird bereits an dieser Stelle das Vorgehen zur Erstellung des HPQ 40 erläutert, sowie der fertige Bogen und dessen Auswertung kurz vorgestellt. Eine vollständige Version des Bogens befindet sich im Anhang (Anlage 5).

\subsubsection{KONZIPIERUNG DES HPQ 40}

Zur Erstellung des neuen HPQ 40 Fragbogens speziell für den Hypoparathyreoidismus wurde gemeinsam mit cand. med. L. Wilken in mehreren Schritten vorgegangen. An dieser Stelle werden lediglich die Analyseschritte für die in dieser Arbeit verwendeten Fragebögen dargelegt. Die Analyse der eher körperlichen Beschwerden und dazugehörigen Fragebögen wird von cand. med. L. Wilken behandelt.

Im ersten Schritt wurden alle auffälligen Items herausgefiltert, unabhängig davon, zu welcher Fragebogenskala sie gehörten. Als „auffällig“ wurden diejenigen Items angesehen, die bei der Beantwortung

- der SCL-90-R von allen Patienten in den Rohdaten einen Median $\geq 1$ hatten.

- des Fragebogens des MVZ endokrinologikum Göttingen über alle Patienten einen Prozentsatz $\geq 40$ hatten.

- der „Abfrage zusätzlicher Beschwerden“ in den Rohdaten einen Median $\geq 2$ aufwiesen.

- $\quad$ des SF-36 eine bestimmte vorab festgelegte Mediangrenze überschritten, die an die unterschiedliche Skalierung der Antwortmöglichkeiten auf diesem Bogen angepasst wurde.

Im zweiten Schritt wurden diese vorab als „auffällig“ identifizierten Fragen in zwei Gruppen sortiert. Die erste Gruppe enthielt alle Items, die einer in der retrospektiven Analyse als signifikant oder auffällig herausgefundenen Skala (s. Ergebnisse unter Punkt 4.1.1 bis 4.1.4) zugehörig waren - hier „sichere Fragen“ genannt. Die 
zweite Gruppe umfasste alle Items, die nicht einer signifikanten Skala zuzuordnen waren - hier „zu diskutierende Fragen" genannt.

Im dritten Konzipierungsschritt wurden alle Items dieser beiden Gruppen auf wörtliche und inhaltliche Überschneidungen geprüft, da das mehrfache Auftauchen ähnlicher Fragen (z. B. „rasche Erschöpfbarkeit“ und „Ziemlich oft erschöpft") als Zeichen ihrer Relevanz gewertet wurde. Dabei gefundene Analogien wurden separat festgehalten, sodass nun drei Gruppen von Fragen entstanden:

- $\quad$ 1. Gruppe $=$ Analogien $/$ sich inhaltlich überschneidende Fragen

- 2. Gruppe = restliche „sichere Fragen“

- 3. Gruppe = restliche „zu diskutierende Fragen“

Mit diesen drei Gruppen wurde wie folgt verfahren: die 3. Gruppe = restliche „zu diskutierende Fragen“ wurde gestrichen, da sie den beiden vorherigen Analyseschritten nicht standgehalten hatte. Aus den Gruppen $1=$ Analogien / sich inhaltlich überschneidende Fragen und 2 = restliche „sichere Frage“ wurden neue Fragen für den krankheitscharakteristischen Fragebogen erstellt. Dabei wurde auf kurze und prägnante Formulierungen Wert gelegt. Nur dort, wo es nötig war, wurden Items in eigenen Worten ausführlicher formuliert, um den Inhalt nicht zu verfälschen. Sich inhaltlich überschneidende Fragen wurden zusammengefasst, um Redundanzen zu vermeiden. Neben einschränkenden Fragen (Wie sehr litten Sie [...] unter...?) gibt es im Fragebogen auch einen Fragenblock mit positiven Formulierungen, z. B. Inwiefern fühlten Sie sich [...] energiegeladen?, um den Aspekt der Lebensqualität - neben den Beschwerden - besser zu berücksichtigen.

Abschließend wurden alle Fragen für den neuen Bogen von einer Endokrinologin mit medizinischem Fachwissen überprüft: Zum einen auf Logik, zum anderen auf fehlende aber aus klinischer Sicht und Erfahrung relevante Inhalte. Daraufhin wurden zwei Screeningfragen für Depression, die den sog. „Depressionsscore“ bilden, eine positive Frage zur körperlichen Fitness und zwei gastrointestinale Items ergänzt.

In Kooperation mit der Klinik für Psychosomatische Medizin und Psychotherapie sowie nach Rücksprache mit der Psychologin Dr. Chavanon wurde der Bogen nochmals überprüft, Formulierungen und Struktur verbessert und inhaltliche Punkte diskutiert. Ein erster Probelauf zur Verständlichkeit und zum Zeitaufwand der Beantwortung wurde mit fünf gesunden Probanden durchgeführt und führte zur Korrektur von Formatierungs- und Rechtschreibfehlern.

Es wurde außerdem der Bogen "Dokumentation Hypoparathyreoidismus“ erstellt, um zum einen die krankheitsrelevanten Eckdaten, wie beispielsweise Erkrankungsdauer und Medikation, abzufragen, und zum anderen Komplikationen, Vorerkrankungen und Laborwerte systematischer zu erfassen. Ein Muster des Bogens findet sich im Anhang dieser Arbeit (Anlage 6), er ist zum Ausfüllen durch den behandelnden Arzt gedacht.

Beim Layout beider Bögen wurden wir professionell von einer Mediengestalterin unterstützt.

Die Bildung der Skalen des Fragebogens erfolgte nach dem Ausfüllen des Bogens durch die verschiedenen Patientengruppen $(n=151)$. Hierzu wurde - unterstützt von Prof. Dr. Herrmann-Lingen, Direktor der Klinik für Psychosomatische Medizin und Psychotherapie - eine Hauptkomponentenanalyse als Teil einer explorativen Faktorenanalyse in SPSS angewandt. Sie wird verwendet, um einen Datensatz auf die wichtigsten Informationen zu reduzieren und eine überschaubare Anzahl an Hauptkomponenten (= Faktoren) herauszufiltern, die dennoch möglichst viel der Varianz der Daten erklären (Bühner 2011; Moosbrugger und Schermelleh-Engel 2012). Daher galt, dass die Varianzaufklärung, also wie viel der Streuung der Daten durch die gefundenen 
Faktoren erklärt wird (Rentzsch et al. 2009), für die gebildeten Skalen stets über $50 \%$ sein sollte. An die Hauptkomponentenanalyse schloss sich eine Varimax-Rotation an, um die einzelnen Items einer Hauptkomponente zuordnen zu können, ohne dass die gefundenen Faktoren untereinander korrelierten, damit man diese unabhängig voneinander interpretieren konnte (Moosbrugger und Schermelleh-Engel 2012). Als Ergebnis dieser Analyse erhielt man eine rotierte Komponentenmatrix, die dabei identifizierten Hauptkomponenten entsprachen den späteren Fragebogenskalen.

Um ein Item in der rotierten Komponentenmatrix sicher einer Fragebogenskala (einer Hauptkomponente) zuzuordnen, sollte die Korrelation mit dieser (= Ladung) mindestens $>0,5$ sein. Hatte ein Item auf zwei Skalen eine Ladung > 0,5, so wurde es der Skala mit der höheren Korrelation zugeordnet. Unter Streichung von Items mit nicht ausreichend hoher Ladung und Reduktion der Skalen von zunächst acht auf fünf - unter Beachtung der Varianzaufklärung - in mehreren Analyseschritten ergaben sich die im Folgenden aufgelisteten Skalen (s. Punkt 3.5.2).

Ziel war es, bei allen diesen Skalen ein möglichst hohes Cronbachs $\alpha(>0,70)$ als Maß für die Korrelation der Items einer Skala untereinander (= interne Konsistenz) zu erhalten (Bühner 2011), aber Redundanz in den Items zu vermeiden. Die interne Konsistenz ist gegeben, wenn mehrere Fragebogenteile (Items) dasselbe messen (Mummendey und Grau 2008). Cronbachs $\alpha$ wird umso höher, je stärker Items miteinander korrelieren, also je eher sie Ähnliches messen (Kemper et al. 2015). Es dient der Beurteilung der Reliabilität eines Fragbogens. Cronbachs $\alpha$ wurde für alle Skalen berechnet, anschließend wurden die Skalen entsprechend beschriftet und sind im Ergebnisteil unter Punkt 4.2.1 zu finden.

\subsubsection{DER HPQ 40 - FRAGEBOGEN FÜR HYPOPARATHYREOIDISMUS}

Es folgt eine kurze Beschreibung des in dieser Arbeit in Kooperation mit cand. med. L.Wilken erstellten Fragebogens HPQ 40. Genauere Informationen zu dessen Inhalten und den Ergebnissen seiner Anwendung im prospektiven Studienteil sind dem Punkt 4.2 im Ergebnisteil und der vollständigen Fragebogenversion im Anhang (Anlage 5) zu entnehmen.

Der HPQ 40 - Fragebogen für Hypoparathyreoidismus enthält insgesamt 40 Fragen zu körperlichen und psychischen Beschwerden und Empfindungen innerhalb der letzten vier Wochen, für die in Voranalysen herausgefunden wurde, dass sie im Rahmen dieser Krankheit auftreten. Die Fragen sind in drei Blöcke gegliedert: ein großer Themenblock mit negativ formulierter Fragestellung (Wie sehr litten Sie [...] unter...?), ein kurzer Block mit positiv formulierten Fragen sowie zwei Fragen zum Depressionsscreening. Antworten können auf einer vierstufigen Skala ( 0 = gar nicht; 1 = ein wenig; 2 = ziemlich; 3 = stark) gegeben werden. Der zeitliche Aufwand beträgt ca. 5 Minuten.

Die einzelnen Items lassen sich zu den folgenden Skalen zusammenfassen:

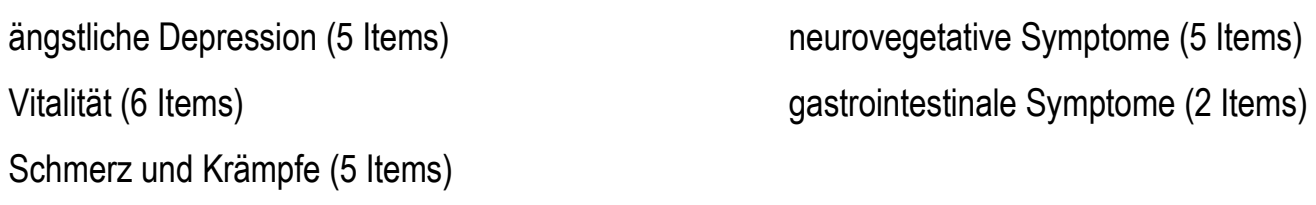


Es werden 23 der insgesamt 40 Fragen auf den beschriebenen fünf Skalen abgebildet. Ein hoher Wert auf einer Skala entspricht dabei ausgeprägten Beschwerden in diesem Bereich.

Der Depressionsscore lässt sich (in Anlehnung an den PHQ-2 = Patient Health Questionnaire) gesondert aus den Items Nr. 39 und 40 errechnen, welche zu keiner der oben genannten Skalen gehören, indem man die Summe der beiden Antwortrohwerte bildet. Er ist zum Screening von Patienten gedacht, nicht aber zur alleinigen Diagnostik, und kann einen Wert zwischen null und sechs annehmen. Ein Wert $\geq 3$ ist als positives Screening im Sinne eines Hinweises auf Depression zu interpretieren (Kroenke et al. 2003; Löwe et al. 2005). In dieser Arbeit wurden die Skalen ängstliche Depression, Vitalität und Schmerz und Krämpfe analysiert. Die beiden weiteren Skalen neuro-vegetative Symptome und gastrointestinale Symptome sind Gegenstand der Arbeit von cand. med. L. Wilken.

Für ausführlichere Informationen über den Patienten und seine Erkrankung kann der HPQ 40 um den Bogen „Dokumentation Hypoparathyreoidismus" ergänzt werden. Hier werden Alter, Geschlecht, Größe, Gewicht, Erstdiagnose und Ursache der Nebenschilddrüsenunterfunktion, Operationszeitpunkt und -grund, Erstmedikation, aktuelle Medikation, Vorerkrankungen, Komplikationen des Hypoparathyreoidismus, bestimmte Diät, psychisch belastende Ereignisse und die wichtigsten Laborparameter abgefragt (s. Anlage 6).

\subsubsection{AUSWERTUNG DES HPQ 40 SOWIE DES DOKUMENTATIONSBOGENS}

Die zur Bildung der einzelnen Fragebogenskalen angewandte Hauptkomponentenanalyse wurde bereits unter Punkt 3.5.1 dargestellt.

Die nach Dateneingabe zunächst ordinal skalierten Rohantworten des Fragebogens $(0=$ gar nicht bis $3=$ stark) wurden zu Skalen zusammengefasst, indem man den Mittelwert aller zu der Skala gehörigen Items für jeden Studienteilnehmer bildete. Durch diese Transformation hatten alle in dieser Arbeit analysierten Beschwerdeskalen ein metrisches Niveau. Dabei war zu beachten, dass die positiv formulierten Items umkodiert werden mussten ( $3=$ gar nicht bis $0=$ stark), um ihre Aussage korrekt wiederzugeben: im Bezug auf das Item gesund fühlen bedeutet die Antwort „gar nicht" eine starke Einschränkung (Wert von 3), wohingegen bei den negativ formulierten Items (z. B. Wie sehr litten Sie [...] unter... Muskelschmerzen?) die Antwort „gar nicht“ eine Beschwerdefreiheit (Wert von 0) innerhalb der letzten vier Wochen anzeigt.

Das metrische Skalenniveau sowie die Tatsache, dass die einzelnen Studienkollektive eine ausreichend hohe Fallzahl hatten $(n \geq 35)$ und die Skalenwerte annähernd normalverteilt waren, ließen eine einfaktorielle Varianzanalyse (ANOVA) bei unseren drei Patientenkollektiven zu. Merkmalsausprägungen einer Variablen können in einer ANOVA erst dann berücksichtigt werden, wenn ihre Häufigkeit $\geq 3$ ist. Als Post-hoc-Test wurde je nach Fragestellung der Dunnett-Test mit dem Kollektiv HypoPT 2016 als Kontrollgruppe oder der Tukey-Test zum Vergleich aller Subgruppen untereinander angewandt.

Für nicht metrische oder nicht normalverteilte Daten wurde analog der Kruskal-Wallis-Test mit dem in SPSS automatisch integrierten Dunn-Bonferroni-Test als post-hoc-Vergleich angewandt, wie beispielsweise für die eigentlich metrischen Laborwerte, da diese nicht alle normalverteilt waren. Bei weniger als drei Subgruppen wurde je nach Datenniveau der nicht-parametrische Mann-Whitney-U-Test oder ein t-Test für unverbundene Stichproben für die jeweilige Fragestellung verwendet. Nominal skalierte Daten wie beispielsweise das Depressionsscreening, die Einnahme von Medikamenten oder Nennung bestimmter krankheitsbedingter Kom- 
plikationen bei der deskriptiven Beschreibung der Patientenkollektive wurden mithilfe vom Chi-Quadrat-Test bzw. Fishers exaktem Test (bei einer erwarteten Häufigkeit pro Zelle $<5$ ) analysiert.

Vor der Testung auf etwaige Korrelationen wurden die zu untersuchenden Parameter mithilfe eines $Q-Q$ (Quantil-Quantil)-Plots auf Normalverteilung getestet. Da diese - trotz z. B. metrischem Datenniveau - nicht bei allen zu testenden Parametern vorlag, wurde zur besseren Vergleichbarkeit der Daten untereinander der Spearman-Koeffizient verwendet. Die grafische Aufarbeitung der Korrelationen erfolge mittels einfacher linearer Regression und LOESS (local regression)-Kurve.

Die Nebenfragestellungen (Einfluss von Operation, Medikamenten und Laborparametern wie PTH auf die Beschwerden als sekundäre Endpunkte) hatten, wie oben erwähnt, einen explorativen Charakter zur Eruierung von Zusammenhängen und wurden daher nur für signifikante Skalen getestet und nicht für alle Skalen nach Bonferroni adjustiert. Die Korrelationen wurden aufgrund der Vielzahl der untersuchten Zusammenhänge für die Anzahl der korrelierten Parameter korrigiert, aber auch ohne Korrektur signifikante Zusammenhänge wurden wegen ihres Hinweischarakters dargestellt und interpretiert.

\subsection{ETHISCHE ASPEKTE}

Die Studie wurde in Übereinstimmung mit der aktuellen Fassung der Deklaration von Helsinki durchgeführt und durch die Ethikkomission der Universitätsmedizin Göttingen genehmigt (25/10/15).

Die Studienteilnahme war freiwillig und konnte jeder Zeit ohne Nennung von Gründen wiederrufen werden. Das entsprechende gewonnene Material wurde dann entweder vernichtet, oder, wenn der Patient einverstanden war, in pseudonymisierter Form weiterverwendet. Weiterhin galt das Bundesdatenschutzgesetz, und alle an der Studie Beteiligten unterlagen der ärztlichen Schweigepflicht. 


\section{Ergebnisse}

\subsection{ERGEBNISSE DES RETROSPEKTIVEN TEILS}

\subsubsection{ERGEBNISSE DER SCL-90-R}

Die Skalenanalyse der Symptom-Checkliste SCL-90-R in der gesamten SHG 2013 im Vergleich zum Normkollektiv ergab die in Tabelle 14 aufgeführten Werte.

Tabelle 14: Skalenwerte, T-Werte (Mittelwerte \pm Standardabweichung) und p-Werte (t-Test) des Skalenwertvergleiches aus der Analyse der SCL-90-R in der SHG 2013 im Vergleich zum gesunden Normkollektiv; BonferroniKorrektur für die Anzahl der Skalen ( $n=9 ; \alpha \leq 0,006) ;{ }^{*}=$ nach Korrektur signifikante Werte

\begin{tabular}{|llllr|}
\hline & Normkollektiv & $\begin{array}{l}\text { Selbsthilfegruppe 2013 } \\
(\text { SHG 2013) }\end{array}$ & $\begin{array}{l}\text { p-Wert } \\
\text { (Skalenwerte) }\end{array}$ \\
\hline & $\begin{array}{l}\text { Skalenwert } \\
(n=2141)\end{array}$ & Skalenwert $(n=33)$ & $\begin{array}{l}\text { T-Wert }(n= \\
32)\end{array}$ \\
\hline Somatisierung & $0,47 \pm 0,47$ & $1,32 \pm 0,91$ & $61,59 \pm 9,84$ & $<0,001^{*}$ \\
\hline Zwanghaftigkeit & $0,45 \pm 0,47$ & $0,91 \pm 0,83$ & $57,50 \pm 11,44$ & $\mathbf{0 , 0 0 3}^{*}$ \\
\hline Unsicherheit & $0,41 \pm 0,49$ & $0,89 \pm 0,97$ & $56,34 \pm 13,13$ & 0,008 \\
\hline Depressivität & $0,44 \pm 0,51$ & $0,92 \pm 0,78$ & $57,94 \pm 10,95$ & $\mathbf{0 , 0 0 1}^{*}$ \\
\hline Ängstlichkeit & $0,34 \pm 0,45$ & $0,82 \pm 0,85$ & $57,19 \pm 11,16$ & $\mathbf{0 , 0 0 3 ^ { * }}$ \\
\hline Aggressivität & $0,35 \pm 0,47$ & $0,48 \pm 0,66$ & $52,75 \pm 11,80$ & 0,251 \\
\hline phobische Angst & $0,22 \pm 0,38$ & $0,60 \pm 0,99$ & $55,31 \pm 11,27$ & 0,033 \\
\hline paranoides Denken & $0,45 \pm 0,54$ & $0,69 \pm 0,74$ & $54,69 \pm 11,61$ & 0,074 \\
\hline Psychotizismus & $0,22 \pm 0,36$ & $0,38 \pm 0,44$ & $54,38 \pm 9,91$ & 0,043 \\
\hline GSI & $0,38 \pm 0,39$ & $0,82 \pm 0,70$ & $58,66 \pm 10,10$ & $\mathbf{0 , 0 0 1}$ \\
\hline
\end{tabular}

Wie man der Tabelle 14 entnehmen kann, waren die Werte auf den Skalen Somatisierung, Zwanghaftigkeit, Depressivität, Ängstlichkeit sowie der GSI für die SHG 2013 signifikant erhöht, wobei die deutliche Signifikanz der somatischen Beschwerden besonders hervorstach.

Nach der im Testmanual empfohlenen Transformation der Skalenwert in T-Wert erhielt man die in Abbildung 6 in Form von Boxplots dargestellte Verteilung. 
T-Werte SCL-90-R - gesamte SHG 2013

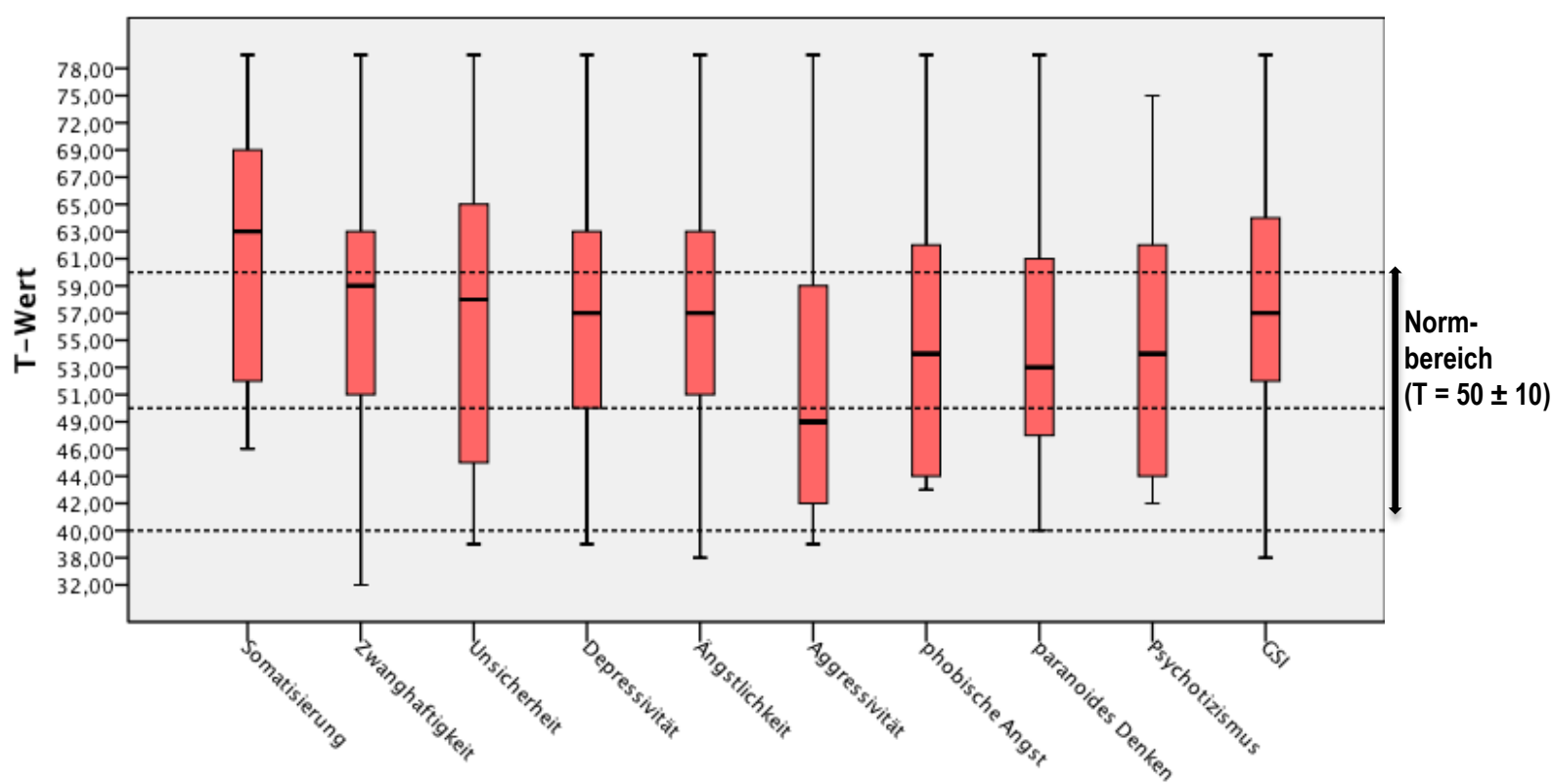

Abbildung 6: Darstellung der T-Werte der einzelnen Skalen der SCL-90-R in der SHG 2013 als Boxplots sowie Kennzeichnung des Normbereichs $(T=50 \pm 10)$ nach $T$-Transformation

In dieser Darstellungsweise wäre nur die Skala Somatisierung auffällig, deren T-Wert über der Norm liegt (> 60). Die Lage der T-Werte der einzelnen Skalen ist ähnlich wie die der Mittelwerte, wobei deutlich zu sehen ist, dass der T-Wert der Aggressivität eher im unteren Normbereich liegt. Da uns für die T-Werte keine Vergleichswerte für Signifikanztests vorlagen und diese vielmehr zur Einordnung von einzelnen Patienten dienen (Goldhammer und Hartig 2012), wurde mit den Skalenwerten und den Gruppenvergleichen weitergearbeitet, auch, um keine mögliche Beschwerdedimension zu übersehen.

Schaut man sich nun die Werte in der Subgruppe der Frauen der SHG 2013 an (s. Tabelle 15), fällt auf, dass hier dieselben Skalen signifikant waren (vgl. dazu Abbildung 7 und Abbildung 8). Auch die Lage der T-Werte in der Frauengruppe hat sich im Großen und Ganzen kaum verändert. 
Tabelle 15: Skalenwerte, T-Werte (Mittelwerte \pm Standardabweichung) und p-Werte (t-Test) des Skalenwertvergleichs der SCL-90-R in der Subgruppe der Frauen der SHG 2013 im Vergleich zu Frauen aus dem gesunden Normkollektiv; Bonferroni-Korrektur für die Anzahl der Skalen ( $n=9 ; \alpha \leq 0,006) ;{ }^{*}=$ nach Korrektur signifikante Werte

\begin{tabular}{|c|c|c|c|c|}
\hline & $\begin{array}{l}\text { Normkollektiv } \\
\text { Frauen }\end{array}$ & $\begin{array}{l}\text { Frauen der Selbsthi } \\
\text { (SHG 2013) }\end{array}$ & egruppe 2013 & $\begin{array}{l}\text { p-Wert (Ska- } \\
\text { lenwerte) }\end{array}$ \\
\hline & $\begin{array}{l}\text { Skalenwert } \\
(n=1222)\end{array}$ & Skalenwert $(n=29)$ & T-Wert $(n=28)$ & \\
\hline Somatisierung & $0,55 \pm 0,51$ & $1,41 \pm 0,92$ & $62,57 \pm 9,69$ & $<0,001^{*}$ \\
\hline Zwanghaftigkeit & $0,50 \pm 0,50$ & $0,93 \pm 0,75$ & $58,68 \pm 9,41$ & $0,005^{*}$ \\
\hline Unsicherheit & $0,47 \pm 0,53$ & $0,89 \pm 0,88$ & $57,12 \pm 12,31$ & 0,015 \\
\hline Depressivität & $0,52 \pm 0,55$ & $0,98 \pm 0,78$ & $58,71 \pm 10,27$ & $0,004^{*}$ \\
\hline Ängstlichkeit & $0,41 \pm 0,49$ & $0,89 \pm 0,86$ & $58,46 \pm 10,18$ & $0,005^{*}$ \\
\hline Aggressivität & $0,40 \pm 0,51$ & $0,51 \pm 0,68$ & $53,18 \pm 11,57$ & 0,384 \\
\hline phobische Angst & $0,28 \pm 0,44$ & $0,65 \pm 1,04$ & $55,43 \pm 11,04$ & 0,068 \\
\hline paranoides Denken & $0,48 \pm 0,55$ & $0,69 \pm 0,69$ & $54,86 \pm 10,87$ & 0,107 \\
\hline Psychotizismus & $0,25 \pm 0,39$ & $0,39 \pm 0,43$ & $54,79 \pm 9,16$ & 0,082 \\
\hline GSI & $0,45 \pm 0,42$ & $0,87 \pm 0,87$ & $59,57 \pm 9,04$ & 0,003 \\
\hline
\end{tabular}

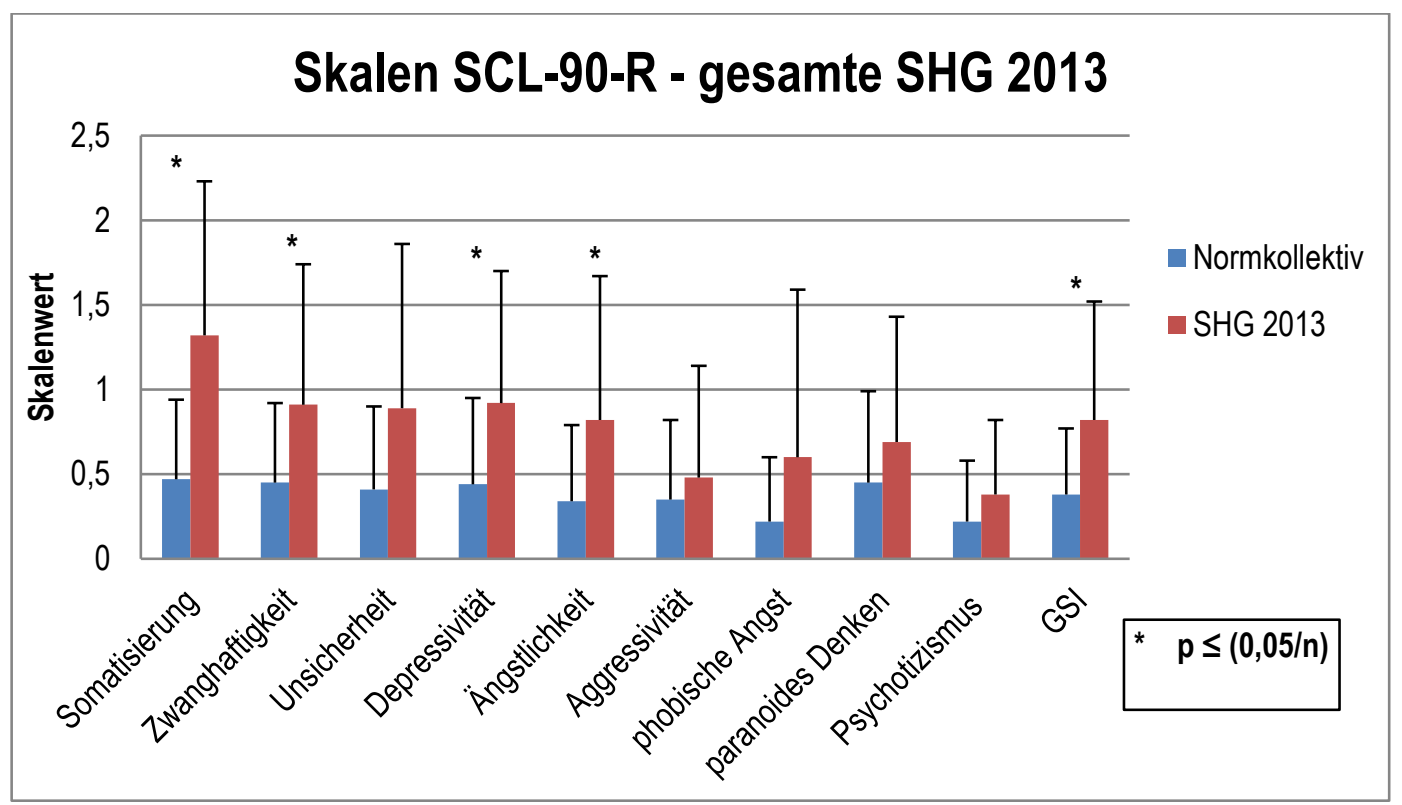

Abbildung 7: Mittelwerte der Skalenwerte (mit Standardabweichung) der SCL-90-R in der gesamten SHG 2013 $(n=33)$ im Vergleich zum gesunden Normkollektiv ( $n=2141)$; nach Bonferroni-Korrektur signifikante Skalen mit Stern markiert 


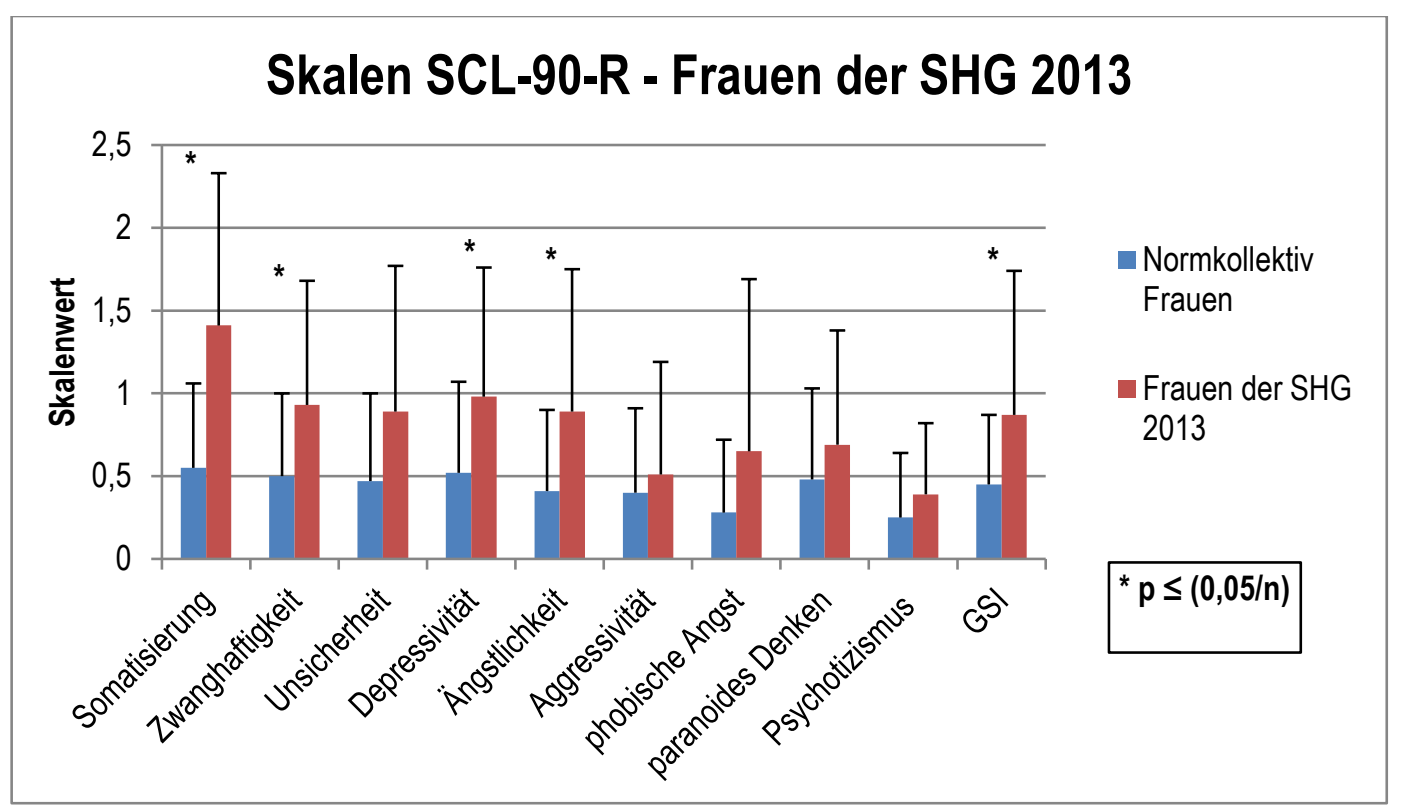

Abbildung 8: Mittelwerte der Skalenwerte (mit Standardabweichung) der SCL-90-R in der Subgruppe der Frauen der SHG 2013 ( $n=29)$ im Vergleich zu Frauen des gesunden Normkollektivs ( $n=1222)$; nach Bonferroni-Korrektur signifikante Skalen mit Stern markiert

Bei der Anwendung des t-Testes bei einer Stichprobe ist zu beachten, dass der Test zwar korrigiert wird, aber etwas ungenauer ist als ein Zweistichprobentest. Ausreißer können hier zu stärkeren Verfälschungen führen.

Das 33 Patienten umfassende Kollektiv der SHG 2013 enthielt nur 3 Männer, wohingegen die Verteilung von Frauen zu Männern im Normkollektiv in etwa 1,3:1 betrug. Wegen der kleinen Anzahl an Männern wurde angenommen, dass die Subgruppenanalyse der Frauen die tatsächlichen Beschwerden besser abbildet als die Analyse des Gesamtkollektivs. Daher wurden für die Erstellung des neuen Fragebogens formal nur die bei den Frauen signifikanten Skalen berücksichtigt, da sie wahrscheinlich repräsentativer für die Beschwerden von Hypoparathyreoidismuspatienten sind, wobei anzumerken ist, dass in beiden Kollektiven dieselben Skalen signifikant waren.

Bei der Anwendung des Spearman-Korrelationskoeffizienten ergab sich keine Korrelation zwischen den Beschwerdeskalen und dem Alter der Patienten.

\subsubsection{ERGEBNISSE DES SF-36}

Die Tabelle 16 gibt die Ergebnisse der Analyse der Skalen des SF-36 Fragebogen zum Gesundheitszustand im Kollektiv der SHG 2015 wieder. 
Tabelle 16: Skalenwerte (Mediane mit Perzentilen) und zugehörige p-Werte des SF-36 im Kollektiv der SHG 2015 im Vergleich zum gesunden Normkollektiv; Bonferroni-Korrektur für die Anzahl der Skalen ( $n=8 ; \alpha \leq 0,006) ;{ }^{*}=$ nach Korrektur signifikante Werte

\begin{tabular}{|c|c|c|c|c|c|}
\hline & \multicolumn{2}{|c|}{ Normkollektiv (gematched) } & \multicolumn{2}{|c|}{$\begin{array}{l}\text { Selbsthilfegruppe } 2015 \\
\text { (SHG 2015) }\end{array}$} & \multirow{2}{*}{$\begin{array}{l}\text { p-Wert } \\
\text { (Wil- } \\
\text { coxon) }\end{array}$} \\
\hline & $\mathrm{n}$ & $\begin{array}{l}\text { Skalenwert } \\
\text { (25\%-Perzentil; 75\%- } \\
\text { Perzentil) }\end{array}$ & $\mathrm{n}$ & $\begin{array}{l}\text { Skalenwert } \\
\text { (25\%-Perzentil; 75\%- } \\
\text { Perzentil) }\end{array}$ & \\
\hline $\begin{array}{l}\text { körperliche Funktionsfähig- } \\
\text { keit }\end{array}$ & 27 & $83,34(74,79 ; 87,27)$ & 27 & $80,00(64,29 ; 90,00)$ & 0,718 \\
\hline körperliche Rollenfunktion & 27 & $77,81(72,34 ; 86,91)$ & 27 & $50,00(00,00 ; 100,00)$ & $0,004^{*}$ \\
\hline körperliche Schmerzen & 27 & $70,41(69,77 ; 76,89)$ & 27 & $62,00(41,00 ; 84,00)$ & 0,071 \\
\hline $\begin{array}{l}\text { allgemeine Gesundheits- } \\
\text { wahrnehmung }\end{array}$ & 27 & $61,08(58,92 ; 68,14)$ & 26 & $43,50(18,75 ; 57,00)$ & $<0,001^{*}$ \\
\hline Vitalität & 27 & $60,01(58,29 ; 62,34)$ & 27 & $40,00(35,00 ; 50,00)$ & $<0,001^{*}$ \\
\hline soziale Funktionsfähigkeit & 26 & $85,30(85,30 ; 87,72)$ & 27 & $62,50(50,00 ; 100,00)$ & $0,004^{*}$ \\
\hline emotionale Rollenfunktion & 27 & $88,05(88,05,89,99)$ & 25 & $33,33(00,00 ; 83,33)$ & $<0,001^{*}$ \\
\hline psychisches Wohlbefinden & 27 & $71,11(70,22 ; 71,81)$ & 27 & $56,00(48,00 ; 64,00)$ & $<0,001^{*}$ \\
\hline
\end{tabular}

Die Skalen körperliche Rollenfunktion, allgemeine Gesundheitswahrnehmung, Vitalität, soziale Funktionsfähigkeit, emotionale Rollenfunktion und psychisches Wohlbefinden waren signifikant erniedrigt. Die allgemeine Gesundheitswahrnehmung, Vitalität, die emotionale Rollenfunktion und das psychische Wohlbefinden stachen aufgrund ihrer $p$-Werte besonders hervor (s. dazu auch Abbildung 9).

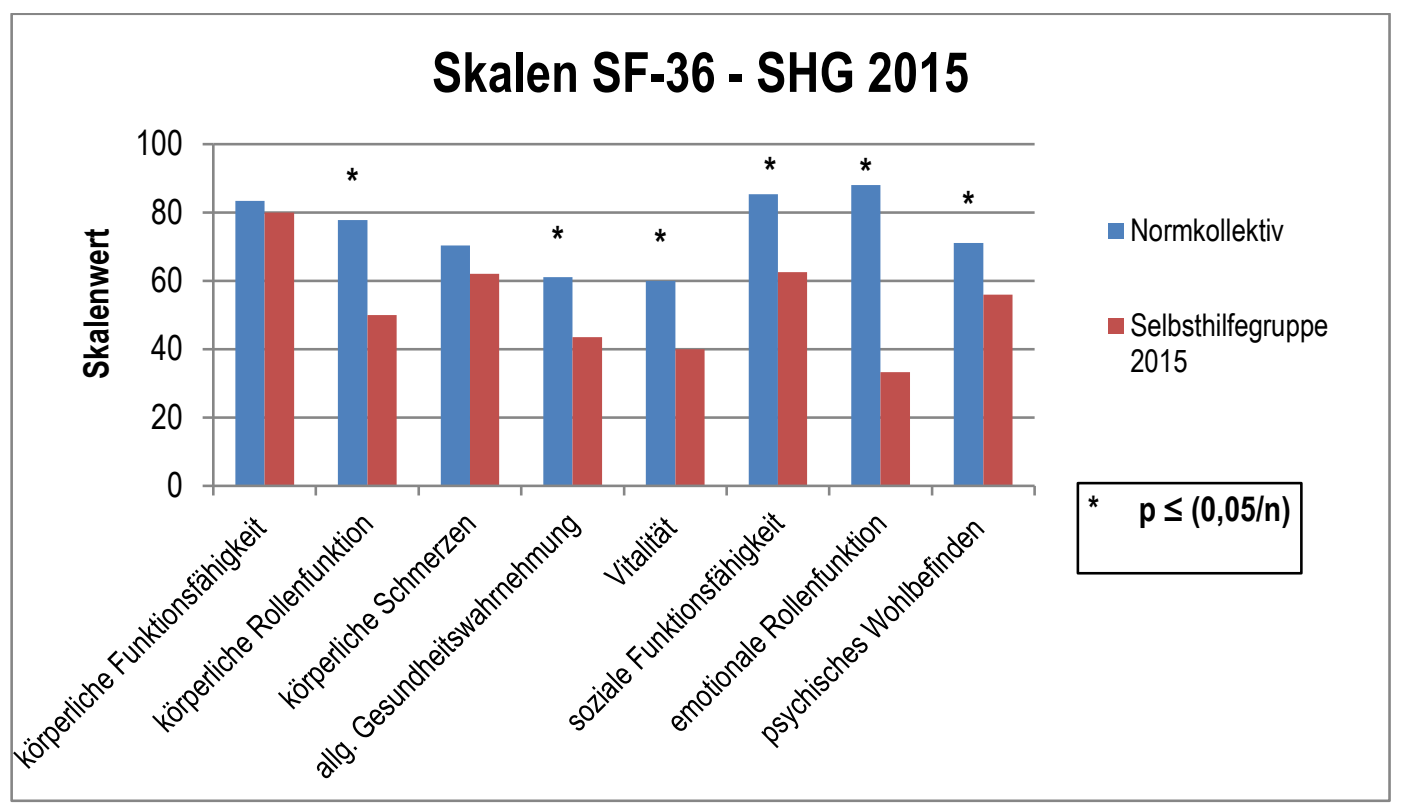

Abbildung 9: Mediane der Skalen des SF-36 im Kollektiv der SHG 2015 im Vergleich zum gesunden Normkollektiv (n=25-27); signifikante Skalen mit Stern markiert

Die Auswertung der körperlichen und psychischen Summenskalen ergab, wie in Tabelle 17 dargestellt, signifikant erniedrigte Werte auf der psychischen Summenskala, was eine hauptsächlich psychische Belastung andeutet. 
Tabelle 17: Summenskalen (Mittelwerte \pm Standardabweichung) des SF-36 im Kollektiv der SHG 2015 im Vergleich zum gesunden Normkollektiv; signifikante Werte dick hervorgehoben

\begin{tabular}{|lllllr|}
\hline Summenskalen SF-36 (hier kein Match möglich) & & \\
& \multicolumn{2}{c}{ Normkollektiv } & Selbsthilfegruppe 2015 (SHG 2015) & \multicolumn{1}{c|}{$\begin{array}{l}\text { p-Wert } \\
\text { (t-Test) }\end{array}$} \\
\hline & $\mathrm{n}$ & Skalenwert & $\mathrm{n}$ & Skalenwert & \\
\hline körperliche Summenskala & 1861 & $50,21 \pm 10,24$ & 24 & $45,95 \pm 10,35$ & 0,055 \\
\hline psychische Summenskala & 1861 & $51,54 \pm 8,14$ & 24 & $36,04 \pm 9,81$ & $<0,001$ \\
\hline
\end{tabular}

Auf eine geschlechtergetrennte Analyse wurde hier verzichtet, da aufgrund des Matchens von Patienten der SHG 2015 und mit alters- und geschlechtsentsprechenden Personen aus dem Normkollektiv keine geschlechtsbedingte Verzerrung erwartet wurde.

\subsubsection{ERGEBNISSE DES FRAGEBOGENS DES MVZ ENDOKRINOLOGIKUM GÖTTINGEN}

Die Analyse der Skalen des Fragebogens des MVZ endokrinologikum Göttingen ergab folgende in Tabelle 18 zu sehende Prozentwerte für die einzelnen Skalen mit ihren dazugehörigen Items:

Tabelle 18: Skalen des Fragebogens des MVZ endokrinologikum Göttingen mit zugehörigen ltems und Prozentsatzanalyse (Anteil der Patienten, die Item mit ,ja“ beantwortet haben); auffällige / relevante Werte dick hervorgehoben

\begin{tabular}{|c|c|}
\hline Skala mit Items & $\begin{array}{l}\text { Prozentsatz (als } \\
\text { Dezimalzahl) }\end{array}$ \\
\hline Schmerz & 0,39 \\
\hline - Kopfschmerzen & 0,39 \\
\hline - Nackenschmerzen & 0,46 \\
\hline - Abdominalschmerz & 0,21 \\
\hline - Rückenschmerzen & 0,55 \\
\hline - Ischiasschmerz & 0,36 \\
\hline Genuss- und Suchtmittel & 0,44 \\
\hline - Alkoholkonsum & 0,50 \\
\hline - Rauchen & 0 \\
\hline - Kaffee & 0,82 \\
\hline psychische Symptome & 0,52 \\
\hline - Schlafstörungen & 0,58 \\
\hline - Konzentrationsstörungen & 0,73 \\
\hline - $\quad$ Niedergeschlagenheit & 0,30 \\
\hline - Lustlosigkeit & 0,27 \\
\hline Depressivität & 0,20 \\
\hline - Appetitlosigkeit & 0,03 \\
\hline - Gewichtsabnahme & 0,21 \\
\hline - $\quad$ Niedergeschlagenheit & 0,30 \\
\hline - Lustlosigkeit & 0,27 \\
\hline unspezifische Symptome & 0,42 \\
\hline - Erschöpfbarkeit & 0,70 \\
\hline - Schwitzen & 0,50 \\
\hline - $\quad$ vermehrter Durst & 0,18 \\
\hline - Alopezie & 0,24 \\
\hline
\end{tabular}


Wie der Tabelle 18 zu entnehmen ist, hatten die Skalen Genuss- und Suchtmittel, psychische Symptome und unspezifische Symptome einen Prozentsatz $\geq 40$ (fett gedruckt) und wurden somit als bedeutsam angesehen. Darüber hinaus ist zu beachten, dass auf der Skala Schmerz einzelne Fragen einen auffällig erhöhten Prozentsatz hatten, wohingegen die gesamte Skala nicht erhöht war. Diese Items wurden dennoch bei der Erstellung gesondert berücksichtigt.

Die Skala Genuss- und Suchtmittel stellt keine Beschwerden, sondern vielmehr eine Verhaltensweise dar und wurde daher nicht in den neuen Fragbogen aufgenommen.

\subsubsection{ERGEBNISSE DER „ABFRAGE ZUSÄTZLICHER BESCHWERDEN“}

Da dieser Fragebogen lediglich zur Itemgenerierung für den neuen HPQ 40 diente und die einzelnen Items auf keiner Skala abgebildet wurden sowie kein Vergleichskollektiv zur Verfügung stand, wurde auf eine detaillierte Darstellung im Ergebnisteil verzichtet. Die Tabelle 19 zeigt alle Items mit auffälliger Mediananalyse (Median $\geq 2$ ), die bei der Konzipierung des neuen Fragebogens für Hypoparathyreoidismus berücksichtigt wurden. Auch wenn die Mediananalyse im Normalfall nicht das geeignetste Mittel zur Identifizierung neuer Fragenitems ist, war sie aufgrund der fehlenden Vergleichsmöglichkeiten bei diesem Bogen der sinnvollste Weg.

Tabelle 19: Inhalte der auffälligen Items der „Abfrage zusätzlicher Beschwerden" mit Angabe des Medians; gemeinsame Daten mit cand. med. L. Wilken

\begin{tabular}{|ll|}
\hline Iteminhalt & Median \\
\hline Muskelzittern & 2 \\
\hline Muskelschmerzen & 2 \\
\hline Muskelkrämpfe & 2 \\
\hline Kribbeln (Arme / Beine / Hände / Füße /Gesicht) & 2 \\
\hline Funktionseinschränkung durch Krankheit generell & 2 \\
\hline Funktionseinschränkung im Alltag / Beruf & 2 \\
\hline Funktionseinschränkung im Privatleben & 2 \\
\hline Trockene Haut & 3 \\
\hline
\end{tabular}

\subsection{ERGEBNISSE DES PROSPEKTIVEN TEILS}

\subsubsection{ERGEBNISSE DER KONZIPIERUNG DES HPQ 40}

Die oben beschriebene Hauptkomponentenanalyse aller Items des HPQ 40 mit anschließender VarimaxRotation ergab insgesamt fünf Beschwerdeskalen (s. Tabelle 37 im Anhang). Davon werden die beiden Skalen gastrointestinale und neurovegetative Symptome in der Arbeit von cand. med. Wilken ausgewertet und dargestellt. Die drei in dieser Arbeit analysierten Skalen mit ihren jeweiligen Items sind in der Tabelle 20 abgebildet. Bei der Hauptkomponentenanalyse wurden die Daten aller Patienten, die den Fragebogen ausgefüllt hatten, verwendet $(n=151)$. 
Tabelle 20: Skalen des HPQ 40 mit Cronbachs $\alpha$ (Korrelation der Items untereinander) und zugehörigen Items sowie deren Korrelation mit der Skala (Hauptkomponente) in der rotierten Komponentenmatrix (= Ladung)

\begin{tabular}{|c|c|c|c|}
\hline Skala & Cronbachs $\alpha$ & Item & Korrelation (Ladung) \\
\hline \multirow{6}{*}{ ängstliche Depression } & 0,860 & & \\
\hline & & Selbstvorwürfe & 0,791 \\
\hline & & innere Anspannung und Unruhe & 0,712 \\
\hline & & sorgenvolle Gedanken & 0,802 \\
\hline & & Schwermut & 0,775 \\
\hline & & Entscheidungsschwierigkeiten & 0,725 \\
\hline \multirow[t]{7}{*}{ Vitalität } & 0,885 & & \\
\hline & & energiegeladen & 0,772 \\
\hline & & fit und vital & 0,685 \\
\hline & & Freude an Sexualität & 0,652 \\
\hline & & ruhig und gelassen & 0,654 \\
\hline & & glücklich & 0,844 \\
\hline & & gesund fühlen & 0,750 \\
\hline \multirow[t]{6}{*}{ Schmerz und Krämpfe } & 0,809 & & \\
\hline & & Kreuz- und Rückenschmerzen & 0,614 \\
\hline & & Gelenk- oder Gliederschmerzen & 0,718 \\
\hline & & Muskelschmerzen & 0,755 \\
\hline & & Nacken- oder Schulterschmerzen & 0,702 \\
\hline & & Muskelkrämpfe & 0,502 \\
\hline
\end{tabular}

Die Skalen wurden nach ihren Inhalten benannt. Die Items der Skala Vitalität generierten sich hauptsächlich aus dem SF-36, weshalb diese Skala einen wichtigen Aspekt der Lebensqualität erfassen soll.

Da die Skala ängstliche Depression auch nach dem letzten Analyseschritt noch 12 Fragen enthielt, wurden nur die Items mit einer besonders hohen Ladung $(>0,7)$ bei der endgültigen Skalenbildung berücksichtigt, wobei Cronbachs a ausreichend hoch blieb (Tabelle 20).

\subsubsection{ERGEBNISSE DES HPQ 40}

Zwecks besserer Wertigkeit und Interpretierbarkeit der Ergebnisse des HPQ 40 und des dazugehörigen Dokumentationsbogens für Hypoparathyreoidismus wurden in den folgenden Analysen nur die Daten der oben beschriebenen 123 gematchten Patienten ausgewertet.

Bei der Analyse der Skalen des HPQ 40 im Gruppenvergleich ergaben sich folgende, in der Tabelle 21 dargestellte Ergebnisse. 
Tabelle 21: Skalenwerte (Mittelwerte \pm Standardabweichung) und zugehörige $p$-Werte aus der Analyse des HPQ 40 im HypoPT 2016-Kollektiv im Vergleich zum SD-OP und pHPT 2016-Kollektiv; * = nach Bonferroni-Korrektur für die Anzahl der Fragebogenskalen ( $n=5)$ signifikant $p$-Werte $(\alpha \leq 0,01)$

\begin{tabular}{|c|c|c|c|c|c|c|}
\hline & $\begin{array}{l}\text { НypoPT } \\
2016\end{array}$ & SD-OP 2016 & & pHPT 2016 & & gesamt \\
\hline & $\begin{array}{l}\text { Skalenwert } \\
(n=49)\end{array}$ & $\begin{array}{l}\text { Skalenwert } \\
(n=39)\end{array}$ & $\begin{array}{l}\text { p-Wert } \\
\text { (Dunnett) }\end{array}$ & $\begin{array}{l}\text { Skalenwert } \\
(n=35)\end{array}$ & $\begin{array}{l}\text { p-Wert } \\
\text { (Dunnett) }\end{array}$ & $\begin{array}{l}\text { p-Wert } \\
\text { (ANOVA) }\end{array}$ \\
\hline $\begin{array}{l}\text { Schmerz und } \\
\text { Krämpfe }\end{array}$ & $1,26 \pm 0,72$ & $0,80 \pm 0,54$ & $0,001^{*}$ & $0,82 \pm 0,50$ & $0,003^{*}$ & $0,001^{*}$ \\
\hline Vitalität & $1,84 \pm 0,70$ & $1,56 \pm 0,61$ & 0,096 & $1,62 \pm 0,67$ & 0,262 & 0,121 \\
\hline $\begin{array}{l}\text { ängstliche } \\
\text { Depression }\end{array}$ & $0,73 \pm 0,69$ & $0,69 \pm 0,61$ & 0,920 & $0,53 \pm 0,54$ & 0,262 & 0,338 \\
\hline
\end{tabular}

Wie auch die Abbildung 10 veranschaulicht, hatten die Patienten mit postoperativem Hypoparathyreoidismus zwar auf allen drei Skalen im Vergleich zu den Kontrollgruppen die höchsten Werte für Beschwerden, signifikant erhöhte Werte lagen allerdings nur für die Skala Schmerz und Krämpfe vor. Hierbei ist hervorzuheben, dass die HypoPT 2016-Patienten auf dieser Skala sowohl im Vergleich zu den SD-OP 2016-Patienten als auch im Vergleich zum laborchemisch gesehen inhomogenen pHPT 2016-Kollektiv mehr Beschwerden angaben.

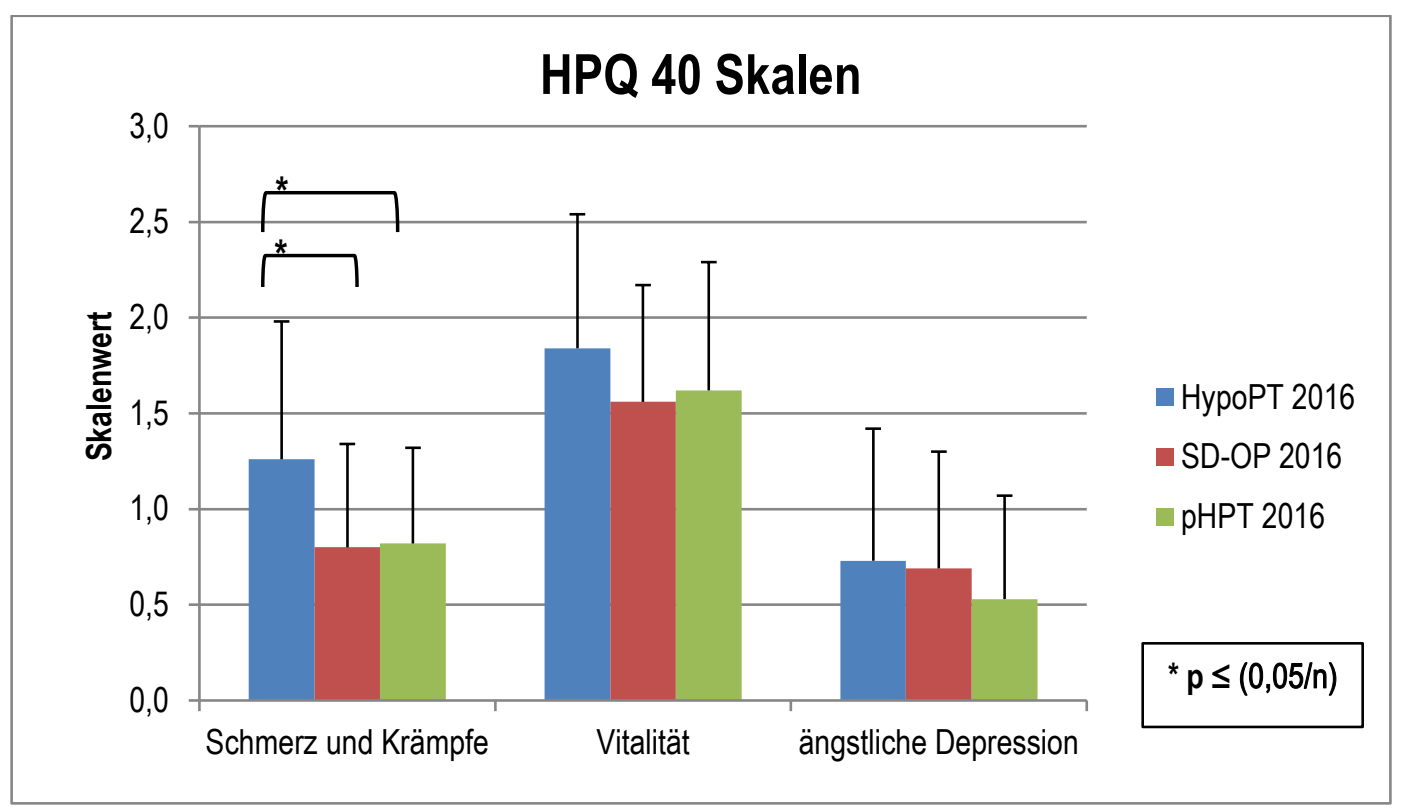

Abbildung 10: Mittelwerte (mit Standardabweichung) der Skalenwerte des HPQ 40 im HypoPT 2016-Kollektiv $(n=49)$ im Vergleich zu den SD-OP 2016 ( $n=39)$ und pHPT 2016-Patienten ( $n=35)$; nach Bonferroni-Korrektur signifikante Unterschiede mit Stern markiert

Bei der prospektiven Dateneingabe fielen mehrere Patienten durch inkonsistentes Antwortverhalten auf, was zu der Überlegung führte, dass der Unterschied zwischen negativ formulierter Fragestellung (gar nicht $=$ keine Beschwerden = 0; Fragen 1-32) und positiv formulierter Fragestellung (gar nicht $=$ deutliche Einschränkung = 3; Fragen 33-38) nicht von allen Pateinten erfasst wurde.

Daher wurden nach den folgenden beiden Kriterien Patienten mit vermutlich falschem Antwortverhalten aufgrund des Wechsels von negativer zu positiver Fragestellung herausgefiltert: 
- A) Frage 1-32: maximal zweimal „2 = ziemlich“ als Antwort, sonst ausschließlich mit „0 = gar nicht“ und/ oder „1 = ein wenig“ beantwortet. Dieses Antwortmuster ließ auf eine geringe allgemeine Beschwerdelast schließen.

- B) Fragen 33-38: ausschließlich mit „2 = ziemlich“ und/ oder „3 = stark“ beantwortet. Dieses Antwortmuster zeigte in Kombination mit Kriterium A) eine (unplausibel) hohe Beschwerdelast bei diesen Items.

Patienten, auf die sowohl Kriterium A) als auch Kriterium B) zutraf, sowie ihre jeweiligen Matches wurden aus der Analyse ausgeschlossen ( $n=21)$ und die ANOVA für die drei Beschwerdeskalen erneut durchgeführt.

Die Tabelle 22 zeigt die Ergebnisse dieser einfaktoriellen Varianzanalyse.

Tabelle 22: Skalenwerte (Mittelwerte \pm Standardabweichung) und zugehörige $p$-Werte aus der Analyse des HPQ 40 im HypoPT 2016-Kollektiv im Vergleich zu den SD-OP 2016 und pHPT 2016-Patienten nach Ausschluss von Patienten (inkl. Matches) mit vermutlich falschem Antwortverhalten; * = nach Bonferroni-Korrektur für die Anzahl der Fragebogenskalen $(n=5)$ signifikant $(\alpha \leq 0,01)$

\begin{tabular}{|c|c|c|c|c|c|c|}
\hline & $\begin{array}{l}\text { HypoPT } \\
2016\end{array}$ & SD-OP 2016 & & pHPT 2016 & & gesamt \\
\hline & $\begin{array}{l}\text { Skalenwert } \\
(n=41)\end{array}$ & $\begin{array}{l}\text { Skalenwert } \\
(n=31)\end{array}$ & $\begin{array}{l}\text { p-Wert } \\
\text { (Dunnett) }\end{array}$ & $\begin{array}{l}\text { Skalenwert } \\
(n=30)\end{array}$ & $\begin{array}{l}\text { p-Wert } \\
\text { (Dunnett) }\end{array}$ & $\begin{array}{l}\text { p-Wert } \\
\text { (ANOVA) }\end{array}$ \\
\hline $\begin{array}{l}\text { Schmerz und } \\
\text { Krämpfe }\end{array}$ & $1,31 \pm 0,74$ & $0,84 \pm 0,58$ & $0,005^{*}$ & $0,86 \pm 0,52$ & $0,008^{*}$ & $0,002^{*}$ \\
\hline Vitalität & $1,82 \pm 0,72$ & $1,50 \pm 0,54$ & 0,078 & $1,57 \pm 0,66$ & 0,215 & 0,095 \\
\hline $\begin{array}{l}\text { ängstliche } \\
\text { Depression }\end{array}$ & $0,78 \pm 0,73$ & $0,74 \pm 0,63$ & 0,947 & $0,56 \pm 0,56$ & 0,275 & 0,345 \\
\hline
\end{tabular}

Die Skala Schmerz und Krämpfe blieb nach wie vor als einzige signifikant. Interessant war jedoch die Veränderung auf der Skala Vitalität (s. Abbildung 11), wo der $p$-Wert $(p=0,095)$ im Vergleich zur ursprünglichen Analyse $(p=0,121)$ nun eine Tendenz in Richtung eines signifikanten Unterschiedes erkennen lässt. 


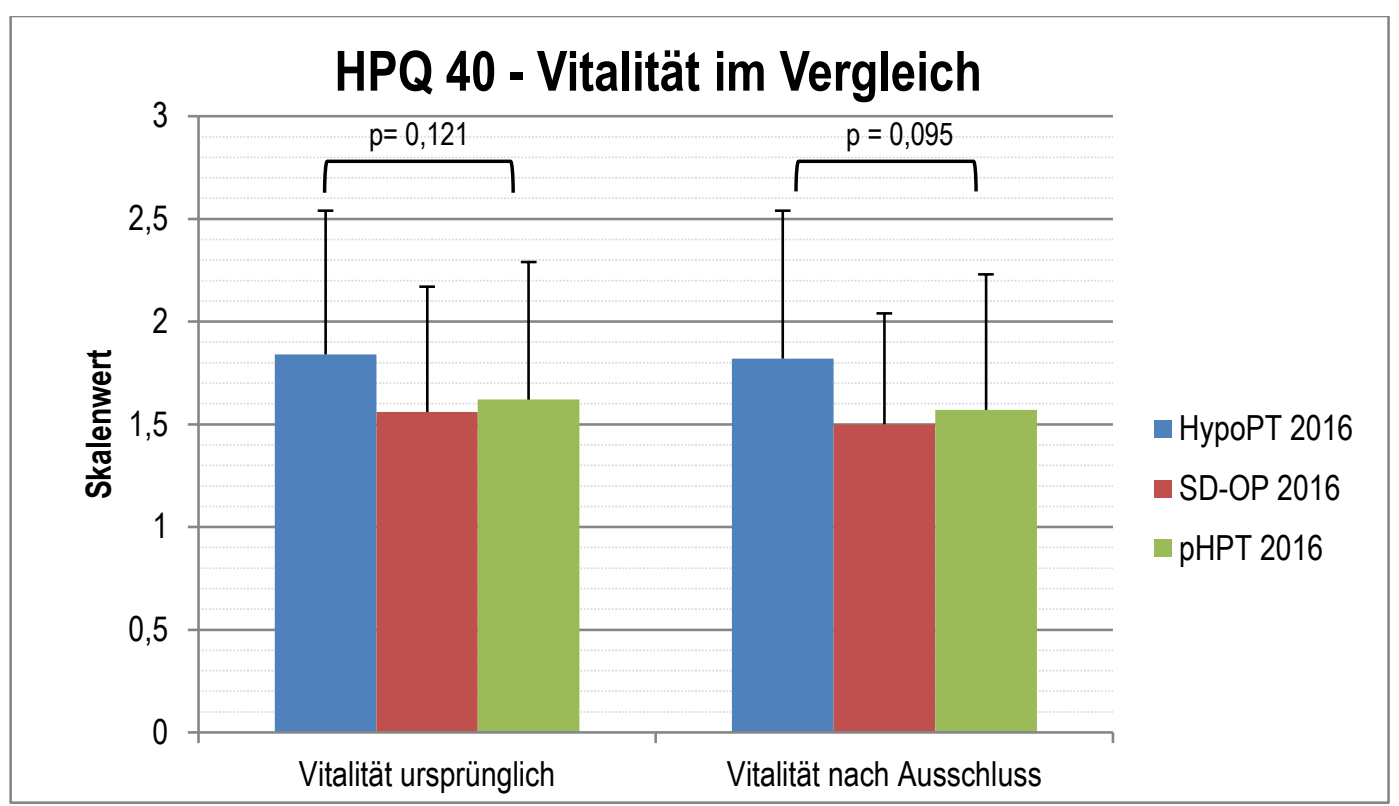

Abbildung 11: Mittelwerte (mit Standardabweichung) der Skalenwerte für die Skala Vitalität des HPQ 40 im HypoPT 2016-Kollektiv ( $n=41)$ im Vergleich zu SD-OP 2016 ( $n=31)$ und pHPT 2016-Patienten ( $n=30)$ vor (,ursprünglich“) und „nach Ausschluss“ von Patienten (inkl. Matches) mit vermutlich falschem Antwortverhalten

Vor allem im Vergleich zwischen den Kollektiven HypoPT 2016 und SD-OP 2016 wird dieser Unterschied deutlich. Dass die Veränderung im Vergleich zur ersten Auswertung auf der Skala Vitalität besonders ausgeprägt ist, kann damit erklärt werden, dass diese aus den „positiv“ formulierten Items 33-38 besteht. Diese Items wurden in der ursprünglichen Analyse vermutlich falsch beantwortet, da die Umstellung von negativ auf positiv formulierte Fragen nicht immer erfasst wurde

Analysierte man das bereits bezüglich der Laborwerte als inhomogen identifizierte Kollektiv der pHPT 2016Patienten im Vergleich zu den HypoPT 2016-Patienten genauer, erhielt man folgende in der Tabelle 23 abgebildete Werte:

Tabelle 23: Skalenwerte (Mittelwerte \pm Standardabweichung) und zugehörige $p$-Werte aus der Analyse des HPQ 40 im HypoPT 2016-Kollektiv im Vergleich zu operierten und nicht operierten pHPT 2016-Patienten für die Skala Schmerz und Krämpfe; signifikante Werte dick hervorgehoben

\begin{tabular}{|lllllll|}
\hline & HypoPT 2016 & \multicolumn{2}{c|}{ pHPT 2016 operiert } & pHPT 2016 nicht operiert & gesamt \\
& $\begin{array}{l}\text { Skalenwert } \\
(n=49)\end{array}$ & $\begin{array}{l}\text { Skalenwert } \\
(n=19)\end{array}$ & $\begin{array}{l}\text { p-Wert } \\
\text { (Dunnett) }\end{array}$ & $\begin{array}{l}\text { Skalenwert } \\
(n=16)\end{array}$ & $\begin{array}{l}\text { p-Wert } \\
\text { (Dunnett) }\end{array}$ & $\begin{array}{l}\text { p-Wert } \\
\text { (ANOVA) }\end{array}$ \\
\hline $\begin{array}{l}\text { Schmerz und } \\
\text { Krämpfe }\end{array}$ & $1,26 \pm 0,72$ & $0,74 \pm 0,50$ & $\mathbf{0 , 0 0 8}$ & $0,92 \pm 0,49$ & 0,135 & $\mathbf{0 , 0 0 9}$ \\
\hline
\end{tabular}

Wie der Tabelle zu entnehmen ist, zeigte sich ein signifikanter Unterschied auf der Skala Schmerz und Krämpfe zwischen den operierten Patienten des pHPT 2016-Kollektivs und dem HypoPT 2016-Kollektiv. Der Unterschied zwischen dem HypoPT 2016-Kollektiv und den nicht operierten pHPT 2016-Patienten war jedoch nicht signifikant. Die Operation an der Nebenschilddrüse scheint ein relevanter Einflussfaktor zu sein, der sich positiv auf die Beschwerden auswirken könnte, was vielleicht erklärt, dass die nicht operierten pHPT 2016Patienten einen höheren Beschwerdescore und keinen signifikanten Unterschied zeigten. Das Kollektiv pHPT 2016 war also auch hinsichtlich der Beschwerden inhomogen. 
Die Abbildung 12 verdeutlicht nochmals die prozentuale Verteilung der Art der Schilddrüsenoperation über die beiden Kollektive HypoPT 2016 und SD-OP 2016. Die näher klassifizierten Schilddrüsenoperationen (linke, orange Kreishälfte) sind genauer aufgeschlüsselt.

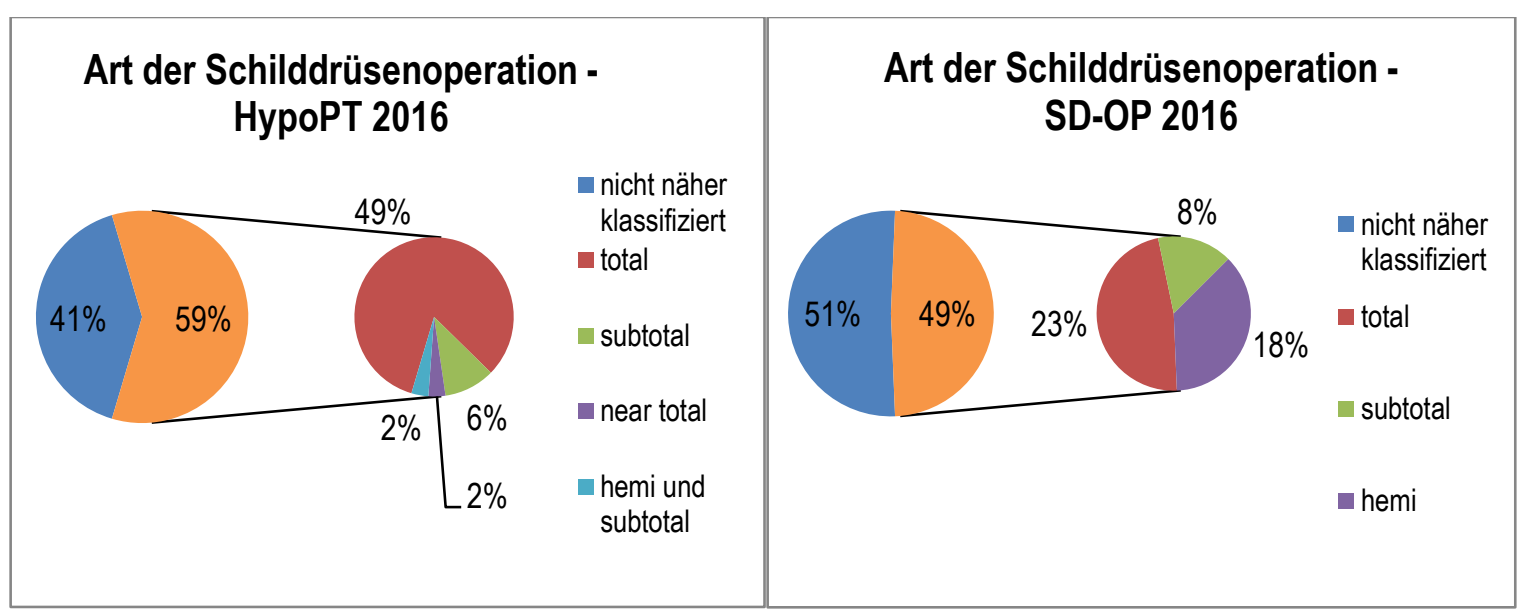

Abbildung 12: prozentualer Anteil der Art der Schilddrüsenoperation in den Patientenkollektiven HypoPT 2016 $(n=49)$ und SD-OP $2016(n=39)$

War der Anteil an nicht näher klassifizierten Thyreoidektomien (TE) in beiden Kollektiven in etwa gleich, so war doch der Anteil der total thyreoidektomierten Patienten in der HypoPT 2016-Gruppe deutlich höher. Ein mildes Operationsausmaß (Hemi-TE) kam erwartungsgemäß im HypoPT 2016-Kollektiv nicht vor. Fishers exakter Test über diese beiden Studiengruppen zeigte eine signifikante Assoziation $(p=0,003)$ der Zugehörigkeit zu einer Studiengruppe mit der Art der Schilddrüsenoperation (s. auch Tabelle 7). Die Bedeutung des Ausmaßes der Schilddrüsenoperation als Risikofaktor für postoperativen Hypoparathyreoidismus wurde bereits mehrfach in der Literatur beschrieben (Nawrot et al. 2014; Thomusch et al. 2003). So konnten Nawrot et al. (2014) in ihrer Studie feststellen, dass ein permanenter postoperativer Hypoparathyreoidismus häufiger bei totaler Thyreoidektomie vorkam als bei Schilddrüseneingriffen geringeren Ausmaßes. Thomusch et al. (2003) zeigten in ihrer Studie ebenfalls, dass das Ausmaß der Schilddrüsenoperation einer der stärksten unabhängigen Risikofaktoren für die Entwicklung eines postoperativen Hypoparathyreoidismus ist.

Um zu untersuchen, ob die Beschwerden der Patienten vom Ausmaß der Schilddrüsenoperation beeinflusst werden, wurde in einer weiteren ANOVA mit HypoPT und SD-OP 2016-Patienten der Einfluss der totalen Thyreoidektomie auf die gefundenen Beschwerden getestet. Die Auswertung wurde nur für die totale TE durchgeführt, da diese in beiden Kollektiven die häufigste konkret angegebene Operationsart war (s. Tabelle 38 im Anhang). Dabei zeigte sich zwar ein signifikanter Unterschied auf der Skala Schmerz und Krämpfe über alle Gruppen ( $p$-Wert gesamt $=0,016$ ), im Tukey Post-hoc-Test war die Lage des Unterschiedes zwischen den Subgruppen jedoch nicht erkennbar ( $p$-Werte $=0,054-0,988$ ). Dies begründet sich wahrscheinlich dadurch, dass nicht die Operationsart an sich, sondern die Zugehörigkeit zu einer Studiengruppe den Unterschied bedingte, wie die Abbildung 13 veranschaulicht: Unabhängig von der Art der Operation gaben die HypoPT 2016-Patienten im Vergleich zu den SD-OP 2016-Patienten einen höheren Beschwerdewert auf der Skala Schmerz und Krämpfe an. 


\section{Einfluss der OP-Art auf die Beschwerden der Skala Schmerz und Krämpfe}

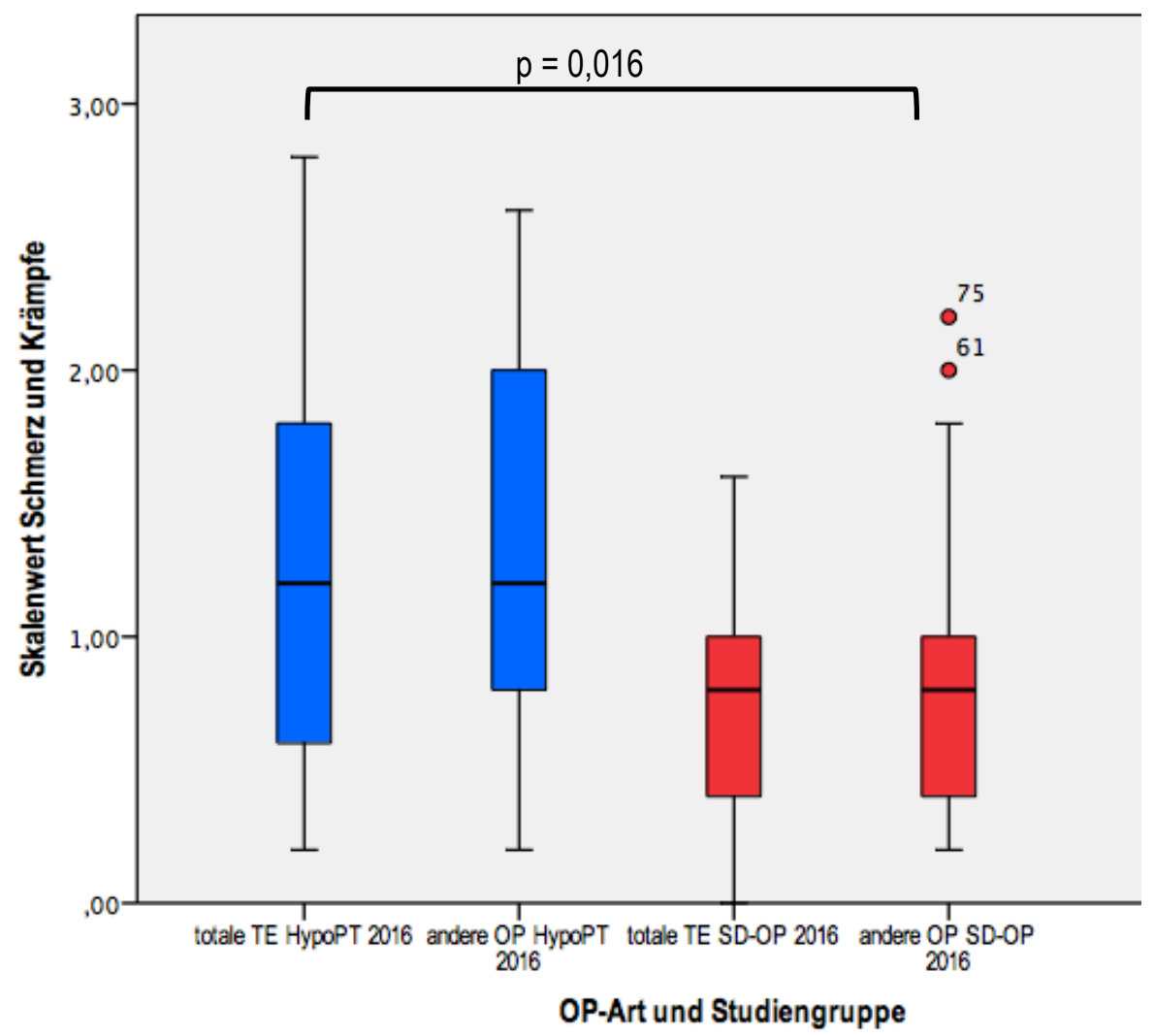

Abbildung 13: Boxplots für die Skalenwerte der Skala Schmerz und Krämpfe aufgetrennt nach Operationsart (= OP-Art) und Studiengruppe; p-Wert der ANOVA über alle Subgruppen ; TE = Thyreoidektomie, OP = Operation

Testete man den Einfluss der unterschiedlichen Operationsarten (HemiTE, (sub)totale TE etc.) innerhalb der Gruppe HypoPT 2016 bzw. SD-OP 2016 separat, ergaben sich keine signifikanten Unterschiede für die Skala Schmerz und Krämpfe zwischen den Subgruppen (ANOVA: $p$-Wert = 0,313 für HypoPT 2016; $p$-Wert = 0,54 für SD-OP 2016; s. Tabelle 39 und Tabelle 40 im Anhang).

Es konnte somit kein eindeutiger Zusammenhang der Beschwerden mit dem Ausmaß der Schilddrüsenoperation ausgemacht werden. Allerdings ist zu beachten, dass sich in beiden Gruppen ein großer Teil an nicht näher klassifizierten Operationen fand und es auch möglich ist, dass sich ein möglicher vorhandener Unterschied bezüglich des Ausmaßes der Operation und der Beschwerden aufgrund der geringen Fallzahl pro Subgruppe nicht darstellte.

Für die Analyse von Depressionen bei Hypoparathyreoidismuspatienten wurden in den HPQ 40 zwei Fragen zum Depressionsscreening integriert. In der gesonderten Auswertung dieser Fragen (Items Nummer 39 und 40) zeigten sich folgende, in der Tabelle 24 dargestellte Ergebnisse:

Tabelle 24: Häufigkeiten (in n und gültigen \%) des negativen (0-2 Punkte)/positiven ( $\geq 3$ Punkte) Depressionsscreenings in den drei Studienkollektiven HypoPT, SD-OP und pHPT 2016; Cut-off für das Screening $\geq 3$ Punkte

\begin{tabular}{|c|c|c|c|c|}
\hline Score & НуроРТ 2016 & SD-OP 2016 & pHPT 2016 & gesamt \\
\hline & n $\%$ & $\mathrm{n} \quad \%$ & $\mathrm{n} \quad \%$ & n $\%$ \\
\hline kein Hinweis auf Depression (0-2) & 3877,6 & $34 \quad 91,9$ & 3088,2 & 10285,0 \\
\hline Hinweis auf Depression ( $\geq 3$ ) & 1122,4 & 38,1 & $4 \quad 11,8$ & $18 \quad 15,0$ \\
\hline
\end{tabular}


In der Literatur (Kroenke et al. 2003; Löwe et al. 2005) wird für das Depressionsscreening ein Wert von $\geq 3$ Punkten als Summe der beiden Antworten als Cut-off-Wert angegeben. Bei elf Patienten der HypoPT 2016Gruppe (22,4 \%) bestanden Hinweise auf eine Depression (Score: $\geq 3$ Punkte), in den anderen beiden Kollektiven traf dies hingegen nur auf 8,1 \% (SD-OP 2016) bzw. 11,8 \% (pHPT 2016) der Patienten zu. Wie Fishers exakter Test jedoch zeigte, gab es keinen signifikanten Zusammenhang $(p=0,167)$ zwischen dem Hinweis auf Depression und den drei Kollektiven.

Unterteilte man die Patienten in zwei Gruppen "mit“ $(n=18)$ und „ohne“ $(n=102)$ Hinweis auf eine Depression im Screening und verglich die Skalenmittelwerte für ängstliche Depression dieser beiden Gruppen im tTest (s. Abbildung 14), so hatten die Patienten mit einem positiven Screening (Score $\geq 3 ; 1,40 \pm 0,62$ ) einen signifikant höheren Skalenwert $(p<0,001)$ als Patienten mit negativem Screening $(0,54 \pm 0,54)$. Patienten mit Hinweis auf eine Depression gaben also auch auf unserer Skala ängstliche Depression vermehrte Beschwerden an, was die Validität dieser Skala unterstreicht.

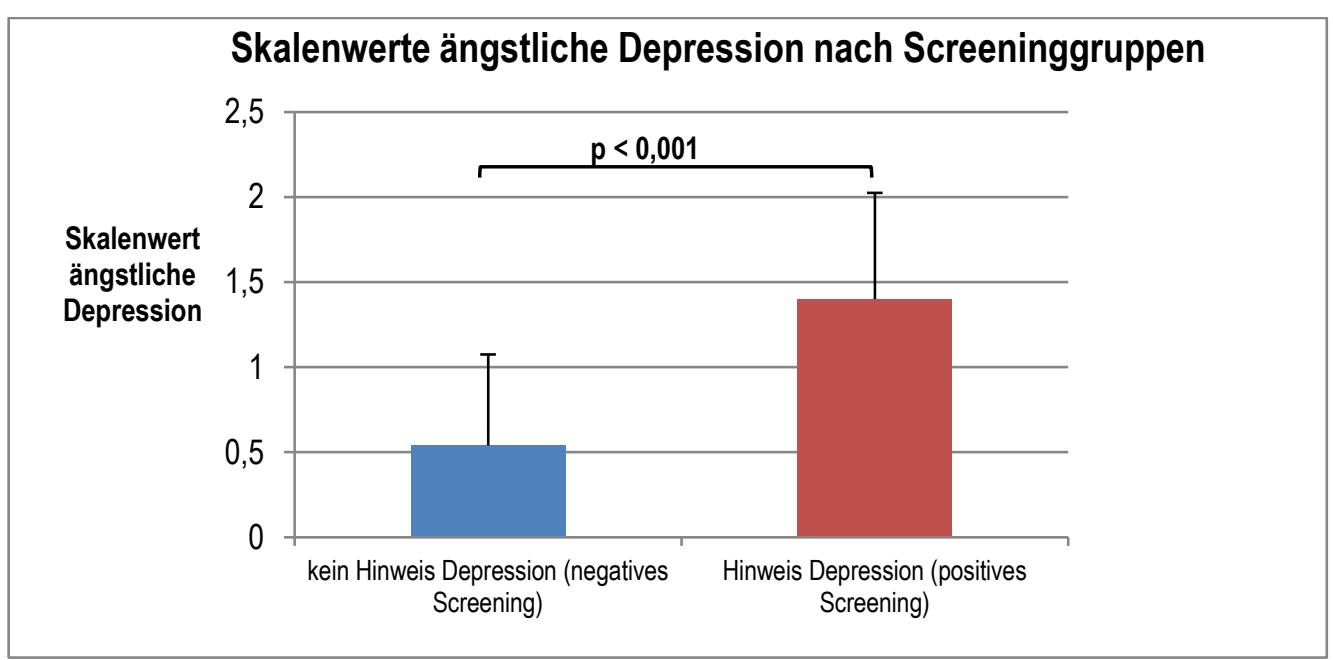

Abbildung 14: Skalenwerte für die Skala ängstliche Depression im Vergleich von negativ gescreenten $(n=102) z u$ positiv gescreenten ( $n=18$ ) Patienten; $p$-Wert des t-Testes

\subsubsection{LABOR UND ERGEBNISSE DES DOKUMENTATIONSBOGENS}

In den folgenden Analysen wurden vor allem diejenigen Laborparameter verwendet, die nach den Leitlinien für die Einstellung des Hypoparathyreoidismus relevant sind. Zusätzlich interessierten die gemessenen PTHWerte, die nur in wenigen Studien überhaupt verfügbar sind. Die Abbildungen 15 bis 18 veranschaulichen die gemessenen Laborparameter Serumcalcium (korr.), Serumphosphat, Parathormon im Serum und Calcium bzw. Phosphat im 24-h-Urin in den drei Studienkollektiven. Es werden - außer beim CP-Produkt und Calcium bzw. Phosphat im 24-h-Urin, bei denen die Normbereiche identisch sind - nur die Patienten der Praxis Göttingen grafisch dargestellt, da sie den größten Teil der an der Studie teilnehmenden Patienten ausmachten $(81,3 \%)$ und für die Patienten der Praxis Saarbrücken andere Referenzwerte galten (vgl. Tabelle 25). 
Tabelle 25: Norm- und Zielbereich der Laborparameter Calcium, Phosphat, Calcium-Phosphat-Produkt und PTH im Serum sowie Calcium und Phosphat im Urin für die beiden Praxen Göttingen und Saarbrücken

\begin{tabular}{|c|c|c|c|c|}
\hline & \multicolumn{2}{|c|}{ Normbereich (NB) } & \multicolumn{2}{|c|}{ Zielbereich (ZB) } \\
\hline Praxis & Göttingen & Saarbrücken & Göttingen & Saarbrücken \\
\hline Calcium (korr.) Serum (in mmol/l) & $2,0-2,6$ & $2,15-2,58$ & $1,87-2,3$ & $2,02-2,25$ \\
\hline Phosphat Serum (in mmol/l) & $0,8-1,6$ & $0,81-1,45$ & & \\
\hline PTH Serum (in pmol/l) & $1,7-6,89$ & $1,6-6,9$ & & \\
\hline Calcium 24-h-Urin (in mmol/d) & $2,5-7,5$ & $2,5-7,5$ & & \\
\hline Phosphat 24-h-Urin (in mmol/d) & $19,37-50,5$ & $19,37-50,5$ & & \\
\hline Calcium-Phosphat-Produkt (in $\mathrm{mmol}^{2} / \mathrm{I}^{2}$ ) & $<4,4$ & $<4,4$ & & \\
\hline
\end{tabular}

Die Abbildung 15 zeigt die Verteilung der für Albumin korrigierten Serumcalciumwerte in den drei Studienkollektiven sowie den jeweiligen Norm- und Zielbereich.

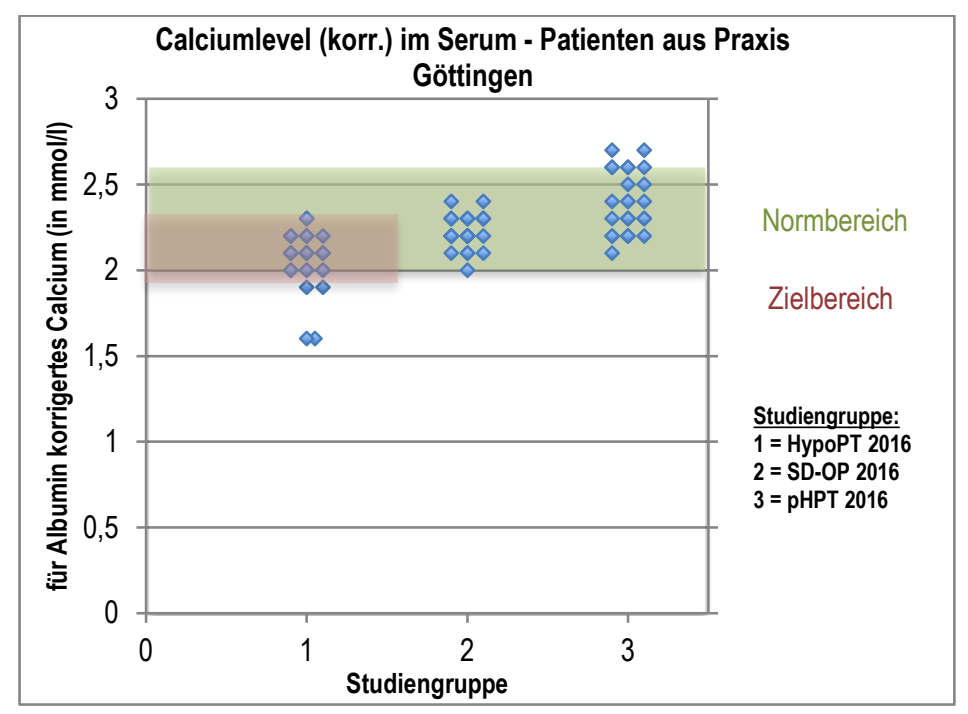

Abbildung 15: für Albumin korrigierte Calciumwerte im Serum (in mmol/l) für Patienten aus der Praxis Göttingen $(n=92)$ aufgeteilt nach Studiengruppe; Normbereich und Zielbereich gekennzeichnet; nicht jeder Punkt repräsentiert einen einzelnen Patienten

Brandi et al. (2016) schlagen in ihren Handlungsempfehlungen einen Zielbereich für das Serumcalcium im unteren Normbereich vor, der aber nicht mehr als $0,5 \mathrm{mg} / \mathrm{dl}(\hat{=} 0,13 \mathrm{mmol} / \mathrm{l})$ unter dem unteren Grenzwert liegen soll. Somit wurde der Zielbereich mit 1,87-2,3 mmol/l (Praxis Göttingen) bzw. mit 2,02-2,25 mmol/I (Praxis Saarbrücken) definiert.

Die weiteren Laborparameter und ihre Verteilung sind in den Abbildungen 16 bis 18 dargestellt. 


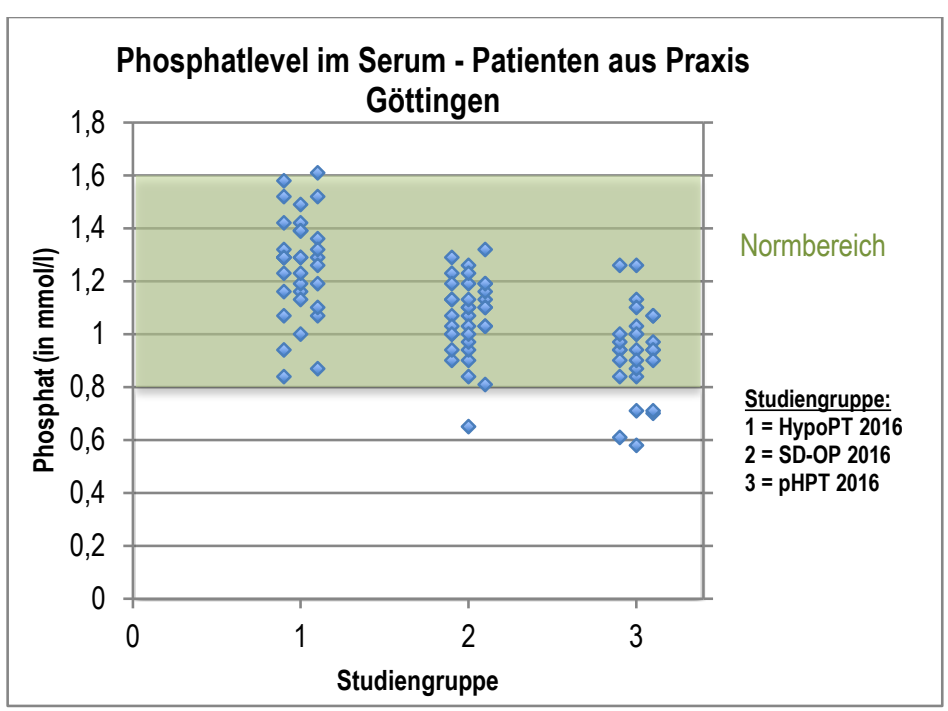

Abbildung 16: Phosphatwerte im Serum (in mmol/l) für Patienten aus der Praxis Göttingen ( $n=98)$ aufgeteilt nach Studiengruppe; Normbereich gekennzeichnet; nicht jeder Punkt repräsentiert einen einzelnen Patienten

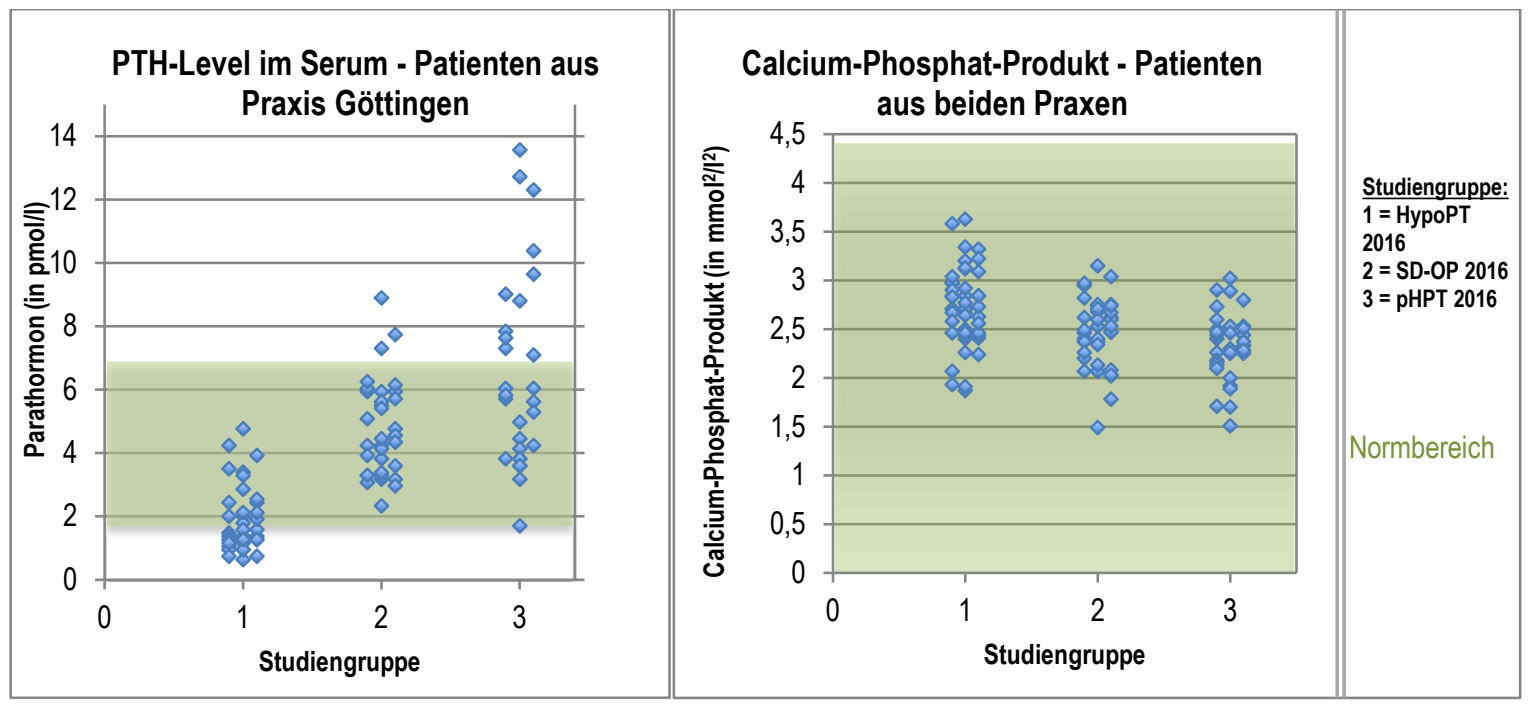

Abbildung 17: Parathormonwerte im Serum (in pmol/l) für Patienten aus der Praxis Göttingen ( $n=97$ ) und Calcium-Phosphat-Produkt (in $\mathrm{mmol}^{2} / \mathrm{I}^{2}$ ) für alle Patienten aus beiden Praxen ( $\mathrm{n}=117$ ) aufgeteilt nach Studiengruppe; Normbereich gekennzeichnet; nicht jeder Punkt repräsentiert einen einzelnen Patienten

Wie Abbildung 17 erkennen lässt, lagen zwar einige HypoPT 2016-Patienten mit ihrem PTH im Normbereich, jedoch nur in dessen unterem Teil.

Nicht für jeden Patienten wurden alle Laborwerte erfasst, da gerade die Calcium- und Phosphatmessung im 24-h-Urin nicht in allen ambulanten Versorgungseinrichtungen Standard ist und beispielsweise bei Patienten nach Schilddrüsenoperation ohne Hypoparathyreoidismus auch nicht regelhaft erforderlich ist. 


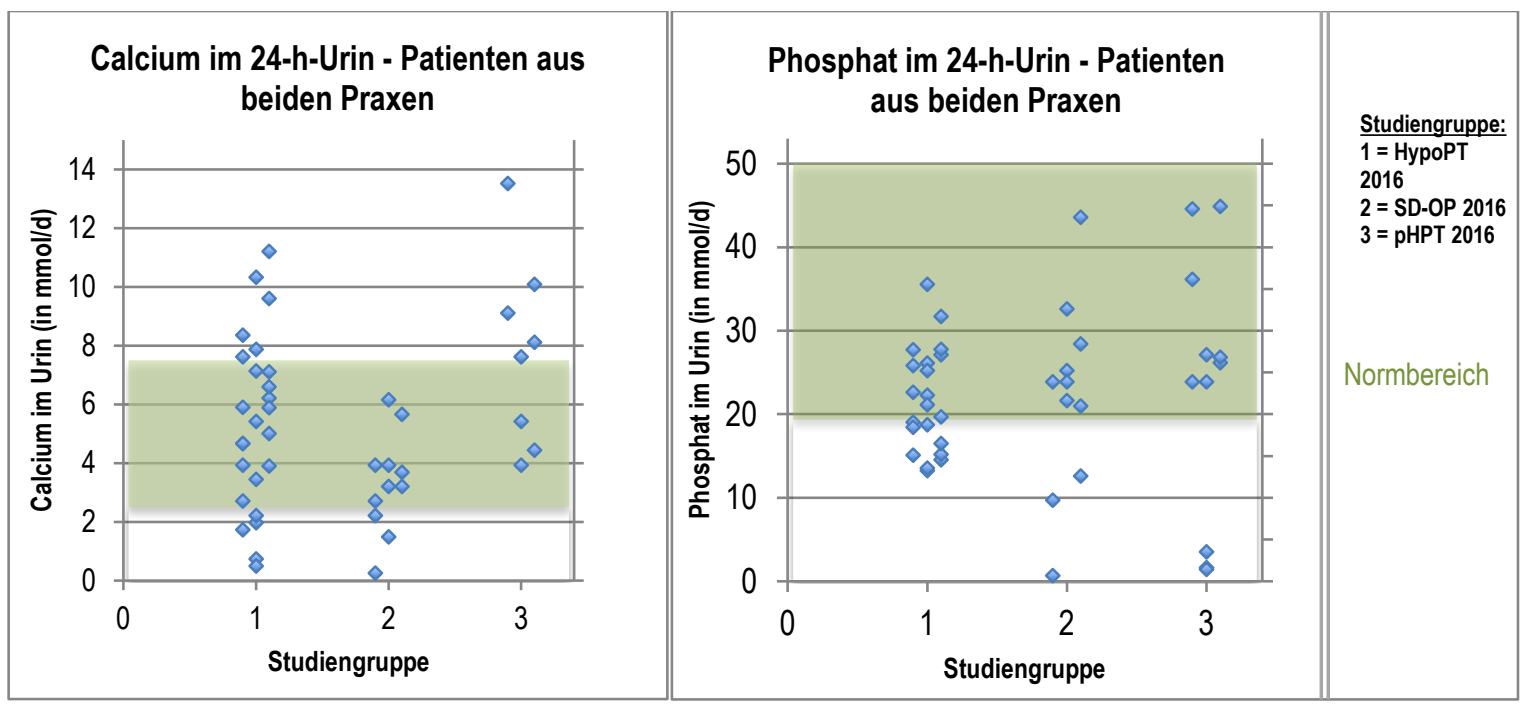

Abbildung 18: Calciumwerte bzw. Phosphatwerte im 24-h-Urin (in mmol/d) für alle Patienten aus beiden Praxen ( $n=44$ bzw. n=43) aufgeteilt nach Studiengruppe; Normbereich gekennzeichnet; nicht jeder Punkt repräsentiert einen einzelnen Patienten

Die Analyse für den Anteil der Patienten im Norm- bzw. Zielbereich der Laborparameter (s. Tabelle 26) wurde für alle Patienten aus beiden Praxen mit den jeweils geltenden Normwerten durchgeführt.

Betrachtet man nun die Anteile der Laborwerte im bzw. außerhalb des Normbereiches genauer, so stellt man fest, dass die Werte der HypoPT 2016-Patienten für das Serumcalcium (korr.) bei 73,9 \% und für Serumphosphat bei 95,7 \% der Patienten im Normbereich lagen. Im Zielbereich des korrigierten Serumcalciums bei Hypoparathyreoidismus lagen sogar $87 \%$ der Patienten.

Bei der Calcium- bzw. Phosphatausscheidung im 24-h-Urin wichen 44 \% bzw. 42,9 \% der HypoPT 2016Patienten vom Normbereich ab. Immerhin 40,4 \% der HypoPT 2016 Patienten hatten ein Parathormon im Normbereich, im Vergleich dazu zeigten 91,9 \% der SD-OP 2016-Gruppe und 51,5 \% der pHPT 2016Patienten ein normwertiges PTH. Das Calcium-Phosphat-Produkt war bei allen Patienten normwertig. 
Tabelle 26: Anteil der Laborwerte (Calcium [korr.], Phosphat im Serum und Urin, PTH und Calcium-PhosphatProdukt [= CP-Produkt] im Serum) im Normbereich (= NB) bzw. Zielbereich (= ZB) in gültigen Prozent (\%; auf Zeile bezogen) sowie dazugehörige Anzahl ( $n$; in Klammern) und Abweichungen vom Normbereich/ Zielbereich für alle drei Studienkollektive; Chi-Quadrat- bzw. Fishers exakter Test über alle Gruppen („gesamt") und für HypoPT 2016 mit Vergleich mit SD-OP bzw. pHPT 2016; Bonferroni-Korrektur für Anzahl der angewandten Tests ( $n=18 ; \alpha \leq$ $0,003) ;{ }^{*}=$ nach Korrektur signifikanter $\mathrm{p}$-Wert

\begin{tabular}{|c|c|c|c|c|c|c|c|c|}
\hline \multicolumn{9}{|c|}{ Anteil in \% (n); Normbereich (= NB); Zielbereich (= ZB) } \\
\hline & \multicolumn{8}{|c|}{ Calcium (korr.) Serum } \\
\hline & im NB & über NB & unter NB & $p$-Wert & im ZB & über ZB & unter ZB & $p$-Wert \\
\hline $\begin{array}{l}\text { НyроРТ } \\
2016\end{array}$ & $73,9(34)$ & & $26,1(12)$ & & $87,0(40)$ & $4,3(2)$ & $8,7(4)$ & \\
\hline $\begin{array}{l}\text { SD-OP } \\
2016\end{array}$ & $97,1(34)$ & & $2,9(1)$ & 0,005 & $94,3(33)$ & $5,7(2)$ & & 0,273 \\
\hline $\begin{array}{l}\text { pHPT } \\
2016\end{array}$ & $90,6(29)$ & $9,4(3)$ & & $<0,001^{*}$ & $43,8(14)$ & $56,3(18)$ & & $<0,001^{*}$ \\
\hline gesamt & $85,8(97)$ & $2,7(3)$ & $11,5(13)$ & $<0,001^{*}$ & 77,0 (87) & $19,5(22)$ & $3,5(4)$ & $<0,001^{*}$ \\
\hline \multicolumn{9}{|c|}{ Anteil in \% (n); Normbereich (= NB); Zielbereich (= ZB) } \\
\hline & \multicolumn{4}{|c|}{ Phosphat Serum } & \multicolumn{4}{|c|}{ PTH Serum } \\
\hline & im NB & über NB & unter NB & $p$-Wert & im NB & über NB & unter NB & p-Wert \\
\hline $\begin{array}{l}\text { НуроРТ } \\
2016\end{array}$ & $95,7(45)$ & $4,3(2)$ & & & $40,4(19)$ & & $59,6(28)$ & \\
\hline $\begin{array}{l}\text { SD-OP } \\
2016\end{array}$ & $97,4(37)$ & & $2,6(1)$ & 0,336 & $91,9(34)$ & $8,1(3)$ & & $<0,001^{*}$ \\
\hline $\begin{array}{l}\text { pHPT } \\
2016\end{array}$ & $84,8(28)$ & & $15,2(5)$ & 0,005 & $51,5(17)$ & $48,5(16)$ & & $<0,001^{*}$ \\
\hline gesamt & $93,2(110)$ & $1,7(2)$ & $5,1(6)$ & 0,005 & $59,8(70)$ & $16,2(19)$ & $23,9(28)$ & $<0,001^{*}$ \\
\hline \multicolumn{9}{|c|}{ Anteil in \% (n); Normbereich (= NB); Zielbereich (= ZB); CP-Produkt = Calcium-Phosphat-Produkt } \\
\hline & \multicolumn{4}{|c|}{ Calcium 24-h-Urin } & \multicolumn{3}{|c|}{ Phosphat 24-h-Urin } & CP-Produkt \\
\hline & im NB & über NB & unter NB & p-Wert & im NB & unter NB & p-Wert & im NB \\
\hline $\begin{array}{l}\text { HypoPT } \\
2016\end{array}$ & 56,0 (14) & $24,0(6)$ & $20,0(5)$ & & $57,1(12)$ & $42,9(9)$ & & $100(46)$ \\
\hline $\begin{array}{l}\text { SD-OP } \\
2016\end{array}$ & $72,7(8)$ & & $27,3(3)$ & 0,226 & $72,7(8)$ & $27,3(3)$ & 0,465 & $100(38)$ \\
\hline $\begin{array}{l}\text { pHPT } \\
2016\end{array}$ & $37,5(3)$ & $62,5(5)$ & & 0,144 & 72,7 (8) & $27,3(3)$ & 0,465 & $100(33)$ \\
\hline gesamt & $56,8(25)$ & $\begin{array}{l}25,0 \\
(11)\end{array}$ & $18,2(8)$ & 0,032 & $65,1(28)$ & $34,9(15)$ & 0,544 & $100(117)$ \\
\hline
\end{tabular}

Es stellte sich eine signifikante Assoziation zwischen der jeweiligen Studiengruppenzugehörigkeit und der Normbereichsanalyse von PTH im Serum über alle drei Studiengruppen dar. Das HypoPT 2016-Kollektiv wies den geringsten Anteil an Patienten im Normbereich auf (40,4 \%). Für die Norm- bzw. Zielbereichsuntersuchung des Serumcalciums hingegen war der Zusammenhang nur im Vergleich zwischen HypoPT 2016 und pHPT 2016 nach Bonferroni-Korrektur signifikant.

Da bereits herausgefunden wurde, dass die pHPT 2016-Gruppe bezüglich ihrer Laborwerte und Beschwerden inhomogen war, wurde die Normbereichsanalyse in diesem Kollektiv nochmals gesondert nach "operiert" und "nicht operiert" durchgeführt (s. Tabelle 27), weil auch hier Unterschiede erwartet wurden. Hierbei zeigte sich eine signifikante Assoziation zwischen der Variable Operation bei pHPT 2016 und dem PTH im Serum. Für die übrigen Parameter (Calcium und Phosphat im Serum bzw. Urin) war der Zusammenhang nicht signifikant (s. Tabelle $41 \mathrm{im}$ Anhang). 
Tabelle 27: Anteil von PTH im Normbereich (= NB) in gültigen Prozenten (\%; auf Zeile bezogen) sowie dazugehörige Anzahl (n; in Klammern) und Abweichungen vom Normbereich für die (nicht) operierten pHPT 2016-

Subgruppen; Chi-Quadrat-Test zum Gruppenvergleich; Bonferroni-Korrektur für Anzahl der angewandten Tests $(n=5 ; \alpha$ $\leq 0,01) ;{ }^{*}=$ nach Korrektur signifikanter $p$-Wert

\begin{tabular}{|c|c|c|c|}
\hline \multicolumn{4}{|l|}{ Anteil in \% (n); Normbereich (= NB) } \\
\hline & \multicolumn{3}{|c|}{ PTH Serum } \\
\hline & im NB & über NB & $p$-Wert \\
\hline pHPT 2016 operiert & $94,1(16)$ & $5,9(1)$ & \\
\hline pHPT 2016 nicht operiert & $6,3(1)$ & $93,8(15)$ & \\
\hline gesamt & $51,5(17)$ & $48,5(16)$ & $<0,001^{*}$ \\
\hline
\end{tabular}

Bei den operierten Patienten des pHPT 2016-Kollektivs lag das Parathormon zu 94 \% im Normbereich, bei den nicht operierten Patienten jedoch nur zu $6 \%$. Unter Punkt 4.2.2 wurde bereits erläutert, dass sich die HypoPT 2016-Patienten bezüglich ihrer Beschwerden nur signifikant von den operierten pHPT 2016Patienten unterscheiden. Diese Beobachtung zusammen mit dem hier ermittelten signifikanten Ergebnis der Normbereichsanalyse für PTH könnte andeuten, dass ein normwertiger PTH-Level im Serum wichtig für die Beschwerdekontrolle ist. Die Ergebnisse lassen vermuten, dass sowohl ein zu viel (nicht operierte pHPT 2016) als auch ein zu wenig an Parathormon (HypoPT 2016) mehr Beschwerden hervorrufen kann.

Um zu untersuchen, ob bestimmte klinische oder laborchemische Parameter einen Zusammenhang mit den gefundenen Beschwerden aufweisen, wurde eine Korrelationsanalyse mit dem Spearman-Koeffizienten durchgeführt. Dazu korrelierte man die Beschwerden auf der zuvor als signifikant identifizierten Skala Schmerz und Krämpfe mit dem Alter der Patienten, dem Zeitabstand bis zur Erstmedikation, den Laborwerten (für Calcium [korr.], 25(OH) $\mathrm{D}_{3}$, Phosphat, Calcium-Phosphat-Produkt, PTH, Magnesium und TSH im Serum, GFR, Calcium und Phosphat im Urin) sowie mit den Medikamentendosierungen (von Vitamin-DSpeicherformen, aktiven Vitamin-D-Subgruppen [Alfacalcidol, Calcitriol, Dihydrotachysterol], Kombipräparaten [Calcium- und nativer Vitamin-D-Anteil], Calcium [Monopräparat], rhPTH, Thiaziden und Magnesium). Unter Berücksichtigung aller Patienten zeigten folgende, in Tabelle 28 dargestellte Konstellationen eine signifikante Korrelation:

Tabelle 28: Korrelation (Spearman-Koeffizient) der Skala Schmerz und Krämpfe mit Medikamentendosierungen (Calcium-Dauermedikation, Alfacalcidol, Thiazide, Magnesium) sowie mit dem Laborparameter Serum-PTH über alle Patienten; $n=$ Anzahl der untersuchten Werte; Bonferroni-Korrektur für die Anzahl der Korrelationen ( $\mathrm{n}=44 ; \alpha \leq$ 0,001); signifikante Werte gekennzeichnet

\begin{tabular}{|c|c|c|c|c|c|}
\hline \multirow[t]{2}{*}{ Skala } & \multicolumn{5}{|l|}{ Korrelation mit } \\
\hline & $\begin{array}{l}\text { Dosis } \\
\text { Calcium (Mono) }{ }^{1 / d} \\
(\mathrm{mg})\end{array}$ & $\begin{array}{l}\text { Dosis } \\
\text { Alfacalcidol/d }(\mu \mathrm{g})\end{array}$ & $\begin{array}{l}\text { Dosis } \\
\text { Thiazide/d (mg) }\end{array}$ & $\begin{array}{l}\text { Dosis } \\
\text { Magnesium/d } \\
\text { (mg) }\end{array}$ & $\begin{array}{l}\text { Serum PTH } \\
(\mathrm{pmol} / \mathrm{l})\end{array}$ \\
\hline $\begin{array}{l}\text { Schmerz und } \\
\text { Krämpfe }\end{array}$ & $0,311^{* *}$ & $0,282^{*}$ & $0,262^{*}$ & $0,254^{*}$ & $-0,201^{*}$ \\
\hline$n$ & 123 & 122 & 123 & 122 & 117 \\
\hline \multicolumn{6}{|c|}{${ }^{* *}$ Korrelation ist nach Bonferroni-Korrektur signifikant. } \\
\hline${ }^{*}$ Korrelation is & і Nliveวu 005 сіал & ia) & & & \\
\hline
\end{tabular}

${ }^{1}$ Calciumanteil aus Monopräparaten 
Es zeigte sich, dass die Skala Schmerz und Krämpfe nach Bonferroni-Korrektur signifikant mit der Höhe der Gesamtdosis an Calciummonopräparaten pro Tag korrelierte. Dabei ist zu beachten, dass auch Patienten, die ein solches Präparat nicht einnahmen, in den Korrelationen berücksichtigt wurden (Dosis $=0$ ), um herauszufinden, ob die Einnahme eines bestimmten Medikamentes möglicherweise Beschwerden hervorrief oder beeinflusste. Eine Calcium-Dauermedikation in Form von Monopräparaten wurde nur von Patienten aus der Gruppe HypoPT 2016 eingenommen.

Weitere relevante Zusammenhänge für die Skala Schmerz und Krämpfe ergaben sich mit der Dosis von Alfacalcidol, Thiaziden und Magnesium pro Tag sowie als einzige negative Korrelation mit dem PTH im Serum. Diese Zusammenhänge waren nach Korrektur zwar nicht mehr signifikant, gaben aber wichtige Tendenzen an und somit Hinweise auf die Faktoren, die möglicherweise die Beschwerden beeinflussten.

Darüber hinaus stellte sich die Frage, ob die beobachteten Zusammenhänge auch in der isolierten Untersuchung der HypoPT 2016-Patienten nachweisbar waren. Analysierte man die oben genannten Parameter sowie den Einfluss der Erkrankungsdauer nur für diese Subgruppe, korrelierte die Skala Schmerz und Krämpfe mit der Gesamtdosis Thiaziden pro Tag sowie mit dem Calcium-Phosphat-Produkt (s. Tabelle 29). Nach Bonferroni-Korrektur war zwar keine dieser Korrelationen mehr signifikant; die Relevanz als Hinweisfaktor für Beschwerdezusammenhänge galt für diese Tendenzen aber gleichermaßen.

Tabelle 29: Korrelation (Spearman-Koeffizient) der Skala Schmerz und Krämpfe mit der Medikamentendosierung von Thiaziden sowie mit dem Laborparameter Calcium-Phosphat-Produkt über alle Patienten der Gruppe HypoPT 2016; $n$ = Anzahl der untersuchten Werte; Bonferroni-Korrektur für die Anzahl der Korrelationen ( $n=46 ; \alpha \leq$ 0,001); signifikante Werte gekennzeichnet

\begin{tabular}{|lll|}
\hline Skala & Korrelation mit & \\
\hline & Dosis Thiazide/d $(\mathrm{mg})$ & Calcium-Phosphat-Produkt $\left(\mathrm{mmol}^{2} / \mathbf{I}^{2}\right)$ \\
\hline Schmerz und Krämpfe & $\mathbf{3 3 2 *}$ &, $\mathbf{2 9 4 ^ { * }}$ \\
\hline $\boldsymbol{n}$ & 49 & 46 \\
\hline * Korrelation ist bei Niveau & $\mathbf{0 , 0 5}$ signifikant (zweiseitig). \\
\hline
\end{tabular}

Alle übrigen klinischen und laborchemischen Parameter korrelierten nicht signifikant mit der Skala Schmerz und Krämpfe.

Wie bereits erwähnt, wurde für alle Korrelationen der Spearman-Koeffizient verwendet, welcher zwar einen Zusammenhang feststellt, dieser muss aber nicht zwingend linear sein. Wie die Abbildung 19 für die Korrelation von PTH und der Skala Schmerz und Krämpfe über alle Patienten veranschaulicht, konnte man neben einer negativen linearen Korrelation auch versuchen, sich dem Zusammenhang mithilfe einer LOESS-Kurve als nicht-parametrische Regressionsmethode zu nähern. Hierbei zeigte sich, dass die Steigung der LOESSKurve und damit der Wert auf der Skala Schmerz und Krämpfe bei Annäherung des PTHs an den mittleren Normbereich (ab ca. 4 pmol/l) abnahm, beim Überschreiten des Normbereichs (ab ca. 7 pmol/l) hingegen aber wieder anstieg. 


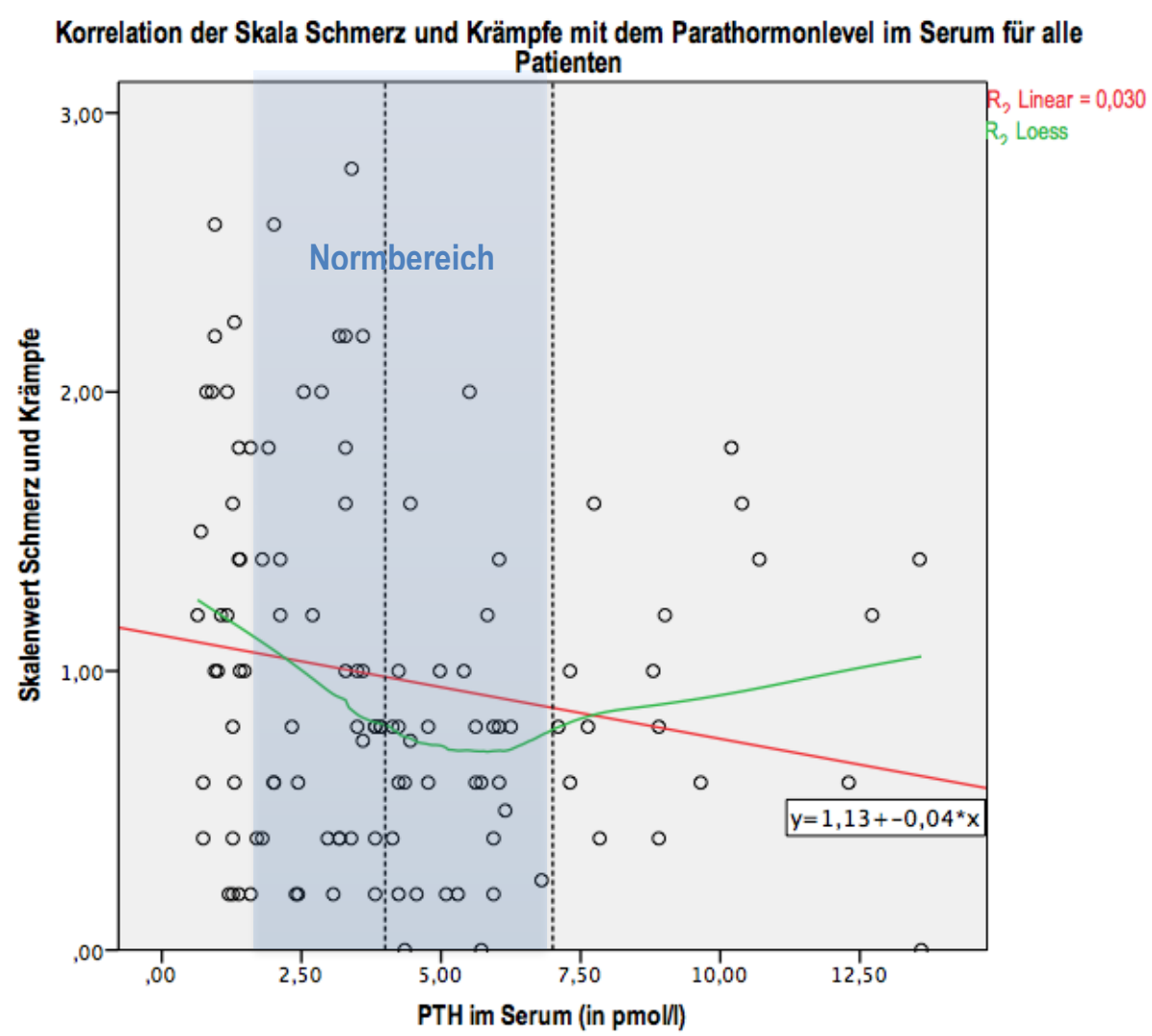

Abbildung 19: Korrelation der Skalenwerte für Schmerz und Krämpfe mit dem Parathormonlevel im Serum für Patienten aus allen Studiengruppen n=117; Lineare Regression und LOESS-Kurve; Bezugslinien bei 4 pmol// und $7 \mathrm{pmol} / \mathrm{l}$ sowie Kennzeichnung des Normbereiches

Das Calcium-Phosphat-Produkt lag zwar bei allen Patienten der HypoPT 2016-Gruppe im Normbereich, dennoch korrelierte es innerhalb dieser Subgruppe mit den Beschwerden auf der Skala Schmerz und Krämpfe. In der folgenden grafischen Darstellung dieser Korrelation (s. Abbildung 20) ließ sich bei beiden Kurven eine höhere Beschwerdelast bei höheren Werten des Calcium-Phosphat-Produktes feststellen.

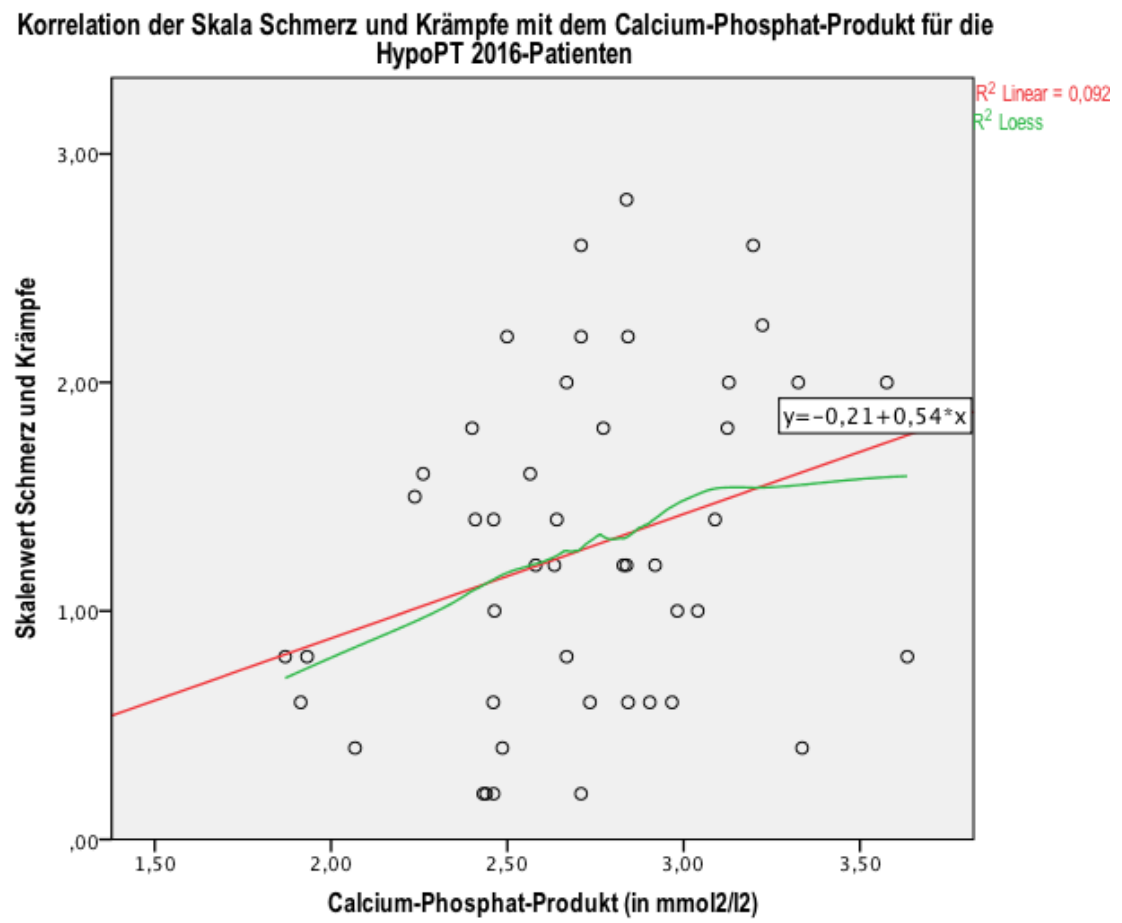

Abbildung 20: Korrelation der Skalenwerte für Schmerz und Krämpfe mit dem Calcium-Phosphat-Produkt für HypoPT 2016-Patienten, n=46; Lineare Regression und LOESS-Kurve; alle Werte im Normbereich 
Weitere Korrelationen ließen sich aufgrund des Messniveaus der Daten und der fehlenden Streuung der Daten (vor allem bei identischen Dosierungen) nicht grafisch aufarbeiten.

Die Korrelationsanalyse zeigte einen Zusammenhang der Beschwerden auf der Skala Schmerz und Krämpfe mit der Einnahme von Alfacalcidol. Hier stellte sich nun die Frage, ob sich auch die Scores auf der Skala Schmerz und Krämpfe unter Einnahme verschiedener aktiver Vitamin-D-Präparate unterschieden. Dabei nahmen hauptsächlich HypoPT 2016-Patienten aktives Vitamin D ein, wohingegen die Patienten der anderen beiden Studiengruppen keines einnahmen. Analysierte man den Einfluss der verschiedenen aktiven VitaminD-Präparate mittels ANOVA, so zeigten sich signifikant höhere Beschwerden auf der Skala Schmerz und Krämpfe unter der Einnahme von Alfacalcidol gegenüber Patienten aus den anderen beiden Studiengruppen (vgl. Tabelle 30).

Tabelle 30: Skalenwerte (Mittelwerte \pm Standardabweichung) und zugehörige $p$-Werte aus der Analyse des HPQ 40 bei Patienten ohne Einnahme von aktivem Vitamin D (气Kollektiven pHPT* und SD-OP $2016=$ „,keine Einnahme andere Studiengruppen“) im Vergleich zur (Nicht-) Einnahme verschiedener aktiver Vitamin-D-Präparate im HypoPT 2016-Kollektiv (= Calcitriol*, Alfacalcidol, Dihydrotachysterol, „keine Einnahme HypoPT 2016“); signifikante Werte dick hervorgehoben

\begin{tabular}{|c|c|c|c|c|c|c|c|c|c|c|}
\hline \multicolumn{11}{|c|}{ Skala Schmerz und Krämpfe } \\
\hline & \multicolumn{2}{|c|}{$\begin{array}{l}\text { keine Einnah- } \\
\text { me andere } \\
\text { Studiengrup- } \\
\text { pen }\end{array}$} & \multicolumn{2}{|c|}{ Calcitriol* $^{*}$} & \multicolumn{2}{|c|}{ Alfacalcidol } & \multicolumn{2}{|c|}{$\begin{array}{l}\text { Dihydrotachys- } \\
\text { terol }\end{array}$} & \multirow{2}{*}{$\begin{array}{l}\text { keine Ein- } \\
\text { nahme } \\
\text { HypoPT } \\
2016 \\
\text { Skalenwert } \\
\text { (n=7) }\end{array}$} & \multirow{2}{*}{$\begin{array}{l}\text { gesamt } \\
\text { p-Wert } \\
\text { (ANOVA) }\end{array}$} \\
\hline & $\begin{array}{l}\text { Skalen- } \\
\text { wert } \\
(n=73)\end{array}$ & $\begin{array}{l}\text { p-Wert } \\
\text { (Tukey) }\end{array}$ & $\begin{array}{l}\text { Ska- } \\
\text { lenwert } \\
\text { ( } n=14)\end{array}$ & $\begin{array}{l}\text { p-Wert } \\
\text { (Tukey) }\end{array}$ & $\begin{array}{l}\text { Ska- } \\
\text { lenwert } \\
\text { (n=21) }\end{array}$ & $\begin{array}{l}\text { p-Wert } \\
\text { (Tukey) }\end{array}$ & $\begin{array}{l}\text { Skalen- } \\
\text { wert }(n=6)\end{array}$ & $\begin{array}{l}\text { p-Wert } \\
\text { (Tukey) }\end{array}$ & & \\
\hline & $\begin{array}{l}0,82 \pm \\
0,53\end{array}$ & & $\begin{array}{l}1,22 \pm \\
0,90\end{array}$ & & $\begin{array}{l}1,39 \pm \\
0,67\end{array}$ & & $\begin{array}{l}1,33 \pm \\
0,52\end{array}$ & & $0,94 \pm 0,66$ & 0,001 \\
\hline Calcitriol $^{*}$ & & 0,162 & & & & & & & & \\
\hline $\begin{array}{l}\text { Alfacal- } \\
\text { cidol }\end{array}$ & & 0,002 & & 0,925 & & & & & & \\
\hline $\begin{array}{l}\text { Dihydro- } \\
\text { tachyste- } \\
\text { rol }\end{array}$ & & 0,276 & & 0,996 & & 1 & & & & \\
\hline $\begin{array}{l}\text { keine } \\
\text { Einnahme } \\
\text { HypoPT }\end{array}$ & & 0,986 & & 0,86 & & 0,441 & & 0,777 & & \\
\hline
\end{tabular}

Zu beachten ist, dass die Gruppe mit Alfacalcidoleinnahme größer war als die anderen Subgruppen innerhalb des HypoPT 2016-Kollektivs. Für die anderen Gruppen fand sich in der Statistik kein Hinweis für einen signifikanten Unterschied. Vergleicht man die Beschwerden unter Medikation mit verschiedenen aktiven Vitamin-DPräparaten innerhalb der HypoPT 2016-Gruppe, ergaben sich keine signifikanten Unterschiede (s. Tabelle 30). 


\section{Diskussion}

Ziel dieser Arbeit war die Entwicklung und prospektive Anwendung eines Fragebogens speziell für den Hypoparathyreoidismus, um die Beschwerden bei Nebenschilddrüsenunterfunktion und mögliche Zusammenhänge besser zu verstehen. In zwei verschiedenen Zentren in Deutschland wurde der neue Fragenbogen für ein Jahr lang (Januar bis Dezember 2016) bei Patienten mit postoperativem Hypoparathyreoidismus sowie bei zwei Vergleichskollektiven eingesetzt.

Die Entwicklung dieses Fragebogens basierte auf Ergebnissen einer retrospektiven Analyse der Beschwerden von Patienten des Netzwerk Hypopara, einer Selbsthilfeorganisation für Patienten mit Nebenschilddrüsenunterfunktion. Dieses Kollektiv wurde bewusst gewählt unter der Annahme, dass diese Patienten eine große Beschwerdelast aufweisen und somit alle für dieses Krankheitsbild relevanten Beschwerden erfasst würden. In Kooperation mit der Klinik für Psychosomatische Medizin und Psychotherapie wurde aus den retrospektiven Ergebnissen der HPQ 40 - Fragebogen für Hypoparathyreoidismus (kurz HPQ 40) erstellt. Im Folgenden wird zunächst auf die Ergebnisse der prospektiven Auswertung des HPQ 40 eingegangen und im Anschluss die Methodik der Erstellung und die Testgüte des neu entwickelten Fragebogens diskutiert. Dabei werden die Ergebnisse der retrospektiven Analyse nur auszugsweise diskutiert, da sie vor allem der Konzipierung des HPQ 40 dienten.

Als Vergleichskollektive für die prospektive Anwendung des HPQ 40 wurden zum einen Patienten nach Schilddrüsenoperation ohne postoperativen Hypoparathyreoidismus herangezogen. So sollte erreicht werden, dass das signifikante Mehrauftreten von Beschwerden bei Patienten mit Hypoparathyreoidismus im Vergleich zur Kontrollgruppe nicht etwa auf die Operation oder auf die Schilddrüsenunterfunktion an sich zurückgeführt werden konnte. Denn Patienten beider Gruppen waren zuvor an der Schilddrüse operiert worden und befanden sich in einer euthyreoten Stoffwechsellage unter Substitution mit Levothyroxin. Der Hypoparathyreoidismus war der entscheidende Unterschied zwischen diesen Gruppen.

Als weiteres Vergleichskollektiv dienten Patienten mit Hyperparathyreoidismus - einer Erkrankung, die ebenfalls den Calciumstoffwechsel betrifft und sich daher als Vergleichsgruppe anbot. Diese Gruppe war allerdings inhomogen: Ein Teil der Patienten wurde bereits an der Nebenschilddrüse operiert und zeigte niedrigere PTH und Serumcalciumwerte als der Teil der Patienten, die sich noch in einer Nebenschilddrüsenüberfunktion befanden. Neben dem möglichen Einfluss eines operativen Halseingriffes interessierte in dieser Gruppe vor allem, ob ein Überschuss an PTH die Beschwerden der Patienten andersartig beeinflusst und wie relevant ein normalisierter Parathormonspiegel für die Beschwerdekontrolle ist.

Die vom HPQ 40 abgefragten Symptome ließen sich in fünf Beschwerdekomplexe (Skalen) gruppieren. In dieser Arbeit wurden die drei Skalen Vitalität, ängstliche Depression und Schmerz und Krämpfe ausgewertet. Die anderen beiden Beschwerdekomplexe werden in der Doktorarbeit von cand. med. L. Wilken behandelt. Auf der Skala Schmerz und Krämpfe zeigten die Hypoparathyreoidismuspatienten signifikant mehr Beschwerden als beide Vergleichsgruppen. Wir stellten Zusammenhänge zwischen diesen Beschwerden und verschiedenen Medikamenten (Thiazide, Calciummonopräparate, Magnesium, Alfacalcidol) sowie dem Parathormonlevel im Serum und dem Calcium-Phosphat-Produkt fest. Zwischen der Art der Schilddrüsenoperation bzw. ihrem Ausmaß und den gefundenen Beschwerden konnte kein Zusammenhang ausgemacht werden. 
Zunächst folgt eine Einordnung unseres HypoPT 2016-Kollektivs bezüglich der Medikation, der Krankheitskomplikationen und der laborchemischen Einstellung im Vergleich zu Vorstudien aus der Literatur.

Vergleicht man die Medikation des HypoPT 2016-Kollektivs mit Studienergebnissen aus anderen europäischen Ländern und den USA (s. Tabelle 31), so fällt auf, dass etwas weniger Patienten aus unserem Studienkollektiv eine Calcium-Dauermedikation einnahmen. 49 \% unserer Patienten nahmen ein Calciummonopräparat ein. Berechnete man den Anteil der Patienten in unserer Studie, die Calcium in irgendeiner Form zu sich nahmen (Calciummono- oder Kombipräparat), so nahmen 65,3\% der Patienten Calcium ein. Im internationalen Vergleich erhielten über $90 \%$ der Patienten eine Calcium-Dauermedikation, nur in Norwegen nahmen ähnlich wenige Patienten regelmäßig ein Calciumpräparat zu sich.

Bezüglich der aktiven Vitamin-D-Medikation scheint es länderspezifische Unterschiede zu geben: In einer dänischen Studie wurden die Patienten ausschließlich mit Alfacalcidol, in den USA nur mit Calcitriol therapiert (Mitchell et al. 2012; Underbjerg et al. 2014). In unserer Studie wurden verschiedene aktive Vitamin-DPräparate verwendet. Das von 12,2 \% Patienten in dieser Studie eingenommene Dihydrotachysterol, welches nicht in allen Ländern zugelassen ist, wurde in keiner der Vergleichsstudien angewandt. Im europäischen Vergleich der HypoPT 2016-Gruppe mit der Studie aus Norwegen (Astor et al. 2016) ähneln sich die jeweiligen Medikamentenverteilungen am ehesten.

Tabelle 31: Übersicht über die Medikation (Calcium-Dauermedikation, aktives Vitamin D [Alfacalcidol, Calcitriol], Kombination, Magnesium, Thiazide, rhPTH) von Hypoparathyreoidismuspatienten in verschiedenen Studien (HypoPT 2016, Astor et al. (2016), Underbjerg et al. (2014), Mitchell et al. (2012), Hadker et al. (2014)); Anteil der Patienten, die das Präparat einnehmen in \%; leeres Feld = keine Angabe

\begin{tabular}{|c|c|c|c|c|c|}
\hline \multicolumn{6}{|c|}{ Medikation (Anteil Patienten) } \\
\hline & $\begin{array}{l}\text { НypoРT } \\
2016\end{array}$ & $\begin{array}{l}\text { Astor et al. } \\
\text { (2016) Nor- } \\
\text { wegen }\end{array}$ & $\begin{array}{l}\text { Underbjerg et al. } \\
\text { (2014) Dänemark }\end{array}$ & $\begin{array}{l}\text { Mitchell et al. } \\
\text { (2012) USA }\end{array}$ & $\begin{array}{l}\text { Hadker et al. } \\
\text { (2014) USA }\end{array}$ \\
\hline $\begin{array}{l}\text { Calcium Dauer- } \\
\text { medikation }\end{array}$ & $49,0-65,3^{1}$ & 70,0 & 93,0 & 94,0 & 92,0 \\
\hline aktives Vitamin D & 85,7 & 84,0 & & & \\
\hline Alfacalcidol & 42,9 & 44,0 & 93,0 & & \\
\hline Calcitriol & 28,6 & 40,0 & & 88,0 & \\
\hline $\begin{array}{l}\text { Kombination (ak- } \\
\text { tives Vitamin D + } \\
\text { Calcium) }\end{array}$ & $47,0-57,01$ & & & & 66,6 \\
\hline Magnesium & 26,5 & 34,0 & 4,0 & & 19,5 \\
\hline Thiazide & 14,3 & & & 20,0 & \\
\hline rhPTH $^{2}$ & 4,1 & 4,0 & & 2,0 & 15,0 \\
\hline
\end{tabular}

${ }_{1}^{1}$ ohne vs. mit Calciumanteil aus fixen Kombipräparaten (= Calcium und natives Vitamin D, z. B. Calcimagon®/ Calcilac® etc.) ${ }^{2}$ rhPTH (1-84) und/ oder rhPTH (1-34)

Eine Einordnung des HypoPT 2016-Kollektivs im internationalen Kontext bezüglich der Medikamente ist durch die unterschiedlichen Angaben der Autoren erschwert. Hadker et al. (2014) gaben beispielsweise den Anteil der Patienten an, die eine Kombination aus Calcium und aktivem Vitamin D einnahmen. Astor et al. (2016) hingegen nannten die aktiven Vitamin-D-Präparate einzeln und schlüsselten nochmals nach Subgruppen auf. Die Medikation mit nativen Vitamin-D-Formen lässt sich kaum vergleichen, weil teilweise alle Anwendungsmöglichkeiten (Kombination mit anderem Vitamin D, Monotherapie additiv oder high dose; (Astor et al. 2016)) oder nur die Patienten mit high dose-Therapie angegeben wurden (Mitchell et al. 2012). Die Patienten in 
unserer Studie bekamen ebenfalls unterschiedliche native Vitamin-D-Therapien: Zum einen in Form von fixen Kombipräparaten zusammen mit Calcium (z. B. Calcimagon®/ Calcilac®), zum anderen als Monotherapeutikum, wobei es sich in Göttingen um eine additive und in Saarbrücken um eine high dose-Therapie handelte. Die Unterschiede in der Anwendung der nativen Vitamin-D-Präparate spiegeln sich auch in den verschiedenen Dosierungen wider (s. Tabelle 32).

Für die meisten von unseren Patienten eingenommenen Medikamente ist die durchschnittliche Dosis mit der aus Vorstudien vergleichbar (s. Tabelle 32). Bezüglich des Calcitriols zeigte sich die niedrigste Dosierung im Kollektiv aus den USA (Mitchell et al. 2012), wo jedoch wiederum mehr Calcium gegeben wurde. Da das therapeutische rhPTH zum Zeitpunkt der meisten Studien nicht für die Therapie des Hypoparathyreoidismus zugelassen war, finden sich hierzu in den Arbeiten keine verwertbaren Vergleichsdaten für die Dosierung.

Tabelle 32: Übersicht über die Dosierung der Medikamente für Hypoparathyreoidismus (CalciumDauermedikation, Alfacalcidol, Calcitriol, Vitamin-D-Speicherform, Magnesium, Thiazide) in verschiedenen Studien (HypoPT 2016, Astor et al. (2016), Underbjerg et al. (2014), Mitchell et al. (2012)); Mittelwert \pm Standardabweichung oder Median mit Range (von-bis) oder mit Quartilen (25\%; 75\%); leeres Feld = keine Angabe

\begin{tabular}{|c|c|c|c|c|}
\hline \multicolumn{5}{|c|}{ Medikation (Dosierungen) } \\
\hline & НyроРТ $2016^{1}$ & $\begin{array}{l}\text { Astor et al. (2016) } \\
\text { Norwegen }{ }^{2}\end{array}$ & $\begin{array}{l}\text { Underbjerg et al. } \\
\text { (2014) Dänemark² }\end{array}$ & $\begin{array}{l}\text { Mitchell et al } \\
\text { (2012) USA }\end{array}$ \\
\hline $\begin{array}{l}\text { Calcium-Dauer- } \\
\text { medikation (in mg/d) }\end{array}$ & $\begin{array}{l}939,88 \pm \\
792,06^{3}\end{array}$ & $1000(167-10000)$ & $1000(800 ; 1600)$ & $2048 \pm 1507$ \\
\hline $\begin{array}{l}\text { Alfacalcidol } \\
\text { (in } \mu \mathrm{g} / \mathrm{d} \text { ) }\end{array}$ & $1,07 \pm 0,42$ & $1,50(0,25-6,00)$ & $1,0(0,5 ; 2,0)$ & \\
\hline Calcitriol (in $\mu g / d$ ) & $0,78 \pm 0,70$ & $0,75(0,13-4,0)$ & & $0,5 \pm 0,44$ \\
\hline $\begin{array}{l}\text { Vitamin-D- } \\
\text { Speicherform (in IE) }\end{array}$ & $\begin{array}{l}7165,64 \pm \\
10298,98\end{array}$ & $\begin{array}{l}800(200-8000) \text { bzw. } \\
4286(1286-150000)^{4}\end{array}$ & & $\begin{array}{l}135714 \pm \\
149204\end{array}$ \\
\hline $\begin{array}{l}\text { Magnesium (in } \\
\mathrm{mg} / \mathrm{d} \text { ) }\end{array}$ & $225,00 \pm 269,97$ & $300(120-1200)$ & $0(0-1080)$ & \\
\hline Thiazide (in mg/d) & $25,00 \pm 7,22$ & & & $31 \pm 15$ \\
\hline
\end{tabular}

Insgesamt $35 \%$ unserer HypoPT 2016-Patienten gaben zumindest eine Komplikation an (vgl. Abbildung 2). Die Prävalenz von Nierensteinen, Niereninsuffizienz und Katarakt lag dabei zwischen 10,4 \% und 12,6 \% (s. Tabelle 33), was niedriger ist als in der amerikanischen Studie von 2014, aber höher als im dänischen Kollektiv. Eine chronische Niereninsuffizienz im Stadium III (GFR $<60 \mathrm{ml} / \mathrm{min} / 1,73 \mathrm{~m}^{2}$ ), Nephrokalzinose und BGC sowie hypo/hyperkalzämische Krisen schienen in unserer Gruppe weniger häufig als in den anderen Studien aufzutreten (Abbildung 21). 
Tabelle 33: Übersicht über Komplikationen des Hypoparathyreoidismus (Nierensteine, Niereninsuffizienz, GFR $<60 \mathrm{ml} / \mathrm{min} / 1,73 \mathrm{~m}^{2}$, Nephrokalzinose, Katarakt, BGC, hypo/hyperkalzämische Krisen) in verschiedenen Studien (HypoPT 2016, Underbjerg et al. (2013,2014), Mitchell et al. (2012), Hadker et al. (2014)); Anteil der Patienten mit Komplikation in \%; leeres Feld = keine Angabe

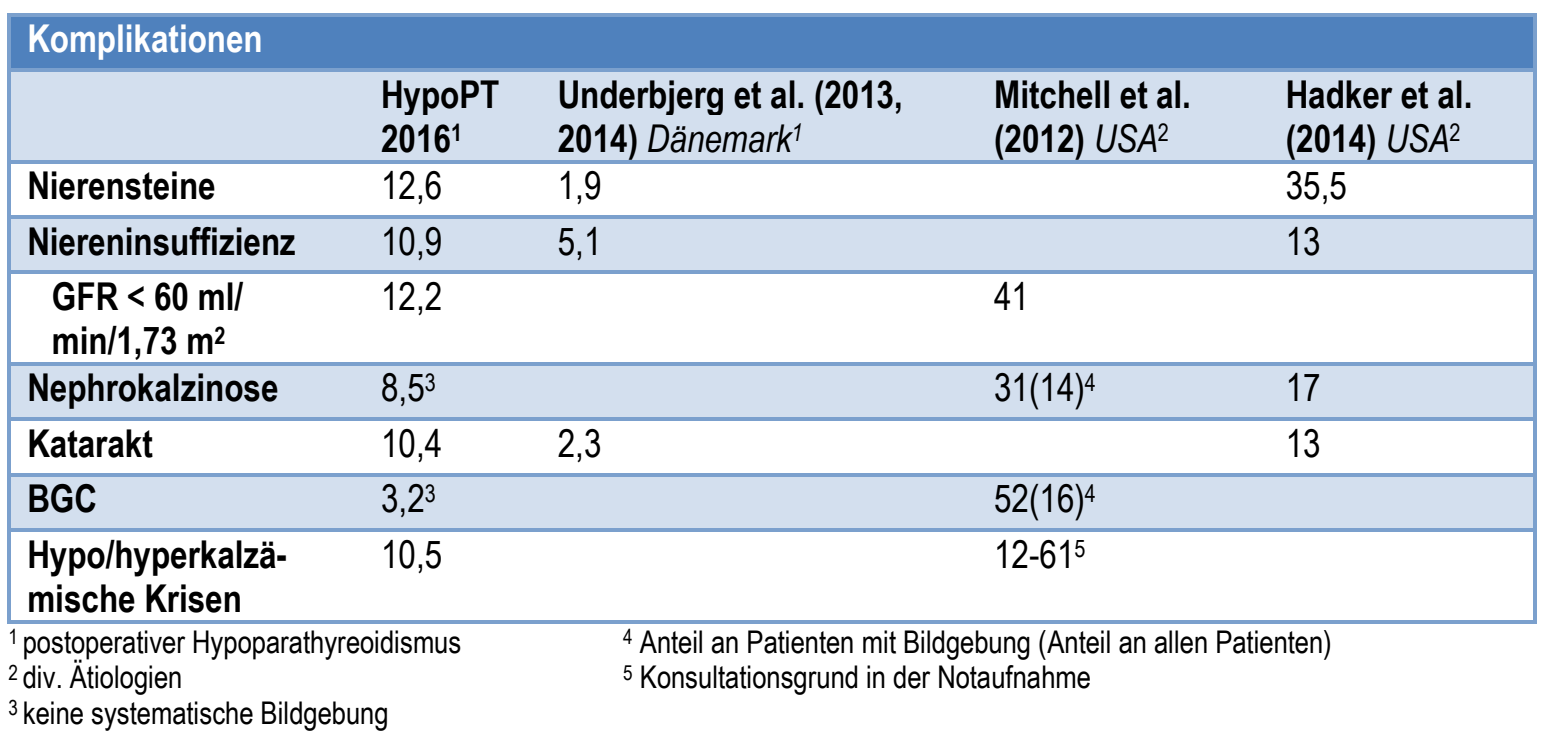

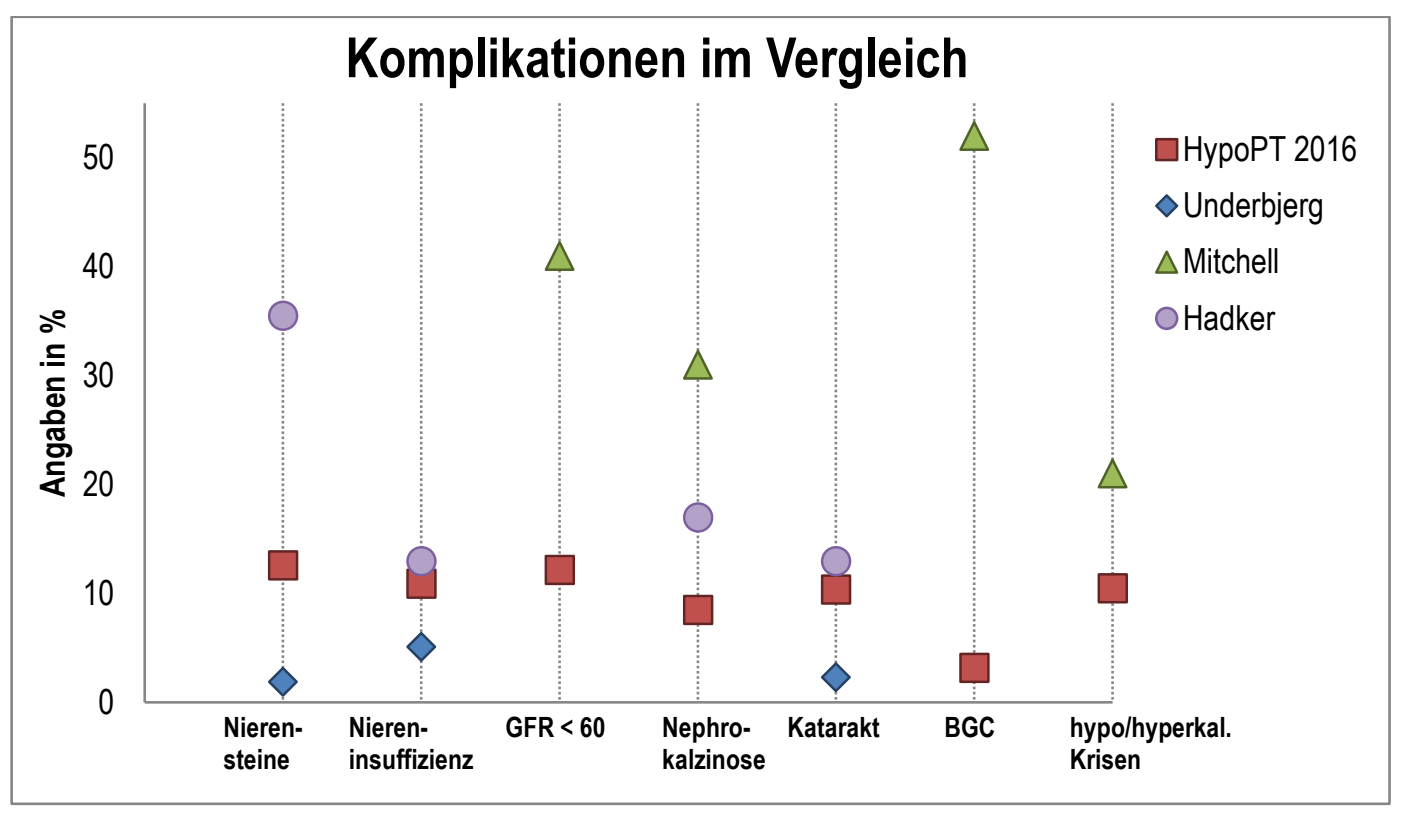

Abbildung 21: Übersicht über Komplikationen des Hypoparathyreoidismus (Nierensteine, Niereninsuffizienz, GFR $<60 \mathrm{ml} / \mathrm{min} / 1,73 \mathrm{~m}^{2}$, Nephrokalzinose, Katarakt, BGC, hypo/hyperkalzämische Krisen) in verschiedenen Studien (HypoPT 2016, Underbjerg et al. (2013,2014), Mitchell et al. (2012), Hadker et al. (2014); Anteil der Patienten mit Komplikation in \%

Die dargestellten Ergebnisse sind jedoch nur orientierend zu bewerten, da es sich nicht um direkte Vergleiche der Primärdaten, sondern um eine sekundäre Literaturanalyse handelt: So wurde für die HypoPT 2016Patienten in unserer Studie keine zusätzliche systematische Bildgebung hinsichtlich einer Nephrokalzinose oder BGC durchgeführt wie bei Mitchell et al. (2012). Darüber hinaus waren die hypo/hyperkalzämischen Krisen nur als „behandlungspflichtig“ aber nicht als Einweisungsgrund ins Krankenhaus definiert. Außerdem ist die Ätiologie des Hypoparathyreoidismus wichtig beim Betrachten der Komplikationshäufigkeiten, denn Underbjerg et al. $(2013,2014,2015)$ zeigten, dass bestimmte Komplikationen häufiger bei postoperativem bzw. bei nicht postoperativem Hypoparathyreoidismus auftreten. In den prospektiven Teil dieser Arbeit mit den hier gezeigten Ergebnissen wurden ausschließlich Patienten mit postoperativem Hypoparathyreoidismus 
eingeschlossen. In den amerikanischen Studien hingegen wurden Patienten mit unterschiedlicher Erkrankungsursache untersucht, sodass die Studienkollektive verschieden zusammengesetzt waren.

Zusammenfassend zeigte unser Kollektiv nicht mehr Komplikationen als in anderen Studien beschrieben. Das deutlich seltenere Vorkommen einer chronischen Niereninsuffizienz im Stadium III könnte damit zusammenhängen, dass ein geringerer Anteil unserer Patienten elementares Calcium einnahm, welches für einige der Beschwerden - zumindest die renalen - verantwortlich gemacht wird (Mitchell et al. 2012). Bezüglich der Nephrokalzinose, BGC und hypo/hyperkalzämischen Krisen zeigen die Daten von Mitchell et al. (2012) höhere Komplikationsraten, welche jedoch nur eingeschränkt mit unseren Daten vergleichbar sind.

Die laborchemische Einstellung unseres HypoPT 2016-Kollektivs wird in der Abbildung 22 mit Werten anderer Studien vergleichen. Das Calcium-Phosphat-Produkt war bei unseren Patienten im Schnitt geringfügig niedriger als bei den Patienten von Mitchell et al. (2012). Für den Parathormonlevel im Serum geben lediglich Sikjaer et al. (2016) den Median ihrer Patienten als Vergleichswert an, da sich die aktuellen Leitlinien bzw. Handlungsempfehlungen nicht für ein routinemäßiges PTH-Monitoring unter Therapie aussprechen (Bollerslev et al. 2015; Brandi et al. 2016). Unsere Patienten zeigten in diesem Vergleich einen höheren durchschnittlichen Parathormonspiegel. Prinzipiell können PTH-Werte jedoch unter Substitution mit aktivem Vitamin D oder Calcium verändert sein (Deroisy et al. 1997).

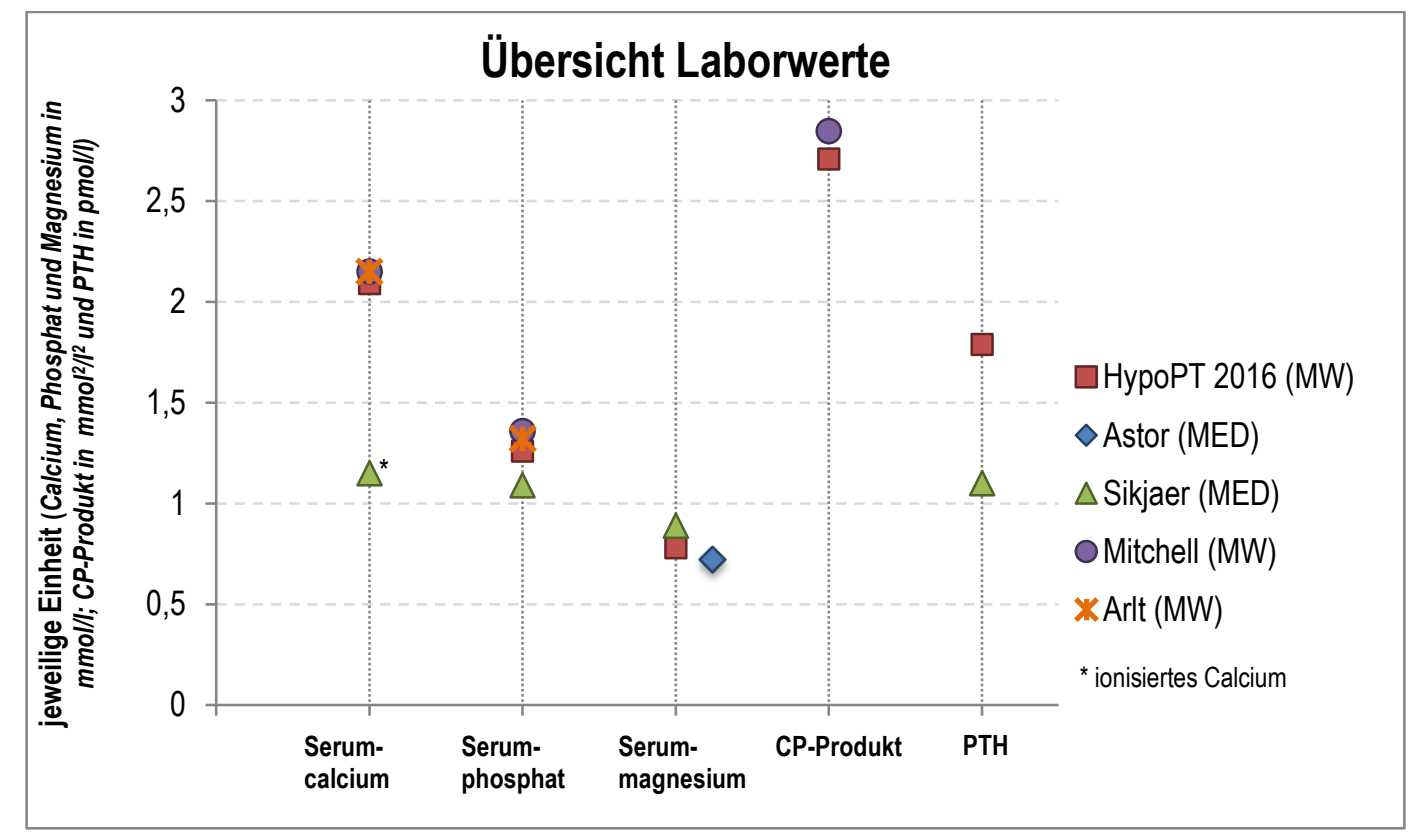

Abbildung 22 Übersicht über Laborwerte bei Hypoparathyreoidismuspatienten (Serumcalcium, -phosphat und -magnesium [alle in mmol/l], Calcium-Phosphat-Produkt [= CP-Produkt; in mmol/2/2] und PTH im Serum [in pmol/l]) in verschiedenen Studien (HypoPT 2016, Astor et al. (2016), Sikjaer et al. (2016), Mitchell et al. (2012), Arlt et al. (2002)); Mittelwert (MW) oder Median (MED)

Beim Serumcalcium, Serumphosphat und Calcium-Phosphat-Produkt lagen in unserem Studienkollektiv mehr Patienten im Ziel- bzw. Normbereich als in den beiden Vergleichsstudien (s. Tabelle 34). Zwar waren die Zielbereiche für das Serumcalcium unterschiedlich definiert (Arlt: 2,00-2,35 mmol//; Mitchell: 1,882,38 mmol/l), unsere Zielbereichsdefinition (2,02-2,25 bzw. 1,87-2,3 mmol/l) in Anlehnung an die amerikanischen Handlungsempfehlungen (Brandi et al. 2016) war jedoch die am engsten gefasste. Hinsichtlich der Calciumausscheidung im 24-h-Urin präsentierten unsere Hypoparathyreoidismus-Patienten einen mit den Patienten von Mitchell et al. (2012) und Arlt et al. (2002) vergleichbaren Anteil im Zielbereich. 
Tabelle 34: Übersicht über den Anteil der Patienten mit Laborparametern (Serumcalcium, Serumphosphat, Cal= cium im 24-h-Urin, Calcium-Phosphat-Produkt) im Normbereich/Zielbereich in verschiedenen Studien (HypoPT 2016, Mitchell et al. (2012), Arlt et al. (2002)); Anteil der Patienten in \%

\begin{tabular}{|c|c|c|c|}
\hline Norm/Zielbereichsanalyse für & НyроРТ 2016 & Mitchell et al. (2012) & Arlt et al. (2002) \\
\hline Serumcalcium ${ }^{1}$ (in $\left.\mathrm{mmol} / \mathrm{l}\right)$ & 87 & 71 & 72 \\
\hline Serumphosphat ${ }^{2}$ (in $\mathrm{mmol} / \mathrm{l}$ ) & 95,7 & & 80 \\
\hline Calcium im 24-h-Urin ${ }^{3}$ (in mmol/d) & 76 & $62-74^{4}$ & 77 \\
\hline Calcium-Phosphat-Produkt ${ }^{2}$ (in mmol2//2) & 100 & $78-97^{4}$ & \\
\hline
\end{tabular}

Fasst man zusammen, so zeigten unsere Patienten eine gute laborchemische Einstellung mit tendenziell mehr Patienten im Norm-/Zielbereich als in den anderen Studien.

Abschließend kann man unser Hypoparathyreoidismuskollektiv wie folgt charakterisieren: Im Vergleich nehmen weniger unserer Patienten eine Calciummedikation ein als in amerikanischen Studien. Bei uns werden unterschiedliche aktive Vitamin-D-Präparate eingesetzt, die nicht in allen Ländern verfügbar sind. Außerdem scheinen in unserem Kollektiv etwas weniger Komplikationen vorzuliegen, wobei nicht alle Daten direkt vergleichbar waren. Die laborchemische Einstellung gelang verglichen mit anderen Studien gut, auch wenn teilweise nicht alle Patienten im Normbereich lagen. Insgesamt handelt es sich in der Zusammenschau der Literatur um ein gut eingestelltes Kollektiv, bei dem man primär keine hohe Beschwerdelast vermuten würde.

Im Weiteren soll auf das psychische Befinden und die Lebensqualität der Patienten eingegangen werden. In unserer retrospektiven Analyse zeigten die Patienten im Vergleich zur Normpopulation signifikante Ergebnisse bezüglich Depressivität, Ängstlichkeit und Einschränkungen der Lebensqualität, vor allem im psychischen Bereich. Bereits mehrere Studien beschrieben Beschwerden im Bereich von Depression und Angst bei Hypoparathyreoidismuspatienten (Arlt et al. 2002; Hadker et al. 2014; Underbjerg et al. 2014) sowie Einschränkungen der Lebensqualität, meist gemessen mit dem SF-36 (Astor et al. 2016; Cusano et al. 2014; Sikjaer et al. 2016). Dabei wurden sowohl Patienten mit Nebenschilddrüsenunterfunktion verschiedener Ätiologie (Astor et al. 2016; Cusano et al. 2014; Hadker et al. 2014) als auch ausschließlich postoperativem Hypoparathyreoidismus berücksichtigt (Arlt et al. 2002; Sikjaer et al. 2016; Underbjerg et al. 2014). Allerdings hatten lediglich Arlt et al. (2002) und Sikjaer et al. (2016) eine direkte Vergleichsgruppe, andere Autoren arbeiteten deskriptiv oder verglichen mit Normwerten bzw. der gesunden Allgemeinbevölkerung.

Bei der Konzipierung des HPQ 40 spiegelte sich die Relevanz dieser Bereiche bei der Skalenbildung mittels Hauptkomponentenanalyse wider, welche unter anderem die Skalen ängstliche Depression und Vitalität ergab. In der prospektiven Auswertung ergaben sich auf diesen beiden Skalen im Vergleich mit den beiden Kontrollgruppen jedoch keine signifikanten Unterschiede.

Dass unsere Patienten mit postoperativem Hypoparathyreoidismus keine signifikant vermehrten psychischen Symptome im Sinne von Depressionen aufwiesen, wurde dadurch bestätigt, dass auch die Auswertung der Screeningfragen zu Depressionen im Gruppenvergleich nicht signifikant war. Die Screeningfragen wiesen in Untersuchungen „sehr gute psychometrische Eigenschaften auf“ (Spangenberg et al. 2012, S.8) zur Erkennung von Depressionen bei einer Sensitivität von 79 \% und Spezifität von 86 \% (Löwe et al. 2005). Daher ist 
es eher unwahrscheinlich, dass sich möglicherweise vorhandene depressive Symptome aufgrund von unpassend formulierten Fragen im HPQ 40 nicht darstellten, da in diesem Fall die Screeningfragen vermutlich ein signifikant vermehrtes Auftreten von Depressionen im HypoPT 2016-Kollektiv gezeigt hätten.

Laut einer Studie des Robert-Koch-Institutes liegt die deutschlandweite Prävalenz von depressiver Symptomatik bei 8,1 \% über beide Geschlechter und bei 10,2 \% für Frauen (Busch et al. 2013). Diese Zahlen entsprechen in etwa den Ergebnissen unserer beiden Vergleichskollektive im Depressionsscreening (8,1 \% SDOP 2016 vs. 11,8 \% pHPT 2016), bei denen der Frauenanteil > 80 \% betrug. Die Kontrollgruppen wiesen demnach keine untypisch hohe Depressivitätsprävalenz im Vergleich zur Allgemeinbevölkerung auf, was den fehlenden Gruppenunterschied erklären könnte. Der Anteil der HypoPT 2016-Patienten mit einem auffälligen Depressionsscreening $(22,4 \%)$ wich jedoch von der genannten deutschlandweiten Prävalenz ab, ebenso waren die Werte der Skala ängstliche Depression höher als die der beiden Vergleichsgruppen. In einem größeren Studienkollektiv würde sich möglicherweise ein signifikanter Unterschied bezüglich der Depressionen zeigen. Trotz der fehlenden Signifikanz in unserem prospektiven Studienteil ist der Symptomkomplex der ängstlichen Depression bei Hypoparathyreoidismus auch wegen der retrospektiv signifikanten Ergebnisse also in Zukunft nicht zu vernachlässigen.

Bei den Fragen zum Bereich der Lebensqualität auf der Skala Vitalität fiel ein Teil der Patienten mit inkonsistentem Antwortverhalten auf, weshalb Nachanalysen durchgeführt wurden. Das Problem lag wahrscheinlich in dem Wechsel von negativ auf positiv formulierte Fragen: Kallus (2016) merkt in seinem Werk zur Fragebogenkonzipierung an, dass ein Wechsel der Fragenskalierung problematisch ist und zu „Fehlern beim Ankreuzen führen [kann]" (Kallus 2016, S. 50). Die Skala blieb zwar vom Wortlaut her gleich, aber durch den Wechsel von negativen zu positiven Fragenformulierungen war die Bedeutung der Antworten auf der Skala umgepolt, was de facto einer Umskalierung entsprach. Die Nachanalysen der Skala Vitalität ergaben eine Tendenz in Richtung einer Einschränkung in diesem Bereich der Lebensqualität bei unseren HypoPT 2016-Patienten, wenn man Patienten mit vermutlich falschem Antwortverhalten aus der Wertung ausschloss.

Abschließend lässt sich feststellen, dass depressive Symptomatik und Einschränkungen der Lebensqualität relevante Beschwerdebereiche bei Hypoparathyreoidismuspatienten sind, die sich in unserer Studie aus verschiedenen Gründen nicht signifikant darstellten.

Im Folgenden werden nun die weiteren Beschwerden betrachtet, die mithilfe des HPQ 40 identifiziert wurden. In unserer Studie zeigten die Patienten mit Hypoparathyreoidismus signifikant mehr Beschwerden auf der Skala Schmerz und Krämpfe im Vergleich zu den pHPT 2016 und SD-OP 2016-Patienten. Dieser Beschwerdekomplex umfasste unter anderem Gelenk-, Rücken- und Gliederschmerzen sowie Muskelschmerzen und krämpfe.

Schmerzen und muskuläre Beschwerden bei Hypoparathyreoidismus sind bereits mehrfach in der Literatur beschrieben worden: In einer Onlineumfrage unter Erwachsenen mit permanenter postoperativer Nebenschilddrüsenunterfunktion in den USA waren drei der sechs häufigsten körperlichen Symptome Muskelschmerz und Krämpfe, Gelenk- oder Knochenschmerzen und Schmerz bzw. Schwere- und Schwächegefühl in den Extremitäten (Hadker et al. 2014). Gliederschmerzen sowie schmerzhafte Krämpfe, Gelenk- und Muskelschmerzen wurden ebenfalls in zwei deutschen Fragebogenstudien zum Hypoparathyreoidismus festge- 
stellt (Arlt et al. 2002; Bohrer et al. 2005). Interessanterweise werden diese Symptome in allen Arbeiten angeführt, jedoch kaum weiter diskutiert. Lediglich Arlt et al. (2002) spekulierten, dass die Beschwerden mit der Einnahme oder dem Serumspiegel von Magnesium in Verbindung stehen könnten. So entsteht der Eindruck, dass Schmerzen und Krämpfe zwar im Zusammenhang mit Hypoparathyreodismus bekannt sind, aber nicht als relevanter Symptomenkomplex wahrgenommen werden. So fanden Cho et al. (2014) in ihrer Studie heraus, dass Beschwerden wie beispielsweise Muskelkrämpfe als Symptome eines permanenten postoperativen Hypoparathyreoidismus sowohl von den behandelnden Chirurgen als auch von gesunden Kontrollen im Vergleich zu tatsächlich betroffenen Patienten unterschätzt wurden (16\% der Chirurgen und $11 \%$ der Kontrollen glaubten, es würden Muskelkrämpfe auftreten vs. 51 \% der Patienten hatten tatsächlich Muskelkrämpfe; $p<$ $0,001)$.

Unsere Ergebnisse zeigen also, dass der Symptomkomplex Schmerz und Krämpfe bei Nebenschilddrüsenfunktion zwar bekannt ist, seine Relevanz für Patienten aber in Zukunft mehr beachtet werden sollte. Er grenzt sich sowohl gegenüber Patienten mit (operiertem) primären Hyperparathyreodismus als auch gegenüber postoperativen Schilddrüsenpatienten ohne Nebenschilddrüsenunterfunktion ab.

Für Muskelprobleme bei einer Nebenschilddrüsenunterfunktion finden sich in der Literatur mehrere Hinweise. Neben reduzierter Muskelkraft (Sikjaer et al. 2016), erhöhten Muskelenzymen und degenerativen Veränderungen in der Muskelbiopsie (Dai et al. 2012; Shane et al. 1980) gibt es mehrere Fallberichte über Patienten mit Hypoparathyreoidismus-assoziierter Myopathie (Nora et al. 2004; Policepatil et al. 2012; Walters 1979). All diesen Berichten ist gemeinsam, dass es sich um Patienten mit teils jahrelang unentdecktem idiopathischen Hypoparathyreoidismus und starker Hypokalzämie handelte, deren Symptome sich unter Substitution mit Calcium und Vitamin D besserten. Daher hielten die Autoren einen Zusammenhang der Muskelschäden mit dem erniedrigten Serumcalcium für wahrscheinlich, und Dai et al. (2012) sahen darin auch eine mögliche Begründung für Muskelschmerzen. Unsere Patienten hingegen litten an einer postoperativen Nebenschilddrüsenunterfunktion; und unter Medikation mit Calcium und/oder Vitamin-D-Formen lagen lediglich 8,7 \% mit ihrem Serumcalcium unterhalb des Zielbereiches. Erniedrigte Calciumwerte stellen somit für die Beschwerden in unserem Kollektiv keine eindeutige Erklärung dar. Zwischenzeitliche hypokalzämische Phasen, welche von den Patienten nicht als solche wahrgenommen oder angegeben wurden, kämen zwar prinzipiell infrage, Sikjaer et al. (2016) merkten jedoch an, dass die Pathogenese der Myopathie bei Hypoparathyroeidismus noch nicht gänzlich aufgeklärt sei. Die Autoren verweisen auf eine mögliche direkte Wirkung des Parathormons auf den Muskel (Sikjaer et al. 2016). Es gibt Berichte über die Expression des Parathormonrezeptors im Skelettmuskel (Smock et al. 2001; Urena et al. 1993) und erste Hypothesen zu dessen Funktion zusammen mit PTH, beispielsweise bei der Myozytendifferenzierung (Kimura und Yoshioka 2014). Darüber hinaus scheinen PTH und sein Rezeptor in die Pathogenese von Muskelschwund und Kachexie involviert zu sein (Kir et al. 2016; Thomas und Mitch 2017). Sikjaer et al. (2014) untersuchten systematisch die Wirkung einer rhPTH(184)-Substitution auf die Muskelfunktion, konnten aber keinen positiven Effekt feststellen. Als mögliche Erklärung führten sie das vermehrte Auftreten von Hyperkalzämie in ihrer Studie an, das der positiven PTHWirkung möglicherweise entgegenstand (Sikjaer et al. 2014). 
Die Analyse mittels nicht-parametrischer LOESS-Kurve zeigte, dass die Höhe der Beschwerden auf der Skala Schmerz und Krämpfe sowohl oberhalb des Normbereiches (ab ca. 7 pmol/l) als auch im unteren Normbereich (unter ca. 4 pmol/l) zunahmen. Ein normwertiges PTH scheint sich demnach positiv auf Beschwerden der Patienten auszuwirken. Dazu passend wiesen unsere Hypoparathyreoidismuspatienten nur im Vergleich zu den operierten Hyperparathyreodismus-Kontrollen mehr Beschwerden auf, nicht aber zu denen ohne Operation. Die beiden Hyperparathyreoidismus-Subgruppen unterschieden sich erwartungsgemäß signifikant bezüglich des Anteils an PTHs im Normbereich, nicht aber hinsichtlich des Calciums im Normbereich. Bei den Kontrollen ohne Operation lag das PTH zu 94 \% oberhalb des Normbereiches. Sie gaben einen höheren Beschwerdewert auf der Skala Schmerz und Krämpfe an. Muskloskelettale Beschwerden können Symptome eines unbehandelten Hyperparathyreoidismus sein (Borgia et al. 2012; Pappu et al. 2016). Verschiedene Studien führen mögliche Pathomechanismen an, welche den schädlichen Einfluss von exzessivem PTH auf den Muskel erklären könnten (Baczynski et al. 1985; Reppe et al. 2007).

Es lässt sich schlussfolgern, dass eine direkte Wirkung des (fehlenden) PTHs auf den Muskel möglich ist und ein Parathormonspiegel innerhalb des Normbereiches wichtig für die muskuläre Beschwerdekontrolle sein könnte.

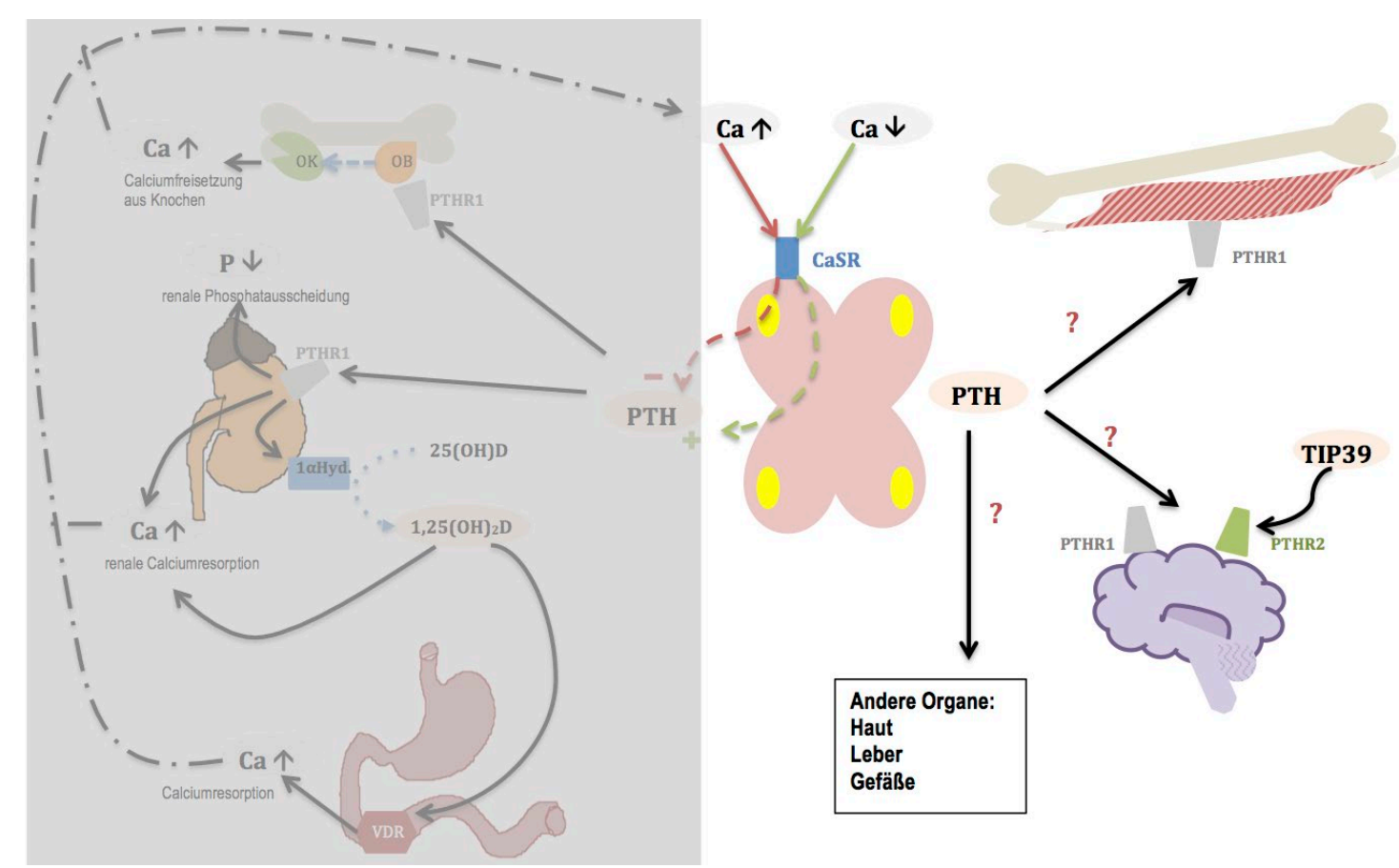

Abbildung 23: bildliche Darstellung möglicher Funktionen von Parathormon (PTH) an Skelettmuskel, Gehirn und weiteren Organen [rechte Seite] sowie mögliche Wirkung von TIP39 als endogener Ligand am PTH2-Rezpetor; Darstellung der bekannten und bereits in der Einleitung beschriebenen Funktionen der PTHs im Calcium- und Phosphatstoffwechsel [linke Seite] (Abkürzungen: $\mathrm{Ca}=$ Calcium, $\mathrm{P}=$ Phosphat, $\mathrm{OB}=$ Osteoblasten, $\mathrm{OK}=$ Osteoklasten, $1 \mathrm{aHydr}$. = 1a-Hydroxylase, PTHR1/2 = PTH-Rezeptor 1/2; VDR = intranukleärer Vitamin-D-Rezeptor)

Es liegen nur wenige Daten zu Parathormon und Schmerz vor. Wie bereits angedeutet, scheint ein normwertiges PTH Einfluss auf Beschwerden der Patienten zu haben. In unserer Studie war für PTH nicht nur der Laborwertvergleich, sondern auch die Normbereichsanalyse im Gruppenvergleich signifikant. Zudem korrelierte PTH über alle Patienten wie bereits erwähnt mit den Beschwerden. Unsere Patienten hatten nicht nur 
signifikant mehr Beschwerden auf der Skala Schmerz und Krämpfe, sondern unterschieden sich auch signifikant hinsichtlich der Parathormonwerte von den Vergleichskollektiven. Dies gibt einen Hinweis auf die herausragende Rolle des PTHs, welche sich neben der bekannten Funktion als Regulator des Calciumhaushaltes auch auf noch unbekannte direkte Effekte des Hormons begründen könnte (s. Abbildung 23).

Nicht nur der PTH1-Rezeptor, sondern vor allem der PTH2-Rezeptor wird im Gehirn exprimiert (Urena et al. 1993; Usdin et al. 2002; Weaver et al. 1995). Es wird daher ein direkter Einfluss des PTHs bzw. seines Mangels auf das Wohlbefinden der Patienten vermutet, ohne dass es notwendigerweise zu einer Änderung in der Calciumhomöostase kommen muss (Astor et al. 2016; Marcucci et al. 2016). Der PTH2-Rezeptor kommt unter anderem vermehrt in Hirnregionen vor, die der Schmerzverarbeitung dienen, wie beispielsweise dem Nucleus spinalis nervi trigemini (Bago et al. 2008; Dobolyi et al. 2002).

Das PTH bindet zwar mit hoher Affinität an den PTH2-Rezeptor (Behar et al. 1996; Clark et al. 1998; Usdin et al. 1995), aber kann im Tiermodell diesen nur wesentlich schwächer aktivieren (Hoare et al. 1999) als TIP39, welches der full Agonist und natürlicher Ligand dieses Rezeptors zu sein scheint (Usdin et al. 2000; Usdin et al. 2002). TIP39 beeinflusst neusten Erkenntnissen zufolge auf supraspinaler Ebene die Schmerzempfindlichkeit: Im Tiermodell kam es bei verminderter TIP39-Aktivität zur Hypoalgesie (Dimitrov et al. 2010). Bei einem Mangel an PTH und dessen verminderter Bindung an den PTH2-Rezeptor ist vorstellbar, dass TIP39 vermehrt binden kann und so das Schmerzerleben negativ beeinflusst. Dennoch ist die Rolle des humanen PTH2-Rezeptors im Gehirn noch nicht abschließend geklärt (Hoare et al. 1999; Usdin et al. 2000); unterschiedliche Signalwege abhängig vom jeweils bindenden Agonisten sind ebenfalls möglich (Dobolyi et al. 2010).

In Zusammenschau der Ergebnisse dieser Studie und der Literatur lässt sich festhalten, dass die Mechanismen des TIP39/PTH2-Rezeptorsystems einen Erklärungsansatz für die signifikant mehr auftretenden Schmerzen unserer Patienten darstellen. Der möglicherweise direkte Einfluss des Parathormons auf das Schmerzempfinden über die genannten Mechanismen unterstreicht, dass ein normwertiges Parathormon wichtig für die Symptomkontrolle erscheint.

Nicht nur für Parathormon, sondern auch für andere Faktoren konnte ein möglicher Einfluss auf die Beschwerden der Skala Schmerz und Krämpfe in unserer Studie ausgemacht werden. Hinsichtlich der Laborparameter zeigten unsere HypoPT 2016-Patienten signifikante Unterschiede bei Calcium, Phosphat, CalciumPhosphat-Produkt und Parathormon im Serum verglichen mit den anderen den beiden Kontrollkollektiven. Da sich der Hypoparathyreoidismus durch Veränderungen des Calcium- und Phosphathaushaltes sowie des Parathormonspiegels auszeichnet, waren diese Gruppenunterschiede zu erwarten. Von den genannten Laborparametern korrelierte neben dem PTH nur das Calcium-Phosphat-Produkt mit den Beschwerden der Skala Schmerz und Krämpfe und zwar innerhalb der HypoPT 2016-Gruppe. Trotz signifikanter Gruppenunterschiede bezüglich des Serumcalciums und -phosphates konnte kein Hinweis auf einen Zusammenhang dieser Parameter mit muskulären und Schmerzbeschwerden in unserer Studie festgestellt werden.

Obwohl es bei allen Patienten mit Hypoparathyreoidismus im Normbereich lag, zeigten unsere HypoPT 2016Patienten ein signifikant höheres Calcium-Phosphat-Produkt als die Patienten mit Hyperparathyreoidismus. Bislang gibt es kaum Studien, die sich systematisch mit dem Effekt des Calcium-Phosphat-Produktes auf 
Beschwerden bei Hypoparathyreoidismus beschäftigt haben. Sowohl Stack et al. (2015) als auch Bollerslev et al. (2015) heben in ihren Empfehlungen die Bedeutung eines normwertigen Calcium-Phosphat-Produktes hervor, um extraskelettale Kalzifikationen bis hin zur Kalziphylaxie zu verhindern, welche mit einem erhöhten Calcium-Phosphat-Produkt einhergeht. Ektope Kalzifikationen an verschiedenen Stellen des Körpers, z. B. Niere, Auge oder Gehirn, sind im Rahmen einer Nebenschilddrüsenunterfunktion beschriebene Komplikationen (Shoback 2008). Aggarwal et al. (2013) konnten sogar feststellen, dass neuropsychologische Defizite mit der Höhe des Calcium-Phosphat-Produktes ansteigen, so wie bei unseren Patienten die Schmerz- und Muskelbeschwerden stiegen. Im Mausmodell im Rahmen anderer Muskelerkrankungen wurde demonstriert, dass Calcium-Phosphat-Ablagerungen im Skelettmuskel möglich sind und zur Kalzifikation führen können (Kikkawa et al. 2009). Es ist denkbar, dass solche Ablagerungen im Rahmen eines Hypoparathyreoidismus Beschwerden herrufen könnten, und Muskelbiopsien würden in diesem Fall weiteren Aufschluss geben.

Dass das Calcium-Phosphat-Produkt - obwohl normwertig - vermutlich im Zusammenhang mit den Beschwerden unserer Patienten steht, hebt nicht nur seine Bedeutung als Zielparameter der Therapiekontrolle einer Nebenschilddrüsenunterfunktion hervor, sondern lässt auch über eine Neudefinition des NormIZielbereiches nachdenken. Wie Mannstadt et al. (2017) kritisch anmerkten, wird der aktuell empfohlene Zielbereich des Calcium-Phosphat-Produktes eigentlich in der Nephrologie zur Risikoreduktion von arteriellen Calciumablagerungen bei chronischer Nierenerkrankung verwendet, und seine Bedeutung für die Hypoparathyreoidismustherapie ist umstritten. Nach dem heutigen Stand der Forschung treten ektope Kalzifikationen nicht erst oder nur nach Überschreiten einer bestimmten Schwelle von Calcium und Phosphat im Serum auf, sondern unterliegen wesentlich komplexeren Mechanismen (O'Neill 2007).

Weil bei unseren Hypoparathyreoidismuspatienten trotz des normwertigen, aber im Vergleich zur Kontrollgruppe erhöhten Calcium-Phosphat-Produktes ein Zusammenhang zwischen diesem und den Beschwerden auf der Skala Schmerz und Krämpfe gefunden wurde, ist es möglich, dass ein hohes Calcium-PhosphatProdukt beispielsweise durch lokale Gewebsveränderungen bis hin zu Calcium-Phosphat-Ablagerungen im Muskel zu den Beschwerden beiträgt. Ein Calcium-Phosphat-Produkt im bislang verwendeten Normbereich ist möglicherweise zu hoch für den Hypoparathyreoidismus. Hier könnten entsprechende Untersuchungen am Muskel bzw. Muskelbiopsien weiteren Aufschluss geben, um mögliche durch Calcium und/oder Phosphat bedingte Gewebsveränderungen zu identifizieren.

Die Beschwerden unserer Patienten auf der Skala Schmerz und Krämpfe korrelierten neben dem CalciumPhosphat-Produkt auch positiv mit der Höhe der eingenommen Calciummonopräparatdosis. Dieser Zusammenhang war über alle Patienten betrachtet signifikant. Innerhalb der HypoPT 2016-Gruppe zeigte sich kein signifikanter Zusammenhang. Da die Calciummonopräparate ausschließlich von HypoPT 2016-Patienten eingenommen wurden, muss man einen möglichen Effekt der Studiengruppenzugehörigkeit - und somit der Krankheitslast durch den Hypoparathyreoidismus an sich - berücksichtigen. Calciummonopräparate können daher nicht allein für die Beschwerden verantwortlich gemacht werden, diese jedoch möglicherweise mitbedingen - zusammen mit anderen Einflussfaktoren auf muskuloskelettale Symptome und Schmerzen, die bereits diskutiert wurden. 
Geht man von einem Zusammenhang der Calciummonopräparate mit den Beschwerden der Patienten aus, stellt sich zunächst die Frage, ob die Calciumeinnahme die Beschwerden mitbedingt, oder ob die Calciummedikation bei stärkeren Beschwerden vermehrt eingenommen wird.

Calciumpräparate wie Calciumcarbonat oder -citrat führen kurzfristig zu einem starken Anstieg des Serumcalciums (Deroisy et al. 1997), und muskuloskelettale Schmerzen sind im Rahmen einer Hyperkalzämie auftretende Symptome (Carroll und Schade 2003; Turner 2017). Passend dazu merkten Mannstadt et al. (2017) in ihrer aktuellen Übersichtsarbeit an, dass Serumcalciumlevel bei Hypoparathyreoidismuspatienten unter Therapie ohne (für sie) offensichtlichen Grund schwanken können. Das im Rahmen der Einnahme eines solchen Präparates vorübergehend entstehende Mehrangebot an Calcium muss sich nicht notwendigerweise in Laborwerten unserer Patienten widerspiegeln: Der HPQ 40 bezieht sich auf die Beschwerden der vergangenen vier Wochen, wohingegen die Blutentnahme nur zum Zeitpunkt des Ausfüllens erfolgte. Exakte Aussagen über kurzfristige Änderungen des Calciumspiegels der Patienten in den letzten Wochen sind somit nicht möglich. Auch medikamentös therapierten Patienten mit Hypoparathyreoidismus fehlt das PTH als Feinregulator für die physiologische Calciumhomöostase, um adäquat auf schnelle Änderungen des Serumcalciums reagieren zu können (Sikjaer et al. 2016). Darüber hinaus sind sie teilweise an extrem niedrige Calciumwerte adaptiert (Abate und Clarke 2016). Die erhöhte Sensitivität für Calcium kann bei diesen Patienten möglicherweise zu Hyperkalzämiesymptomen führen, obwohl das Serumcalcium sich noch im Normbereich befindet (Bilezikian et al. 2016). Ausschlaggebend dabei könnte die relative Änderung des Calciumwertes sein - sowohl nach oben als auch nach unten.

Eine andere Möglichkeit wäre hingegen, dass mehr Calcium eingenommen wurde, um die Beschwerden zu beeinflussen. Bei einer lebensbedrohlichen Hypokalzämie mit Tetanie bis hin zum Krampfanfall kann Kalzium zur Symptomlinderung intravenös verabreicht werden (Bilezikian et al. 2016). Zur Wirkung von oralem Calcium bei muskulären Beschwerden und Schmerz gibt es allerdings nur wenige Studien. Im Bereich der schwangerschaftsassoziierten Muskelkrämpfe ist die Wirksamkeit einer Calciumsubstitution umstritten (Shahraki 2006; Young und Jewell 2002; Zhou et al. 2015). Es sollte außerdem berücksichtig werden, dass auch bei der Therapie von muskulären Beschwerden durch Calciumgabe das Serumcalcium nur kurzfristig angehoben werden kann (Karkkainen et al. 2001; Reginster et al. 1993).

Falls also die Einnahme von Calciummonopräparaten die Beschwerden der Patienten mitverursacht, so wären Schwankungen im Serumcalciumspiegel im Rahmen einer oralen Calciumsubstitution ein möglicher Erklärungsansatz. Entscheidend ist dabei womöglich, dass das PTH fehlt, um auf kurzfristige Änderungen des Calciumspiegels adäquat zu reagieren. Die Frage nach der Einnahme von Calciumpräparate wegen der Beschwerden lässt sich nicht endgültig beantworten. Da außerdem die Studiengruppenzugehörigkeit einen möglichen Einflussfaktor darstellt, ist dem Ergebnis eher ein Hinweis- als einen Beweischarakter beizumessen. In zukünftigen Studien sollte ein Augenmerk auf den Änderungen des Serumcalciums bei Calciumeinnahme liegen, um die Hypothesen weitergehend zu überprüfen.

Die Thiaziddosis korrelierte nicht nur über alle Patienten, sondern auch innerhalb der HypoPT 2016-Gruppe mit den Beschwerden auf der Skala Schmerz und Krämpfe. Thiazide erhöhen den Serumcalciumspiegel (Brickman et al. 1972), und auch bei dieser Medikamentengruppe ist eine Hyperkalzämie als Nebenwirkung 
zu beobachten (Carroll und Schade 2003; Wermers et al. 2007). Die Einnahme von Thiaziden könnte also durch einen ähnlichen Pathomechanimus wie bei den Calciumpräparaten zu den bei unseren Patienten festgestellten Beschwerden beitragen. In einer kleinen Fallstudie wurde ein signifikanter Anstieg des Serumcalciums (teilweise über den Normbereich hinaus) bei Hypoparathyreoidismus unter Thiazidgabe beschrieben, wohingegen bei der Kontrollgruppe das Serumcalcium nahezu unverändert blieb (Parfitt 1972). Aber Thiazide können auch andere Elektrolytstörungen hervorrufen durch Verlust von Natrium (Sonnenblick et al. 1993), Kalium (Rodenburg et al. 2014) oder Magnesium (Ernst und Moser 2009; Hollifield 1986). Bei Hyponatriämie ist das muskuläre System nicht typischerweise mitbetroffen, bei Kalium- und Magnesiummangel hingegen schon, und es können Krämpfe oder Muskelschmerzen auftreten (Ayuk und Gittoes 2011; Knochel 1984; Shils 1969).

Zusammenfassend lässt sich festhalten, dass Elektrolytveränderungen unter Gabe von Thiaziddiuretika einen möglichen Erklärungsansatz für die Beschwerden unserer Patienten darstellen. Aktuelle und systematische Studien dazu bei Hypoparathyreoidimus mit ausreichender Fallzahl gibt es auch für diesen Zusammenhang nicht.

Ein weiterer möglicher Zusammenhang der Beschwerden wurde mit der eingenommenen Magnesiumdosis gefunden. Die Höhe dieser Medikation korrelierte mit den Beschwerden der Skala Schmerz und Krämpfe über alle Patienten. Da sich innerhalb der HypoPT 2016-Gruppe keine Korrelation zeigte, ist ein Effekt der Studiengruppenzugehörigkeit nicht ausgeschlossen. Allerdings wurde Magnesium nicht nur ausschließlich von HypoPT 2016-Patienten eingenommen.

Ein gut eingestellter Magnesiumspiegel ist bei Hypoparathyreoidismus essentiell, da sowohl zu viel als auch zu wenig Magnesium die PTH-Sekretion und Wirkung beeinträchtigt (Shoback et al. 2016). Arlt et al. (2002) merkten in ihrer Studie über psychische Beschwerden bei Hypoparathyreoidismuspatienten kritisch an, dass die Magnesiumeinnahme und -serumwerte möglicherweise einen Einfluss auf die angegebenen Beschwerden hatten, welcher aber nicht weiter untersucht wurde. Unsere Patienten zeigten jedoch weder im Vergleich zu anderen Studien noch zu den beiden Kontrollgruppen auffällige Serummagnesiumwerte. Dass eine Magnesiumüberdosierung bei unseren Patienten die Beschwerden hervorrief, ist auch deshalb unwahrscheinlich, da Magnesium wichtig für die Membranstabilität und Muskelkontraktion ist (Fawcett et al. 1999; Weisinger und Bellorin-Font 1998). Muskuläre Krämpfe sind vielmehr typisches Symptom einer Hypomagnesiämie (Berkelhammer und Bear 1985). Eine Magnesiumsubstitution ist weit verbreitet zur Therapie und Prophylaxe von Muskelkrämpfen (Garrison et al. 2011; Garrison et al. 2012; Roffe et al. 2002). Allerdings ist die Wirksamkeit von Magnesium bei Muskelkrämpfen umstritten, da randomisiert-kontrollierte Studien zur Wirksamkeit bei krankheitsassoziierten Krämpfen fehlen und bisherige Studienergebnisse keinen klaren Mehrwert zeigten (Garrison et al. 2012). Es wäre somit möglich, dass unsere Patienten umso mehr Magnesium zur Therapie einnahmen, je mehr Beschwerden sie im Bereich Schmerz und Krämpfe hatten. Ob darüber hinaus die Menge des eingenommenen Magnesiums möglicherweise unzureichend ist, lässt sich nur schwer beurteilen, da weder in den Leitlinien bzw. Empfehlungen zur Nebenschilddrüsenunterfunktion (Bollerslev et al. 2015; Brandi et al. 2016) noch in der Leitlinie für Muskelkrämpfe der Deutschen Gesellschaft für Neurologie (Leitlinie Crampi/Muskelkrampf 2017) eine exakte Dosierungsempfehlung zu finden ist. Garrison et al. (2012) 
konnten in ihrer Metaanalyse Dosierungen in der Größenordnung von 200-366 mg täglich finden. Bilezikian et al. (2016) nennen Werte zwischen 320-420 mg pro Tag. Unsere Patienten liegen im unteren Bereich dieser Empfehlungen.

Geht man von einem Zusammenhang der Beschwerden mit der Magnesiumeinnahme aus, so lässt sich das vorgestellte Ergebnis sich am ehesten so interpretieren, dass unsere Patienten bei vermehrten Muskel- und Schmerzbeschwerden mehr Magnesium einnahmen. Die therapeutische Wirksamkeit ist jedoch umstritten. Für die Ursache der Beschwerden bei Hypoparathyreoidimus würde die Magnesiumeinnahme demnach eine untergeordnete Rolle spielen. Analog zu den Einschränkungen bei den Calciummonopräparaten ist dieses Ergebnis jedoch unter Vorbehalt zu interpretieren.

Im Folgenden soll auf den Einfluss der aktiven Vitamin-D-Medikation auf die Beschwerden eingegangen werden. Unsere Auswertung zeigte einen Zusammenhang zwischen der Höhe der Alfacalcidoldosis und den Beschwerden auf der Skala Schmerz und Krämpfe über alle Patienten. Des Weiteren gaben unsere HypoPT 2016-Patienten unter Einnahme von Alfacalcidol signifikant mehr Beschwerden auf der Skala Schmerz und Krämpfe an als Patienten anderer Gruppen, die kein aktives Vitamin-D-Präparat einnahmen.

Zunächst sollte hinterfragt werden, ob sich der Effekt nur abbildete, weil die Mehrheit (43\%) unserer HypoPT 2016-Patienten Alfacalcidol zu sich nahmen. Bei der entsprechenden Analyse der Beschwerden der Skala neurovegetative Symptome, zeigten sich jedoch unter Einnahme von Calcitriol signifikant vermehrte Beschwerden, welches nur 28,6\% unserer Patienten einnahmen (Wilde et al. 2018). Diese Beobachtung steht der Vermutung entgegen, dass sich Alfacalcidol nur aufgrund der Gruppengröße signifikant abhebt. Daher könnten unsere Ergebnisse darauf hinweisen, dass Alfacalcidol die Beschwerden möglicherweise mitbeeinflusst. Der Vergleich der Beschwerden unter aktiver Vitamin-D-Medikation innerhalb der HypoPT 2016Gruppe zeigte jedoch keinen signifikanten Unterschied. Ebenso korrelierte Alfacalcidol zwar über alle Patienten, aber nicht innerhalb der HypoPT 2016-Gruppe mit den Beschwerden. Dies könnte zum einen an der geringen Gesamtgruppengröße ( $n=48)$ liegen. Außerdem ist es möglich, dass alle Patienten wegen ihrer Grunderkrankung schon eine so hohe Beschwerdelast hatten, dass sich ohne Kontrollgruppen kein aktives Vitamin-D-Präparat besonders abhebt. Ein (zusätzlicher) Effekt der Studiengruppenzugehörigkeit kann jedoch nicht ausgeschlossen werden. Unter dieser Annahme kann die Einnahme von Alfacalcidol nur einen Teil der vermehrten Beschwerdelast in unserem Patientenkollektiv erklären. Weitere Pathomechanismen, die zu muskulären Beschwerden und Schmerzen im Rahmen einer Nebenschilddrüsenunterfunktion beitragen, wurden bereits oben diskutiert. Insgesamt können unsere Ergebnisse einen Hinweis geben, dass die Einnahme von Alfacalcidol einen möglichen Faktor darstellen könnte, der sich verstärkend auf die ohnehin schon bestehenden Beschwerden im Bereich Schmerz und Krämpfe bei dieser Krankheit auswirkt.

Nimmt man einen Zusammenhang an, so bestand prinzipiell die Möglichkeit, dass die Patienten wegen ihrer Beschwerden mehr Alfacalcidol einnahmen, oder aber, dass sie wegen der Einnahme von Alfacalcidol mehr Beschwerden hatten. In unserer Studie wurde der Zusammenhang zwischen Alfacalcidol und den Beschwerden erstmals in dieser Form bei Hypoparathyreoidismus beschrieben. Eine aktive Vitamin-D-Therapie bei muskulären Beschwerden und Schmerzen ist keine weit verbreitete Praxis. Daher ist es unwahrscheinlich, dass Alfacalcidol bewusst bei muskulären Schmerzen vermehrt eingenommen wurde. Darüber hinaus wird in 
den Packungsbeilagen von Alfacalcidolpräparaten auf Muskel-, Knochen- und/oder Gelenkschmerzen als Nebenwirkungen des Medikamentes hingewiesen (Alfacalcidol(1APharma®) 2014; Alfacalcidol(Hexal囚) 2014; Alfacalcidol(ratiopharm®) 2009).

Nun stellte sich die Frage, wie Alfacalcidol die Beschwerden hervorrufen könnte: In den Packungsbeilagen von Alfacalcidol werden Schmerzsymptome im Rahmen einer Hyperkalzämie angegeben (Alfacalcidol(1APharma®) 2014; Alfacalcidol(ratiopharm®) 2009; Bondiol® 2013). Ein erhöhtes Serumcalcium als Pathomechanismus für die Beschwerden ist denkbar, und es ist beschrieben, dass eine Hyperkalzämie bei einer unzureichend überwachten Alfacalcidoltherapie auftreten kann (Rubinger et al. 1982; Turner 2017). Auch wenn unsere Patienten mit ihrem Calciumwert zu 87 \% im Zielbereich lagen, ist eine transiente Hyperkalzämie im Zusammenhang mit der Alfacalcidoleinnahme möglich. Mitchell et al. (2012) beobachteten ebenfalls hyper- (und hypo)kalzämische Symptome bei ihren Patienten, obwohl diese zu 86 \% der Zeit mit dem Serumcalcium im Zielbereich lagen. Ähnlich wie für die Calciumpräparate beschrieben könnte eine kurzzeitige Hyperkalzämie nach Einnahme von Alfacalcidol die gefundenen Symptome hervorrufen wegen des Unvermögens, bei Parathormonmangel auf eine rasche Blutcalciumspiegeländerung adäquat zu reagieren. Allerdings kann auch Calcitriol eine Hyperkalzämie als Nebenwirkung verursachen (Decostriol囚 2009; Rocaltrol@ 2016). Neer et al. (1975) fanden in einer kleinen Fallstudie mit Hypoparathyreoidismuspatienten sowohl für Alfacalcidol als auch für Calcitriol innerhalb von $24 \mathrm{~h}$ einen Calciumanstieg im Serum, wobei jedoch keine stündlichen Messungen stattfanden. Eine engmaschige Messung der Calciumwerte im Blut unter Behandlung mit Alfacalcidol vs. Calcitriol im Setting des Hypoparathyreoidismus wäre interessant, um zu überprüfen ob passagere Hyperkalzämien eine Rolle bei den Beschwerden spielen und ob es Unterschiede zwischen den Präparaten in diesem Kontext gibt.

Da eine Hyperkalzämie sowohl bei Calcitiriol als auch Alfacalcidol potentiell möglich ist, müssen auch andere Mechanismen von Alfacalcidol für die Beschwerden in Betracht gezogen werden. Weitere mögliche Wirkweisen von Alfacalcidol auf das muskuloskelettale System, welche die vermehrten Beschwerden unter diesem Präparat erklären könnten, werden vor allem im Rahmen der Therapie von Osteoporose und chronischer Niereninsuffizienz mit ossärer Beteiligung diskutiert (Ringe und Schacht 2004; Schacht et al. 2008; Vervloet 2014). Allerdings bieten beide Erkrankungen einen anderen pathophysiologischen Rahmen als der Hypoparathyreoidismus, sodass die Daten nicht direkt vergleichbar sind, aber vielleicht Hinweise geben können. Es werden mehrfach „pleiotrope Effekte“ von Alfacalcidol bezüglich seiner Wirkung auf den Muskel diskutiert (Ringe und Schacht 2004, 2009; Schacht et al. 2008). Dabei wird nicht nur die Möglichkeit der Bindung von Alfacalcidol an den VDR im Muskel angeführt, sondern es werden auch Effekte auf den Muskelstoffwechsel und die Faserzusammensetzung genannt (Bischoff et al. 2001; Boland 1986; Sorensen et al. 1979). In einer Tierstudie wurde ein negativer Effekt von hohen Alfacalcidoldosen auf Muskelkraft und -masse festgestellt (Testerink et al. 2011). Außerdem scheint Alfacalcidol den FGF23 zu beeinflussen, der v. a. in den Phosphataber auch in den Vitamin-D- und Calciumstoffwechsel involviert ist (Hansen et al. 2012). Abgesehen von Effekten, die möglicherweise über $1,25(\mathrm{OH})_{2} \mathrm{D}_{3}$ als „aktivierte“ Form von Alfacalcidol ausgelöst werden, gibt es auch Hypothesen zu direkten Wirkungen des noch nicht aktivieren Alfacalcidols oder dessen anderen Metaboliten, welche die beobachteten Effekte von in den Zielgeweben erklären könnten (Brandi et al. 2002; Brown et al. 2006; Holick et al. 1977). Dabei sind sowohl VDR-abhängige als auch andere Wege denkbar 
(Panda et al. 2004; Vervloet 2014). Alle diese Mechanismen und alternativen Wirkweisen von Alfacalcidol bieten mögliche Angriffspunkte zur Erklärung der negativen Wirkung dieses Medikamentes auf muskuloskelettale Schmerzen im Rahmen von Hypoparathyreoidismus.

Zusammengefasst geben die Ergebnisse dieser Arbeit einen Hinweis darauf, dass sich die Einnahme von Alfacalcidol in der speziellen Situation des Hypoparathyreoidismus verstärkend auf muskuloskelettale Schmerzen auswirken könnte. Eine Alfacalcidol-induzierte transiente Hyperkalzämie kommt zwar als möglicher Pathomechanismus für die gefunden Beschwerden infrage; alternative direkte Wirkweisen von Alfacalcidol stellen jedoch einen wahrscheinlicheren Erklärungsansatz dar. Insgesamt liefern unsere Daten wichtige Anhaltspunkte für zukünftige Untersuchungen zur optimalen medikamentösen Einstellung bei Nebenschilddrüsenunterfunktion. Weitere Studien werden zeigen, ob sich unsere Ergebnisse in anderen Kollektiven mit Hypoparathyreoidismus bestätigen.

Nach Abschluss und Auswertung unserer Studie ergaben sich Verbesserungsmöglichkeiten für die Durchführung weiterer Studien mit dem neu entwickelten Fragebogen.

Schon Rejnmark et al. (2015) merkten im Zusammenhang mit der Erforschung des Einflusses der rhPTHTherapie auf die Lebensqualität der Patienten an, dass eine Vergleichsgruppe nötig ist, um belastbare Daten zu erhalten. Aus diesem Grund wählten wir für den prospektiven Teil unserer Studie nach vorab festgelegten Ein- und Ausschlusskriterien zwei Vergleichskollektive aus.

Das SD-OP 2016 Kollektiv wurde - wie auch in anderen Studien zum Hypoparathyreoidismus, z. B. von Arlt et al. (2002) - ausgewählt, um mögliche Einflüsse des Schilddrüseneingriffes an sich und der daraus resultierenden Hypothyreose auf die Beschwerden der Patienten als Störfaktoren auszuschließen. Dennoch sind in dieser Studie die meisten Kontrollen des SD-OP 2016 (89,7 \%) aus einem endokrinologischen Schwerpunktzentrum rekrutiert worden, was impliziert, dass ihre Schilddrüsenerkrankung komplexer ist und der Behandlung eines Spezialisten bedarf. Diese Patienten könnten aufgrund der Schwere ihrer Schilddrüsenerkrankung eine generell höhere Beschwerdelast aufweisen. Außerdem wurde in diesem Kollektiv ein höherer Anteil an Lungenerkrankungen festgestellt, welche zusätzlich die Beschwerdelast erhöhen und die Antworten im HPQ 40 beeinflussen könnten. Darüber hinaus wiesen beide Kontrollgruppen einen höheren Anteil an Osteoporose als Vorerkrankung auf als die HypoPT 2016-Patienten.

In unserer Studie wurden erstmalig in dieser Form Patienten mit Hypoparathyreoidismus mit Patienten mit primärem Hyperparathyreoidismus bezüglich ihrer Beschwerden verglichen. Die Hyperparathyreoidismuspatienten waren teilweise operiert, teilweise noch in der Nebenschilddrüsenüberfunktion. Erwartungsgemäß wiesen die beiden pHPT 2016-Subgruppen signifikante Unterschiede hinsichtlich des PTHs und Calciums im Serum auf. Dieses Kollektiv wurde gewählt, um den Einfluss eines normwertigen bzw. erhöhten PTHs auf die Beschwerden zu untersuchen. Diese Möglichkeit des Vergleiches hätten die ausschließlich Schilddrüsenoperierten nicht geboten. Darüber hinaus können die Symptome auch nach Operation eines Hyperparathyreoidismus unterschiedlich lang anhalten (Murray et al. 2013). Für zukünftige Studien wäre jedoch - insbesondere bezüglich der Bedeutung des PTHs für die Beschwerden - eine homogene Gruppe mit nicht operiertem Hyperparathyreoidismus vorzuziehen. 
Bezüglich der prinzipiellen Beantwortung von Fragebögen sind außerdem weitere Faktoren zu berücksichtigen: So sind Effekte wie die „Tendenz zur sozialen Erwünschtheit“ (Kallus 2016, S. 57) oder die „Tendenz zur positiven Selbstdarstellung" (Kallus 2016, S. 57) nicht ausgeschlossen. Gerade bei Fragen zur Sexualität oder Depressivität kann durch solche Tendenzen das Antwortverhalten in Fragebogenstudien beeinflusst werden. Durch die vorab erfolgte Information der Patienten, dass alle Daten pseudonymisiert verarbeitet werden, sowie die Anordnung von heiklen Fragen wie beispielsweise zur Freude an Sexualität am Ende des Bogens, kann dem in gewissem Maße vorgebeugt werden (Mummendey und Grau 2008). Anderen Antworttendenzen wie der "Tendenz zur Mitte" konnte mithilfe der vierstufigen Itemskalierung entgegengewirkt werden, welche "keine neutrale Mittelkategorie“ (Jonkisz et al. 2012, S. 60-61) enthielt.

Abschließend folgt nun eine Beurteilung des neu entwickelten Fragebogens sowie die Abgrenzung zu ähnlichen Vorstudien. In dieser Erstanwendung konnte der HPQ eine Reihe von geforderten Testgütekriterien erfüllen: Im Sinne der Durchführungsobjektivität enthält der HPQ eine einheitliche schriftliche Testinstruktion für den Patienten. Die vierstufige Skala stellt ein geschlossenes Antwortformat dar, und die Auswertung des Fragebogens erfolgte standardisiert, indem jeder Antwort ein vor Studienbeginn definierter Zahlenwert zugeordnet wurde, um das Kriterium der Auswertungsobjektivität zu erfüllen (Kemper et al. 2015). Die Interpretationsobjektivität wird durch vorgegebene Bildung und Auswertung der Skalen mithilfe einer SPSS-Syntax verbessert. Für zukünftige Studien wäre außerdem wäre eine Normierung vorteilhaft.

Von den insgesamt 40 Items des HPQ 40 konnten nach der Hauptkomponentenanalyse 23 Items auf fünf verschiedenen Skalen abgebildet werden. Es wurde auf eine ausreichende Varianzaufklärung (> $50 \%$ ), eine gute Korrelation der Items mit ihrem Faktor (Ladung; >0,5) und ein möglichst hohes Cronbachs $\alpha(>0,70)$ als Maß für die interne Konsistenz geachtet. Die Faktorenladung in diesem Zusammenhang gibt an, „wie gut ein einzelnes Item eine Skala bzw. einen Faktor repräsentiert" (Kemper et al. 2015, S. 208). Cronbachs $\alpha$ ist eine Kenngröße für die Reliabilität eines Testes, „ein hohes a spricht für eine präzise Abbildung der Merkmalsfacette" (Kallus 2016, S. 93). Dennoch sollten die Werte nicht zu extrem sein, um Redundanzen zu vermeiden (Mummendey und Grau 2008). Es werden Werte von 0,7 bis 0,9 empfohlen (Fayers und Machin 2007).

Da in dieser Studie der klinische Aspekt, also die Erforschung von Beschwerden und ihren Zusammenhängen, im Vordergrund stand, wurde bei der Itemselektion auf zusätzliche Parameter wie beispielsweise die Ermittlung der Trennschärfe verzichtet und die Reliabilitätsprüfung auf die Berechnung von Cronbachs $\alpha$ beschränkt. Wollte man in folgenden Anwendungsstudien die Reliabilität des HPQ weitergehend untersuchen, könnte man beispielsweise eine Testwiederholung durchführen, um die Retest-Reliabilität zu bestimmen (Lienert und Raatz 1998).

Die inhaltliche Validität der ausgewählten Items wurde durch Expertenbegutachtung erhöht, was ein gängiges Verfahren bei einer Fragebogenkonstruktion ist (Hartig et al. 2012; Mummendey und Grau 2008). Die qualitative Vorstudie mit Fokusgruppe (die Selbsthilfegruppe) zur Itemidentifizierung trug ebenfalls zur Validität des Bogens bei, da die Einbeziehung der Fragebogenzielgruppe bei der Itemgenerierung zur Verbesserung der Inhaltsvalidität empfohlen wird (Terwee et al. 2007). Unser Vorgehen entspricht dem analytisch-empirischen Ansatz der Testkonstruktion, welcher aufgrund des damit verbundenen Aufwandes jedoch nur selten angewandt wird (Bühner 2011). 
Basierend auf den Ergebnissen der retrospektiven Analyse konnte erwartet werden, dass sich die Themenbereiche Lebensqualität und psychischen Beschwerden wahrscheinlich im neuen Fragebogen darstellen würden. Das Ergebnis der explorativen Faktorenanalyse mit den Skalen ängstliche Depression und Vitalität, welche einen wichtigen Aspekt der Lebensqualität erfasst, bestätigte diese Annahme. Eine solche Analyse kann als struktursuchender Ansatz zur Identifizierung und Validierung verschiedener Fragebogendimensionen dienen (Moosbrugger und Kelava 2012; Moosbrugger und Schermelleh-Engel 2012; Mummendey und Grau 2008) und eignet sich vor allem dann, wenn unklar ist, welche Items zu einem Konstrukt gehören (Kemper et al. 2015).

Der hoch signifikante Unterschied im t-Test für die Skalenwerte ängstliche Depression im Vergleich von bezüglich Depressionen positiv gescreenten zu negativ gescreenten Patienten lieferte einen zusätzlichen, wichtigen Hinweis für die (Konstrukt)Validität dieser Skala.

Ganz anders konnte die im Gruppenvergleich signifikante Skala Schmerz und Krämpfe auf Basis der retrospektiven Analyse zunächst nicht als eigener Themenbereich vermutet werden. Die Skala körperliche Schmerzen im SF-36 war bei unserem retrospektiven Studienkollektiv unauffällig. Dass die Faktorenanalyse die neue prospektive Skala Schmerz und Krämpfe ergab, entsprach unserem Studienziel, möglicherweise neue Beschwerdekomplexe aufzudecken. Die daraus abgeleitete Hypothese, dass Schmerz und muskuläre Beschwerden ein für Hypoparathyreoidismus relevanter Themenbereich sind, sollte zur Validierung des Fragebogens hinsichtlich dieser Skala in Zukunft weiter untersucht werden. Dazu eignet sich eine Paralleltestung des HPQ mit validierten Fragebögen für den entsprechenden Themenbereich und die anschließende Ermittlung und Beurteilung der Konstruktvalidität nicht nur für die Skala Schmerz und Krämpfe, sondern auch für die anderen beiden Skalen. Für die weitere Validierung wird ein von der Konstruktionsstichprobe - also von den prospektiven Patienten unserer Studie - unabhängiges Kollektiv empfohlen, um zu vermeiden, dass die Testgüte überschätzt wird, da die erfolgten Modifikationen zu einer Überanpassung des Fragebogens an die Patientencharakteristika der Stichprobe führen (Kemper et al. 2015).

Nach Durchführung der Studie wurde eine überarbeitete Fragebogenversion erstellt, der HPQ 28 - Fragebogen für Hypoparathyreoidismus (kurz: HPQ 28) (s. Anlage 7). Die komplette Überarbeitung des Fragebogens und Kürzung auf 28 Fragen werden in der Arbeit von cand. med. L. Wilken detailliert beschrieben.

Alle Fragen des HPQ 40 sowie des HPQ 28 sind auf einer DIN A4 Seite abgebildet, und die vorgegebenen Werte von null bis drei erleichtern die Auswertung. Nach Eingabe der Ergebnisse können die Skalen mit einer SPSS-Syntax einfach und schnell ermittelt werden. Es wurde auf ein ansprechendes Design, auf einen unkomplizierten Aufbau im Sinne einer Symptomliste und gerade bei der überarbeiteten Version nochmals auf die Lesbarkeit des Bogens geachtet, um die Bearbeitungszeit möglichst kurz zu halten. Im Hinblick auf Materialkosten und Testaufwand kann somit das Kriterium der Testökonomie als erfüllt bezeichnet werden (Kemper et al. 2015).

Die überarbeitete Fragebogenversion wird für zukünftige Studien zur Verfügung gestellt. Die praktische Relevanz eines möglichst krankheitsspezifischen Fragebogens zur genauen Symptomerfassung ist gerade in der Endokrinologie hoch (Lovas et al. 2010), und potentielle Einsatzbereiche des HPQ sind vielfältig: Erhebungen zur Therapie mit aktivem Vitamin D oder rhPTH sowie das Langzeit-Follow-Up von ambulanten Patienten könnten mit dem HPQ realisiert werden. Für mehr Informationen über die zeitliche Entwicklung von Sympto- 
men nach Schilddrüseneingriffen könnte der Fragebogen direkt postoperativ das erste Mal am Patienten angewandt und die Änderungssensitivität (Responsiveness) der Skalen im Krankheitsverlauf ermittelt werden (Fayers und Machin 2007). Die Nützlichkeit des Fragebogens kann erst nach Abschluss weiterer Studien mit diesem Instrument endgültig beurteilt werden (Moosbrugger und Kelava 2012).

Der Zeitaufwand zur vollständigen Beantwortung des Fragebogens ist relativ gering. Für den hier verwendeten $\mathrm{HPQ} 40$ werden ca. 5 min benötigt, für die nach Überarbeitung gekürzte Version des HPQ 28 sollten es ca. 3 min sein. Die Kürze des Fragebogens ist eine Besonderheit im Vergleich zu dem von Bohrer et al. (2005) in Würzburg entwickelten „Hypoparathyreoidismusbogen“, welcher mit 45 Fragen auf zwei Seiten deutlich länger ist als der überarbeitete HPQ 28 und für den mind. 7 min benötigt werden. Dies mag einer der Gründe sein, weshalb dieser Würzburger Bogen bislang nicht deutschlandweit eingesetzt wird. Lange Bögen mögen für klinische Studien aufschlussreich sein, sind aber nicht immer praxistauglich. Bei zunehmender (subjektiv empfundener) Testlänge sinkt die Bearbeitungsqualität und ab einem gewissen Testumfang ergibt sich kein Reliabilitätsgewinn mehr (Jonkisz et al. 2012). Ein einfacher, kurzer und wenig zeitaufwändiger Bogen hingegen mag regelmäßiger verwendet werden (Alrubaiy et al. 2015). Der HPQ 28 als kurzes, speziell für den Hypoparathyreoidismus entworfenes Messinstrument könnte bei Routineuntersuchungen ohne großen zusätzlichen Aufwand angewandt werden und erfüllt somit das Kriterium der Zumutbarkeit (Bühner 2011).

Ein weiterer grundlegender Unterschied des HPQ zu dem von Bohrer et al. (2005) entwickelten Bogen ist die Methodik bei der Konzipierung: Der „Hypoparathyreoidismusbogen“ ist v. a. auf Literaturrecherche und Expertenmeinung basiert. Diese Form von Inhaltsvalidität bzw. Augenscheinvalidität wird jedoch in ihrer Bedeutung teilweise überschätzt (Kallus 2016; Moosbrugger und Kelava 2012). Prior et al. (2012) fanden bei ihrer Fragebogenkonzipierungsstudie heraus, dass Experten andere Symptome als relevant angaben als die Patienten. Daraus schlussfolgerten sie, dass die Expertensicht auf eine Krankheit sich nicht zwingend mit der Patientenwahrnehmung derselben decken muss. Zwar gab es bei Bohrer et al. (2005) für Patienten die Möglichkeit, Zusatzitems anzugeben, welche im aktuellen Bogen fehlten, diese Angaben wurden jedoch sehr subjektiv interpretiert: Die von 30 \% der Patienten angegeben zusätzlichen Beschwerden wurden als „lediglich von den Patienten umformuliert" (Bohrer et al. 2005, S. 443) und somit bereits im Bogen enthalten angesehen, sodass es zu keiner inhaltlichen Änderung des Fragebogens kam. Dennoch wurde auf Basis dieser Methodik geschlossen, dass der Bogen alle relevanten Symptome beinhaltete. Das Vorgehen in unserer Studie - basierend auf der mehrfachen Befragung von Selbsthilfegruppemitgliedern mit vermutlich sehr ausgeprägter Beschwerdelast - trägt wie oben beschrieben zur Validität unseres Fragbogens bei. Hadker et al. (2014) fanden in ihrer Onlinebefragung von Hypoparathyreoidismuspatienten heraus, dass mit einer zunehmenden Krankheitsschwere häufiger und mehr unterschiedliche Symptome angegeben wurden. Basierend auf der Beobachtung, dass gerade Patienten mit hoher Krankheitsschwere sich Selbsthilfegruppen anschließen (Haack et al. 2017; Sherman et al. 2008), kann vermutet werden, dass der HPQ, welcher auf Daten eines Selbsthilfegruppenkollektivs basiert, mit hoher Wahrscheinlichkeit die meisten für die Patienten bedeutsamen Beschwerden beinhaltet.

Darüber hinaus lassen sich die Beschwerden im Würzburger Bogen lediglich auf Ebene eines sogenannten „Summenscore[s] aus der Gesamtzahl der Symptome“ (Bohrer et al. 2005, S. 442) bzw. eines Belastungs- 
scores auswerten, welche keine differenzierten Rückschlüsse auf einzelne relevante Symptomkomplexe zulassen wie unsere Skalenbildung es erlaubt. Einen weiteren Unterschied unserer Fragebogenstudie zu der von Bohrer et al. (2005) stellten die Vergleichsgruppen dar: Bohrer et al. zogen neben einem Kollektiv von Medizinstudenten eine heterogene Gruppe mit chirurgischen Poliklinikpatienten sowie präoperative Patienten mit (Neben)Schilddrüsenerkrankungen zum Vergleich heran. So konnte nicht beurteilt werden, inwiefern die Ergebnisse des Fragbogens bei den Hypoparathyreoidismuspatienten ggf. dem Einfluss der Schilddrüsenoperation oder einer Hypothyreose geschuldet waren. Unsere Vergleichskollektive wurden wie bereits beschreiben gezielt ausgewählt, um solche Einflussfaktoren zu vermindern. Dennoch zogen Bohrer et al. (2005) die Gruppenunterschiede des Summen- bzw. Belastungsscores im Vergleich zu den drei Kontrollkollektiven als Kriterium der Konstruktvalidität ihres Fragebogens heran. Die gefundenen Unterschiede sollen also die Aussagekraft des Fragebogens stärken, was - aus den genannten Gründen - aber nicht unkritisch zu sehen ist.

Arlt et al. (2002) hingegen hatten in ihrer Studie zwar mit Schilddrüsenoperierten ohne Hypoparathyreoidismus eine ähnliche Vergleichsgruppe wie in unserer Untersuchung, zur Erhebung der Beschwerden ihrer Patienten wurden jedoch mehrere, teilweise sehr lange Fragebögen verwendet. An diesen validierten Fragebögen (z. B. SCL-90-R) wurde sich in der retrospektiven Analyse dieser Arbeit orientiert. Das Problem dieser etablierten Bögen besteht jedoch darin, dass in der speziellen Situation des Hypoparathyreoidismus unklar ist, ob die vorab definierten Skalen die tatsächlichen Beschwerdeprioritäten der Patienten abbilden. Speziell für eine Krankheit entwickelte Bögen sind mit höherer Wahrscheinlichkeit passend und patientensensitiver für die Bereiche, die man zu untersuchen wünscht (Webb et al. 2002). Ein anschauliches Beispiel dafür ist die signifikante Skala Schmerz und Krämpfe dieser Arbeit: Retrospektiv war, wie bereits erwähnt, die Skala körperliche Schmerzen im SF-36 in unserem Kollektiv unauffällig. Die Items der prospektiven Skala Schmerz und Krämpfe generierten sich aus der in der SCL-90-R hochsignifikanten Skala Somatisierung, der Abfrage zusätzlicher Beschwerden und Skalen des hier nicht dargestellten Gießener Beschwerdebogens. Nur durch die Neuanalyse konnten die Items aus den unterschiedlichen Skalen zu einem neuen Symptomkomplex gegliedert werden, welcher im retrospektiven Studienteil nicht als signifikant zu erkennen war. Darüber hinaus wären wichtige Informationen ohne die „Abfrage zusätzlicher Beschwerden“ möglichweise verloren gegangen. Die Tatsache, dass die Skala Schmerz und Krämpfe bei der prospektiven Auswertung im Mittelpunkt stand, demonstriert die Relevanz eines krankheitscharakteristischen Fragebogens. Ein solcher Bogen deckt nicht nur diejenigen Themenbereiche ab, die für die Patienten eines bestimmten Krankheitsbildes bedeutsam sind, sondern ist möglicherweise auch empfindlicher gegenüber zeitlichen Veränderungen (Lovas et al. 2010). Insgesamt erfültt unser Fragebogen viele Punkte der Testgütekriterien der Objektivität und Reliabilität sowie bereits einige Aspekte der Validität. Darüber hinaus ist er ökonomisch und zumutbar und hebt sich in mehreren Punkten vom „Hypoparathyreoidismusbogen“ von Bohrer et al. (2005), aber auch von anderen Studien zur Beschwerdelast bei Hypoparathyreoidismus ab. Daher erscheint unser Fragebogen in Kombination mit dem Dokumentationsbogen geeignet für Einsatz im Praxisalltag oder in Studien mit unterschiedlicher Fragestellung. In seiner Konzipierung und Form ist er als Messinstrument für den Hypoparathyreoidismus neu und einzigartig. 
Zuletzt soll nun ein Ausblick erfolgen bezüglich der weiteren Bearbeitung und Verwendung des neu entwickelten Fragebogens für zukünftige Studien außerhalb dieser Arbeit.

Die beiden Skalen ängstliche Depression und Vitalität werden in der hier beschriebenen Form im zukünftigen, überarbeiteten Fragebogen, dem HPQ 28, enthalten bleiben. Die bereits zu Beginn der Diskussion aufgeführten Studien von Arlt et al. (2002), Hadker et al. (2014), Astor et al. (2016) und Sikjaer et al. (2016) demonstrieren die Relevanz der Bereiche psychische Beschwerden und Lebensqualität nicht nur für den einzelnen Patienten, sondern auch im Hinblick auf weitere prospektive Untersuchungen zur Nebenschilddrüsenunterfunktion (Shoback et al. 2016). Diese Bereiche sollen im HPQ 28 durch die beiden Skalen ängstliche Depression und Vitalität erfasst werden. Die Probleme mit der wechselnden Skalierung bei den Items für Vitalität wurden bei der Überarbeitung berücksichtigt: Die entsprechenden Fragen wurden ans Ende des Bogens gestellt, optisch abgetrennt und mit einem Hinweistext versehen. Die Vitalitätsskala soll auch in der überarbeiteten Fragebogenversion einen wichtigen Aspekt der Lebensqualität erfassen. Ob die erfolgten Änderungen zur besseren Verständlichkeit beitragen, muss in weiteren Studien überprüft werden.

Um die Validität der Skalen Schmerz und Krämpfe, ängstliche Depression und Vitalität weitergehend zu untersuchen, sollten in zukünftigen Erhebungen etablierte Fragebögen parallel angewendet werden. So kann überprüft werden, ob die Skalen tatsächlich das messen, was sie zu messen beanspruchen (Bühner 2011). Dafür würden sich beispielsweise der SF-12 Fragebogen zum Gesundheitszustand (Lebensqualität (Bullinger und Kirchberger 1998)), die Hospital Anxiety and Depression Scale - Deutsche Version (HADS-D; Angst und Depression (Herrmann und Buss 1994)), die Schmerzempfindungsskala SES (Geissner 1996) oder der Pain Disability Index (PDI; Schmerz (Tait et al. 1990)) eignen. Es handelt sich dabei um etablierte, relativ kurze, aber valide Fragebogeninstrumente, die gut auswertbar und auf Skalenebene mit dem HPQ 28 vergleichbar sind. Sie würden sich daher also für eine Validierungsstudie eignen.

Um den HPQ 28 als Standardinstrument im Klinik- und Praxisalltag einzusetzen, ist darüber hinaus eine Normierung sinnvoll, um die Beschwerden des einzelnen Patienten bewerten und mögliche Konsequenzen für die Therapie ableiten zu können. Eine solche Normierung könnte gleichzeitig an der Validierungsstichprobe erfolgen (Kemper et al. 2015). Es wurde außerdem eine englische Übersetzung des HPQ 28 erarbeitet, um inn international an größeren Gruppen testen zu können.

Ferner wurde der Bogen "Dokumentation Hypoparathyreoidismus" optimiert: Patientennummer, Art der Schilddrüsenoperation, Hinweise zur beruflichen Situation und das Calcium-Phosphat-Produkt wurden ergänzt. Die nebenschilddrüsenspezifische Medikation sowie die hypo/hyperkalzämischen Krisen wurden genauer definiert und die Abfrage der Komplikationen und Vorerkrankungen um die Antwortmöglichkeit „unbekannt" erweitert. Neben kleinen inhaltlichen und grammatikalischen Korrekturen wurden außerdem die geforderten Laborparameter an die Empfehlungen der ESE Leitlinien für Hypoparathyreoidismus angepasst. Die überarbeitete Version des Dokumentationsbogens befindet sich im Anhang dieser Arbeit (s. Anlage 8).

Da in dieser Arbeit Hinweise darauf gefunden wurden, dass bestimmte Medikamente die Beschwerden der Patienten negativ beeinflussten, sollte bei zukünftigen Studien zu diesem Thema der Einfluss der bisherigen Standardtherapie mit verschiedenen aktiven Vitamin-D-, Calcium- und ergänzenden Präparaten - neben der aktuell viel diskutierten rhPTH-Medikation - unbedingt gesondert berücksichtig werden. 
Zusammenfassend wurde ein neuer Bogen für die Beschwerden bei Hypoparathyreoidismuspatienten entwickelt, der viele Testgütekriterien erfüllt und bei dessen Anwendung neue Zusammenhänge mit Beschwerdeursachen aufdeckt werden konnten. Die Validität der einzelnen Skalen sollte weitergehend untersucht werden und eine Normierung wäre vorteilhaft. Der HPQ kann zusammen mit dem Dokumentationsbogen als spezielles Hypoparathyreoidismus-Instrument vielfältig zur Erhebung der Beschwerden bei dieser Erkrankung eingesetzt werden. 


\section{Zusammenfassung}

Der Hypoparathyreoidismus (Nebenschilddrüsenunterfunktion) ist eine relativ seltene Hormonstörung, die sich meist im Calcium- und Phosphatstoffwechsel mit niedrigen Calciumwerten bei inadäquat niedrigem Parathomonspiegel manifestiert. Die Patienten leiden unter verschiedenen Symptomen und Komplikationen, deren Hintergründe noch nicht vollends geklärt sind.

Ziel dieser Studie war die Konzipierung und einjährige prospektive Testung eines Fragebogens speziell für Hypoparathyreoidismus an betroffenen Patienten (HypoPT 2016) und zwei Vergleichskollektiven (Schilddrüsenoperierte ohne Hypoparathyreoidismus [= SD-OP 2016] und Patienten mit (operiertem) primären Hyperparathyreoidismus [= pHPT 2016]). Durch den Fragebogen zusammen mit einem Dokumentationsbogen sollten Beschwerdekomplexe und Zusammenhänge mit diesen Komplexen identifiziert werden, um die Hintergründe der Krankheit und der von ihr hervorgerufenen Symptome besser zu verstehen.

Basierend auf retrospektiven Studienergebnissen aus der Befragung einer Selbsthilfegruppe für Hypoparathyreoidismus zu zwei unterschiedlichen Zeitpunkten ( $n=33$ bzw. $n=27)$ mit verschiedenen etablierten Fragebögen (z. B. SF-36 Fragebogen zum Gesundheitszustand), wurde nach bestimmten Kriterien der HPQ 40 Fragebogen für Hypoparathyreoidismus entwickelt. Nach der Anwendung an insgesamt 151 Patienten aus den oben genannten drei Gruppen konnten in einer explorativen Faktorenanalyse fünf Beschwerdeskalen aufgedeckt werden, von denen die Skalen Schmerz und Krämpfe (5 Items, Cronbachs $\alpha=0,809$ ), ängstliche Depression ( 5 Items, $a=0,860$ ) und Vitalität (6 Items, $\alpha=0,885)$ in dieser Arbeit analysiert wurden.

Unsere weiteren prospektiven Untersuchungen führten wir an 49 HypoPT, 39 SD-OP und 35 pHPT 2016Patienten durch, die nach Alter \pm 3 Jahre und Geschlecht gematcht wurden. Signifikante Unterschiede zwischen den untersuchten Studiengruppen zeigten sich erwartungsgemäß bei den Parametern des Calciumund Phosphatstoffwechsels (Serumcalcium [inkl. Norm- und Zielbereich], Serumphosphat, Calcium-PhosphatProdukt und Parathormon [inkl. Normbereich]; für alle: $p<0,001)$. Das HypoPT 2016-Kollektiv war in den Punkten Medikation (inkl. Dosierung) und Komplikationen mit Vorstudien aus der Literatur trotz kleinerer Abweichungen bei der Calcium- und aktiven Vitamin-D-Medikation vergleichbar, und die laborchemische Einstellung war gut.

Der Bereich Lebensqualität der Patienten wurde mit der ursprünglichen formulierten Skala Vitalität noch nicht optimal erfasst ( $p=0,121-0,095)$. Die Skala wird aber aufgrund ihrer Relevanz in überarbeiteter Form im revidierten Bogen, dem HPQ 28 - Fragebogen für Hypoparathyreoidismus, enthalten sein. Ein vermehrtes Auftreten von Depressionen im Screening $(p=0,167)$ oder im Gruppenvergleich für die Skala ängstliche Depression $(p=0,338)$ konnte - anders als in der retrospektiven Analyse - im prospektiven Studienkollektiv nicht festgestellt werden. Ein vermehrtes Vorkommen von Vorerkrankungen (Lungenerkrankungen: $p=0,041$ Osteoporose: $p=0,026$;) in einer bzw. beiden Kontrollgruppen könnte deren Beschwerden beeinflusst haben. Der Symptomkomplex Schmerz und Krämpfe wurde als neues relevantes Themengebiet des Hypoparathyreoidismus identifiziert. Die Beschwerden auf dieser Skala grenzten sich signifikant von Patienten beider Vergleichskollektive ab (SD-OP 2016: $p=0,001$; pHPT 2016: $p=0,003$ ), obwohl das pHPT 2016-Kollektiv bezüglich der Operation der Grunderkrankung und der Laborparameter inhomogen war. Muskuläre Beschwerden und auch Schmerz können möglicherweise über Pathomechanismen, die mit dem Parathormon- 
mangel zusammenhängen, erklärt werden und wurden in bisherigen Untersuchungen an Betroffenen vermutlich nicht ausreichend berücksichtigt. Weitere potentielle Zusammenhänge der analysierten Beschwerden wurden neben dem PTH (Korrelation: $p<0,05)$ mit dem Calcium-Phosphat-Produkt $(p<0,05)$ sowie mit der Höhe der eingenommen Thiaziddosis $(p<0,05)$ gefunden. Hinweise ergaben sich für die Calcium- $(p<0,001)$ und Magnesiumeinnahme $(p<0,05)$ und für Alfacalcidol (Korrelation: $p<0,05$ bzw. Gruppenvergleich: $p=$ 0,002). Mögliche Pathomechanismen könnten Ablagerungen im Muskel, Elektrolytstörungen oder eine transiente Hyperkalzämie bei Medikamenteneinnahme sein. Bei Alfacalcidol wären alternative direkte Wirkeffekte hinsichtlich der muskuloskelettalen Symptome denkbar. Keiner der gefundenen Mechanismen kann allein für die Beschwerden verantwortlich gemacht werden. Wahrscheinlich tragen alle Einflüsse zusammen einen Teil zur Beschwerdelast bei Nebenschilddrüsenunterfunktion bei.

Der HPQ 40 erfüllte bereits eine Reihe von Testgütekriterien, z. B. war das oben erwähnte Cronbachs a als Maß für die Reliabilität > 0,7 für alle hier untersuchten Skalen. Zur Validität des Bogens bei trug eine Expertenbegutachtung und unser analytisch-empirischer Ansatz zur Fragebogenkonstruktion mit Befragung von Selbsthilfegruppenmitgliedern mit vermutlich hoher Beschwerdelast bei. Der HPQ 40 grenzte sich von anderen Fragebogenstudien zur Nebenschilddrüsenunterfunktion ab, sollte jedoch noch in weiteren Anwendungsstudien validiert und normiert werden. Dabei sollte auf gut definierte Kontrollkollektive und den Einfluss der Medikation geachtet werden. Der Fragebogen kann aufgrund seiner Kürze, einfachen Handhabung und geringen Kosten als für den Praxisalltag geeignet bezeichnet werden. Ein Einsatz für vielfältige klinische Fragestellungen ist denkbar. Mithilfe dieses speziellen Fragebogens könnten in Zukunft weitere neue Erkenntnisse über den Hypoparathyreoidismus gewonnen werden. 


\section{$7 \quad$ Anhang}

Tabelle 35: Diäten der drei Patientenkollektive HypoPT 2016, pHPT 2016 und SD-OP 2016 als Übersicht $(n=A n-$ zahl, \% = gültige Prozent des jeweiligen Parameters bzw. seiner Ausprägung nach Studiengruppe (Spaltenhäufigkeit), freie Felder = keine Angabe für jeweilige Subgruppe); p-Wert des Chi-Quadrat- bzw. Fishers exakten Tests

\begin{tabular}{|c|c|c|c|c|c|c|c|c|c|c|}
\hline & & \multicolumn{2}{|c|}{ НуроРТ 2016} & \multicolumn{2}{|c|}{ pHPT 2016} & \multicolumn{2}{|c|}{ SD- OP 2016} & \multicolumn{2}{|c|}{ gesamt } & \multirow[t]{2}{*}{ p-Wert } \\
\hline & & $\mathrm{n}$ & $\%$ & $\mathrm{n}$ & $\%$ & $\mathrm{n}$ & $\%$ & $\mathrm{n}$ & $\%$ & \\
\hline \multirow[t]{7}{*}{ Diät } & Diabeteskost & 1 & 2,1 & 1 & 2,9 & 2 & 5,3 & 4 & 3,3 & 0,808 \\
\hline & $\begin{array}{l}\text { low carb/ } \\
\text { kalorienarm }\end{array}$ & 2 & 4,2 & & & 2 & 5,3 & 4 & 3,3 & \\
\hline & vegetarisch & 2 & 4,2 & & & 1 & 2,6 & 3 & 2,5 & \\
\hline & calciumreich & 2 & 4,2 & & & 1 & 2,6 & 3 & 2,5 & \\
\hline & laktosefrei & 1 & 2,1 & & & 1 & 2,6 & 2 & 1,7 & \\
\hline & sonstige & 2 & 4,2 & 2 & 5,8 & 2 & 5,2 & 6 & 4,8 & \\
\hline & keine Angabe & 38 & 79,2 & 32 & 91,4 & 29 & 76,3 & 99 & 81,8 & \\
\hline
\end{tabular}

Tabelle 36: Laborparameter ( $\mathrm{n}=$ Anzahl; Mittelwerte \pm Standardabweichung) der beiden pHPT 2016-Subgruppen (operiert und nicht operiert) mit jeweiligem Normbereich: Phosphat, Calcium-Phosphat-Produkt, TSH im Serum sowie Calcium und Phosphat im 24-h-Urin; Mann-Whitney-U-Test zum Vergleich der pHPT-Subgruppen untereinander; Bonferroni-Korrektur für die Anzahl der Laborparameter ( $n=7 ; \alpha \leq 0,007$ )

\begin{tabular}{|c|c|c|c|c|}
\hline & & $\begin{array}{l}\text { pHPT } 2016 \\
\text { operiert }\end{array}$ & $\begin{array}{l}\text { pHPT } 2016 \text { nicht ope- } \\
\text { riert }\end{array}$ & p-Wert \\
\hline Serumphosphat (mmol/l) & $n$ & 17 & 16 & \\
\hline Normbereich: 0,8-1,6** & Mittelwert & $0,98 \pm 0,17$ & $0,88 \pm 0,12$ & 0,025 \\
\hline $\begin{array}{l}\text { Calcium-Phosphat- } \\
\text { Produkt }\left(\mathrm{mmol}^{2 / 2} \mathrm{I}^{2}\right)\end{array}$ & $n$ & 17 & 16 & \\
\hline Normbereich: $<4,4$ & Mittelwert & $2,34 \pm 0,37$ & $2,32 \pm 0,33$ & 0,719 \\
\hline TSH (mIU/l) & $\mathrm{n}$ & 18 & 11 & \\
\hline Normbereich: 0,27-4,2 & Mittelwert & $1,54 \pm 0,61$ & $1,30 \pm 0,71$ & 0,323 \\
\hline $\begin{array}{l}\text { Calcium 24-h-Urin } \\
\text { (mmol/d) }\end{array}$ & $\mathrm{n}$ & 4 & 4 & \\
\hline Normbereich: $2,5-7,5$ & Mittelwert & $6,39 \pm 2,59$ & $9,16 \pm 3,48$ & 0,248 \\
\hline $\begin{array}{l}\text { Phosphat 24-h-Urin } \\
\text { (mmol/d) }\end{array}$ & $n$ & 5 & 6 & \\
\hline Normbereich: 19,37-50,5 & Mittelwert & $25,25 \pm 15,32$ & $22,29 \pm 17,30$ & 0,583 \\
\hline
\end{tabular}

**kombinierter Normbereich für beide Praxen, separate Normbereiche: Serumphosphat = 0,8-1,6 (Göttingen) und 0,81-1,45 (Saarbrücken) 
Tabelle 37: Skalen des HPQ 40 (ängstliche Depression, Vitalität, Schmerz und Krämpfe, neurovegetative Symptome, gastrointestinale Symptome) und zugehörige Items; gemeinsame Ergebnis mit cand. med. L. Wilken

\begin{tabular}{|lllll|}
\hline $\begin{array}{l}\text { ängstliche Depres- } \\
\text { sion }\end{array}$ & Vitalität & $\begin{array}{l}\text { Schmerz und } \\
\text { Krämpfe }\end{array}$ & $\begin{array}{l}\text { neurovegetative } \\
\text { Symptome }\end{array}$ & $\begin{array}{l}\text { gastrointestinale } \\
\text { Symptome }\end{array}$ \\
\hline Selbstvorwürfe & energiegeladen & $\begin{array}{l}\text { Kreuz- und Rü- } \\
\text { ckenschmerzen }\end{array}$ & Muskelzittern & $\begin{array}{l}\text { Ubelkeit oder Ma- } \\
\text { genverstimmung }\end{array}$ \\
\hline $\begin{array}{l}\text { innere Anspannung } \\
\text { und Unruhe }\end{array}$ & $\begin{array}{l}\text { körperlich fit und } \\
\text { vital }\end{array}$ & $\begin{array}{l}\text { Gelenk- oder } \\
\text { Gliederschmerzen }\end{array}$ & $\begin{array}{l}\text { Hitzewallungen und } \\
\text { Kälteschauer }\end{array}$ & $\begin{array}{l}\text { Bauchschmerzen } \\
\text { oder Bauchkrämpfe }\end{array}$ \\
\hline $\begin{array}{l}\text { sorgenvolle Gedan- } \\
\text { ken }\end{array}$ & $\begin{array}{l}\text { Freude an Se- } \\
\text { xualität }\end{array}$ & Muskelschmerzen & Schwächegefühl & \\
\hline Schwermut & $\begin{array}{l}\text { ruhig und gelas- } \\
\text { sen }\end{array}$ & $\begin{array}{l}\text { Nacken- oder } \\
\text { Schulterschmer- } \\
\text { zen }\end{array}$ & $\begin{array}{l}\text { Schwindelgefühle } \\
\text { oder das Gefühl in } \\
\text { Ohnmacht zu fallen }\end{array}$ & \\
\hline $\begin{array}{l}\text { Entscheidungs- } \\
\text { schwierigkeiten }\end{array}$ & glücklich & Muskelkrämpfe & Durchfall & \\
\hline & gesund fühlen & & & \\
\hline
\end{tabular}

Tabelle 38: Skalenwerte (Mittelwerte \pm Standardabweichung) und zugehörige $p$-Werte aus der Analyse des HPQ 40 für die Skala Schmerz und Krämpfe von total thyreoidektomierten („,totale TE“) und anders operierten (,,andere OP") HypoPT bzw. SD-OP 2016-Patienten; Vergleiche untereinander mit dem Tukey-Test; signifikante Werte dick hervorgehoben

\begin{tabular}{|c|c|c|c|c|c|c|c|c|}
\hline \multicolumn{9}{|c|}{ Skala Schmerz und Krämpfe } \\
\hline & \multicolumn{2}{|c|}{$\begin{array}{l}\text { totale TE } \\
\text { HypoPT } 2016\end{array}$} & \multicolumn{2}{|c|}{$\begin{array}{l}\text { andere OP } \\
\text { HypoPT } 2016\end{array}$} & \multicolumn{2}{|c|}{$\begin{array}{l}\text { totale TE } \\
\text { SD-OP } 2016\end{array}$} & \multirow{2}{*}{$\begin{array}{l}\text { andere OP } \\
\text { SD-OP } 2016 \\
\text { Skalen-wert } \\
(\mathrm{n}=30)\end{array}$} & \multirow{2}{*}{$\begin{array}{l}\text { gesamt } \\
\text { p-Wert } \\
\text { (ANOVA) }\end{array}$} \\
\hline & $\begin{array}{l}\text { Skalen- } \\
\text { wert } \\
(n=24)\end{array}$ & $\begin{array}{l}\text { p-Wert } \\
\text { (Tukey) }\end{array}$ & $\begin{array}{l}\text { Skalen- } \\
\text { wert } \\
(n=25)\end{array}$ & $\begin{array}{l}\text { p-Wert } \\
\text { (Tukey) }\end{array}$ & $\begin{array}{l}\text { Skalen- } \\
\text { wert }(n=9)\end{array}$ & $\begin{array}{l}\text { p-Wert } \\
\text { (Tukey) }\end{array}$ & & \\
\hline & $\begin{array}{l}1,23 \pm \\
0,73\end{array}$ & & $\begin{array}{l}1,29 \pm \\
0,73\end{array}$ & & $\begin{array}{l}0,71 \pm \\
0,48\end{array}$ & & $0,83 \pm 0,56$ & 0,016 \\
\hline $\begin{array}{l}\text { andere OP } \\
\text { НypoPT } 2016\end{array}$ & & 0,988 & & & & & & \\
\hline $\begin{array}{l}\text { totale TE SD- } \\
\text { OP } 2016\end{array}$ & & 0,195 & & 0,118 & & & & \\
\hline $\begin{array}{l}\text { andere OP } \\
\text { SD-OP } 2016\end{array}$ & & 0,125 & & 0,054 & & 0,968 & & \\
\hline
\end{tabular}

Tabelle 39: Analyse der Operationsart innerhalb des HypoPT 2016-Kollektivs: Skalenwerte (Mittelwerte \pm Standardabweichung) und zugehörige p-Werte für die Skala Schmerz und Krämpfe von Patienten mit unterschiedlicher Thyreoidektomie (TE); Vergleiche untereinander mit dem Tukey-Test

\begin{tabular}{|c|c|c|c|c|c|c|}
\hline \multicolumn{7}{|c|}{ Skala Schmerz und Krämpfe } \\
\hline & \multicolumn{2}{|c|}{$\begin{array}{l}\text { totale TE } \\
\text { HypoPT } 2016\end{array}$} & \multicolumn{2}{|c|}{$\begin{array}{l}\text { subtotale TE } \\
\text { HypoPT } 2016\end{array}$} & \multirow{2}{*}{$\begin{array}{l}\text { nicht näher klassiff- } \\
\text { ziert HypoPT } 2016 \\
\text { Skalenwert (n=20) }\end{array}$} & \multirow{2}{*}{$\begin{array}{l}\text { Gesamt } \\
\text { p-Wert } \\
\text { (ANOVA) }\end{array}$} \\
\hline & $\begin{array}{l}\text { Skalen- } \\
\text { wert }(n=24)\end{array}$ & $\begin{array}{l}\text { p-Wert } \\
\text { (Tukey) }\end{array}$ & $\begin{array}{l}\text { Skalen- } \\
\text { wert }(n=3)\end{array}$ & $\begin{array}{l}\text { p-Wert } \\
\text { (Tukey) }\end{array}$ & & \\
\hline & $1,23 \pm 0,73$ & & $1,87 \pm 0,70$ & & $1,20 \pm 0,69$ & 0,313 \\
\hline $\begin{array}{l}\text { subtotale TE HypoPT } \\
2016\end{array}$ & & 0,314 & & & & \\
\hline $\begin{array}{l}\text { nicht näher klassifiziert } \\
\text { HypoPT } 2016\end{array}$ & & 0,991 & & 0,293 & & \\
\hline
\end{tabular}


Tabelle 40: Analyse der Operationsart innerhalb des SD-OP 2016-Kollektivs: Skalenwerte (Mittelwerte \pm Standardabweichung) und zugehörige p-Werte für die Skala Schmerz und Krämpfe von Patienten mit unterschiedlicher Thyreoidektomie (TE); Vergleiche untereinander mit dem Tukey-Test

\begin{tabular}{|c|c|c|c|c|c|c|c|c|}
\hline \multicolumn{9}{|c|}{ Skala Schmerz und Krämpfe } \\
\hline & \multicolumn{2}{|c|}{$\begin{array}{l}\text { totale TE } \\
\text { SD-OP } 2016\end{array}$} & \multicolumn{2}{|c|}{$\begin{array}{l}\text { hemi TE } \\
\text { SD-OP } 2016\end{array}$} & \multicolumn{2}{|c|}{$\begin{array}{l}\text { subtotale TE } \\
\text { SD-OP } 2016\end{array}$} & \multirow{2}{*}{$\begin{array}{l}\text { nicht näher } \\
\text { klassifiziert } \\
\text { SD-OP } 2016 \\
\text { Skalen-wert } \\
\text { (n=20) }\end{array}$} & \multirow{2}{*}{$\begin{array}{l}\text { gesamt } \\
\text { p-Wert } \\
\text { (ANOVA) }\end{array}$} \\
\hline & $\begin{array}{l}\text { Skalen- } \\
\text { wert } \\
(n=9)\end{array}$ & $\begin{array}{l}\text { p-Wert } \\
\text { (Tukey) }\end{array}$ & $\begin{array}{l}\text { Skalen- } \\
\text { wert } \\
(n=7)\end{array}$ & $\begin{array}{l}\text { p-Wert } \\
\text { (Tukey) }\end{array}$ & $\begin{array}{l}\text { Skalen- } \\
\text { wert } \\
(n=3)\end{array}$ & $\begin{array}{l}\text { p-Wert } \\
\text { (Tukey) }\end{array}$ & & \\
\hline & $\begin{array}{l}0,71 \pm \\
0,48\end{array}$ & & $\begin{array}{l}0,63 \pm \\
0,29\end{array}$ & & $\begin{array}{l}0,63 \pm \\
0,15\end{array}$ & & $0,92 \pm 0,65$ & 0,540 \\
\hline $\begin{array}{l}\text { hemi TE SD-OP } \\
2016\end{array}$ & & 0,991 & & & & & & \\
\hline $\begin{array}{l}\text { subtotale TE SD- } \\
\text { OP } 2016\end{array}$ & & 0,997 & & 1 & & & & \\
\hline $\begin{array}{l}\text { nicht näher klassi- } \\
\text { fiziert SD-OP } 2016\end{array}$ & & 0,773 & & 1 & & 0,829 & & \\
\hline
\end{tabular}

Tabelle 41: Anteil der Laborwerte (Calcium [korr.], Phosphat im Serum und Urin) im Normbereich (= NB) in gültigen Prozenten (\%; auf Zeile bezogen) sowie dazugehörige Anzahl ( $n$; in Klammern) und Abweichungen vom Normbereich für die (nicht) operierten pHPT 2016-Subgruppen; Chi-Quadrat- bzw. Fishers exakter Test zum Gruppenvergleich; Bonferroni-Korrektur für Anzahl der angewandten Tests ( $n=5 ; \alpha \leq 0,01)$

\begin{tabular}{|c|c|c|c|c|c|c|}
\hline \multicolumn{7}{|l|}{ Anteil in \% (n); Normbereich (= NB) } \\
\hline & \multicolumn{3}{|c|}{ Calcium (korr.) Serum } & \multicolumn{3}{|c|}{ Phosphat Serum } \\
\hline & im NB & über NB & $p$-Wert & im NB & unter NB & p-Wert \\
\hline pHPT 2016 operiert & $100(16)$ & & & $88,2(15)$ & $11,8(2)$ & \\
\hline pHPT 2016 nicht operiert & $81,3(13)$ & $18,8(3)$ & & $81,3(13)$ & $18,8(3)$ & \\
\hline \multirow[t]{3}{*}{ gesamt } & $90,6(29)$ & $9,4(3)$ & 0,226 & $84,8(28)$ & $15,2(5)$ & 0,656 \\
\hline & \multicolumn{3}{|c|}{ Calcium 24-h-Urin } & \multicolumn{3}{|c|}{ Phosphat 24-h-Urin } \\
\hline & im NB & über NB & $p$-Wert & im NB & unter NB & $\mathrm{p}$-Wert \\
\hline pHPT 2016 operiert & $50(2)$ & $50,0(2)$ & & $80,0(4)$ & $20,0(1)$ & \\
\hline pHPT 2016 nicht operiert & $25,0(1)$ & $75,0(2)$ & & $66,7(4)$ & $33,3(2)$ & \\
\hline gesamt & $37,5(3)$ & $62,5(5)$ & 1 & 72,7 (8) & $27,3(3)$ & 1 \\
\hline
\end{tabular}


Anlage 1: Symptom-Checkliste SCL-90-R

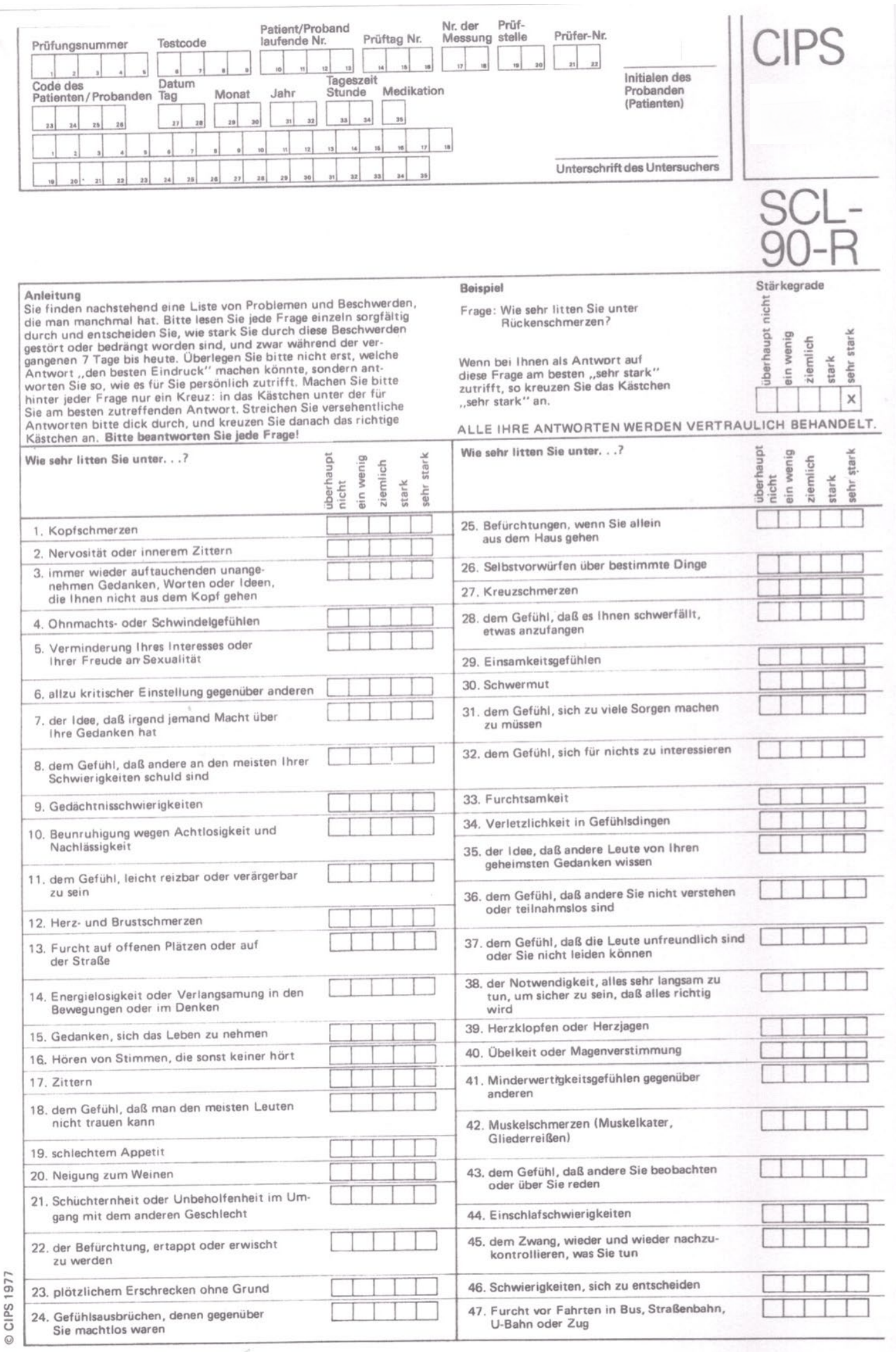




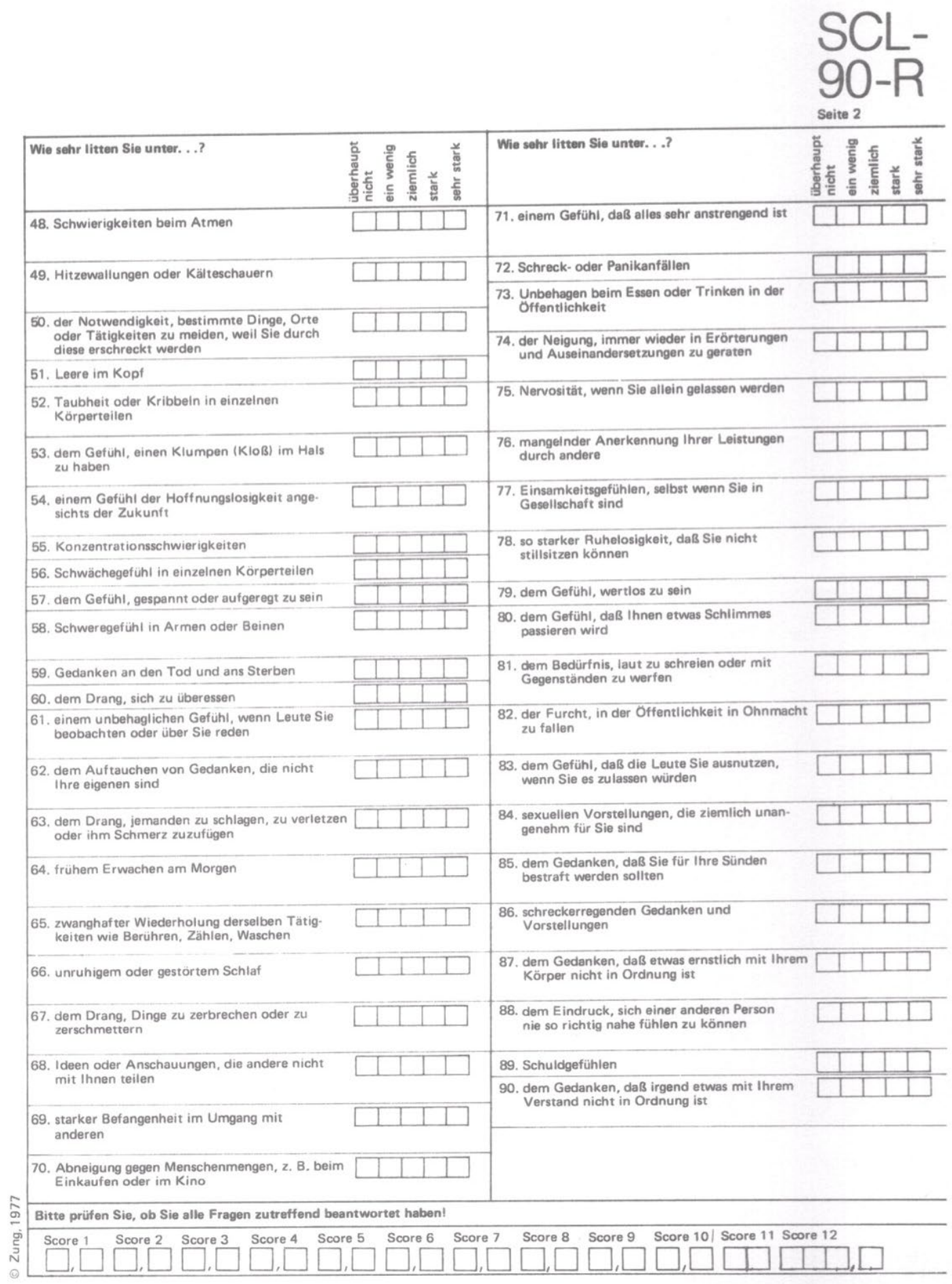




\section{Fragebogen zum allgemeinen Gesundheitszustand SF-36}

In diesem Fragebogen geht es um die Beurteilung Ihres Gesundheitszustandes. Der Bogen ermöglicht es, im Zeitverlauf nachzuvollzichen, wie Sie sich fühlen und im Alltag zurecht kommen. Bitte beantworten Sie jede Frage indem Sie bei den Antwortmöglichkeiten dic Zahl ankreuzen, die am besten auf Sic zutrifft.

\begin{tabular}{|c|c|c|c|c|c|}
\hline & $\begin{array}{c}\text { Ausge- } \\
\text { zeichnet }\end{array}$ & Schr gut & Gut & Weniger gut & Schlecht \\
\hline $\begin{array}{c}\text { 1.Wie würden Sie Ihren Gesundheitszu- } \\
\text { stand im Allgemeinen beschreiben? }\end{array}$ & 1 & 2 & 3 & 4 & 5 \\
\hline
\end{tabular}

\begin{tabular}{|c|c|c|c|c|c|}
\hline & $\begin{array}{l}\text { Derzeit } \\
\text { viel } \\
\text { besser }\end{array}$ & $\begin{array}{l}\text { Derzeit } \\
\text { etwas } \\
\text { besser }\end{array}$ & $\begin{array}{l}\text { Etwa wic } \\
\text { vor } \\
\text { Einem Jahr }\end{array}$ & $\begin{array}{l}\text { Derzeit } \\
\text { etwas } \\
\text { schlechter }\end{array}$ & $\begin{array}{l}\text { Derzeit } \\
\text { viel } \\
\text { schlechter }\end{array}$ \\
\hline $\begin{array}{c}\text { 2. Im Vergleich zum vergangenen } \\
\text { Jahr, wie würden Sie Ihren } \\
\text { derzeitigen Gesundheitszustand } \\
\text { beschreiben? }\end{array}$ & 1 & 2 & 3 & 4 & 5 \\
\hline
\end{tabular}

3. Im Folgenden sind einige Tätigkeiten beschrieben, dic Sic vielleicht an einem normalen Tag ausüben. Sind Sie durch Ihren derzeitigen Gesundheitszustand in diesen Tätigkeiten eingeschränkt? Wenn ja, wie stark?

\begin{tabular}{|l|c|c|c|}
\hline & $\begin{array}{l}\text { Ja, stark } \\
\text { eingeschränkt }\end{array}$ & $\begin{array}{l}\text { Ja, etwas } \\
\text { eingeschränkt }\end{array}$ & $\begin{array}{l}\text { Nein, überhaupt } \\
\text { nicht } \\
\text { eingeschränkt }\end{array}$ \\
\hline $\begin{array}{l}\text { 3a) anstrengende Tätigkeiten, z.B. schnell } \\
\text { laufen, schwere Gegenstände heben, } \\
\text { anstrengenden Sport treiben }\end{array}$ & 1 & 2 & 3 \\
\hline $\begin{array}{l}\text { 3b) mittelschwere Tätigkeiten, z.B. einen } \\
\text { Tisch verschicben, staubsaugen, Kegeln, } \\
\text { Golf spielen }\end{array}$ & 1 & 2 & 3 \\
\hline 3c) Einkaufstasche heben oder tragen & 1 & 2 & 3 \\
\hline 3d) mehrere Treppenabsätze steigen & 1 & 2 & 3 \\
\hline 3e) einen Treppenabsatz steigen & 1 & 2 & 3 \\
\hline 3f) sich beugen, knien, bücken & 1 & 2 & 3 \\
\hline 3g) mehr als einen Kilometer zu Fuß gehen & 1 & 2 & 3 \\
\hline 3h) mehrere Straßenkreuzungen weit zu & 1 & 2 & 3 \\
\hline Fuß gehen & 1 & 2 & 3 \\
\hline 3i) eine Straßenkreuzung weit zu Fuß gehen & 1 & 2 & 3 \\
\hline 3j) sich waschen und anzichen & & & \\
\hline
\end{tabular}


4. Hatten Sie in den vergangenen 4 Wochen auf Grund Ihrer körperlichen Gesundheit irgendwelche Schwierigkeiten bei der Arbeit oder anderen alltäglichen Tätigkeiten im Beruf bzw. zu llause?

\begin{tabular}{|l|c|c|}
\hline & Ja & Nein \\
\hline 4a) Ich konnte nicht so lange wie üblich tätig sein & 1 & 2 \\
\hline 4b) Ich habe weniger geschafft als ich wollte & 1 & 2 \\
\hline 4 c) Ich konnte nur bestimmte Dinge tun & 1 & 2 \\
\hline 4 d) Ich hatte Schwierigkeiten bei der Ausführung & 1 & 2 \\
\hline
\end{tabular}

5. Hatten Sie in den vergangenen 4 Wochen auf Grund seelischer Probleme irgendwelche Schwierigkeiten bei der Arbeit oder anderen alltäglichen Tätigkeiten im Beruf bzw. zu llause (z. B. weil Sie sich niedergeschlagen oder ängstlich gefühlt haben)?

\begin{tabular}{|l|c|c|}
\hline & Ja & Nein \\
\hline 5a) Ich konnte nicht so lange wie üblich tätig sein & $\mathrm{l}$ & 2 \\
\hline 5b) Ich habe weniger geschafft als ich wollte & 1 & 2 \\
\hline 5c) Ich konnte nicht so sorgfältig wic üblich arbeiten & $\mathrm{I}$ & 2 \\
\hline
\end{tabular}

\begin{tabular}{|l|c|c|c|c|c|}
\hline & $\begin{array}{c}\text { Überhaupt } \\
\text { nicht }\end{array}$ & Etwas & Mäßig & Ziemlich & Sehr \\
\hline $\begin{array}{l}\text { 6. Wie sehr haben körperliche Gesundheit oder } \\
\text { seelische Probleme in den letzten 4 Wochen } \\
\text { Ihre normalen Kontakte zu Freunden, } \\
\begin{array}{l}\text { Familienangehörigen, Nachbarn, oder zum } \\
\text { Bekanntenkreis beeinträchtigt? }\end{array}\end{array}$ & 1 & 2 & 3 & 4 & 5 \\
\hline
\end{tabular}

\begin{tabular}{|l|l|l|c|c|c|c|}
\hline & $\begin{array}{l}\text { Keine } \\
\text { Schmerzen }\end{array}$ & $\begin{array}{l}\text { Sehr } \\
\text { leicht }\end{array}$ & Leicht & Mäßig & stark & $\begin{array}{l}\text { Sehr } \\
\text { stark }\end{array}$ \\
\hline $\begin{array}{l}\text { 7. Wie stark waren Ihre Schmerzen in } \\
\text { den letzten 4 Wochen? }\end{array}$ & 1 & 2 & 3 & 4 & 5 & 6 \\
\hline
\end{tabular}

\begin{tabular}{|l|c|c|c|c|c|}
\hline & $\begin{array}{l}\text { Überhaupt } \\
\text { nicht }\end{array}$ & $\begin{array}{l}\text { Ein } \\
\text { bisschen }\end{array}$ & Mäßig & Ziemlich & Schr \\
\hline $\begin{array}{l}\text { 8. Inwieweit haben die Schmerzen Sie in } \\
\text { den vergangenen 4 Wochen bei der } \\
\begin{array}{l}\text { Ausübung Ihrer Alltagstätigkeiten im } \\
\text { Beruf und zu Hause behindert? }\end{array}\end{array}$ & 1 & 2 & 3 & 4 & 5 \\
\hline
\end{tabular}


9. In diesen Fragen geht es darum, wie Sic sich fühlen und wie es Ihnen in den vergangenen 4 Wochen ergangen ist (Bitte krewzen Sic in jeder Zeile dic Zahl an, dic am ehesten Ihrem Belinden entspricht). Wie oft waren Sie in der letzten Woche....

\begin{tabular}{|c|c|c|c|c|c|c|}
\hline & Imnier & Meistens & $\begin{array}{l}\text { Ziemlich } \\
\text { oft }\end{array}$ & Manchmal & Selten & Nie \\
\hline 9a) ... voller Schwung? & 1 & 2 & 3 & 4 & 5 & 6 \\
\hline 9b) ... sehr nervös? & 1 & 2 & 3 & 4 & 5 & 6 \\
\hline $\begin{array}{l}\text { 9c) ... so niedergeschlagen, dass } \\
\text { sie nichts autheitern konnte? }\end{array}$ & 1 & 2 & 3 & 4 & 5 & 6 \\
\hline 9d) ... rulig und gelassen & 1 & 2 & 3 & 4 & 5 & 6 \\
\hline $9 \mathrm{c})$... entmutigt und traurig? & 1 & 2 & 3 & 4 & 5 & 6 \\
\hline 9f) ... voller Energie? & 1 & 2 & 3 & 4 & 5 & 6 \\
\hline $9 \mathrm{~g}) \ldots$ erschöpft? & 1 & 2 & 3 & 4 & 5 & 6 \\
\hline 9h) ... glücklich? & 1 & 2 & 3 & 4 & 5 & 6 \\
\hline 9i) ... müde? & 1 & 2 & 3 & 4 & 5 & 6 \\
\hline
\end{tabular}

\begin{tabular}{|l|c|c|c|c|c|}
\hline & Immer & Meistens & Manchmal & Selten & Nic \\
\hline $\begin{array}{l}\text { 10. Wie häufig haben körperliche } \\
\text { Gesundheit oder seclische Probleme } \\
\text { in den vergangenen 4 Wochen Kontakte } \\
\text { zu anderen Menschen }\end{array}$ & 1 & 2 & 3 & 4 & 5 \\
(Besuche bei Freunden, Verwandten \\
usw.) beeinträchtigt?
\end{tabular}

11. Inwieweit trifft jede der folgenden Aussagen auf Sie zu?

\begin{tabular}{|l|c|c|c|l|l|}
\hline & $\begin{array}{l}\text { Trift } \\
\text { ganz } \\
\text { zu }\end{array}$ & $\begin{array}{l}\text { Triff } \\
\text { weitgehend } \\
\text { zu }\end{array}$ & $\begin{array}{l}\text { Weiß } \\
\text { nicht }\end{array}$ & $\begin{array}{l}\text { Trifft } \\
\text { weitgehend } \\
\text { nicht zu }\end{array}$ & $\begin{array}{l}\text { Trift } \\
\text { überhaupt } \\
\text { nicht zu }\end{array}$ \\
\hline $\begin{array}{l}\text { 11a) Mich macht Sie leichter etwas krank } \\
\text { als Andere. }\end{array}$ & 1 & 2 & 3 & 4 & 5 \\
\hline $\begin{array}{c}\text { 11b) Ich bin genauso gesund wie alle } \\
\text { Anderen, die ich kenne. }\end{array}$ & 1 & 2 & 3 & 4 & 5 \\
\hline $\begin{array}{c}\text { 11c) Ich erwarte, dass meine Gesundheit } \\
\text { nachlässt. }\end{array}$ & 1 & 2 & 3 & 4 & 5 \\
\hline $\begin{array}{c}\text { 11d) Ich erfreue mich ausgezeichneter } \\
\text { Gesundheit. }\end{array}$ & 1 & 2 & 3 & 4 & 5 \\
\hline
\end{tabular}


Anlage 3: Fragebogen des MVZ endokrinologikum Göttingen

\section{Ärztliche Fragen vor der Untersuchung \\ Mit welchen Beschwerden kommen Sie zu uns?}

(alle Ihre Angaben unterliegen der ärztlichen Schweigepflicht)

Größe: Gewicht: Alter:

Beantworten Sie bitte die folgenden Fragen durch Ankreuzen mit "Ja" oder "Nein" bezeichneten Kästchen.

Haben Sie zur Zeit:

Kopf- oder Gesichtsschmerzen

Nackenschmerzen

Sehstörungen, Doppelbilder

Hörstörungen, Ohrensausen

Riech- oder Geschmacksstörungen

Schwindelgefühl

starken Haarausfal

Atemnot

Plötzliches Herzjagen

Herzstolpern

Appetitlosigkeit

Gewichtsabnahme

Leibschmerzen

Durchfall

Verstopfung

Nächtliches Wasserlassen

Wenn ja, wie oft

Rückenschmerzen

Ischiasschmerzen

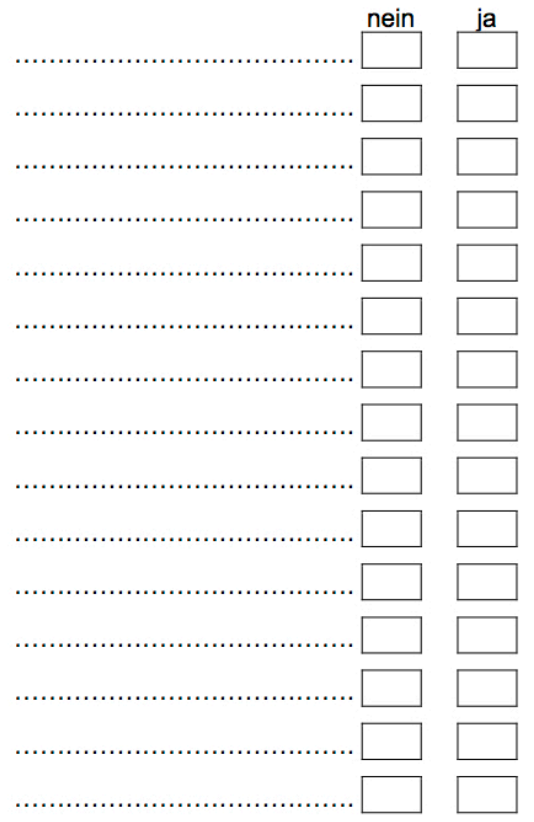

Kribbeln, Ameisenlaufen, Taubheitsgefühl in Armen, Beinen oder im Gesicht

Schwellungen (Gesicht, Arme, Beine)

Venenentzündungen

Häufige blaue Flecke

Langes Bluten nach Verletzungen

Drüsenschwellungen

Schlafstörungen

Leichte Erschöpfbarkeit

Konzentrations- und Gedächtnisstörungen

Vermehrtes Schwitzen

Vermehrter Durst

Wieviel Liter trinken Sie pro Tag:
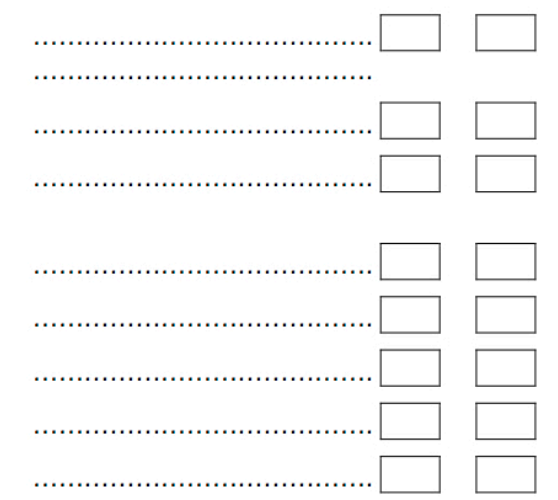

Fühlten Sie sich im letzten Monat häufig niedergeschlagen,

traurig, bedrückt oder hoffnungslos?

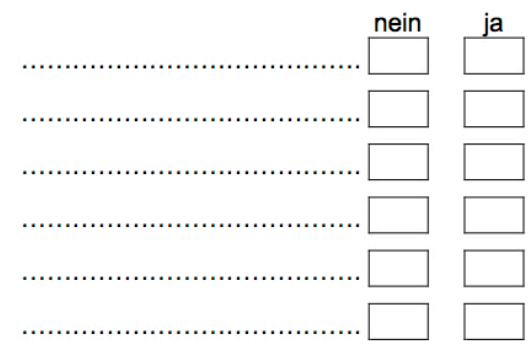

Hatten Sie im lezten Monat deutlich weniger Lust und

Freude an Dingen, die Sie sonst gern tun? 
Genußmittel (bitte genau angeben)

1. Alkoholische Getränke (z. B. Bier, Wein, Sch

Was trinken Sie und wieviel pro Tag?

2. Rauchen (z. B. Zigaretten, Zigarren, Pfeife)

Was rauchen sie und wieviel pro Tag?

3. Andere Genußmittel (z. B. Kaffee, Tee)

Medikamente (bitte genau angeben)

Nehmen Sie regelmäßig Medikamente ein?

Welche?

Gelegentliche Einnahme?

Welche?

Sind Sie überempfindlich gegen bestimmte

Speisen, Medikamente oder anderes?

(bitte ankreuzen)

Haben Sie früher einmal eine der folgenden Krankheiten gehabt

Gelbsucht (Hepatitis)

Hirnhautentzündung

Kinderlähmung

Geschlechtskrankheit

Tuberkulose

Andere ansteckende Krankheiten

Gelenkkrankheiten, Rheuma

Nieren- und Blasenkrankheiten

Nierensteine

Herzerkrankungen

Bluthochdruck festgestellt

seit wann

Lungenerkrankungen

Magenerkrankungen

Lebererkrankungen
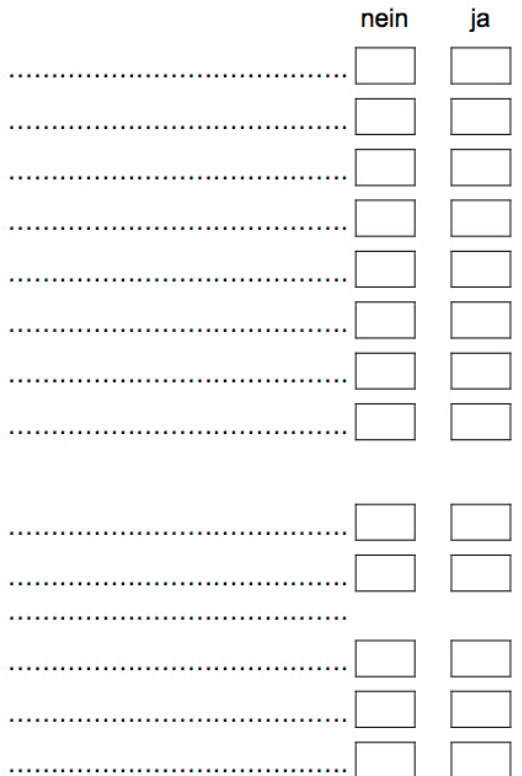
Gallenblasenerkrankungen

Bauchspeicheldrüsenerkrankungen

Darmerkrankungen

Zuckerkrankheit festgestellt

Schilddrüsenerkrankungen

Hormonstörungen

Bestrahlungen

Wenn ja, wann?

Unfallverletzungen

Gehirnerschütterung, Schädelbruch

Operationen

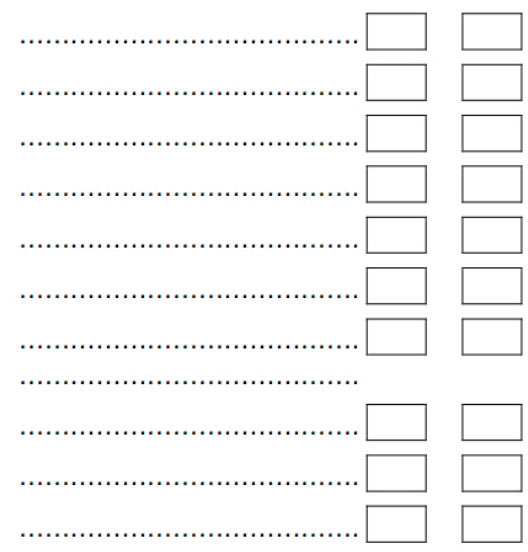

$1 .:$

2.

3.

Haben Sie eine Pflegestufe?

wenn ja, welche

Haben Sie eine Pflegestufe beantragt?

Sind Sie schwerbehindert und haben einen Schwerbehindertenausweis? .

Welchen Beruf üben Sie augenblicklich aus?

Für Frauen

(Zutreffendes bitte ankreuzen)

Erste Monatsblutung mit Jahren

Letzte Monatsblutung am (Datum/Jahr)

Haben Sie Regelstörungen?

Hatten Sie Geburten?

Wieviel und in welchem Jahr?

Wie lange haben Sie insgesamt gestillt?

(in Monaten)

Nehmen Sie z. Zt. Eine Antibabypille?

Wenn ja, wie lange?

Wurde Gebärmutter entfernt?

Wurden Eierstöcke entfernt?

Hormontherapie wegen Wechselbeschwerden? 


\section{Familienvorgeschichte}

(Eltern, Großeltern, Geschwister der Eltern, eigene Geschwister, eigene Kinder, nicht Sie selbst) Hat oder hatte jemand in Ihrer Familie eine der folgenden Krankheiten:

nein ja wer?

Zuckerkrankheit

Hoher Blutdruck

Herzinfarkt

Schlaganfall

Asthma

Krebs

Fettleibigkeit

Rundrücken oder Osteoporose

Knochenbrüche

Anlage 4: „Abfrage zusätzlicher Beschwerden“; gemeinsames Ergebnis mit cand. med. L. Wilken

\section{Abfrage zusätzlicher Beschwerden, die nicht (ausreichend) durch die Standardfragebögen erfasst wurden}

Litten Sie in den letzten vier Wochen unter einer der unten genannten Beschwerden?

Wenn ja, kreuzen sie bitte an wie stark $(1=$ extrem schwach; $2=$ schwach; $3=$ mittelstark; $4=$ sehr stark).

Wenn nein, bitte $0=$ überhaupt nicht ankreuzen.

In die beiden freien Felder dürfen Sie Beschwerden eintragen, unter den Sie in den letzten vier Wochen litten, die aber weder in den vorherigen Bögen noch in der jetzigen Abfrage ausreichend berücksichtigt wurden.

Wenn Sie keine weiteren Beschwerden hatten, bitte freilassen.

\begin{tabular}{|l|l|l|l|l|l|}
\hline Wie sehr litten sie unter...? & $\begin{array}{l}0= \\
\text { überhaupt } \\
\text { nicht }\end{array}$ & $\begin{array}{l}1= \\
\text { Extrem } \\
\text { schwach }\end{array}$ & $\begin{array}{l}2= \\
\text { schwach }\end{array}$ & $\begin{array}{l}3= \\
\text { mittel- } \\
\text { stark }\end{array}$ & $\begin{array}{l}4= \\
\text { sehr } \\
\text { stark }\end{array}$ \\
\hline 1. Muskelzittern & & & & & \\
\hline 2. Muskelschmerzen & & & & & \\
\hline 3. Muskelkrämpfe & & & & & \\
\hline 4. Muskelschwäche & & & & & \\
\hline $\begin{array}{l}\text { 5. Kribbeln (an Armen/ Beinen/ } \\
\text { Händen/Füßen / Gesicht) }\end{array}$ & & & & & \\
\hline 6. Trockene Haut & & & & & \\
\hline 7. Haarausfall & & & & & \\
\hline $\begin{array}{l}\text { 8. Funktionseinschränkung durch } \\
\text { Krankheit generell }\end{array}$ & & & & & \\
\hline $\begin{array}{l}\text { 9. Funktionseinschränkung im Alltag } \\
\text { / Beruf }\end{array}$ & & & & & \\
\hline $\begin{array}{l}\text { 10. Funktionseinschränkung im } \\
\text { Privatleben }\end{array}$ & & & & & \\
\hline 11. & & & & & \\
\hline 12. & & & & & \\
\hline
\end{tabular}


Anlage 5: HPQ 40 - Fragebogen für Hypoparathyreoidismus; gemeinsames Ergebnis mit cand. med. L. Wilken

\section{HPQ 40 - Fragebogen für Hypoparathyreoidismus}

Name/Nr.:

Dieser Fragbogen enthält verschieden Fragen zu Symptomen und Beschwerden, die im Rahmen einer Nebenschilddrüsenunterfunktion auftreten können.

Bitte überlegen Sie bei jeder Frage, welche Antwort auf Sie am besten zutrifft und machen Sie ein Kreuz im entsprechenden Feld. Beantworten Sie bitte jede Frage.

\begin{tabular}{|c|}
\hline Wie sehr litten Sie in den letzten vier Wochen unter...? \\
\hline 1. ...Taubheit oder Kribbeln in bestimmten Körperteilen? \\
\hline 2. ...schneller Erschöpfbarkeit? \\
\hline 3. ...dem Gefühl, sich zu häufig Sorgen zu machen? \\
\hline 4. ...Kreuz- und Rückenschmerzen? \\
\hline 5. ...Einschränkungen aufgrund von seelischen Problemen? \\
\hline 6. ...Konzentrationsschwierigkeiten? \\
\hline 7. ...Muskelzittern? \\
\hline 8. ....Herzklopfen oder Herzrasen? \\
\hline 9. ...Gelenk- oder Gliederschmerzen? \\
\hline 10. ...Gedächtnisschwierigkeiten? \\
\hline 11. ...Selbstvorwürfen? \\
\hline 12. ...Müdigkeit? \\
\hline 13. ...Übelkeit oder Magenverstimmung? \\
\hline 14....innerer Anspannung und Unruhe? \\
\hline 15. ...Einschränkungen aufgrund von körperlichen Beschwerden? \\
\hline 16. ...Bauchschmerzen oder Bauchkrämpfen? \\
\hline 17. ...Nervosität? \\
\hline 18. ...Hitzewallungen oder Kälteschauern? \\
\hline 19. ...Muskelschmerzen? \\
\hline 20. ....sorgenvollen Gedanken? \\
\hline $\begin{array}{l}\text { 21....dem Gefühl, dass bereits Alltagsaktivitäten sehr } \\
\text { anstrengend sind? }\end{array}$ \\
\hline 22. ...Nacken- oder Schulterschmerzen? \\
\hline 23. ...trockener Haut? \\
\hline 24. ...dem Gefühl, einsam zu sein? \\
\hline 25. ...Schwermut? \\
\hline $\begin{array}{l}\text { 26. ... seelischen oder körperlichen Problemen, die den Kontakt } \\
\text { zu Mitmenschen beeinträchtigt haben? }\end{array}$ \\
\hline 27. ...Kopfschmerzen? \\
\hline 28. ...Schwächegefühl? \\
\hline 29. ...Schwindelgefühlen oder dem Gefühl in Ohnmacht zu fallen? \\
\hline 30. ...Entscheidungsschwierigkeiten? \\
\hline 31. ...Durchfall? \\
\hline 32. ...Muskelkrämpfen? \\
\hline
\end{tabular}

\begin{tabular}{|c|c|c|c|}
\hline gar nicht & ein wenig & ziemlich & stark \\
\hline$\square$ & $\square$ & $\square$ & $\square$ \\
\hline$\square$ & $\square$ & $\square$ & $\square$ \\
\hline$\square$ & $\square$ & $\square$ & $\square$ \\
\hline$\square$ & $\square$ & $\square$ & $\square$ \\
\hline$\square$ & $\square$ & $\square$ & $\square$ \\
\hline$\square$ & $\square$ & $\square$ & $\square$ \\
\hline$\square$ & $\square$ & $\square$ & $\square$ \\
\hline$\square$ & $\square$ & $\square$ & $\square$ \\
\hline$\square$ & $\square$ & $\square$ & $\square$ \\
\hline$\square$ & $\square$ & $\square$ & $\square$ \\
\hline$\square$ & $\square$ & $\square$ & $\square$ \\
\hline$\square$ & $\square$ & $\square$ & $\square$ \\
\hline$\square$ & $\square$ & $\square$ & $\square$ \\
\hline$\square$ & $\square$ & $\square$ & $\square$ \\
\hline$\square$ & $\square$ & $\square$ & $\square$ \\
\hline$\square$ & $\square$ & $\square$ & $\square$ \\
\hline$\square$ & $\square$ & $\square$ & $\square$ \\
\hline$\square$ & $\square$ & $\square$ & $\square$ \\
\hline$\square$ & $\square$ & $\square$ & $\square$ \\
\hline$\square$ & $\square$ & $\square$ & $\square$ \\
\hline$\square$ & $\square$ & $\square$ & $\square$ \\
\hline$\square$ & $\square$ & $\square$ & $\square$ \\
\hline$\square$ & $\square$ & $\square$ & $\square$ \\
\hline$\square$ & $\square$ & $\square$ & $\square$ \\
\hline$\square$ & $\square$ & $\square$ & $\square$ \\
\hline$\square$ & $\square$ & $\square$ & $\square$ \\
\hline$\square$ & $\square$ & $\square$ & $\square$ \\
\hline$\square$ & $\square$ & $\square$ & $\square$ \\
\hline$\square$ & $\square$ & $\square$ & $\square$ \\
\hline$\square$ & $\square$ & $\square$ & $\square$ \\
\hline$\square$ & $\square$ & $\square$ & $\square$ \\
\hline$\square$ & $\square$ & $\square$ & $\square$ \\
\hline
\end{tabular}

Inwiefern...

\begin{tabular}{|c|c|c|c|}
\hline gar nicht & ein wenig & ziemlich & stark \\
\hline$\square$ & $\square$ & $\square$ & $\square$ \\
\hline$\square$ & $\square$ & $\square$ & $\square$ \\
\hline$\square$ & $\square$ & $\square$ & $\square$ \\
\hline$\square$ & $\square$ & $\square$ & $\square$ \\
\hline$\square$ & $\square$ & $\square$ & $\square$ \\
\hline$\square$ & $\square$ & $\square$ & $\square$ \\
\hline
\end{tabular}

38. ... fühlten Sie sich in den letzten vier Wochen gesund?

\begin{tabular}{|c|c|c|c|c|}
\hline $\begin{array}{l}\text { Wie oft haben Sie sich im Verlauf der letzten zwei Wochen } \\
\text { beeinträchtigt gefühlt durch...? }\end{array}$ & $\begin{array}{l}\text { überhaupt } \\
\text { nicht }\end{array}$ & $\begin{array}{l}\text { an einzel- } \\
\text { nen Tagen }\end{array}$ & $\begin{array}{c}\text { an mehr als } \\
\text { der Hälfte } \\
\text { der Tage }\end{array}$ & $\begin{array}{l}\text { beinahe } \\
\text { jeden Tag }\end{array}$ \\
\hline 39. ...weniger Interesse und Freude an Ihren Tätigkeiten? & $\square$ & $\square$ & $\square$ & $\square$ \\
\hline 40. ...Niedergeschlagenheit, Schwermut oder Hoffnungslosigkeit? & $\square$ & $\square$ & $\square$ & $\square$ \\
\hline
\end{tabular}


Anlage 6: Dokumentation Hypoparathyreoidismus; gemeinsames Ergebnis mit cand. med. L. Wilken

\section{Dokumentation Hypoparathyreoidismus}

Name, Vorname:

Geburtsdatum:

Geschlecht: $\quad w \square \quad m \square \quad$ Gewicht $(\mathrm{kg})$ :

Größe (cm):

1 Ursache des Hypoparathyreoidismus:

2 Erstdiagnose Hyopoarathyreoidismus:

Nur für iatrogenen Hypoparathyreoidismus

Grund der Operation:

Zeitpunkt der (Schilddrüsen-) Operation:

Zeitabstand zwischen OP und erster Medikation:

3 Aktuelle Medikation: (bei Platzmangel bitte auf der Rückseite fortfahren)

\begin{tabular}{|l|l|l|}
\hline Medikament & Dosierung $(0-0-0-0)$ & Einnahme seit: (Monat/Jahr) \\
\hline & \\
\hline
\end{tabular}

4 Diät oder spezielle Ernährungsgewohnheiten?

5 Komplikationen

Nierensteine

nen

Niereninsuffizienz

ja $\square$

nein $\square$

ja $\square \quad$ nein $\square$

Nephrocalcinose $\quad$ ja $\square \quad$ nein $\square$

\begin{tabular}{lll}
\hline Osteoporose & ja $\square$ & nein $\square$ \\
\hline Katarakt & ja $\square$ & nein $\square$ \\
\hline Basalganglienverkalkung & ja $\square$ & nein $\square$
\end{tabular}

Anzahl der behandlungspflichtigen

hypo-/hypercalzämischen Krisen im letzten Jahr:

6 Vorerkrankungen

Herzerkrankungen $\quad$ ja $\square \quad$ nein $\square$

Welche?

nein $\square$

Hypertonus

ja $\square$

nein $\square$

\begin{tabular}{lcc} 
Diabetes Mellitus & ja $\square$ & nein $\square$ \\
\hline $\begin{array}{l}\text { neurologische - oder } \\
\text { psych. Erkrankungen }\end{array}$ & ja $\square$ & \\
Welche? & \\
\hline $\begin{array}{l}\text { Asthma, COPD } \\
\text { (Zutreffendes bitte unterstreichen) }\end{array}$ & nein $\square$ \\
\hline $\begin{array}{l}\text { Neoplasien } \\
\text { Welche? }\end{array}$ & ja $\square$ \\
\hline $\begin{array}{l}\text { Gastrointestinale } \\
\text { Erkrankungen }\end{array}$ & ja $\square$ \\
$\begin{array}{l}\text { Welche? } \\
\text { Arthrose, Rheuma, }\end{array}$ & \\
$\begin{array}{l}\text { Gelenkerkrankungen } \\
\text { (Zutreffendes bitte unterstreichen) }\end{array}$ & \\
\hline
\end{tabular}

7 belastende psychische Ereignisse in den letzten vier Wochen (z. B. Tod eines Angehörigen, Unfall, Erkrankung...)

8 Alle Laborwerte angefordert?
$\square$ Calcium (Serum)
$\square$ Phosphat (Serum)
$\square$ Magnesium (Serum)
$\square$ PTH
$\square$ GFR, Krea
$\square$ Vit. D
$\square$ Calcium/Phosphat (24-h-Urin)
$\square$ BAP
$\square$ CTX
$\square$ DPD (24-h-Urin) 


\section{HPQ 28 - Fragebogen für Hypoparathyreoidismus}

Name/Nr.:

Datum:

Dieser Fragebogen enthält verschiedene Fragen zu Symptomen und Beschwerden, die im Rahmen einer Nebenschilddrüsenunterfunktion auftreten können.

Bitte überlegen Sie bei jeder Frage, welche Antwort auf Sie am besten zutrifft und machen Sie ein Kreuz im entsprechenden Feld. Beantworten Sie bitte jede Frage.

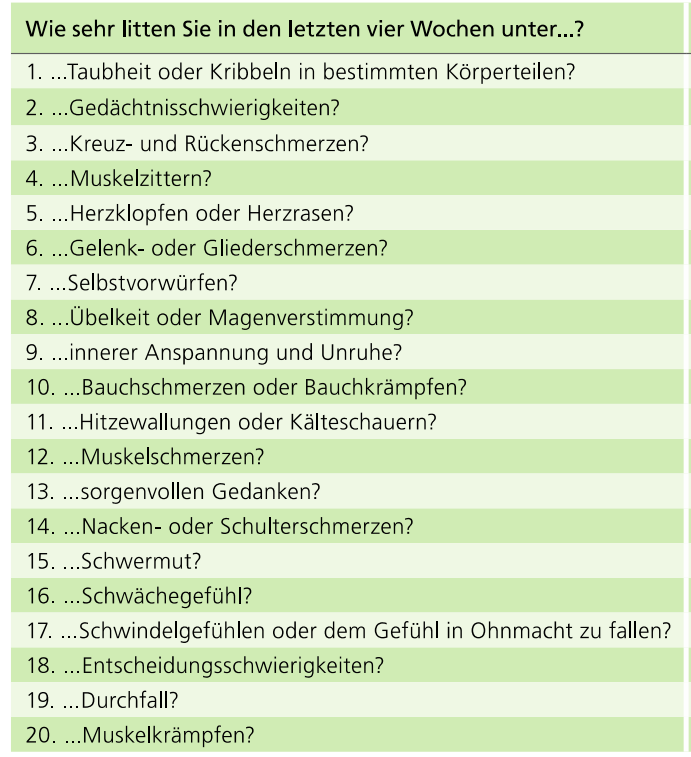

\begin{tabular}{|c|c|c|c|}
\hline gar nicht & ein wenig & ziemlich & stark \\
\hline$\square$ & $\square$ & $\square$ & $\square$ \\
\hline$\square$ & $\square$ & $\square$ & $\square$ \\
\hline$\square$ & $\square$ & $\square$ & $\square$ \\
\hline$\square$ & $\square$ & $\square$ & $\square$ \\
\hline$\square$ & $\square$ & $\square$ & $\square$ \\
\hline$\square$ & $\square$ & $\square$ & $\square$ \\
\hline$\square$ & $\square$ & $\square$ & $\square$ \\
\hline$\square$ & $\square$ & $\square$ & $\square$ \\
\hline$\square$ & $\square$ & $\square$ & $\square$ \\
\hline$\square$ & $\square$ & $\square$ & $\square$ \\
\hline$\square$ & $\square$ & $\square$ & $\square$ \\
\hline$\square$ & $\square$ & $\square$ & $\square$ \\
\hline$\square$ & $\square$ & $\square$ & $\square$ \\
\hline$\square$ & $\square$ & $\square$ & $\square$ \\
\hline$\square$ & $\square$ & $\square$ & $\square$ \\
\hline$\square$ & $\square$ & $\square$ & $\square$ \\
\hline$\square$ & $\square$ & $\square$ & $\square$ \\
\hline$\square$ & $\square$ & $\square$ & $\square$ \\
\hline$\square$ & $\square$ & $\square$ & $\square$ \\
\hline$\square$ & $\square$ & $\square$ & $\square$ \\
\hline
\end{tabular}

\begin{tabular}{|c|c|c|c|c|}
\hline $\begin{array}{l}\text { Wie oft haben Sie sich im Verlauf der letzten zwei Wochen } \\
\text { beeinträchtigt gefühlt durch...? }\end{array}$ & $\begin{array}{l}\text { überhaupt } \\
\text { nicht }\end{array}$ & $\begin{array}{l}\text { an einzel- } \\
\text { nen Tagen }\end{array}$ & $\begin{array}{c}\text { an mehr als } \\
\text { der Hälfte } \\
\text { der Tage }\end{array}$ & $\begin{array}{l}\text { beinahe } \\
\text { jeden Tag }\end{array}$ \\
\hline 21. ...weniger Interesse und Freude an Ihren Tätigkeiten? & $\square$ & $\square$ & $\square$ & $\square$ \\
\hline 22. ...Niedergeschlagenheit, Schwermut oder Hoffnungslosigkeit? & $\square$ & $\square$ & $\square$ & $\square$ \\
\hline
\end{tabular}

Im nächsten Abschnitt stellen wir Ihnen einige Fragen zur Lebensqualität. Die Antwort "gar nicht" bedeutet bei diesen Fragen, dass Sie in Ihrem Wohlbefinden stark eingeschränkt sind. Die Antwort "stark" bedeutet in diesem Zusammenhang, dass Sie wenige oder kaum Einschränkungen bezüglich Ihres Wohlbefindens haben.

\begin{tabular}{|c|c|c|c|c|}
\hline Inwiefern... & gar nicht & ein wenig & ziemlich & stark \\
\hline 23. ...fühlten Sie sich in den letzten vier Wochen energiegeladen? & $\square$ & $\square$ & $\square$ & $\square$ \\
\hline $\begin{array}{l}\text { 24. ...fühlten Sie sich in den letzten vier Wochen körperlich fit } \\
\text { und vital? }\end{array}$ & $\square$ & $\square$ & $\square$ & $\square$ \\
\hline 25. ...hatten Sie in den letzten vier Wochen Freude an Sexualität? & $\square$ & $\square$ & $\square$ & $\square$ \\
\hline 26. ...waren Sie in den letzten vier Wochen ruhig und gelassen? & $\square$ & $\square$ & $\square$ & $\square$ \\
\hline 27. ...waren Sie in den letzten vier Wochen glücklich? & $\square$ & $\square$ & $\square$ & $\square$ \\
\hline 28. ...fühlten Sie sich in den letzten vier Wochen gesund? & $\square$ & $\square$ & $\square$ & $\square$ \\
\hline
\end{tabular}


Anlage 8: Dokumentation Hypoparathyreoidismus nach Überarbeitung; gemeinsames Ergebnis mit cand. med. L. Wilken

\section{Dokumentation Hypoparathyreoidismus}

Name, Vorname:

Geburtsdatum:

Pat.-Nr.:

Geschlecht:

$w \square \quad m \square$

Gewicht $(\mathrm{kg})$

Größe $(\mathrm{cm})$ :

1 Ursache des Hypoparathyreoidismus:

2 Erstdiagnose Hypoparathyreoidismus:

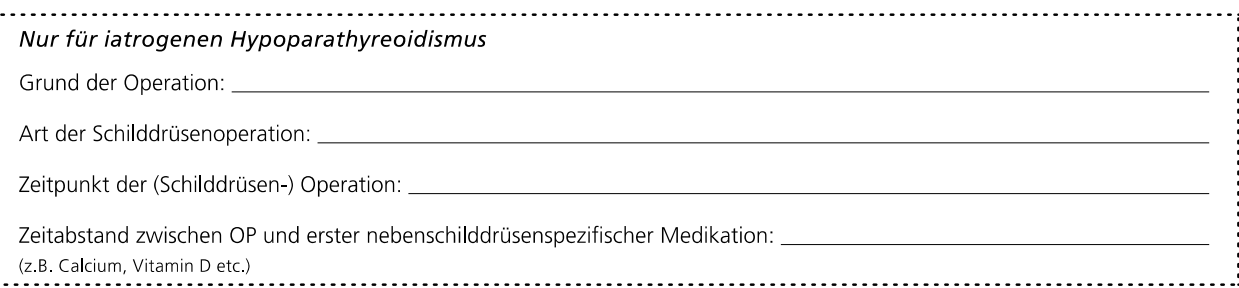

(z.B. Calcium, Vitamin D etc)

3 Aktuelle Medikation: (ggf. Medikamentenplan oder Arztbrief anfügen)

\begin{tabular}{|l|l|l|}
\hline Medikament & Dosierung $(0-0-0-0)$ & Einnahme seit: (Monat/Jahr) \\
\hline & \\
\hline
\end{tabular}

4 Diät oder spezielle Ernährungsgewohnheiten?

\section{Komplikationen}

Nierensteine

Niereninsuffizienz

Nephrocalcinose

ja $\square \quad$ nein $\square \quad$ unbekannt $\square$

ja $\square \quad$ nein $\square \quad$ unbekannt $\square$

ja $\square \quad$ nein $\square \quad$ unbekannt $\square$

\begin{tabular}{lll}
\hline Katarakt $\quad$ ja $\square \quad$ nein $\square \quad$ unbekannt $\square$ \\
\hline
\end{tabular}

Basalganglienverkalkung ja $\square \quad$ nein $\square \quad$ unbekannt $\square$

Anzahl der ärztlich diagnostizierten, behandlungspflichtigen hypo-/hypercalzämischen Krisen im letzten Jahr:

6 Vorerkrankungen

Herzerkrankungen

Welche?

Hypertonus

ja $\square \quad$ nein $\square \quad$ unbekannt $\square$

\begin{tabular}{lcc} 
Hypertonus & ja $\square \quad$ nein $\square \quad$ unbekannt $\square$ \\
\hline Diabetes Mellitus & ja $\square \quad$ nein $\square \quad$ unbekannt $\square$
\end{tabular}

7 belastende psychische Ereignisse in den letzten vier Wochen: (z. B. Tod eines Angehörigen, Unfall, Erkrankung...)

\section{Aktuelle Beschäftigungssituation?}

$\square$ normal arbeitend $\quad \square$ krank geschrieben $\quad \square$ ohne Arbeit $\square$ berentet
$\square$ anderes:

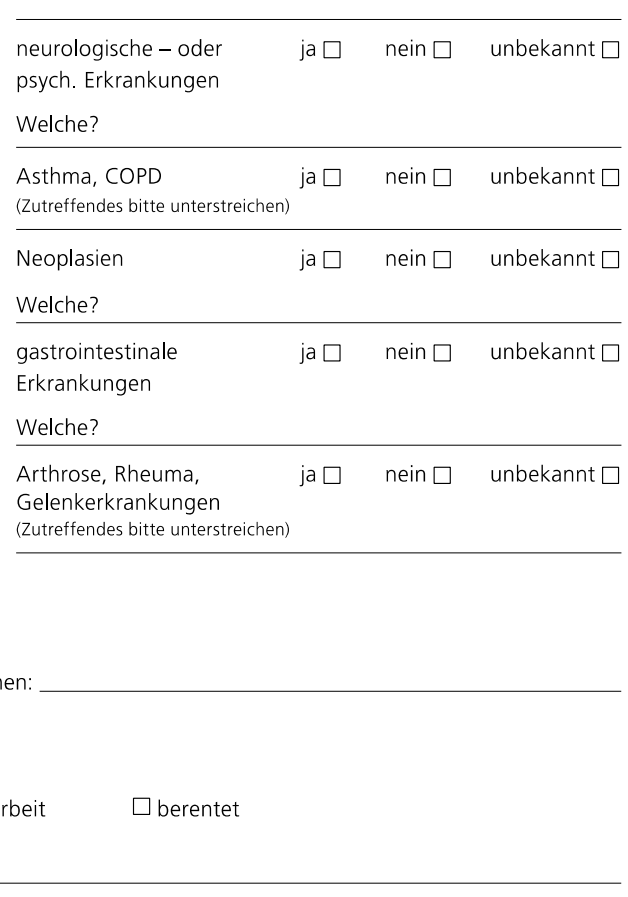




\section{Für den Arzt/Ärztin}

9 Alle Laborwerte angefordert? (adaptiert nach europäischen Leitlinien für Hypoparathyreoidismus)
$\square$ Calcium (Serum)
$\square$ Phosphat (Serum)
$\square$ Magnesium (Serum)
$\square$ Ca x Phos-Produkt (errechnet)
$\square$ GFR, Krea
$\square$ Vit. D 25-OH
$\square$ Calcium (24h-Urin)
ggf. zusätzlich:
$\square$ PTH
$\square$ Vit. D 1,25(OH)
$\square$ BAP $\quad \square$ CTX $\quad \square$ DPD (24h-Urin)

10 Alle Zusatzuntersuchungen angefordert? (adaptiert nach europäischen Leitlinien für Hypoparathyreoidismus)
$\square$ Sono Niere
$\square$ CT Nieren
$\square$ CT Kopf
$\square$ augenärztliche Untersuchung
$\square$ HPQ 28
$\square$ DXA-Messung
$\square$ Trabecular Bone Score (TBS)

anderer Validationsfragebogen:

Validationsfragebogen:

Dokumentation wurde durchgeführt von am (Datum)

Paraphe: 


\section{Literaturverzeichnis}

Aaltonen J, Bjorses P, Perheentupa J, Horelli-Kuitunen N, Palotie A, Peltonen L, Lee YS, Francis F, Henning S, Thiel C (1997): An autoimmune disease, APECED, caused by mutations in a novel gene featuring two PHD-type zincfinger domains. Nat Genet $\underline{17}, 399-403$

Abate EG, Clarke BL (2016): Review of Hypoparathyroidism. Front Endocrinol (Lausanne) $\underline{7}, 172$

Abboud B, Daher R, Boujaoude J (2011): Digestive manifestations of parathyroid disorders. World J Gastroenterol $\underline{17}$, 4063-4066

Aggarwal S, Kailash S, Sagar R, Tripathi M, Sreenivas V, Sharma R, Gupta N, Goswami R (2013): Neuropsychological dysfunction in idiopathic hypoparathyroidism and its relationship with intracranial calcification and serum total calcium. Eur J Endocrinol 168, 895-903

Agha A, Scherer MN, Moser C, Karrasch T, Girlich C, Eder F, Jung EM, Schlitt HJ, Schaeffler A (2016): Living-donor parathyroid allotransplantation for therapy-refractory postsurgical persistent hypoparathyroidism in a nontransplant recipient - three year results: a case report. BMC Surg $\underline{16}, 51$

Akerstrom G, Hellman P, Hessman O, Segersten U, Westin G (2005): Parathyroid glands in calcium regulation and human disease. Ann N Y Acad Sci 1040, 53-58

Alfacalcidol(1APharma®): Fachinformation Alfacalcidol-1 A Pharma® 0,25 $\mu \mathrm{g}$ Weichkapseln, 0,5 $\mu \mathrm{g}$ Weichkapseln,1 $\mu \mathrm{g}$ Weichkapseln. 1 A Pharma $\mathrm{GmbH}$, Oberhaching 2014

Alfacalcidol(Hexal囚): Gebrauchsinformation: Information für Anwender Alfacalcidol HEXAL® 0,25 $\mu$ g Weichkapseln. Hexal AG, Holzkirchen 2014

Alfacalcidol(ratiopharm®): Gebrauchsinformation: Information für den Anwender Alfacalcidol-ratiopharm® $1 \mu \mathrm{g}$ Weichkapseln. ratiopharm $\mathrm{GmbH}$, Ulm 2009

Alimohammadi M, Bjorklund P, Hallgren A, Pontynen N, Szinnai G, Shikama N, Keller MP, Ekwall O, Kinkel SA, Husebye ES (2008): Autoimmune polyendocrine syndrome type 1 and NALP5, a parathyroid autoantigen. N Engl J Med $\underline{358}, 1018-1028$

Alrubaiy L, Cheung WY, Dodds P, Hutchings HA, Russell IT, Watkins A, Williams JG (2015): Development of a short questionnaire to assess the quality of life in Crohn's disease and ulcerative colitis. J Crohns Colitis $\underline{9}, 66-76$

Andrews EB, Gilsenan AW, Midkiff K, Sherrill B, Wu Y, Mann BH, Masica D (2012): The US postmarketing surveillance study of adult osteosarcoma and teriparatide: study design and findings from the first 7 years. J Bone Miner Res $\underline{27}, 2429-2437$

Andrysiak-Mamos E, Zochowska E, Kazmierczyk-Puchalska A, Popow M, Kaczmarska-Turek D, Pachucki J, Bednarczuk T, Syrenicz A (2016): Treatment of severe life threatening hypocalcemia with recombinant human teriparatide in patients with postoperative hypoparathyroidism - a case series. Endokrynol Pol $\underline{67}, 403-412$

Arlt W, Fremerey C, Callies F, Reincke M, Schneider P, Timmermann W, Allolio B (2002): Well-being, mood and calcium homeostasis in patients with hypoparathyroidism receiving standard treatment with calcium and vitamin D. Eur J Endocrinol 146, 215-222

Armas LA, Hollis BW, Heaney RP (2004): Vitamin D2 is much less effective than vitamin D3 in humans. J Clin Endocrinol Metab $\underline{89}, 5387-5391$

Astor MC, Lovas K, Debowska A, Eriksen EF, Evang JA, Fossum C, Fougner KJ, Holte SE, Lima K, Moe RB (2016): Epidemiology and health related quality of life in hypoparathyroidism in Norway. J Clin Endocrinol Metab 101, 3045-3053

Avioli LV (1974): The therapeutic approach to hypoparathyroidism. Am J Med $\underline{57}, 34-42$

Ayuk J, Gittoes NJ (2011): How should hypomagnesaemia be investigated and treated? Clin Endocrinol (Oxf) $\underline{75}$, 743746 
Baczynski R, Massry SG, Magott M, el-Belbessi S, Kohan R, Brautbar N (1985): Effect of parathyroid hormone on energy metabolism of skeletal muscle. Kidney Int $\underline{28}, 722-727$

Bago AG, Palkovits M, Usdin TB, Seress L, Dobolyi A (2008): Evidence for the expression of parathyroid hormone 2 receptor in the human brainstem. Ideggyogy Sz $\underline{61}, 123-126$

Ballane GT, Sfeir JG, Dakik HA, Brown EM, El-Hajj Fuleihan G (2012): Use of recombinant human parathyroid hormone in hypocalcemic cardiomyopathy. Eur J Endocrinol $\underline{166}, 1113-1120$

Bassett JH, Thakker RV (1995): Molecular genetics of disorders of calcium homeostasis. Baillieres Clin Endocrinol Metab $\underline{9}, 581-608$

Behar V, Pines M, Nakamoto C, Greenberg Z, Bisello A, Stueckle SM, Bessalle R, Usdin TB, Chorev M (1996): The human PTH2 receptor: binding and signal transduction properties of the stably expressed recombinant receptor. Endocrinology 137, 2748-2757

Bergwitz C, Jüppner H (2010): Regulation of phosphate homeostasis by PTH, vitamin D, and FGF23. Annu Rev Med 61, 91-104

Berkelhammer C, Bear RA (1985): A clinical approach to common electrolyte problems: 4. Hypomagnesemia. Can Med Assoc J 132, 360-368

Bilezikian JP (2008): Combination anabolic and antiresorptive therapy for osteoporosis: opening the anabolic window. Curr Osteoporos Rep $\underline{6}, 24-30$

Bilezikian JP, Khan A, Potts JT, Brandi ML, Clarke BL, Shoback D, Jüppner H, D'Amour P, Fox J, Rejnmark L (2011): Hypoparathyroidism in the adult: epidemiology, diagnosis, pathophysiology, target-organ involvement, treatment, and challenges for future research. J Bone Miner Res $\underline{26}, 2317-2337$

Bilezikian JP, Brandi ML, Cusano NE, Mannstadt M, Rejnmark L, Rizzoli R, Rubin MR, Winer KK, Liberman UA, Potts JT (2016): Management of Hypoparathyroidism: Present and Future. J Clin Endocrinol Metab 101, 2313-2324

Bischoff HA, Borchers M, Gudat F, Duermueller U, Theiler R, Stahelin HB, Dick W (2001): In situ detection of 1,25dihydroxyvitamin D3 receptor in human skeletal muscle tissue. Histochem J $\underline{33}, 19-24$

Bohrer T, Fleischmann P, Tersteegen A, Hasse C (2005): Das weitgehend unbekannte Krankheitsbild des postoperativen permanenten Hypoparathyreoidismus - Konzeption und Validierung eines innovativen Fragebogenmessinstrumentes. Zentralbl Chir $\underline{130}, 440-448$

Bohrer T, Hagemeister M, Elert O (2007): A clinical chameleon: postoperative hypoparathyroidism. Langenbecks Arch Surg $\underline{392}, 423-426$

Boland R (1986): Role of vitamin D in skeletal muscle function. Endocr Rev ㄱ, 434-448

Bollerslev J, Rejnmark L, Marcocci C, Shoback DM, Sitges-Serra A, van Biesen W, Dekkers OM (2015): European Society of Endocrinology Clinical Guideline: Treatment of chronic hypoparathyroidism in adults. Eur $\mathrm{J}$ Endocrinol $\underline{173}, \mathrm{G} 1-\mathrm{G} 20$

Bondiol@: Gebrauchsinformation Bondiol $(0,25 \mu \mathrm{g}$ Weichkapseln. TEVA GmbH, Ulm 2013

Borgia AR, Cavallasca JA, Costa CA, Musuruana JL (2012): Hyperparathyroidism, a forgotten cause of musculoskeletal pain. Reumatol Clin $\underline{8}, 299-301$

Brandi L, Egfjord M, Olgaard K (2002): Pharmacokinetics of 1,25(OH)(2)D(3) and 1alpha(OH)D(3) in normal and uraemic men. Nephrol Dial Transplant 17, 829-842

Brandi ML, Bilezikian JP, Shoback D, Bouillon R, Clarke BL, Thakker RV, Khan AA, Potts JT, Jr. (2016): Management of Hypoparathyroidism: Summary Statement and Guidelines. J Clin Endocrinol Metab 101, 2273-2283

Brenza HL, DeLuca HF (2000): Regulation of 25-hydroxyvitamin D3 1alpha-hydroxylase gene expression by parathyroid hormone and 1,25-dihydroxyvitamin D3. Arch Biochem Biophys $\underline{381}$, 143-152 
Brickman AS, Massry SG, Coburn JW (1972): changes in serum and urinary calcium during treatment with hydrochlorothiazide: studies on mechanisms. J Clin Invest $\underline{51}, 945-954$

Brickman AS, Coburn JW, Friedman GR, Okamura WH, Massry SG, Norman AW (1976): Comparison of effects of 1 alpha-hydroxy-vitamin D3 and 1,25-dihydroxy-vitamin D3 in man. J Clin Invest $\underline{57}, 1540-1547$

Brown AJ, Ritter CS, Knutson JC, Strugnell SA (2006): The vitamin D prodrugs 1alpha(OH)D2, 1alpha(OH)D3 and BCI210 suppress PTH secretion by bovine parathyroid cells. Nephrol Dial Transplant 21, $644-650$

Brown EM (2009): Anti-parathyroid and anti-calcium sensing receptor antibodies in autoimmune hypoparathyroidism. Endocrinol Metab Clin North Am 38, 437-445

Brown EM, MacLeod RJ (2001): Extracellular calcium sensing and extracellular calcium signaling. Physiol Rev $\underline{1}$, 239297

Bühner M: Einführung in die Test- und Fragebogenkonstruktion. 3. Auflage; Pearson, München 2011

Bullinger M, Kirchberger I: Fragebogen zum Gesundheitszustand. SF-36 ; Handanweisung. Hogrefe, Göttingen 1998

Busch M, Maske U, Ryl L, Schlack R, Hapke U (2013): Prävalenz von depressiver Symptomatik und diagnostizierter Depression bei Erwachsenen in Deutschland: Ergebnisse der Studie zur Gesundheit Erwachsener in Deutschland (DEGS1). Bundesgesundheitsbl $\underline{56}, 733-739$

Carroll MF, Schade DS (2003): A practical approach to hypercalcemia. Am Fam Physician $\underline{67}$, 1959-1966

Cho NL, Moalem J, Chen L, Lubitz CC, Moore FD, Jr., Ruan DT (2014): Surgeons and patients disagree on the potential consequences from hypoparathyroidism. Endocr Pract $\underline{20}, 427-446$

Cianferotti L, Parri S, Gronchi G, Marcucci G, Cipriani C, Pepe J, Raglianti M, Minisola S, Brandi ML (2018): Prevalence of Chronic Hypoparathyroidism in a Mediterranean Region as Estimated by the Analysis of Anonymous Healthcare Database. Calcif Tissue Int, doi: 10.1007/s00223-018-0405-5

Cipriani C, Biamonte F, Costa AG, Zhang C, Biondi P, Diacinti D, Pepe J, Piemonte S, Scillitani A, Minisola S (2015): Prevalence of kidney stones and vertebral fractures in primary hyperparathyroidism using imaging technology. $\mathrm{J}$ Clin Endocrinol Metab 100, 1309-1315

Clark JA, Bonner TI, Kim AS, Usdin TB (1998): Multiple regions of ligand discrimination revealed by analysis of chimeric parathyroid hormone 2 (PTH2) and PTH/PTH-related peptide (PTHrP) receptors. Mol Endocrinol 12, 193-206

Clarke BL (2014): Bone disease in hypoparathyroidism. Arq Bras Endocrinol Metabol $\underline{58}, 545-552$

Clarke BL, Brown EM, Collins MT, Jüppner H, Lakatos P, Levine MA, Mannstadt MM, Bilezikian JP, Romanischen AF, Thakker RV (2016): Epidemiology and Diagnosis of Hypoparathyroidism. J Clin Endocrinol Metab 101, 22842299

Cochran M, Peacock M, Sachs G, Nordin BE (1970): Renal effects of calcitonin. Br Med J 1, 135-137

Cole DEC, Hendy GN, Bastepe M: Hypoparathyroidism and Pseudohypoparathyroidism. In: De Groot LJ, Beck-Peccoz P, Chrousos G, Dungan K, Grossman A, Hershman JM, Koch C, McLachlan R, New M, Rebar R (Hrsg.): Endotext. (Stand 01.08.2011); MDText.com, Inc., South Dartmouth 2000, 0.S. https://www.ncbi.nlm.nih.gov/books/NBK279165

Cusano NE, Rubin MR, Irani D, Sliney J, Jr., Bilezikian JP (2013a): Use of parathyroid hormone in hypoparathyroidism. J Endocrinol Invest $\underline{36}, 1121-1127$

Cusano NE, Rubin MR, McMahon DJ, Zhang C, Ives R, Tulley A, Sliney J, Jr., Cremers SC, Bilezikian JP (2013b): Therapy of hypoparathyroidism with $\mathrm{PTH}(1-84)$ : a prospective four-year investigation of efficacy and safety. $\mathrm{J}$ Clin Endocrinol Metab 98, 137-144

Cusano NE, Rubin MR, McMahon DJ, Irani D, Anderson L, Levy E, Bilezikian JP (2014): PTH(1-84) is associated with improved quality of life in hypoparathyroidism through 5 years of therapy. J Clin Endocrinol Metab $\underline{99}$, 36943699 
D'Amour P (2012): Acute and chronic regulation of circulating PTH: significance in health and in disease. Clin Biochem 45, 964-969

Dai CL, Sun ZJ, Zhang X, Qiu MC (2012): Elevated muscle enzymes and muscle biopsy in idiopathic hypoparathyroidism patients. J Endocrinol Invest $\underline{35}$, 286-289

Davey RA, Findlay DM (2013): Calcitonin: physiology or fantasy? J Bone Miner Res $\underline{28}, 973-979$

De Sanctis V, Soliman A, Fiscina B (2012): Hypoparathyroidism: from diagnosis to treatment. Curr Opin Endocrinol Diabetes Obes $\underline{19}, 435-442$

Decostrio|ß: Gebrauchsinformation: Information für den Anwender Decostriol@ 0,5 Mikrogramm Weichkapseln. mibe GmbH Arzneimittel, Brehna 2009

DeLuca HF, Schnoes HK (1976): Metabolism and mechanism of action of vitamin D. Annu Rev Biochem 45, 631-666

Deroisy R, Zartarian M, Meurmans L, Nelissenne N, Micheletti MC, Albert A, Reginster JY (1997): Acute changes in serum calcium and parathyroid hormone circulating levels induced by the oral intake of five currently available calcium salts in healthy male volunteers. Clin Rheumatol $\underline{16}, 249-253$

Diaz GA, Gelb BD, Ali F, Sakati N, Sanjad S, Meyer BF, Kambouris M (1999): Sanjad-Sakati and autosomal recessive Kenny-Caffey syndromes are allelic: evidence for an ancestral founder mutation and locus refinement. Am J Med Genet $\underline{\text { 85, }}$ 48-52

Dimitrov EL, Petrus E, Usdin TB (2010): Tuberoinfundibular peptide of 39 residues (TIP39) signaling modulates acute and tonic nociception. Exp Neurol 226, 68-83

Dobolyi A, Ueda H, Uchida H, Palkovits M, Usdin TB (2002): Anatomical and physiological evidence for involvement of tuberoinfundibular peptide of 39 residues in nociception. Proc Natl Acad Sci U S A $\underline{99}$, 1651-1656

Dobolyi A, Palkovits M, Usdin TB (2010): The TIP39-PTH2 receptor system: unique peptidergic cell groups in the brainstem and their interactions with central regulatory mechanisms. Prog Neurobiol $\underline{90}, 29-59$

Dralle H (2015): Chirurgische Begutachtung von Komplikationen nach Schilddrüsenoperationen. Chirurg $\underline{86}, 70-77$

Eastell R, Brandi ML, Costa AG, D'Amour P, Shoback DM, Thakker RV (2014): Diagnosis of asymptomatic primary hyperparathyroidism: proceedings of the Fourth International Workshop. J Clin Endocrinol Metab 99, 35703579

Eisenbarth GS, Gottlieb PA (2004): Autoimmune polyendocrine syndromes. N Engl J Med $\underline{350}, 2068-2079$

Epstein M, McGrath S, Law F (2006): Proton-pump inhibitors and hypomagnesemic hypoparathyroidism. N Engl J Med $\underline{355}, 1834-1836$

Ernst ME, Moser M (2009): Use of diuretics in patients with hypertension. N Engl J Med 361, 2153-2164

Fawcett WJ, Haxby EJ, Male DA (1999): Magnesium: physiology and pharmacology. Br J Anaesth $\underline{83}, 302-320$

Fayers PM, Machin D: Quality of life. The assessment, analysis and interpretation of patient-reported outcomes. 2. Auflage; John Wiley \& Sons Ltd, Chichester 2007

Felsenfeld AJ, Levine BS (2015): Calcitonin, the forgotten hormone: does it deserve to be forgotten? Clin Kidney J $\underline{8}$, 180-187

Feroci F, Rettori M, Borrelli A, Coppola A, Castagnoli A, Perigli G, Cianchi F, Scatizzi M (2014): A systematic review and meta-analysis of total thyroidectomy versus bilateral subtotal thyroidectomy for Graves' disease. Surgery $\underline{155}$, $529-540$

Forster IC, Hernando N, Biber J, Murer $\mathrm{H}$ (2006): Proximal tubular handling of phosphate: A molecular perspective. Kidney Int $\underline{70}$, 1548-1559

Franke GH: Symptom-Checkliste von L.R. Derogatis - deutsche Version -: Manual. 2. Auflage; Belz Test, Göttingen 2002 
Fukushima M, Suzuki Y, Tohira Y, Nishii Y, Suzuki M (1976): 25-Hydroxylation of 1alpha-hydroxyvitamin D3 in vivo and in perfused rat liver. FEBS Lett $\underline{65}$, 211-214

Gafni RI, Brahim JS, Andreopoulou P, Bhattacharyya N, Kelly MH, Brillante BA, Reynolds JC, Zhou H, Dempster DW, Collins MT (2012): Daily parathyroid hormone 1-34 replacement therapy for hypoparathyroidism induces marked changes in bone turnover and structure. J Bone Miner Res $\underline{27}, 1811-1820$

Garabedian M, Holick MF, Deluca HF, Boyle IT (1972): Control of 25-hydroxycholecalciferol metabolism by parathyroid glands. Proc Natl Acad Sci U S A $\underline{69}$, 1673-1676

Garcia-Pascual L, Barahona MJ, Perea V, Simo R (2017): Serum 1,25-Dihydroxyvitamin D as a Biomarker of the Absence of Hypercalciuria in Postsurgical Hypoparathyroidism. J Clin Endocrinol Metab 102, 259-266

Gardella TJ, Jüppner H (2001): Molecular properties of the PTH/PTHrP receptor. Trends Endocrinol Metab 12, 210-217

Gardella TJ, Jüppner H, Brown EM, Kronenberg HM, Potts Jr JT: Chapter 56 - Parathyroid Hormone and the Parathyroid Hormone Receptor Type 1 in the Regulation of Calcium and Phosphate Homeostasis and Bone Metabolism. In: Jameson JL, De Groot LJ, de Kretser DM, Giudice LC, Grossman AB, Melmed S, Potts JT, Weir GC (Hrsg.): Endocrinology: Adult and Pediatric. Band I; 7. Auflage; W.B. Saunders, Philadelphia 2016, 969-990

Garmendia Madariaga A, Santos Palacios S, Guillen-Grima F, Galofre JC (2014): The incidence and prevalence of thyroid dysfunction in Europe: a meta-analysis. J Clin Endocrinol Metab 99, 923-931

Garrison SR, Birmingham CL, Koehler BE, McCollom RA, Khan KM (2011): The effect of magnesium infusion on rest cramps: randomized controlled trial. J Gerontol A Biol Sci Med Sci $\underline{66}, 661-666$

Garrison SR, Allan GM, Sekhon RK, Musini VM, Khan KM (2012): Magnesium for skeletal muscle cramps. Cochrane Database Syst Rev, Cd009402

Geissner E: Die Schmerzempfindungs-Skala (SES). Handanweisung. Hogrefe, Göttingen 1996

Gensure RC, Gardella TJ, Jüppner H (2005): Parathyroid hormone and parathyroid hormone-related peptide, and their receptors. Biochem Biophys Res Commun $\underline{328}$, 666-678

Giordano D, Valcavi R, Thompson GB, Pedroni C, Renna L, Gradoni P, Barbieri V (2012): Complications of central neck dissection in patients with papillary thyroid carcinoma: results of a study on 1087 patients and review of the literature. Thyroid $\underline{22}, 911-917$

Goldhammer F, Hartig J: 8 - Interpretation von Testresultaten und Testeichung. In: Moosbrugger H, Kelava A (Hrsg.): Testtheorie und Fragebogenkonstruktion. 2. Auflage; Springer, Berlin 2012, 174-201

Goswami R, Ray D, Sharma R, Tomar N, Gupta R, Gupta N, Sreenivas V (2008): Presence of spondyloarthropathy and its clinical profile in patients with hypoparathyroidism. Clin Endocrinol (Oxf) $\underline{68}, 258-263$

Goswami R, Sharma R, Sreenivas V, Gupta N, Ganapathy A, Das S (2012): Prevalence and progression of basal ganglia calcification and its pathogenic mechanism in patients with idiopathic hypoparathyroidism. Clin Endocrinol (Oxf) $\underline{77}, 200-206$

Goswami R, Millo T, Mishra S, Das M, Kapoor M, Tomar N, Saha S, Roy TS, Sreenivas V (2014): Expression of osteogenic molecules in the caudate nucleus and gray matter and their potential relevance for Basal Ganglia calcification in hypoparathyroidism. J Clin Endocrinol Metab $\underline{99}$, 1741-1748

Groscurth P: Nebenschilddrüsen. In: Drenckhahn D, Asan E, Benninghoff A (Hrsg.): Anatomie / makroskopische Anatomie, Histologie, Embryologie, Zellbiologie. Band 2; 16. Auflage; Elsevier Urban \& Fischer, München 2004, 203-206

Guarnieri V, Valentina D'Elia A, Baorda F, Pazienza V, Benegiamo G, Stanziale P, Copetti M, Battista C, Grimaldi F, Damante $G$ (2012): CASR gene activating mutations in two families with autosomal dominant hypocalcemia. Mol Genet Metab 107, 548-552

Haack M, Kramer S, Seidel G, Nickel S, Kofahl C, Dierks ML (2017): Wer besucht eine Selbsthilfegruppe - und warum? Ergebnisse aus der SHILD-Studie. Gesundheitswesen $\underline{79}$, 656-804 
Hadker N, Egan J, Sanders J, Lagast H, Clarke BL (2014): Understanding the burden of illness associated with hypoparathyroidism reported among patients in the paradox study. Endocr Pract $\underline{20}, 671-679$

Halabe A, Arie R, Mimran D, Samuel R, Liberman UA (1994): Hypoparathyroidism--a long-term follow-up experience with 1 alpha-vitamin D3 therapy. Clin Endocrinol (Oxf) $\underline{40}, 303-307$

Hansen D, Rasmussen K, Pedersen SM, Rasmussen LM, Brandi L (2012): Changes in fibroblast growth factor 23 during treatment of secondary hyperparathyroidism with alfacalcidol or paricalcitol. Nephrol Dial Transplant 27, 22632269

Hartig J, Frey A, Jude N: Validität. In: Moosbrugger H, Kelava A (Hrsg.): Testtheorie und Fragebogenkonstruktion. 2. Auflage; Springer, Berlin 2012, 143-171

Hauch A, Al-Qurayshi Z, Randolph G, Kandil E (2014): Total thyroidectomy is associated with increased risk of complications for low- and high-volume surgeons. Ann Surg Oncol 21, 3844-3852

Haussler MR, Cordy PE (1982): Metabolites and analogues of vitamin D. Which for what? JAMA 247, 841-844

Haussler MR, Whitfield GK, Haussler CA, Hsieh JC, Thompson PD, Selznick SH, Dominguez CE, Jurutka PW (1998): The nuclear vitamin D receptor: biological and molecular regulatory properties revealed. J Bone Miner Res $\underline{13}$, $325-349$

Herrmann C, Buss U (1994): Vorstellung und Validierung einer deutschen Version der "Hospital Anxiety and Depression Scale" (HAD-Skala) : Ein Fragebogen zur Erfassung des psychischen Befindens bei Patienten mit körperlichen Beschwerden. Diagnostica 40, 143-154

Hoare SR, Bonner TI, Usdin TB (1999): Comparison of rat and human parathyroid hormone 2 (PTH2) receptor activation: PTH is a low potency partial agonist at the rat PTH2 receptor. Endocrinology 140, 4419-4425

Holick MF, de Blanco MC, Clark MB, Henley JW, Neer RM, DeLuca HF, Potts JT, Jr. (1977): The metabolism of [6$3 \mathrm{H}] 1 \mathrm{alpha}$, hydroxycholecalciferol to [6-3H]1alpha,25-dihydroxycholecalciferol in a patient with renal insufficiency. J Clin Endocrinol Metab 44, 595-598

Hollifield JW (1986): Thiazide treatment of hypertension. Effects of thiazide diuretics on serum potassium, magnesium, and ventricular ectopy. Am J Med $\underline{80}, 8-12$

Inomata N, Akiyama M, Kubota N, Jüppner H (1995): Characterization of a novel parathyroid hormone (PTH) receptor with specificity for the carboxyl-terminal region of PTH-(1-84). Endocrinology $\underline{136}$, 4732-4740

Ito A, Yoshimura M (2017): Mechanisms of the analgesic effect of calcitonin on chronic pain by alteration of receptor or channel expression. Mol Pain $\underline{13}, 1-11$

Jakkani RK, Sureka J, Mathew J (2011): Spondyloarthropathy occurring in long-standing idiopathic hypoparathyroidism. Radiol Case Rep $\underline{6}, 545$

Jensterle M, Pfeifer M, Sever M, Kocjan T (2010): Dihydrotachysterol intoxication treated with pamidronate: a case report. Cases $\mathrm{J} \underline{3}, 78$

Jones $G$ (2013): Extrarenal vitamin $D$ activation and interactions between vitamin $D(2)$, vitamin $D(3)$, and vitamin $D$ analogs. Annu Rev Nutr $\underline{33}, 23-44$

Jones G, Strugnell SA, DeLuca HF (1998): Current understanding of the molecular actions of vitamin D. Physiol Rev $\underline{78}$, 1193-1231

Jonkisz E, Moosbrugger $\mathrm{H}$, Brandt $\mathrm{H}$ : Planung und Entwicklung von Tests und Fragebogen. In: Moosbrugger $\mathrm{H}$, Kelava A (Hrsg.): Testtheorie und Fragebogenkonstruktion. 2. Auflage; Springer, Berlin 2012, 27-74

Kagen MH, Bansal MG, Grossman M (2000): Calcinosis cutis following the administration of intravenous calcium therapy. Cutis $\underline{65}, 193-194$

Kallus KW: Erstellung von Fragebogen. 2. Auflage; facultas, Wien 2016 
Kanis JA, Russell RG (1977): Rate of reversal of hypercalcaemia and hypercalciuria induced by vitamin D and its 1alphahydroxylated derivatives. Br Med J 1, 78-81

Karkkainen MU, Lamberg-Allardt CJ, Ahonen S, Valimaki M (2001): Does it make a difference how and when you take your calcium? The acute effects of calcium on calcium and bone metabolism. Am J Clin Nutr 74, 335-342

Kemper CJ, Ziegler M, Krumm S, Heene M, Bühner M: Testkonstruktion. In: Stemmler G, Margraf-Stiksrud J (Hrsg.): Lehrbuch psychologische Diagnostik. 1. Auflage; Huber, Bern 2015, 157-222

Khryshchanovich V, Ghoussein Y (2016): Allotransplantation of macroencapsulated parathyroid cells as a treatment of severe postsurgical hypoparathyroidism: case report. Ann Saudi Med $\underline{36}, 143-147$

Kifor O, McElduff A, LeBoff MS, Moore FD, Jr., Butters R, Gao P, Cantor TL, Kifor I, Brown EM (2004): Activating antibodies to the calcium-sensing receptor in two patients with autoimmune hypoparathyroidism. J Clin Endocrinol Metab $\underline{89}$, 548-556

Kikkawa N, Ohno T, Nagata Y, Shiozuka M, Kogure T, Matsuda R (2009): Ectopic calcification is caused by elevated levels of serum inorganic phosphate in mdx mice. Cell Struct Funct $\underline{34}, 77-88$

Kimura S, Yoshioka K (2014): Parathyroid hormone and parathyroid hormone type-1 receptor accelerate myocyte differentiation. Sci Rep $\underline{4}, 5066$

Kir S, Komaba H, Garcia AP, Economopoulos KP, Liu W, Lanske B, Hodin RA, Spiegelman BM (2016): PTH/PTHrP Receptor Mediates Cachexia in Models of Kidney Failure and Cancer. Cell Metab 23, 315-323

Knochel JP (1984): Diuretic-induced hypokalemia. Am J Med $\underline{77}, 18-27$

Ko B (2017): Parathyroid hormone and the regulation of renal tubular calcium transport. Curr Opin Nephrol Hypertens $\underline{26}$, 405-410

Kobrynski LJ, Sullivan KE (2007): Velocardiofacial syndrome, DiGeorge syndrome: the chromosome 22q11.2 deletion syndromes. Lancet $\underline{370}, 1443-1452$

Koytchev R, Alken RG, Vagaday M, Kunter U, Kirkov V (1994): Differences in the bioavailability of dihydrotachysterol preparations. Eur J Clin Pharmacol $\underline{47}, 81-84$

Kroenke K, Spitzer RL, Williams JB (2003): The Patient Health Questionnaire-2: validity of a two-item depression screener. Med Care $\underline{41}, 1284-1292$

Kruse K (1997): Neue Aspekte zum Hypoparathyreoidismus und Pseudohypoparathyreoidismus im Kindes- und Jugendalter. Monatsschr Kinderheilkd 145, 1264-1280

Kurtz A: Der Säure-Basen- und Mineralhaushalt. In: Heinrich PC, Müller M, Graeve L, Löffler G, Petrides PE (Hrsg.): Löffler/Petrides Biochemie und Pathobiochemie. 9. Auflage; Springer, Berlin 2014, 840-856

Lakatos P, Bajnok L, Lagast H, Valkusz Z (2016): An Open-Label Extension Study of Parathyroid Hormone rhPTH(1-84) in Adults with Hypoparathyroidism. Endocr Pract 22, 523-532

Lawson DE, Fraser DR, Kodicek E, Morris HR, Williams DH (1971): Identification of 1,25-dihydroxycholecalciferol, a new kidney hormone controlling calcium metabolism. Nature $\underline{230}, 228-230$

Leitlinie Crampi/Muskelkrampf s. Leitlinien für Diagnostik und Therapie in der Neurologie 2017

Leitlinien für Diagnostik und Therapie in der Neurologie - Crampi/Muskelkrampf. Hrsg. v. der Kommission Leitlinien der $\begin{array}{lllll}\text { Deutschen Gesellschaft } \quad \text { für } & \text { Neurologie. } & \text { o.Verl., } & 0.0 . & 2017\end{array}$ http://www.awmf.org/uploads/tx szleitlinien/030-037I S1 Crampi Muskelkrampf 2017-05.pdf (Zugriff am 09.07.17)

Letz S, Rus R, Haag C, Dorr HG, Schnabel D, Mohlig M, Schulze E, Frank-Raue K, Raue F, Mayr B (2010): Novel activating mutations of the calcium-sensing receptor: the calcilytic NPS-2143 mitigates excessive signal transduction of mutant receptors. J Clin Endocrinol Metab 95, E229-233

Levine MA (1999): Pseudohypoparathyroidism: from bedside to bench and back. J Bone Miner Res $\underline{14}, 1255-1260$ 
Levine MA (2012): An update on the clinical and molecular characteristics of pseudohypoparathyroidism. Curr Opin Endocrinol Diabetes Obes $\underline{19}, 443-451$

Lienert GA, Raatz U: Testaufbau und Testanalyse. 6. Auflage; Beltz, Weinheim 1998

Liu HG, Chen ZC, Zhang XH, Yang K (2015): Replantation with cryopreserved parathyroid for permanent hypoparathyroidism: a case report and review of literatures. Int J Clin Exp Med $\underline{8}, 4611-4619$

Lorente-Poch L, Sancho JJ, Munoz-Nova JL, Sanchez-Velazquez P, Sitges-Serra A (2015a): Defining the syndromes of parathyroid failure after total thyroidectomy. Gland Surg $\underline{4}, 82-90$

Lorente-Poch L, Sancho JJ, Ruiz S, Sitges-Serra A (2015b): Importance of in situ preservation of parathyroid glands during total thyroidectomy. Br J Surg $\underline{102}$, 359-367

Lorente-Poch L, Sancho J, Munoz JL, Gallego-Otaegui L, Martinez-Ruiz C, Sitges-Serra A (2017): Failure of fragmented parathyroid gland autotransplantation to prevent permanent hypoparathyroidism after total thyroidectomy. Langenbecks Arch Surg 402, 281-287

Lovas K, Curran S, Oksnes M, Husebye ES, Huppert FA, Chatterjee VK (2010): Development of a disease-specific quality of life questionnaire in Addison's disease. J Clin Endocrinol Metab 95, 545-551

Löwe B, Kroenke K, Gräfe K (2005): Detecting and monitoring depression with a two-item questionnaire (PHQ-2). J Psychosom Res $\underline{58}, 163-171$

Lowe H, Cusano NE, Binkley N, Blaner WS, Bilezikian JP (2011): Vitamin D toxicity due to a commonly available "over the counter" remedy from the Dominican Republic. J Clin Endocrinol Metab 96, 291-295

Malberti F (2013): Hyperphosphataemia: treatment options. Drugs $\underline{73}$, 673-688

Mannstadt M, Clarke BL, Vokes T, Brandi ML, Ranganath L, Fraser WD, Lakatos P, Bajnok L, Garceau R, Mosekilde L (2013): Efficacy and safety of recombinant human parathyroid hormone (1-84) in hypoparathyroidism (REPLACE): a double-blind, placebo-controlled, randomised, phase 3 study. Lancet Diabetes Endocrinol 1 , 275-283

Mannstadt M, Bilezikian JP, Thakker RV, Hannan FM, Clarke BL, Reijnmark L, Mitchell DM, Vokes TJ, Winer KK, Shoback DM (2017): Hypoparathyroidism. Nat Rev Dis Primers $\underline{3}, 17055$

Mantovani G, Elli FM, Spada A (2012): GNAS epigenetic defects and pseudohypoparathyroidism: time for a new classification? Horm Metab Res $\underline{44}, 716-723$

Marcucci G, Della Pepa G, Brandi ML (2016): Natpara for the treatment of hypoparathyroidism. Expert Opin Biol Ther $\underline{16}$, 1417-1424

Marx SJ (2000): Hyperparathyroid and hypoparathyroid disorders. N Engl J Med $\underline{343}, 1863-1875$

Maschio G, Tessitore N, D'Angelo A, Fabris A, Pagano F, Tasca A, Graziani G, Aroldi A, Surian M, Colussi G (1981): Prevention of calcium nephrolithiasis with low-dose thiazide, amiloride and allopurinol. Am J Med $\underline{71}, 623-626$

Mawer EB, Davies M (2001): Vitamin D nutrition and bone disease in adults. Rev Endocr Metab Disord 2, 153-164

Miao D, Tong XK, Chan GK, Panda D, McPherson PS, Goltzman D (2001): Parathyroid hormone-related peptide stimulates osteogenic cell proliferation through protein kinase $\mathrm{C}$ activation of the Ras/mitogen-activated protein kinase signaling pathway. J Biol Chem $\underline{276}$, 32204-32213

Mitchell DM, Regan S, Cooley MR, Lauter KB, Vrla MC, Becker CB, Burnett-Bowie SA, Mannstadt M (2012): Long-term follow-up of patients with hypoparathyroidism. J Clin Endocrinol Metab 97, 4507-4514

Moosbrugger H, Kelava A: Qualitätsanforderungen an einen psychologischen Test (Testguitekriterien). In: Moosbrugger H, Kelava A (Hrsg.): Testtheorie und Fragebogenkonstruktion. 2. Auflage; Springer, Berlin 2012, 7-26 
Moosbrugger $\mathrm{H}$, Schermelleh-Engel $\mathrm{K}$ : Exploratorische (EFA) und Konfirmatorische Faktorenanalyse (CFA). In: Moosbrugger H, Kelava A (Hrsg.): Testtheorie und Fragebogenkonstruktion. 2. Auflage; Springer, Berlin 2012, $325-343$

Morfeld M: Fragebogen zum Gesundheitszustand (SF-36). In: Dorsch F, Wirtz MA, Strohmer J (Hrsg.): Dorsch - Lexikon der Psychologie. 17. Auflage; Huber, Bern 2014, 600

Mummendey HD, Grau I: Die Fragebogen-Methode. 5. Auflage; Hogrefe, Göttingen 2008

Mundy GR (1990): Pathophysiology of cancer-associated hypercalcemia. Semin Oncol 17, 10-15

Murray SE, Pathak PR, Pontes DS, Schneider DF, Schaefer SC, Chen H, Sippel RS (2013): Timing of symptom improvement after parathyroidectomy for primary hyperparathyroidism. Surgery $\underline{154}, 1463-1469$

Murray TM, Rao LG, Divieti P, Bringhurst FR (2005): Parathyroid hormone secretion and action: evidence for discrete receptors for the carboxyl-terminal region and related biological actions of carboxyl- terminal ligands. Endocr $\operatorname{Rev} \underline{26}, 78-113$

Natpar (2017): $\quad$ http://www.prnewswire.com/news-releases/shire-granted-eu-conditional-marketingauthorisation-for-natpar-parathyroid-hormone-for-the-treatment-of-patients-with-chronichypoparathyroidism-620439673.html (erschienen am 26.04.2017)

Nawrot I, Pragacz A, Pragacz K, Grzesiuk W, Barczynski M (2014): Total thyroidectomy is associated with increased prevalence of permanent hypoparathyroidism. Med Sci Monit 20, 1675-1681

Neer RM, Holick MF, DeLuca HF, Potts JT (1975): Effects of 1alpha-hydroxy-vitamin D3 and 1,25-dihydroxy-vitamin D3 on calcium and phosphorus metabolism in hypoparathyroidism. Metabolism 24, 1403-1413

Nemeth EF, Goodman WG (2016): Calcimimetic and Calcilytic Drugs: Feats, Flops, and Futures. Calcif Tissue Int $\underline{98}$, $341-358$

Nora DB, Fricke D, Becker J, Gomes I (2004): Hypocalcemic myopathy without tetany due to idiopathic hypoparathyroidism: case report. Arq Neuropsiquiatr $\underline{62}, 154-157$

O'Neill WC (2007): The fallacy of the calcium-phosphorus product. Kidney Int 72, 792-796

Oberleithner H: Salz- und Wasserhaushalt. In: Kurtz A, Pape H-C, Silbernagl S (Hrsg.): Physiologie. 7., vollst. überarb. und erw. Auflage; Thieme, Stuttgart 2014, 440-473

Okano K, Furukawa Y, Morii H, Fujita T (1982): Comparative efficacy of various vitamin D metabolites in the treatment of various types of hypoparathyroidism. J Clin Endocrinol Metab $\underline{55}, 238-243$

Paek SH, Lee YM, Min SY, Kim SW, Chung KW, Youn YK (2013): Risk factors of hypoparathyroidism following total thyroidectomy for thyroid cancer. World J Surg $\underline{37}, 94-101$

Palazzo FF, Sywak MS, Sidhu SB, Barraclough BH, Delbridge LW (2005): Parathyroid autotransplantation during total thyroidectomy--does the number of glands transplanted affect outcome? World J Surg 29, 629-631

Panda DK, Miao D, Bolivar I, Li J, Huo R, Hendy GN, Goltzman D (2004): Inactivation of the 25-hydroxyvitamin D 1alpha-hydroxylase and vitamin $D$ receptor demonstrates independent and interdependent effects of calcium and vitamin D on skeletal and mineral homeostasis. J Biol Chem $\underline{279}$, 16754-16766

Pappu R, Jabbour SA, Reginato AM, Reginato AJ (2016): Musculoskeletal manifestations of primary hyperparathyroidism. Clin Rheumatol $\underline{35}$, 3081-3087

Parfitt AM (1972): The interactions of thiazide diuretics with parathyroid hormone and vitamin D. Studies in patients with

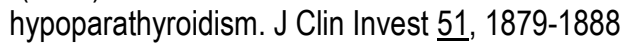

Park YS, Kim HS, Jin YM, Yu Y, Kim HY, Park HS, Jung SC, Han KH, Park YJ, Ryu KH (2015): Differentiated tonsilderived mesenchymal stem cells embedded in Matrigel restore parathyroid cell functions in rats with parathyroidectomy. Biomaterials $\underline{65}, 140-152$ 
Parvari R, Hershkovitz E, Grossman N, Gorodischer R, Loeys B, Zecic A, Mortier G, Gregory S, Sharony R, Kambouris M (2002): Mutation of TBCE causes hypoparathyroidism-retardation-dysmorphism and autosomal recessive Kenny-Caffey syndrome. Nat Genet $\underline{32}$, 448-452

Pines M, Adams AE, Stueckle S, Bessalle R, Rashti-Behar V, Chorev M, Rosenblatt M, Suva LJ (1994): Generation and characterization of human kidney cell lines stably expressing recombinant human PTH/PTHrP receptor: lack of interaction with a C-terminal human PTH peptide. Endocrinology $\underline{135}$, 1713-1716

Policepatil SM, Caplan RH, Dolan M (2012): Hypocalcemic myopathy secondary to hypoparathyroidism. WMJ 111, 173175

Potts JT (2005): Parathyroid hormone: past and present. J Endocrinol 187, 311-325

Prior N, Remor E, Gomez-Traseira C, Lopez-Serrano C, Cabanas R, Contreras J, Campos A, Cardona V, Cimbollek S, Gonzalez-Quevedo T (2012): Development of a disease-specific quality of life questionnaire for adult patients with hereditary angioedema due to $\mathrm{C} 1$ inhibitor deficiency (HAE-QoL): Spanish multi-centre research project. Health Qual Life Outcomes $\underline{10}, 82$

Quack I, Zwernemann C, Weiner SM, Sellin L, Henning BF, Waldherr R, Buchner NJ, Stegbauer J, Vonend O, Rump LC (2005): Dihydrotachysterol therapy for hypoparathyroidism: consequences of inadequate monitoring. Five cases and a review. Exp Clin Endocrinol Diabetes 113, 376-380

Quarles LD (2012): Role of FGF23 in vitamin D and phosphate metabolism: implications in chronic kidney disease. Exp Cell Res $\underline{318}, 1040-1048$

Recker RR (1985): Calcium absorption and achlorhydria. N Engl J Med $\underline{313}, 70-73$

Reginster JY, Denis D, Bartsch V, Deroisy R, Zegels B, Franchimont P (1993): Acute biochemical variations induced by four different calcium salts in healthy male volunteers. Osteoporos Int $\underline{3}, 271-275$

Rejnmark L, Underbjerg L, Sikjaer T (2014): Therapy of hypoparathyroidism by replacement with parathyroid hormone. Scientifica 2014, 765629

Rejnmark L, Underbjerg L, Sikjaer T (2015): Hypoparathyroidism - Replacement Therapy with Parathyroid Hormone. Endocrinol Metab $\underline{30}$, 436-442

Rentzsch K, Schütz A, Leplow B: Psychologische Diagnostik. Grundlagen und Anwendungsperspektiven. 1. Auflage; Kohlhammer, Stuttgart 2009

Reppe S, Stilgren L, Abrahamsen B, Olstad OK, Cero F, Brixen K, Nissen-Meyer LS, Gautvik KM (2007): Abnormal muscle and hematopoietic gene expression may be important for clinical morbidity in primary hyperparathyroidism. Am J Physiol Endocrinol Metab 292, E1465-1473

Richards ML, Bingener-Casey J, Pierce D, Strodel WE, Sirinek KR (2003): Intraoperative parathyroid hormone assay: an accurate predictor of symptomatic hypocalcemia following thyroidectomy. Arch Surg 138, 632-635

Richards ML, Thompson GB, Farley DR, Grant CS (2008): Reoperative parathyroidectomy in 228 patients during the era of minimal-access surgery and intraoperative parathyroid hormone monitoring. Am J Surg 196, 937-942

Ringe JD, Schacht E (2004): Prevention and therapy of osteoporosis: the roles of plain vitamin D and alfacalcidol. Rheumatol Int $\underline{24}, 189-197$

Ringe JD, Schacht E (2009): Potential of alfacalcidol for reducing increased risk of falls and fractures. Rheumatol Int $\underline{29}$, $1177-1185$

Ritter C, Gobel CH, Liebig T, Kaminksy E, Fink GR, Lehmann HC (2015): An epigenetic cause of seizures and brain calcification: pseudohypoparathyroidism. Lancet $\underline{385}, 1802$

Ritter K, Elfenbein D, Schneider DF, Chen H, Sippel RS (2015): Hypoparathyroidism after total thyroidectomy: incidence and resolution. J Surg Res 197, 348-353

Rocaltrol@: Gebrauchsinformation: Information für Anwender Rocaltrol@ $0,25 \mu \mathrm{g}$ Weichkapseln Calcitriol. Roche Pharma AG, Grenzach-Wyhlen 2016 
Rodenburg EM, Visser LE, Hoorn EJ, Ruiter R, Lous JJ, Hofman A, Uitterlinden AG, Stricker BH (2014): Thiazides and the risk of hypokalemia in the general population. J Hypertens $\underline{32}, 2092-2097$

Roffe C, Sills S, Crome P, Jones P (2002): Randomised, cross-over, placebo controlled trial of magnesium citrate in the treatment of chronic persistent leg cramps. Med Sci Monit $\underline{8}$, Cr326-330

Rubin MR, Bilezikian JP (2010): Hypoparathyroidism: clinical features, skeletal microstructure and parathyroid hormone replacement. Arq Bras Endocrinol Metabol 54, 220-226

Rubin MR, Sliney J, Jr., McMahon DJ, Silverberg SJ, Bilezikian JP (2010): Therapy of hypoparathyroidism with intact parathyroid hormone. Osteoporos Int 21, 1927-1934

Rubin MR, Cusano NE, Fan WW, Delgado Y, Zhang C, Costa AG, Cremers S, Dworakowski E, Bilezikian JP (2016): Therapy of Hypoparathyroidism With PTH(1-84): A Prospective Six Year Investigation of Efficacy and Safety. J Clin Endocrinol Metab 101, 2742-2750

Rubinger D, Friedlaender MM, Bernheim J, Shachner E, Ronen M, Czaczkes WJ (1982): Long-term effects of 1 alphahydroxycholecalciferol therapy in chronic hemodialysis patients. Isr J Med Sci 18, 1019-1026

Saba A, Podda M, Messina Campanella A, Pisanu A (2017): Early prediction of hypocalcemia following thyroid surgery. A prospective randomized clinical trial. Langenbecks Arch Surg $\underline{402}, 1119-1125$

Saleem S, Aslam HM, Anwar M, Anwar S, Saleem M, Saleem A, Rehmani MA (2013): Fahr's syndrome: literature review of current evidence. Orphanet J Rare Dis $\underline{8}, 156$

Santonati A, Palermo A, Maddaloni E, Bosco D, Spada A, Grimaldi F, Raggiunti B, Volpe R, Manfrini S, Vescini F (2015): PTH(1-34) for Surgical Hypoparathyroidism: A Prospective, Open-Label Investigation of Efficacy and Quality of Life. J Clin Endocrinol Metab 100, 3590-3597

Sarinc Ulasli S, Bozbas SS, Ozen ZE, Ozyurek BA, Ulubay G (2013): Effect of thyroid function on COPD exacerbation frequency: a preliminary study. Multidiscip Respir Med $\underline{8}, 64$

Schacht E, Kneer W, Dambacher MA (2008): Die Wirkungen von Alfacalcidol auf den Muskel, das neuromuskuläre System, auf die Sturzgefahr und auf Frakturen. J Miner Stoffwechs $\underline{15}, 132-139$

Schafer AL, Shoback DM: Hypocalcemia: Diagnosis and Treatment. In: De Groot LJ, Chrousos G, Dungan K, Feingold KR, Grossman A, Hershman JM, Koch C, Korbonits M, McLachlan R, New M, et al. (Hrsg.): Endotext. (Stand 03.01.2016); MDText.com, Inc., South Dartmouth (MA) 2000, $0 . S$. http://www.endotext.org/?s=hypocalcemia+diagnosis+and+treatment

Schietroma M, Cecilia EM, Carlei F, Sista F, De Santis G, Lancione L, Amicucci G (2013): Dexamethasone for the prevention of recurrent laryngeal nerve palsy and other complications after thyroid surgery: a randomized double-blind placebo-controlled trial. JAMA Otolaryngol Head Neck Surg 139, 471-478

Shah M, Bancos I, Thompson GB, Richards ML, Kasperbauer JL, Clarke BL, Drake MT, Stan MN (2015): Teriparatide Therapy and Reduced Postoperative Hospitalization for Postsurgical Hypoparathyroidism. JAMA Otolaryngol Head Neck Surg 141, 822-827

Shahraki AD (2006): Effects of Vitamin E, Calcium Carbonate and Milk of Magnesium on Muscular Cramps in Pregnant Women. J Med Sci (Faisalabad, Pakistan) $\underline{6}$, 979-983

Shane E, McClane KA, Olarte MR, Bilezikian JP (1980): Hypoparathyroidism and elevated muscle enzymes. Neurology $\underline{30}, 192-195$

Shepet K, Alhefdhi A, Usedom R, Sippel R, Chen H (2013): Parathyroid cryopreservation after parathyroidectomy: a worthwhile practice? Ann Surg Oncol 20, 2256-2260

Sherman AC, Pennington J, Simonton S, Latif U, Arent L, Farley H (2008): Determinants of participation in cancer support groups: the role of health beliefs. Int J Behav Med $\underline{15}, 92-100$

Shils ME (1969): Experimental human magnesium depletion. Medicine (Baltimore) $\underline{48}, 61-85$ 
Shimizu M, Joyashiki E, Noda H, Watanabe T, Okazaki M, Nagayasu M, Adachi K, Tamura T, Potts JT, Gardella TJ (2016): Pharmacodynamic Actions of a Long-Acting PTH Analog (LA-PTH) in Thyroparathyroidectomized (TPTX) Rats and Normal Monkeys. J Bone Miner Res 31, 1405-1412

Shoback D (2008): Clinical practice. Hypoparathyroidism. N Engl J Med 359, 391-403

Shoback DM, Bilezikian JP, Costa AG, Dempster D, Dralle H, Khan AA, Peacock M, Raffaelli M, Silva BC, Thakker RV (2016): Presentation of Hypoparathyroidism: Etiologies and Clinical Features. J Clin Endocrinol Metab 101, 2300-2312

Shprintzen RJ (2008): Velo-cardio-facial syndrome: 30 Years of study. Dev Disabil Res Rev 14, 3-10

Sieniawski K, Kaczka K, Paduszynska K, Fendler W, Tomasik B, Pomorski L (2016): Early Predictors of Post Thyroidectomy Hypoparathyroidism. Pol Przegl Chir 요, 305-314

Siggelkow H (2017): State of the Art - Standardtherapie und Ausblick bei der Behandlung des Hypoparathyreoidismus. Endokrinologie Informationen Sonderheft 2017, 11-14

Silin H, Lundgren E, Mallmin H, Mellstrom D, Ohlsson C, Karlsson M, Orwoll E, Ljunggren O (2011): Prevalence of primary hyperparathyroidism and impact on bone mineral density in elderly men: MrOs Sweden. World J Surg $\underline{35}, 1266-1272$

Sikjaer T, Rejnmark L, Rolighed L, Heickendorff L, Mosekilde L (2011): The effect of adding PTH(1-84) to conventional treatment of hypoparathyroidism: a randomized, placebo-controlled study. J Bone Miner Res $\underline{26}$, 2358-2370

Sikjaer T, Rolighed L, Hess A, Fuglsang-Frederiksen A, Mosekilde L, Rejnmark L (2014): Effects of PTH(1-84) therapy on muscle function and quality of life in hypoparathyroidism: results from a randomized controlled trial. Osteoporos Int 25, $1717-1726$

Sikjaer T, Moser E, Rolighed L, Underbjerg L, Bislev LS, Mosekilde L, Rejnmark L (2016): Concurrent Hypoparathyroidism Is Associated With Impaired Physical Function and Quality of Life in Hypothyroidism. J Bone Miner Res $\underline{31}$, 1440-1448

Singh R, Bhat MH, Bhansali A (2006): Hypomagnesaemia masquerading as hypoparathyroidism. J Assoc Physicians India $54,411-412$

Sitges-Serra A, Ruiz S, Girvent M, Manjon H, Duenas JP, Sancho JJ (2010): Outcome of protracted hypoparathyroidism after total thyroidectomy. Br J Surg $\underline{97}$, 1687-1695

Sitges-Serra A, Lorente-Poch L, Sancho J (2018): Parathyroid autotransplantation in thyroid surgery. Langenbecks Arch Surg, doi: 10.1007/s00423-018-1654-5

Smock SL, Vogt GA, Castleberry TA, Lu B, Owen TA (2001): Molecular cloning and functional characterization of the canine parathyroid hormone/parathyroid hormone related peptide receptor (PTH1). Mol Biol Rep 2ㅇ, 235-243

Song CM, Jung JH, Ji YB, Min HJ, Ahn YH, Tae K (2014): Relationship between hypoparathyroidism and the number of parathyroid glands preserved during thyroidectomy. World J Surg Oncol $\underline{12}, 200$

Sonnenblick M, Friedlander Y, Rosin AJ (1993): Diuretic-induced severe hyponatremia. Review and analysis of 129 reported patients. Chest $\underline{103}, 601-606$

Sorensen OH, Lund B, Saltin B, Lund B, Andersen RB, Hjorth L, Melsen F, Mosekilde L (1979): Myopathy in bone loss of ageing: improvement by treatment with 1 alpha-hydroxycholecalciferol and calcium. Clin Sci (Lond) $\underline{56}$, 157161

Spangenberg L, Brahler E, Glaesmer H (2012): Wie gut eignen sich verschiedene Versionen des Depressionsmoduls des Patient Health Questionnaires zur Identifikation depressiver Personen in der Allgemeinbevolkerung? Z Psychosom Med Psychother $\underline{58}, 3-10$

Srirangarajan S, Satyanarayan A, Ravindra S, Thakur S (2014): Dental manifestation of primary idiopathic hypoparathyroidism. J Indian Soc Periodontol $\underline{18}, 524-526$ 
Stack BC, Jr., Bimston DN, Bodenner DL, Brett EM, Dralle H, Orloff LA, Pallota J, Snyder SK, Wong RJ, Randolph GW (2015): American Association of Clinical Endocrinologists and American College of Endocrinology Disease State Clinical Review: Postoperative Hypoparathyroidism - Definitions and Management. Endocr Pract 21, 674685

Straub DA (2007): Calcium supplementation in clinical practice: a review of forms, doses, and indications. Nutr Clin Pract 22, 286-296

Streeten EA, Mohtasebi Y, Konig M, Davidoff L, Ryan K (2017): Hypoparathyroidism: Less Severe Hypocalcemia With Treatment With Vitamin D2 Compared With Calcitriol. J Clin Endocrinol Metab 102, 1505-1510

Sunthornthepvarakul T, Churesigaew S, Ngowngarmratana S (1999): A novel mutation of the signal peptide of the preproparathyroid hormone gene associated with autosomal recessive familial isolated hypoparathyroidism. $\mathrm{J}$ Clin Endocrinol Metab 84, 3792-3796

Tait RC, Chibnall JT, Krause S (1990): The Pain Disability Index: psychometric properties. Pain 40, 171-182

Tamura T, Noda H, Joyashiki E, Hoshino M, Watanabe T, Kinosaki M, Nishimura Y, Esaki T, Ogawa K, Miyake T (2016): Identification of an orally active small-molecule PTHR1 agonist for the treatment of hypoparathyroidism. Nat Commun 7, 13384

Terwee CB, Bot SD, de Boer MR, van der Windt DA, Knol DL, Dekker J, Bouter LM, de Vet HC (2007): Quality criteria were proposed for measurement properties of health status questionnaires. J Clin Epidemiol $\underline{60}, 34-42$

Terzano C, Romani S, Paone G, Conti V, Oriolo F (2014): COPD and thyroid dysfunctions. Lung 192, 103-109

Testerink J, Degens H, Rittweger J, Shiraishi A, Jaspers RT, de Haan A (2011): Effects of alfacalcidol on the contractile properties of the gastrocnemius medialis muscle in adult and old rats. J Physiol Pharmacol $\underline{62}, 111-118$

Thomas SS, Mitch WE (2017): Parathyroid hormone stimulates adipose tissue browning: a pathway to muscle wasting. Curr Opin Clin Nutr Metab Care 20, 153-157

Thomee C, Schubert SW, Parma J, Le PQ, Hashemolhosseini S, Wegner M, Abramowicz MJ (2005): GCMB mutation in familial isolated hypoparathyroidism with residual secretion of parathyroid hormone. J Clin Endocrinol Metab 90, 2487-2492

Thomusch O, Machens A, Sekulla C, Ukkat J, Brauckhoff M, Dralle H (2003): The impact of surgical technique on postoperative hypoparathyroidism in bilateral thyroid surgery: a multivariate analysis of 5846 consecutive patients. Surgery $\underline{133}, 180-185$

Tolone S, Roberto R, del Genio G, Brusciano L, Parmeggiani D, Amoroso V, Casalino G, Verde I, Bosco A, D'Alessandro A, et al. (2013): The impact of age and oral calcium and vitamin D supplements on postoperative hypocalcemia after total thyroidectomy. A prospective study. BMC Surg 13 Suppl 2, S11

Tregear GW, Van Rietschoten J, Greene E, Keutmann HT, Niall HD, Reit B, Parsons JA, Potts JT (1973): Bovine parathyroid hormone: minimum chain length of synthetic peptide required for biological activity. Endocrinology $\underline{93}, 1349-1353$

Turner JJO (2017): Hypercalcaemia - presentation and management. Clin Med (Lond) 17, 270-273

Underbjerg L, Sikjaer T, Mosekilde L, Rejnmark L (2013): Cardiovascular and renal complications to postsurgical hypoparathyroidism: a Danish nationwide controlled historic follow-up study. J Bone Miner Res $\underline{28}, 2277-2285$

Underbjerg L, Sikjaer T, Mosekilde L, Rejnmark L (2014): Postsurgical hypoparathyroidism--risk of fractures, psychiatric diseases, cancer, cataract, and infections. J Bone Miner Res $\underline{29}, 2504-2510$

Underbjerg L, Sikjaer T, Mosekilde L, Rejnmark L (2015): The Epidemiology of Nonsurgical Hypoparathyroidism in Denmark: A Nationwide Case Finding Study. J Bone Miner Res $\underline{30}$, 1738-1744

Urena P, Kong XF, Abou-Samra AB, Jüppner H, Kronenberg HM, Potts JT, Jr., Segre GV (1993): Parathyroid hormone (PTH)/PTH-related peptide receptor messenger ribonucleic acids are widely distributed in rat tissues. Endocrinology 133, 617-623 
Usdin TB, Gruber C, Bonner TI (1995): Identification and functional expression of a receptor selectively recognizing parathyroid hormone, the PTH2 receptor. J Biol Chem $\underline{270}$, 15455-15458

Usdin TB, Wang T, Hoare SR, Mezey E, Palkovits M (2000): New members of the parathyroid hormone/parathyroid hormone receptor family: the parathyroid hormone 2 receptor and tuberoinfundibular peptide of 39 residues. Front Neuroendocrinol 21, 349-383

Usdin TB, Bonner TI, Hoare SR (2002): The parathyroid hormone 2 (PTH2) receptor. Receptors Channels $\underline{8}, 211-218$

Vahle JL, Sato M, Long GG, Young JK, Francis PC, Engelhardt JA, Westmore MS, Linda Y, Nold JB (2002): Skeletal changes in rats given daily subcutaneous injections of recombinant human parathyroid hormone (1-34) for 2 years and relevance to human safety. Toxicol Pathol $\underline{30}, 312-321$

Vervloet M (2014): Clinical uses of 1-alpha-hydroxycholecalciferol. Curr Vasc Pharmacol 12, 300-305

Walker Harris V, Jan De Beur S (2009): Postoperative hypoparathyroidism: medical and surgical therapeutic options. Thyroid $\underline{19}, 967-973$

Walters RO (1979): Idiopathic hypoparathyroidism with extrapyramidal and myopathic features. Arch Dis Child $\underline{54}$, 236238

Weaver DR, Deeds JD, Lee K, Segre GV (1995): Localization of parathyroid hormone-related peptide (PTHrP) and PTH/PTHrP receptor mRNAs in rat brain. Brain Res Mol Brain Res $\underline{28}, 296-310$

Webb SM, Prieto L, Badia X, Albareda M, Catala M, Gaztambide S, Lucas T, Paramo C, Pico A, Lucas A (2002): Acromegaly Quality of Life Questionnaire (ACROQOL) a new health-related quality of life questionnaire for patients with acromegaly: development and psychometric properties. Clin Endocrinol (Oxf) $\underline{57}, 251-258$

Weisinger JR, Bellorin-Font E (1998): Magnesium and phosphorus. Lancet 352, 391-396

Weisman D: Hypoparathyreoidimus, Hypokalzämie und Pseudohypoparathyreoidismus. In: Allolio B, Schulte HM (Hrsg.): Praktische Endokrinologie. Mit 184 Abbildungen. 2. Auflage; Urban \& Fischer, München 2010, 297-302

Wermers RA, Kearns AE, Jenkins GD, Melton LJ, 3rd (2007): Incidence and clinical spectrum of thiazide-associated hypercalcemia. Am J Med $\underline{120}, 911 . e 919-915$

Whyte MP, Weldon VV (1981): Idiopathic hypoparathyroidism presenting with seizures during infancy: X-linked recessive inheritance in a large Missouri kindred. J Pediatr $\underline{99}, 608-611$

Wilde D, Wilken L, Chavanon M-L, Herrmann-Lingen C, Siggelkow H: Development of a Disease-Specific Quality of Life Questionaire HPQ 40 in Hypoparathyroidism. 60. Deutscher Kongress für Endokrinologie, Würzburg 15.17.03.2017

Wilde D, Wilken L, Stamm B, Heppner C, Leha A, Herrmann-Lingen C, Siggelkow H: Use of a Disease-Characteristic Questionnaire identified Pain and Cramps and Neuro-Vegetative Symptoms as significantly elevated and affected by Medication in mainly well-controlled Hypoparathyroid Patients. 20th European Congress of Endocrinology, Barcelona 19.05.-22.05.2018

Winer KK, Yanovski JA, Cutler GB, Jr. (1996): Synthetic human parathyroid hormone 1-34 vs calcitriol and calcium in the treatment of hypoparathyroidism. JAMA $\underline{276}, 631-636$

Winer KK, Ko CW, Reynolds JC, Dowdy K, Keil M, Peterson D, Gerber LH, McGarvey C, Cutler GB, Jr. (2003): Longterm treatment of hypoparathyroidism: a randomized controlled study comparing parathyroid hormone-(1-34) versus calcitriol and calcium. J Clin Endocrinol Metab 으, 4214-4220

Winer KK, Zhang B, Shrader JA, Peterson D, Smith M, Albert PS, Cutler GB, Jr. (2012): Synthetic human parathyroid hormone 1-34 replacement therapy: a randomized crossover trial comparing pump versus injections in the treatment of chronic hypoparathyroidism. J Clin Endocrinol Metab $\underline{97}$, 391-399

Winterborn MH, Mace PJ, Heath DA, White RH (1978): Impairment of renal function in patients on 1alphahydroxycholecalciferol. Lancet $\underline{2}, 150-151$

Wysolmerski JJ (2012): Parathyroid hormone-related protein: an update. J Clin Endocrinol Metab 97, 2947-2956 
Young GL, Jewell D (2002): Interventions for leg cramps in pregnancy. Cochrane Database Syst Rev, Cd000121

Zhang C, Miller CL, Brown EM, Yang JJ (2015): The calcium sensing receptor: from calcium sensing to signaling. Sci China Life Sci $\underline{58}$, 14-27

Zhang P, Zhang HW, Han XD, Di JZ, Zheng Q (2015): Meta-analysis of comparison between minimally invasive videoassisted thyroidectomy and conventional thyroidectomy. Eur Rev Med Pharmacol Sci $\underline{19}$, 1381-1387

Zhao Y, Luo B (2016): Adipose-derived stem cells: A novel source of parathyroid cells for treatment of hypoparathyroidism. Med Hypotheses $\underline{93}$, 143-145

Zhou K, West HM, Zhang J, Xu L, Li W (2015): Interventions for leg cramps in pregnancy. Cochrane Database Syst Rev, Cd010655 